\title{
New land, new town, new health care system : primary care based health care planning in a modern, industrialized society : a case-study evaluating the health care demonstration project in the new Dutch town of Almere
}

Citation for published version (APA):

Sixma, H. J. (1997). New land, new town, new health care system : primary care based health care planning in a modern, industrialized society: a case-study evaluating the health care demonstration project in the new Dutch town of Almere. [Doctoral Thesis, Maastricht University]. NIVEL. https://doi.org/10.26481/dis.19971217hs

Document status and date:

Published: 01/01/1997

DOI:

$10.26481 /$ dis.19971217hs

Document Version:

Publisher's PDF, also known as Version of record

Please check the document version of this publication:

- A submitted manuscript is the version of the article upon submission and before peer-review. There can be important differences between the submitted version and the official published version of record. People interested in the research are advised to contact the author for the final version of the publication, or visit the DOI to the publisher's website.

- The final author version and the galley proof are versions of the publication after peer review.

- The final published version features the final layout of the paper including the volume, issue and page numbers.

Link to publication

\footnotetext{
General rights rights.

- You may freely distribute the URL identifying the publication in the public portal. please follow below link for the End User Agreement:

www.umlib.nl/taverne-license

Take down policy

If you believe that this document breaches copyright please contact us at:

repository@maastrichtuniversity.nl

providing details and we will investigate your claim.
}

Copyright and moral rights for the publications made accessible in the public portal are retained by the authors and/or other copyright owners and it is a condition of accessing publications that users recognise and abide by the legal requirements associated with these

- Users may download and print one copy of any publication from the public portal for the purpose of private study or research.

- You may not further distribute the material or use it for any profit-making activity or commercial gain

If the publication is distributed under the terms of Article $25 \mathrm{fa}$ of the Dutch Copyright Act, indicated by the "Taverne" license above,

Download date: 26 Apr. 2023 


\section{NEW LAND, NEW TOWN, NEW HEALTH CARE SYSTEM}

Primary care based health care planning in a modern, industrialized society;

a case-study evaluating the health care demonstration project in the new Dutch town of Almere

\section{PROEFSCHRIFT}

ter verkrijging van de graad van doctor aan de Universiteit Maastricht,

op gezag van de Rector Magnificus, Prof.mr. M.J. Cohen, ingevolge het besluit van het College van Decanen

in het openbaar te verdedigen op woensdag 17 december 1997 om 14.00 uur

door Herman Johan Marinus Sixma geboren op 22 april 1949 te Groningen 


\section{Promotoren:}

Prof.dr. J. van der Zee

Prof.dr.P.P. Groenewegen (Universiteit Utrecht)

\section{Beoordelingscommissie:}

Prof,dr. J.A.M. Maarse (voorzitter)

Prof.dr. H.F.J.M. Crebolder

Prof.dr. L.J. Gunning-Schepers (Universiteit van Amsterdam)

Prof.dr. H. Philipsen

Prof.dr. A.J.P. Schrijvers (Universiteit Utrecht)

The study presented in this thesis was conducted at the Netherlands institute of Primary Health Care (NIVEL), which participates in the Netherlands School of Primary Care Research (CaRe), acknowledged in 1995 by the Royal Dutch Academy of Science (KNAW). The study was (partly) financed by the Ministry of Health, Welfare and Sports in the Netherlands.

ISBN $90-6905-357-8$ 


\section{CONTENTS}

1 INTRODUCTION

1.1 The opportunity 2

1.2. The motive 6

1.3 The instruments or means 10

1.4 Research questions 11

1.5 Structure of the book 13

2 THE POLICY CONTEXT BETWEEN 1945 AND 1983

2.1 Introduction 15

2.2 General political and economical developments 16

2.3 Health care policy between 1945 and $1983 \quad 19$

2.4 Costs development in the Dutch health care sector 26

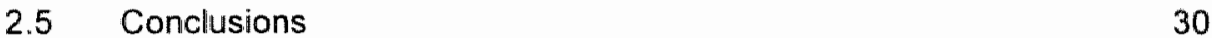

3 CONCEPTUAL FRAMEWORK FOR EVALUATING THE ALMERE HEALTH CARE EXPERIMENT

3.1 The conceptual framework 33

3.2 Research questions and their elaboration 35

3.2.1 Goals and instruments directed towards quality of care 36

3.2.2 Goals and instruments directed towards substitution

3.2.3 Cost related goals and instruments $\quad 41$

3.3 Relationships between goals, instruments and conditions 42

3.3.1 The relationship between instruments and goals 42

3.3.2 The expected conditions 45

3.4 The different evaluation studies conducted as part of

3.5 Summary and conclusions $\quad 55$

4 IMPLEMENTATION OF THE ALMERE HEALTH CARE DEMONSTRATION PROJECT

4.1 The organization of health care in the Netherlands 58

4.2 The implementation process $\quad 62$

4.2.1 The pre-experimental period $\quad 62$

4.2.2 The implementation phase 66

4.2.3 The post-experimental phase 70

4.3 Implementation of the instruments 71

4.3.1 Implementation of the instruments directed towards quality of care 72 
4.3.2 Implementation of the instruments directed towards substitution of care

4.3.3 Implementation of the instruments with respect to cost containment

4.4 Conclusions with respect to the implementation process and the instruments realized

5 CONDITIONS EXPERIENCED DURING THE ALMERE HEALTH CARE DEMONSTRATION PROJECT

5.1 The 'tabula rasa' situation

5.2 The Almere population 82

5.3 The policy context in the years between 1983 and $1993 \quad 85$

5.3.1 The general policy context, political and economical developments in the $1983-1993$ period

5.3.2 Health care policy in the Netherlands between 1983 and 1993

5.3.2 Cost developments in the Dutch health care sector between 1983 and 1993

5.4 Conclusions with respect to the conditions experienced

6 QUALITY OF CARE IN ALMERE

6.1 Structure of the care provision 93

6.1.1 The Numbers of Care Providers in Almere 94

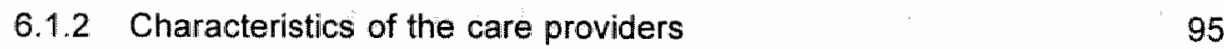

6.1.3 Attitudes of the care providers 97

6.1.4 The equipment of the facilities 99

$\begin{array}{ll}6.2 & \text { The process of health care provision } \\ & 100\end{array}$

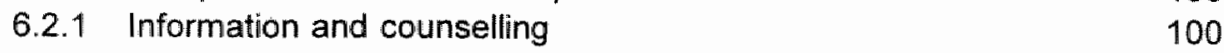

6.2.2 Coordination of work within and between the echelons 101

$\begin{array}{ll}6.2 .3 \text { Professional guidelines } & 103\end{array}$

$\begin{array}{ll}6.2 .4 \text { Continuity of care } & 106\end{array}$

6.3 Quality of care from the patients perspective 108

6.3.1 Opinions about the organization of Health Care in Almere 108

$\begin{array}{ll}\text { 6.3.2 Opinions about the child health clinics } & 111\end{array}$

6.3.3 Opinions about the accessibility of health care facilities in Almere 113

6.3.4 Opinions about waiting times for health care providers in Almere 116

6.3.5 Opinions about the providers of health care and the care provided in Almere

$\begin{array}{ll}\text { 6.3.6 Care according to needs } & 122\end{array}$

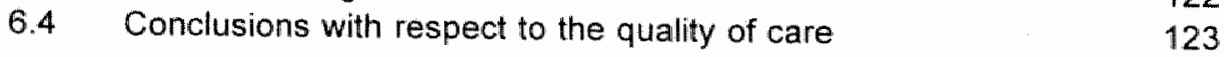

$7 \quad$ SUBSTITUTION OF CARE 127

$\begin{array}{ll}7.1 & \text { Substitution in the hospital and nursing home sector } \\ 7.127\end{array}$

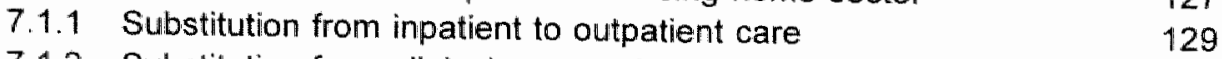

7.1.2 Substitution from clinical care to day treatment 133

iv Now land, new town, new health care system 
7.1.3 Substitution fram Nursing Home to Old People's home

7.1.4 Referral within the intramural sector

7.1.5 Shortening the duration of stay in intramural facilities $\quad 134$

7.2 Substitution from secondary to primary care

7.2.1 Hospital admissions

7.2.2 Restriction of the number of interventions in hospital

7.2.3 Increasing the number of interventions in primary care $\quad 142$

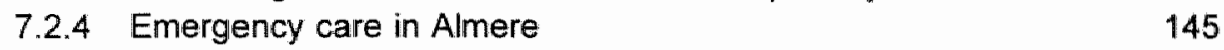

$\begin{array}{ll}7.2 .5 \text { Numbers of referrals to medical specialists } & 148\end{array}$

$\begin{array}{ll}\text { 7.2.6 Primary care contribution in the nursing home } & 151\end{array}$

7.3 Substitution from professional care to informal care , and from curative care to preventive care

7.3.1 Professional care and informal care

$\begin{array}{ll}\text { 7.3.2 Prevention and prevention programmes } & 156\end{array}$

$\begin{array}{ll}7.4 \text { Conclusions with respect to substitution of care } & 158\end{array}$

8 COSTS OF HEALTH CARE IN ALMERE 161

$\begin{array}{ll}8.1 \text { Introduction } & 161\end{array}$

$\begin{array}{ll}\text { 8.2 Costs of hospital care } & 162\end{array}$

$\begin{array}{lll}8.3 \text { Costs of primary care } & 164\end{array}$

$\begin{array}{ll}8.4 \text { Costs of care for the elderly } & 170\end{array}$

$\begin{array}{lll}8.5 & \text { Conclusions } & 171\end{array}$

9 THE EMPIRICAL RELATIONSHIP BETWEEN GOALS, INSTRUMENTS AND CONDITIONS 173

9.1 The empirical relationships, an introduction

9.2 Quality of care in general practice from the professional perspective

9.3 Quality of care in general practice from patient's perspective

9.4 Substitution of care and cost containment at the level of the population of Almere

9.5 Substitution of care and cost containment in general practice

9.6 Conclusions

10 CONCLUSIONS

10.1 Conceptual framework and research questions

10.2 The political context of the Almere Health Care Demonstration Project; research questions Q1

10.3 The theoretical relationship between goals, instruments, and conditions; research question Q2

10.4 The relationship between theory and practice; research question Q3

10.4.1 The process of implementation 
10.4.3 Instruments directed towards substitution of care

10.4.4 Instruments aimed at the costs of health care

10.4.5 The operative conditions

10.4.6 Goals realized

10.5 The empirical relationship between instruments, goals, and conditions; research question 4

10.6 Conclusions

SAMENVATTING

REFERENCES

APPENDIX

ACKNOWLEDGEMENTS 


\section{PREFACE}

This thesis describes the introduction of primary care based health care planning in a modern, highly industrialized society. The Almere Health Care Demonstration Project on which the thesis focuses, can subsequently be labelled as a field experiment to test the basic ideas of Dutch health care policy developed in the mid 1970s, when health care policy shifted from a 'laissez faire' situation to governmental control in the planning and financing sectors. The most important assumption behind the experiment was, that a reinforced primary health care system in combination with a decreased capacity of the hospital sector and salaried employment for all health care professionals, would result in a more cost-effective system of health care services.

This thesis can also be seen as a summary of almost ten years of evaluation research, conducted as part of the Almere Health Care Demonstration Project. In this ten year period a series of nineteen reports was published by the two research institutes involved in this project: the Netherlands institute of primary health care (NIVEL) and the Netherlands Hospital institute (NZi); NIVEL concentrated on research in the primary health care sector of Almere, whereas NZi focused on the hospital sector. Because the thesis is based on the results of this evaluation research, there is some overiap between the different chapters in this thesis and the reports published as part of the demonstration project, especially with the concluding report published in 1993. References and footnotes will provide the reader with information about these earlier publications. 
Like a good detective story, a major policy event like the introduction of a new health care system requires three elements: the opportunity, the motive, and the means or instruments. This thesis describes and analyses the health care demonstration project in the town of Almere. The opportunity was provided by the fact that in the Flevoland polders completely new towns had to be developed and built. One of these new towns, Almere, set the stage for the introduction of a new system of health care services, different from the health care system in the rest of the Netherlands. A combination of three factors provided the motive. These were: 1) The increasing costs of health care, particularly during the second half of the nineteen-sixties. (2) The dominant ideas in national health care policy of the seventies, which emphasized planning and government influence as ways to redirect health care in the direction of greater cost effectiveness. (3) Trends towards democratization and patient participation in the health care sector.

The new system of health care services in Almere was again based on three principles. (1) A strengthened primary health care system, organized around multidisciplinary health centres and the population's participation. (2) A deliberately limited hospital sector. (3) Carefully planned cooperation between the different health care services as well as between the authorities responsible for the planning and financing of parts of the health care system. These last three elements provided the instruments of the Almere health care demonstration project.

This thesis focuses on describing and evaluating the Almere Health Care Demonstration Project (AHCDP) as a policy programme. In doing so, the results of almost ten years of evaluation research that was conducted during the period when the demonstration project was implemented will be summarized. In addition to this, the political context in which the Almere health care demonstration project was implemented will be investigated, and a description will be provided of what happened after the demonstration project officially came to an end. Finally, where possible, up-to-date figures with respect to the functioning of the health care system in Almere up to 1996 will be provided.

In the introductionary chapter of this book the opportunities, motives and instruments related to the Almere Health Care Demonstration Project will be introduced. Section 1.4 describes the underlying research questions of the study and is concluded by a brief outline of the book's structure. 


\subsection{The opportunity}

The opportunity was formed by the availability of a new town on newly reclaimed land without pre-existing health care structures. As one observer accurately stated "... The typical Dutch way of constructing a health care system is as follows. Take a large quantity of water, build a dyke around it, pump the water out of it, build a couple of new towns and villages and provide this newly reclaimed land with a (new) health care system...." (Zee, 1990). This citation refers to the situation in the new Noordoost- and Flevo-polders where a new health care system was part of the new service-infrastructure.

For centuries, particularly in the period after the beginning of the industrial revolution in the second half of the 19th century "plans had been developed for one of the Netherlands largest inland seas, the Zuyder Zee. These plans varied from reclaiming small parts of land for agricultural development, to the complete reclamation of the whole area. These different plans were subsequently channelled into various strategies in the early part of the 20th century. First, it was shown that a combination of damming of the inland sea and the reclamation of large pieces of land, was feasible and realistic (Landheer, 1978). The introduction of the Zuyder Zee Project was followed by the acceptance of the bill to dam the Zuyder Zee and to reclaim new land from the former Zuyder Zee by the Dutch Parliament in 1918. Work on the dam started in 1920 and was completed in 1932. The former Zuyder Zee was subsequently renamed IJsselmeer. In 1930, the Wieringermeer polder became the first substantial piece of new land cleared of all water and in 1942 was followed by the Noordoostpolder. In 1957 and 1968 this was followed by the two Flevoland polders (see Chart 1). Plans to clear all water from the Markerwaard however were not carried out.

A few years after discussions about the next polders to be reclaimed from the IJsselmeer had started in the late 1930 s, proposals to structure future health care facilities in these new Flevoland polders were submitted to the Dutch Health Care Council (Gezondheidsraad), during the years of occupation by the German forces (Tuntler and Wassink, 1943). With reference to these first proposals, the 1942 Ministry of Health yearbook, published during the 5-year period of occupation, gives details (Dienst van de Nederlandse Staatscourant, 1943). Important areas considered by the national government at that time were "... careful and periodical health examinations of the entire population of the new polder, both by the medical profession as well as by anthropologists. A special public health service will be established to carry out these examinations. The result will clarify the relationship between the physical and mental norms among different social and biological groups in a newly formed society..... The number of general practitioners will be limited, free establishing is not allowed, and all general practitioners will be civil servants employed by the central 
government...". (Dienst van de Nederlandse Staatscourant, 1943, p. 733)!. Following discussion at the Department of Social Affairs these plans were partially rectified, although suggestions that refer to the future position of general practitioners were rejected.

Chart $1 \mathrm{l} / \mathrm{sselmeer}$ Polders and neighbouring reclamations from the former Zuyder Zee (Source: Dienst der Zuiderzeewerken)

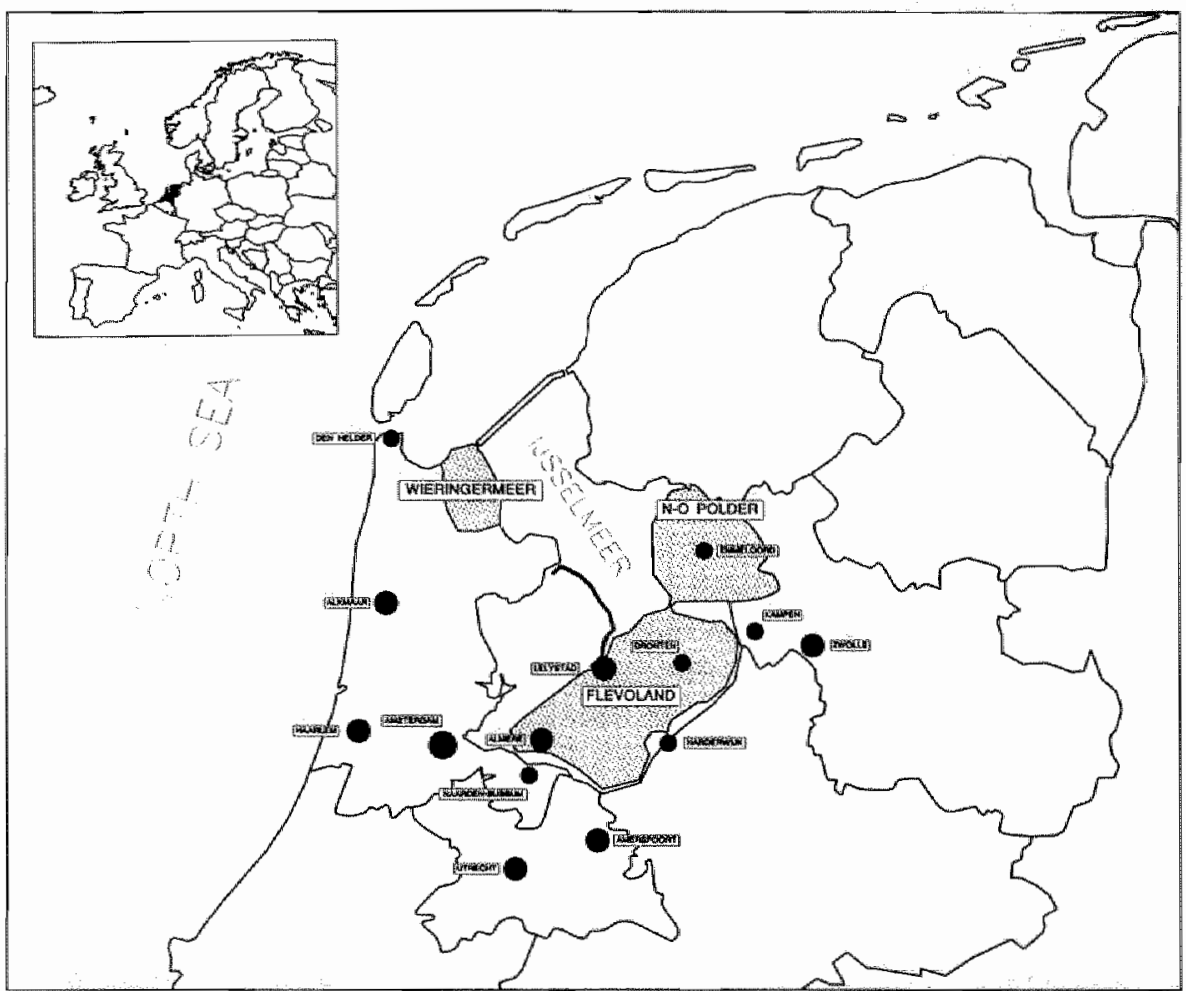

In reviewing the proposals made in 1943 , reasons why these plans were not implemented were " ... mistakes that have been made with respect to the coordination in our efforts to get things started under the difficult circumstances of an ongoing World War II. Also, I believe times were not yet ready to appreciate the proposed radical change of the health care system ....". (Tuntler and Wassink, 1953, p. 323; translation HS).

1 The original text of this statement was in Dutch. The statement, as well as the other statements that were originally published in the Dutch langulage, were translated by the author. This is mentioned as part of the reference as 'translation HS'. However, references refer to the originall publications. 
In 1953 Tuntler (ibid) was still optimistic about the possibilities to create a new society and a new system of health care services in the new polders, breaking away from the existing patterns. The central points of interest were: the key position of the general practitioner, close co-operation between health care professionals in different sectors, adequate administration for both practice management and research purposes, periodic health care examinations among the population by the general practitioners established in the polder and particular attention to the special circumstances of the population of these new polders. In respect of the status of the general practitioners, Tuntler still had the idea that "... In the new polders there will be no room for self-employed general practitioners, although a position as a civil servant is not absolutely necessary" .... "General practitioners will have to be selected by the local authorities of the new polders ...". (Tuntler and Wassink, 1953, p. 328-329; translation HS). In the same speech Tuntler concluded that "... Two experimental fields were already lost to realize the new structure I proposed: the Wieringermeer and the Noordoostpolder."... "Three more experimental areas will be available, including one at very short notice. [...] In case the experiment in the first polder fails, it will be easy to return to the old system. If corrections are necessary, the next polders will offer the opportunities to gain further experience on the way the new health care system can be organized. If the experiments succeed, it will be a blessing not only for these polders but also for the entire country...". (Tuntler and Wassink, 1953, p.326; translation HS). The three experimental areas Tuntler referred to, to be reclaimed in subsequent years, were: Flevoland Oost (including Lelystad and Dronten), Flevoland Zuidwest (including Almere), and the Markerwaard. At this time the option to develop the Markerwaard polder was still open.

Based on the first proposals by Tuntler and Wassink published in 1943, detailed plans for an experimental setting of the financial and organizational structure of health care facilities in the new polders, starting with the Flevoland East polder, were published in 1962 by the Health Care Committee Zuiderzeepolders (Commissie Gezondheidszorg Zuiderzeepolders). These proposals concentrated on the development of an experimental health care setting in the new Flevoland polder. This was characterized as an integrated health care system, with the general practitioner holding a central position and with governmental influence on the development of specialized health care services and preventive health care institutions. Key words in these proposals were (1) integration, (2) improvement of administrative services to support GPs, (3) co-operation between different health care services and sectors, and (4) the strengthening of health care services due to the specific circumstances in the polder (Commissie van Advies Gezondheidszorg Zuiderzeepolders, 1962). In order to coordination all activities the East Flevoland Health Care Foundation (Stichting Gezondheidszorg Oostelijk Flevoland) was established on the 4th of December 1963. The Foundation was to be responsible for parts of the health care budget, which 
came from regular sources as well as additional financial support from the Dutch Ministry of Social Affairs and Health on a year-to-year basis. in addition to that the Foundation was to take control over the existing health care centre in Dronten. The experimental health care setting in the new polder started in 1962 for a ten-year period.

For various reasons - Landheer ${ }^{2}$ (1978) mentions (1) the absence of a more detailed blue-print of the new structure, (2) the absence of financial support, (3) the departure of key-persons, and (4) the fact that a national framework for regional and local changes was missing - the plans to create a new health care structure in the East-Flevoland were unsuccessful. However, here one has to make a distinction between the plans for Lelystad and the surrounding area. including Dronten. With respect to the plans for East Flevoland excluding Lelystad, Landheer concludes that in 1972 most plans for this part of the polder were realized. Ideas to strengthen the position of the GPs, however, were not realized. Contrary to the original plans, people who had moved to the new polder were not given a first consultation with the GP to get acquainted with each other. Also not realized were the combination of curative and scientific work and structuralized co-operation between the different services, such as the integration between dental care and other primary health care services.

With respect to Lelystad it was decided at an early phase of the experiment, that Lelystad would be excluded from the activities of the East Flevoland Health Care Foundation and was put under the control of the Health Care Committee Lelystad (Commissie Gezondheidszorg Lelystad), established on 13 November 1967. The health care policy was in the hands of an administrator holding a medieval title of bailiff or 'landdrost' and with corresponding (full) powers. He directly governed under the Minister of the Interior. As a consequence of a decision taken in 1966, to make a distinction between Lelystad and the remainder of the polder, one of the original key elements of the plans accepted in 1962 - an experimental health care setting in the entire polder - was abandoned. Following this decision, no detailed plans were developed to (re)organize the health care structure in Lellystad. When summarizing the results of the plans developed by the Health Care Committee Lelystad in the period between 1967 - 1975, Landheer concludes that "... Plans were realized with respect to the combination of curative and preventive services of the GPS. Plans to limit the list size of the GPS, the integration of primary care services in health care centres and cooperation with midwives were not realized. Also the combination of curative and preventive dental care could not be reached. It is

Ton Landheer was appointed as Public Health Inspector for the prowince of Overijssel in 1963. As a public health inspector he was closely involved in the development process of $a$ health care structure for the Noordoostpolder and the Flevolandpolders (see Chart 1). 
still uncentain when the hospital will be realized ...". (Landheer, 1978, p.66; translation HS).

The new town of Almere, situated in the Southeastern part of the same polder. provided a new (and probably last) opportunity to develop a different health care system on reclaimed land under special circumstances. Local government was provided by the Openbaar Lichaam Zuidelijke IJselmeerpolders (0.I. ZIJP). This public body was installed by the central government and did not have any formal or direct relationship with the population of Almere. Due to the undemocratic nature of the system at that time developments could be speeded up. Democratic support and control by the local population is missing. Provincial authorities were absent until 1 January 1986. At that date Flevoland became Holland's twelfth province. Two years earlier, on 1 January 1984 "Almere reached the official status of municipality.

\subsection{The motive}

Undeveloped land itself is an insufficient condition for the successful implementation of a new health care system. This was shown by the failure of the East Fevoland experiment to provide the town and region with a coherent, wellorganized, health centre based system. It is also necessary that there is a motive behind the implementation of a health care experiment. With respect to the AHCDP the motive can be found in a combination of factors.

The health care system to be implemented in Almere, was based on the prevailing ideas in Dutch politics about the planning and functioning of health care services in the 1970 s and early 1980 s. In the early 1970s, health care in the Netherlands, and especially the primary health care sector, was characterized by a lack of cohesion, poor organization "fragmented financial resources and an uneven geographical distribution of health care providers (Schrijvers, 1983; Bakker, 1989). These elements, together with an emphasis on hospital care during the post-war period, caused an unprecedented growth of health expenditures in the period 1965-1975. Figures from the Organisation for Economic Co-operation and Development (OECD) show that in 1960 approximately 3.9 per cent of the Gross National Product in the Netherlands was spent on health care. In 1975 this percentage had almost increased twofold to 7.6 per cent (OECD, 1990). In the absence of instruments able to effectively limit growth in health care expenditures, the alternative policy was to offer a comprehensive and organizationally coherent set of health services at the local government level, in combination with planning and financing responsibilities at the central level. Based on the 1974 Memorandum on the future structure of Dutch health care services (Ministerie van Volksgezondheid en Milieuhygiëne, 
1974), health care authorities saw for the first time the opportunity to direct events instead of following them. For the health care workers, the introduction of community based health centres with different professions, working closely together, was to result in improved working conditions and quality of care from the perspective of the patient and the provider.

At this stage it can be argued that the basic ideas behind the AHCDP fit into the general line of policy-making in the Netherlands as it developed from 1974 onwards. This will be discussed further in chapter 2. Moreover, they also fit into a broader trend in national health policy developments in other European countries, such as the United Kingdom, Finland, and Sweden, as well as in supra-national developments stimulated by the World Health Organization (WHO).

At the time that the Tuntler and Wassink's proposals to restructure the Dutch health care system were offered to the Health Care Council, the UK set the stage for the implementation of a National Health Service (NHS). While the nationalization of the health care system, as suggested by the proposals of the Van Rhijn Committee in 1945 (Commissie Van Rhijn, 1945) was neither a possibility nor a priority in post-war Netherlands, the situation in the UK was different with the implementation of the NHS in 1948 which continued to be of interest to Dutch policy-makers. This was especially so during the second half of the 1960's, when planning and government intervention were seen as the most obvious way to solve the problems of the health care system. At this time the NHS was preparing a major restructuring which took place in 1974, in order to integrate the different services provided by the NHS and to improve the regional structure of the NHS (Schrijvers, 1980). The issue of the integration of services closely resembles part of the Dutch diagnosis of a patchwork of services, with a lack of demarcation between primary and secondary care and lack of integration within primary care. To solve the problem of having three separate services in the UK's NHS - hospital services, community services and family practice services - each with their own planning and operating regimen, a clear structure of hierarchical planning was created and efforts were made to integrate the different health care services by stimulating health centres and group practices. These developments in the United Kingdom were studied and emphasized by Dutch observers during the sixties and early seventies (Brandt et al, 1965), and may have at that time served as examples for the future Dutch health care system. However, here one has to keep in mind that such an NHSbased structure of health care services differed fundamentally from the existing Bismarckian system. This was characterized by insufficient influence from the central government on the provision of health care services, the strength of employee and employer organizations, as well as a division between private and public based insurance. 
In Finland, local authorities and municipalities had legal responsibilities for organizing health care services (Bäckman, 1988), functioning within a framework of national rules and legislation. At the national level, the National Board of Health took charge of health problems of nationwide importance, as well as the planning and supervision of public health, hospital and pharmaceutical services, the training of health personnel and the collection of data for health information schemes on a national basis (Purola, Kalimo and Nyman, 1974). To balance the need for and utilization of the different health care services from hospital care to primary care, a National Sickness Insurance Scheme was introduced in 1964, but its effect was labelled as 'evident but still insufficient' (Pekurinen, Vohlonen \& Hakkinen, 1987). Other developments, such as regional inequalities in health and differences in the use of outpatient health care services between regions and selected groups of the population, contributed in 1972 to a shift towards a more primary care oriented health care system in 1972. With the acceptance of the Primary Health Care Act, systematic planning was introduced on all three levels, based on five year planning periods and organizing the different communal activities into one entity. The level of state subsidy was equalized in primary and specialized hospital care, and regional balance was facilitated by granting subsidies inversely to the financial status of the local authority and by allocating additional resources to primary care services. Facilities ran separately before 1972, were brought together under local management in the form of networks of health centres (Aro, 1990). Although decision making remained strongly decentralized, national-set priorities and activities were channelled to the local authorities, using the system of state subsidies as a central steering mechanism. This new system of planning and state-subsidies, with health centres being Finland's basic primary care units, serving an average of some 20,000 people, became fully operative in 1974. The Finnish example showed that a primary care based system can be implemented successfully on a nationwide level (Schrijvers, 1980).

In Sweden, financing, control and delivery of the different health care services was predominantly governmented by the public sector (Stephen, 1979; Calltorp, 1989; Schrijvers, 1980). Planning and provision of health care services were decentralized. This decentralization of health care responsibilities to county councils became an official policy of the Swedish government with the new Health Care Act of 1982. This Act gave counties the explicit obligation to plan and deliver all health service requirements, including private care financed by the National Health Insurance system. Three planning perspectives were used: longterm planning (10-15 years), medium-range planning (3-5 years) and year-toyear planning. The Ministry of Health and Social Affairs and the National Board of Health and Welfare took care of the legal framework and the development of health care services from the centre (Diderichson, 1993). Within the county council's administrative and financial structure, the delivery of medical care was divided into three separate components which were primary, county hospital, and 
regional hospital care. The primary health care delivery system was based on small geographical districts consisting of some 20-50,000 people, with each district operating a number of health centres, nursing homes and child health centres. With few exceptions, general practitioners and medical specialists in Sweden were salaried employees (Salmela, 1991; Rosenthal and Frenkel, 1992). The Swedish system may have been for the Dutch policy makers as an important example, with the exception of the position of the primary health care services.

On a supra-national level, in 1977 the World Health Assembly (WHO) - the WHO's worldwide 'parliament' - officially agreed on the statement that national governments and the WHO should enable all citizens worldwide to attain, by the year 2000 , a level of health that will permit them to lead a socially and economically productive life (WHO, 1981). The key instrument in making this 'Health for all' in the year 2000 effective, was an organized system of primary health care services to which all persons have access (Vuori, 1986). National health services were to be organized in a coherent system, with primary health care in all its facets being regarded as an integral component of such a system. For highly industrialized societies, the primary health care (PHC) concept was considered as an important instrument to limit the growth of the hospitall sector. In this respect, the concept was seen as an elegant combination of political, social and economic factors. This was politically, because it offered national governments the opportunity to improve the quality of care by bringing facilities closer to the people, and socially because it can be seen as part of a process of democratization. Finally, economically, because in the long run a PHC-based health care system is probably cheaper than a hospital based system.

Health policy at the national and international level is transient, and during the years of implementation of a new health care system in Almere, gradual changes took place in nationall health care policy and were implemented nationwide. Although the new Almere experimental health care setting was supported by central government funds, there was no political intention to await the results of the Almere project. Especially during the 1980 s, ideas concerning national health policy deviated increasingly from those implemented in Almere, and from 1985 onwards a shift in health policy towards market elements and competition became apparent (Lapré, 1988; Janssen and Made, 1990). Five years after the start of the Almere demonstration project, the administrative and legall conditions for the experiment were finally fulfilled (Staatsblad van het Koninkrijk der Nederlanden, 1988). National policy was already in the process of redirection 
towards a more market oriented system of health care provision ${ }^{3}$. Therefore, one might say that in terms of opportunities, motives and instruments, the motives and corresponding means gradually changed during the AHCDP.

\subsection{The instruments or means}

The first official inhabitants of Almere arrived on the 30th of November, 1976 (Sixma and Voort, 1985). From that time on the implementation of the Almere health care system commenced; initially in an unofficial way and without detailed plans for future health care services. However, after the 28th of January 1983 this became official with the installation of a complete administrative structure and with detailed plans leading to the achievement of the ultimate goals of the health care system.

An important idea behind the 'Almere model' was that patient participation based on the patients' perspective would lead to better quality of care, and that the local (community) level provided the right political and administrative framework for such a form of democratization. The blue-print for the future health care system in Almere, introduced different ways of patient participation: direct participation, participation in policy making through representatives, participation in advisory bodies and supporting activities in interest groups around health care facilities. Implementation was part of the Almere Health Care Experiment (Stuurgroep Gezondheidszorg Almere, 1983). In this published document democratization was not limited to patients only and was also defined as "... influence of the population, health care providers, private organizations, insurers and authorities on local health care policy. ..." (Stuurgroep Gezondheidszorg Almere, 1983 , p.24; translation HS).

A second and important aspect was the establishing of integrated organizations for the different tiers of care including community based health centres, regionalization and the decentralization of planning authority and the strengthening of primary care services (Bakker, 1989, p.59-60). This aspect was related to the PHC-concept adopted by the WHO in its Alma Ata declaration (WHO, 1981), which had proven to be successful in developing countries (Muller, 1995) and in countries at an early stage of the industrial revolution (The World Bank, 1993). The PHC concept was put into practice in Finland (and with respect to the planning of services in Sweden) in the 1970 s and early $1980 \mathrm{~s}$.

3 For a recently published view on future health care policy in the Netherlands and the organization of the system of health care services, as well as the instruments to reach these policy goals, see the report Health Care Policy ("Volksgezongheidszorg") published by the Wetenschappelijke Raad woor het Regeringsbeleid (1997). 
The application of these instruments in a modern, western society without a tradition of a community based health care system like the Netherlands would contribute to the overall acceptance of the PHC-model for future health care policy developments. Also it might prove that the PHC-concept could be the answer to the request for more cost-effectiveness in health care policies. Here, the AHCDP (AHCDP) could be the instrument to find out if a change in policy from hospital oriented care towards $\mathrm{PHC}$, might be a workable solution to overcome problems of the existing health care system.

Key-words related to the instruments applied in the AHCDP were: (1) cohesion and comprehensiveness versus fragmentation (all services in one organization; no self-employment, no fragmentated funding), (2) planning versus spontaneous developments, (3) primary care based versus hospital centred, (4) community level versus national level, (5) patient influence. These instruments should result in a more cost/effective health service, providing an alternative health care structure without losing quality of care. In this way, the local health care system in Almere can be subsequently seen as a first empirical test to implement this new strategy on a small scale basis.

The 'Almere model' was meant to serve as an example for the rest of the Netherlands, which can be derived from the official decree that marked the start of the AHCDP, signed by the Secretary of State for Welfare, Health and Culture and the bailiff of the polder on the 28th of January 1983. This decree emphasizes the importance of the Almere-model for future health care policy "... experiences acquired on the basis of the project can be important for the future national policy in the health care sector and the social services sector. ..." (Projectgroep Gezondheidszorg Almere, 1983, p.1; translation HS)

\section{$1.4 \quad$ Research questions}

During the Almere Health Care Demonstration Project, progress and developments in Almere were closely monitored in order to establish if such a comprehensive, planned approach would be feasible for the remainder of the Netherlands. However, it should be recognized that to a certain extent Almere can be characterized as 'an organized isle in a far less structured surrounding sea'. Although measures were taken nationwide by governmental authorities to limit the growth of health care expenditure in general and in the hospital sector in particular, the provision and funding of health services did not change fundamentally. In total, the period of government dominated health care planning lasted for a relatively short period of time and was mainly implemented on paper. The 1974 Memorandum regarding the health care structure marked the start of a period during which governmental planning was the leading principle of Dutch 
health care policy ${ }^{4}$ and covers the prologue and the first three years of the demonstration project. From 1986 proposals of the Dekker Committee (Committee on the Structure and Financing of the health care system, 1987), towards more market driven elements and less government control, became the leading principle of Dutch health care policy. Both preceding and following the start of the AHCDP, government influence on health care organization was less fashionable than between 1975 and 1985 . This implies that one cannot study the demonstration project without taking into account a longer period of health care policy-making than the 10 year period of the demonstration project. The Almere project should be embedded in a policy analysis, covering a timespan longer that the project lasted, and should take into account that national policy and Almere policy were at odds and in harmony during different periods. The first research question (Q1) is related to this policy context, which provided the motive for the demonstration project.

Q1 How does the Almere health care project fit into the increased tendency to allow more government influence in the organization of the Dutch health services in the mid 1970 s and the subsequent shift in national health policy towards the introduction of market elements in the mid 1980 s?

The policy context of the situation in Almere will form the background of this study. A background that should be taken into account in the 'final' judgment about the Almere achievements at the point in time when the demonstration project officially came to an end. The demonstration project in itself will be evaluated as a policy programme. The project was designed to stimulate substitution of care and to increase quality of care on the benefit side against reasonable and controllable costs. Discrepancies between goals, instruments and outcomes will be examined. Based on this perspective three basic questions arise:

Q2 Was it realistic to expect that given the instruments chosen and the conditions expected, the Almere Health Care Experiment would be successfull in reaching its goals of substitution, quality and costs?

\footnotetext{
At least on paper, as we will show in more detail in the chapters 3 and 5 of this bonk. The 23 year period between 1974, when the White Paper on the futhre structure of health care services in the Netherlands was published, and 1997 can be diwided in three sub-periads. The first period covered the years between 1974 and 1982, and can be characterized as a period with strong belief in and emphasis on governmental planning. The four year period between 1982 and 1986 showed a gradually diminishing emphasisi on govermmental planning and a growing attention for the introduction of market elements in the health care sector. Finally. the period since 1986 can be characterized by the introduction of market elements as the leading principle for health care policy in the Netherlands.
} 
Q3 Was the experimental health care setting in Almere successfully implemented and were the goals formulated in 1983 actually reached?

Q4 Are the results of the Almere Health Care Experiment empirically related to the way the health care system in Almere was shaped?

Q2 refers to the expected feasibility of the AHCDP on the basis of existing literature and experiences with similar projects. The expected conditions refer to the opportunities provided by the context in which the demonstration project was conducted. Q3 concerns the implementation period that started in 1983 and ended in 1993. Q4 is expected to be the more complex to answer as it relates to the empirical findings with respect to the goals, instruments and conditions of the Almere Health Care Experiment to each other. Therefore these last three research questions can be rephrased as follows (1) Was it a good plan? (2) Was it realized? (3) Did it work according to the expectations? These three questions will be discussed in chapter 3 .

\subsection{Structure of the book}

The structure of this book follows the research questions of the previous section. In order to indicate the time frame of the Almere Health Care Experiment the policy question is addressed in two chapters. Chapter 2 describes the period before the official start of the experiment, starting in 1945 and finishing in 1983. Chapter 5 concentrates on the developments during and after the Experiment and covers the years between 1983 and 1997. Both chapters 2 and 5 will be limited to the policy developments in the Netherlands, describing the changes in prevalent ideas concerning the structure and functioning of the health care system as well as some of the reasons which may have contributed to these changes between 1945 and 1995 . This description in chapters 2 and 5 provide the answer to the first research question Q1: "How does the Almere Health Care Demonstration Project fit into the increased tendency to allow more government influence in the organization of the Dutch health care services in the mid 1970 s and the subsequent shift in national health policy towards the introduction of market elements in the mid 1980s?

Chapters 3 to 8 deal with the three policy programme questions. Following the description of a conceptual framework in chapter 3 , regarding programme evaluation in general and health care programme evaluation in particular, chapter 4 deals (in hindsight) with question Q2: "Is it realistic to expect that, given the instruments chosen and the conditions expected, the Almere Health Care Experiment will be successful in reaching its goals?". Chapter 4 also illustrates that there is an important pre-experimental phase between the early 
1970s and 1983. In this period, the ideas to give Almere an experimental health care system were shaped, as were the conditions behind this field experiment. Chapter 4 will also include a description of the implementation process, in addition to a review of the instruments and the conditions experienced during the implementation process.

Chapters 5 through 8 focus on finding an answer to question Q3: "Was the experimental health care setting in Almere successfully implemented and were the goals regarding substitution, quality and costs of care formulated in 1983 actually reached?". Chapter 5 is devoted to the question as to whether substitution of care has been reached (1) within the hospital and institutionalized sector, (2) from hospital and institutionalized care to outpatient and primary care, (3) from professional to informal care, and (4) from curative to preventive care. Chapter 6 focuses on various aspects of the "quality of care" concept. In doing so a distinction will be made between the process of care provision and the Almere population's perceptions of different aspects of the care provided. While chapters 5 and 6 deal with the benefits of the Experiment, the cost-benefit relationship will be described in chapter 7 . Details will be given about the costs of the hospital sector, the costs in the primary care sector and costs of care of the elderly.

Chapter 9 will answer question Q4: "Are the results of the Almere Health Care Experiment empirically related to the way the health care system in Almere was shaped?" This will be achieved by comparing age- and morbidity specific information concerning the situation in Almere with the situation in other populations. Although such a comparison does not guarantee the existence of an empirical relationship between the 'Almere model' and the resulting figures, it does provide us with the opportunity to rule out at least some of the alternative explanations for differences between Almere and the Netherlands in general.

In conclusion, chapter 10 will provide the answers to the research questions briefly formulated in section 1.4 and more extensively discussed in chapters 2 and 3 . 
This chapter deals with the development of a new health policy in the Netherlands within a general political and economic context, to provide a (partial) answer to research question Q1: "How does the Almere health care project fit into the increased tendency towards more government influence in the organization of the Dutch health services in the mid 1970 s and the subsequent shift in national health policy towards the introduction of market elements in the mid 1980s?" Policy and developments will be described for the period between 1945 and 1983. The year 1945 marked the end of World War II. The year 1983 is chosen in relationship to the official start of the Almere Health Care Demonstration Project in 1983.

\section{$2.1 \quad$ Introduction}

Dutch politics is coalition politics, and thus consensus politics. This means that in the Netherlands, in contrast to Westminster systems of one-party governments, a longer period of deliberations preceeds plans and ideas, and as a consequence a greater chance of discontinuities between original plans and actual implementation of these plans. Different parties have to keep in mind the fact that a change of coalition is always possible, and that therefore plans developed by one government are maybe implemented by the next. The statement, that Dutch politics is consensus politics holds for policy in general as well as health care politics, particularly when it concerns important issues such as the planning and functioning of health care services and the way the health care system is financed. This chapter will focus on three issues: (1) the political and economical developments in general, (2) developments in health care policy, and (3) health care expenditure.

The thesis will be dealing with these topics in a time frame consisting of three periods, determined by a combination of political and economic developments in the Netherlands. Part one covers the immediate postwar period between the end of World War II in 1945 and the end of 1958, when the first post-war coalition government without the labour party came into power. This period can be seen as one dealing with the economic, physical and emotional consequences of the war period. The rebuilding process was carefully orchestrated, in both the economic and the health care sectors. The second period between 1958 and the early $1970 \mathrm{~s}$, is characterized by undisrupted economic growth. Under these prevailing conditions and changing political ideologies, governmental control in the health care sector was no longer seen 
as a necessary condition to secure the position as one of the stronger economic societies in the world. This period of economic growth lasted until the early 1970s, when Western societies faced a period of economic recession following the oil crisis of 1973. As a consequence Dutch health care policy was tailored to be more cost-effective. To realize the necessary change towards more costeffectiveness the idea was to establish a certain amount of governmental influence in the health care sector. The Almere Health Care Demonstration Project (AHCDP) can subsequently be seen as a small scale experiment of the ideas developed in the first half of the 1970s, which were strongly influenced by the political and economical context in which they emerged ${ }^{1}$.

\subsection{General political and economical developments}

During World War II both the Queen and the government resided in London, but were re-installed in 1945. The political arena, however, had changed by the emergence of new political configurations, especially in respect of the liberal and labour parties. Social democrats and progressive liberals united in a broad labour party, whilst the so-called liberal party retained its conservative policies. During this period, christian politics remained separate for catholics, reformed protestants and re-reformed protestants until 1978, when a broad christian democratic party was formed by merging the denominational parties.

In the years immediately following World War II, political power was in the hands of coalition cabinets that consisted of the Labour party and a number of christian parties. From June 1945 until December 1958, the minister or secretary of state responsible for health care policy was a member of the Labour party. The main task the labour and christian party coalition had set themselves directly after the war, was the rebuilding of the Dutch economy and society and solving the colonial heritage. The so-called Reconstruction Act passed parliament in 1950. It was meant to orchestrate all building activities including the health care sector. Wages and prices were strictly regulated in order to facilitate the development of the economy until 1961. During this period governmental authorities had almost full control over the provision of health care services. Control was considered necessary in order to facilitate economic growth and welfare, economically supported by funds provided by the United States of America as part of the Marshall plans. At the end of the dominance of the coalition cabinets of labour and christian parties in 1958, the first cornerstones of the welfare state were legislations covering retirement pensions and unemployment.

Another review about policy reforms in this period, based on a historical analysis of the (changing) positions and alliances of the different parties in the political debate and the implementation period following this debate "is given by Okma (1997), whereas Heffen and Kerkhoff (1997) especially focused on policy developments related to the public health sector. 
Changes in the political situation became apparent after December 1958 , when a period of central-left government domination was followed by a series of cabinets where the christian parties formed coalitions with the liberal conservatives. This lasted until May 1973 with only a short interruption between April 1965 and November 1966, when the labour party was back in the coalition. In the central-right coalitions the Ministry of Social Affairs and Health was firmly in the hands of the christian democrats.

Following the introduction of central-right governments by the end of the 1950 s, ideas concerning the role of central government became more liberal. Although the Restructuring Act remained in force, constraints were gradually reduced due to the improving economic situation, and were partly abolished in 1965. In this period, a tendency towards democratization developed in society in general, and especially among younger people. From an international perspective one of the most pronounced examples of this tendency was the 1968 student revolt in Paris. On a national level, examples included the 'provo' and 'hippie' movement in Amsterdam. As a consequence of the prevalent ideas among leading christian democrats and conservatives, that strong governmental influence on the planning and structuring of society was no longer necessary, controlling agencies and advisory boards in which civil servants and private organizations played the important roles were able to strengthen their positions.

By the end of the 1960s the political and economic climate started to change. When the development of the institutions within the welfare state reached its peak, the first cracks became visible in an uncontrolled increase of expenditure including health care. Solutions were expected from state intervention in the form of planning and regulation. On 11 May 1973 a central-left government came to power, after a lang and difficult period of formation lasting almost half a year. Although holding power for only a four-year period - the christian democrat and conservative liberal coalition returned to government in 1977 and remained in power with the exception of a brief interruption until 1990 - this change clearly left its marks on Dutch health care policy. In line with the change in views with respect to the role of the state and planning in society, the central-left coalition attempted to realized a number of labour party ideals. These included the complete restructuring of the health care sector and the introduction of a population-wide, compulsory health insurance. Although fiscal austerity was the prevailing government ideology, an alternative to government planning and intervention had to wait to the second half of the $1980 \mathrm{~s}$.

The success in restoring welfare and wellbeing between 1945 and 1958 by the strict regulation of different services, can be illustrated by a number of graphs and statistics. The Gross Domestic Product (GPD) increased from DFL 10,900 million in 1946, via DFL 42,305 million in 1960 and DFL 121,180 in 1970, to over 336,000 million in 1980 . In the years between 1960 and 1980 , purchasing power 
parities (PPPs) for the GPD in the Netherlands increased from 2.04 in 1960 to 2.75 in 1980 (OECD, 1996). Figures from the Dutch Central Bureau for Statistics (CBS) show that during the period between 1960 and the early 1980 s, unemployment rates remained low until the early 1970s (CBS, 1994). However, between 1970 and 1983 , the percentage of unemployed people increased from $1.1 \%$ to $6.0 \%$ in 1980 and reached its maximum of around $17 \%$ in $1983 / 1984$ (see Graph 2.1).

Graph 2.1 Trend in unemployment rates for the Netherlands between 1952 and 1983 ; percentage unemployed persons as part of the total number of wage earners. (Source: CBS, 1994)

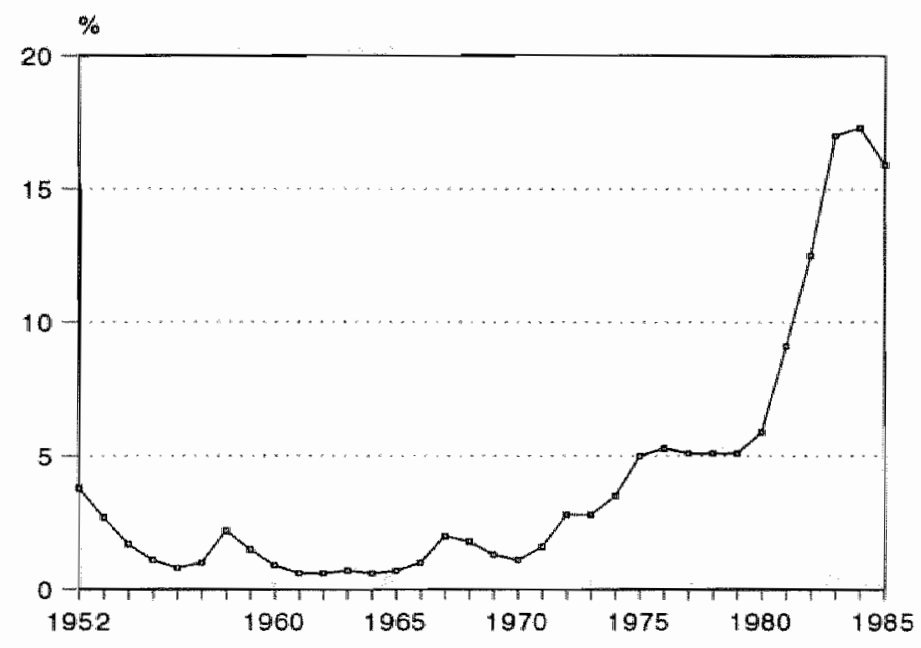

In the same period the number of people employed in public services and the commercial sector steadily increased, whilst the number of people employed in the agricultural and fishery sector decreased. The number of people working in the industrial sector (including mining, building and industries n.e.c.) increased until approximately 1960 , followed by a decrease in the following years. This is illustrated in Graph 2.2.

The rapid development of the economy in the 1950 s and 1960 s provided the opportunity for extension of the welfare state. When welfare states reached their peak in the early 1970 s and the use of relatively cheap natural resources such as oil was taken for granted, economic growth was suddenly disrupted in 1973. An event which is best known as 'the oll crisis'. 
Graph 2.2 Distribution of people, working in the different sectors in society, between 1947 and 1982, in percentages (Source: CBS, 1994)

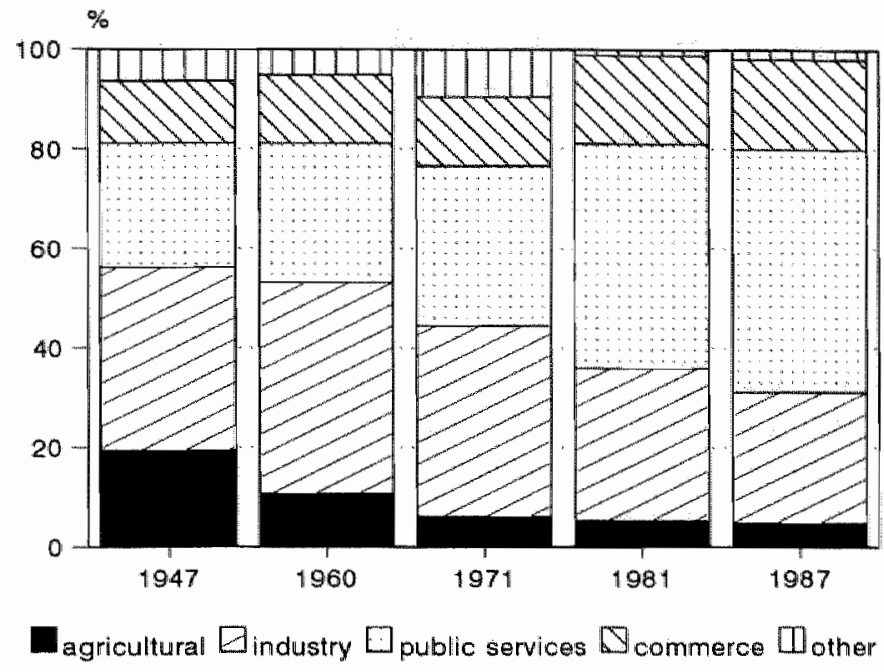

To secure an income for the unemployed, three steps were taken: (1) old age pensions for the increasing number of elderly people, (2) social security and income assistance for those people who were unable to work for other reasons than incapacity, and (3) income substituting benefits for employees and selfemployed who were unable to work. Increasing life expectancy and a fixed pensionable age of 65 necessitated an extension of the system of pensions by means of additional arrangements. With respect to the second group it can be noticed that, as part of the economic depression unemployment rates increased rapidly from around 5 per cent in 1975 to over 17 per cent in 1983 , in conjunction of dependence upon relief funds provided by the State for other reasons than incapacity to work. The fact that children were no longer taking care of their parents was officially recognized by in the Generall Welfare Act (Algemene Bijstands Wet) in 1965, and it became common practice that frail elderly people became institutionalized in old people's homes or nursery homes instead of staying with the (extended) family. Finally, social security for those incapacitated to work was introduced in 1968. Benefits were based on the level of income up to a certain (rather high) level and consisted of $70 \%$ of the actual income or of the income ceiling.

\subsection{Health care policy between 1945 and 1983}

In accordance with the general political and economic developments, health care policy between 1945 and 1983 can be labelled as one of rebuilding and growth. 
However, in the health care sector not all remnants disappeared. After the end of World War II the public health insurance legislation of November 1941, remains a sound underpinning of the Dutch health care system today. Discussions with respect to the introduction of a public health insurance system in the Netherlands go back to as early as 1900 , when a series of social security acts, including the Workmen's Compensation Act (1901) and the introduction of an Invalidity and Retirement Pension (1913), was enacted. A sickness insurance law was already discussed in 1913. The implementation of a sickness insurance law was first delayed until 1930, and finally brought in by the occupying Germans in 1941. Regarding this implementation process, De Swaan (1988, p.210) refers to this period as 'The Netherlands: a long sizzle and a late bang". Apparently the appeal of the Sick-Fund legislation, forming a mandatory base for appraximately $70 \%$ of the Dutch population with earnings below a fixed ceiling, was such that it fitted seamlessly into the postwar construction of the Welfare State. The fact that the Sick-fund legislation can not be considered as a typical Nazi policy-instrument and can be traced back to the much older Bismarckian social security laws (Swaan, 1988) , contributed to the fact that this legislation remained in force after 1945. Thus resembling the Alsatians returning to French authority after World War I; they too, opted for the German social security legislation (Swaan 1988, p.202).

\section{The period $1945-1958$}

The first plans to restore and reconstruct the Dutch health care system following World War II were published in 1945 by the Van Rhijn Committee. This blue-print for what could be the future structure of the Dutch health care system, was prepared by order of the Dutch government, temporarily located in the UK. Not surprisingly, the proposals in this report were influenced by the discussion in the UK following the publication of the 'Social Insurance and Allied Services' proposals by Sir William Beveridge in 1942 (Juffermans, 1982). These proposals included the fundament for the National Health Services (NHS) Act in 1946, and the intraduction of NHS on 5 July 1948. In terms of Beveridge, social security could be reached by "... a comprehensive national service for the prevention and the cure of diseases and disability ... for every citizen .... whatever medical treatment he requires, in whatever form he requires it, domiciliary or institutional, general, specialist or consultant ..." (cited in Juffermans, 1982; translation HS).

From an organizational point of view, the Van Rhijn Committee was strongly in favour of a system with 16 to 18 health care districts in which the organizational power would be in the hands of governmental bodies. This was because of "... the great interests that are involved in the organization of health care services ...". (Van Rhijn Committee, 1945, cited in Juffermans, 1982 p.142; translation HS). Due to the way the Dutch health care system was to be financed, the plans 
of the Committee Van Rhijn differed from the NHS model, in introducing a premium financed insurance system for the entire population rather than a system financed by the State.

If the Van Rhijn proposals had been selected as guidelines for future Dutch health care policy immediately after World War $\|$ and subsequently had been carried out, this would probably have resulted in a health care system similar to the NHS. However, consensus and coalition democracy in the Netherlands differs from one-party democracy in the United Kingdom. Whereas in the UK the Labour Party successfully had the NHS-proposals passed through Parliament, the Dutch labour party could not accomplish the same with the plans of the Van Rhijn Committee. This was due to the strong opposition from private health care and labour organizations, who supported the current social security system. Following the Van Rhijn proposals, a series of reports were published. With reference to plans to reorganize the planning and structure of health care services, solutions varied from systems completely (see the Van Rhijn proposals) or partly (Commissie Banning, 1946) based on strong governmental influence, to a system entirely based on private initiatives (Cientrum voor Staatkundige Vorming, 1950). Under such a private system, regional governmental authorities - which could be compared with districts - had an important coordinating function between the different private organizations and could also function as advisory bodies for central government and private organizations (Vreeze, 1968). The discussion ended with the acceptation of a new Health Care Act (Gezondheidswet) in 1956 by the Dutch parliament, leaving the traditional freedom for the private organizations uneffected. The new organization created on the basis of this act the Central Board for Health Care Affairs (Centrale Raad voor de Volksgezondheid), should be regarded as an advisory committee, without any real power to change the prevalent health care system.

In summary, the 1945 - 1958 period can best be described as a period of controlled growth of the health care sector. Ambitious plans to restructure the planning and financing of health care services, developed during and shortly after World War II, were soon substituted by a more realistic scenario. The restructuring of the health care planning and financing system did, however, not have top priority in this scenario. Governmental influence with respect to the planning and costs of health care services (especially in the hospital sector) remained an important issue until the late 1950s.

\section{The period $1958-1973$}

At the end of 1958, the level of governmental control in the health care sector started to diminish. First, because the flourishing economic situation allowed the reins to be slackened. Secondly, because liberalization and deregulation were 
more in line with the views of the central-right governments that had come into power in 1959. What proved to be possible in the economic sector - a national policy to rebuild a new society after the terror of World War II - could not be reached in the health care sector. One might say that in the 20 years after the second World War health care policy simply did not have the central position on the political agenda that was reserved for social-economical problems.

Also in this period, health care policy power gradually shifted from central government to those controlling agencies in which civil servants and private organizations were represented. Health care providers, their professional and health care insurance organizations maintained and even strengthened their dominant positions with respect to the functioning of health care services. As within the economic sector, the tight framework of planning and structuring health care activities that dominated this part of Dutch health care policy after 1945 became increasingly more liberalized, following the improving economic situation. In 1961 the existing Act on Tariffs and Prices, which dated from 1938, was succeeded by a New Act on Prices. However, this new act left most of the prices untouched. For the expanding hospital sector the solution was considered to be a new Act on Hospital Tariffs, accepted in 1965. According to this Act, the Ministry of Health had limited authority to interfere in the tariff negotiations between the Sick Funds and hospitals.

With respect to the way the health care system was to be financed, discussions changed from the introduction of a social security system for the entire population to minor modifications of the existing German Sick-Fund legislation. Or "... Social Security from the cradle to the grave .... is not a slogan you will ever hear from my mouth. Only a totalitarian state, which has the power to enforce such a thing, can dangle this before the eyes of its inhabitants ...", as expressed by the Dutch Minister of Social Affairs and Health and member of the Labour Party in 1952 (see Muntendam, 1965; translation HS). The discussion was also influenced by the fact that from 1945 until the end of the 1950 s central government maintained a policy in which wages and social insurance contributions were kept at a minimum, so as not to frustrate the post-war rebuilding process. Further developments towards a health insurance funds for all citizens " as proposed by the Van Rhijn Committee, were not in line with this governmental policy and consequently not implemented. The discussion whether or not the German Sick Fund Act was to be superseded by new legislation ended in 1966, when the 1962 proposals for a new Sick Fund Act were finally accepted by the Dutch parliament.

Nevertheless, the 1966 Sick Fund Act can be considered as a codification of the existing health care insurance system.

Implementation of the Sick Fund Act in 1966 was followed by the General Exceptional Medical Expenses Act (Algemene Wet Bijzondere Ziektekosten 
(AWBZ)), which covered exceptional medical expenses for the entire population including hospital admissions longer than one year. This act passed Dutch Parliament on October 25, 1967, and was implemented in January 1968. Acceptance of the two Health care financing acts created a situation in which almost everybody could legally claim access to the different health care services (Roscam Abbing, 1979). As will be shown in the next section, the Exceptional Medical Expenses Act in particular had serious consequences for the costs developments in the health care sector.

The planning and structuring of health care services in the first half of the period between 1958 and 1973 , can be described as a process of continuing expansion and liberalization (Juffermans, 1982). Guided by the prosperous economic circumstances of continued growth, this process was set in motion between 1959 and 1964. Planning regulations that still existed as a relic from the post-war period, such as the Restructuring Act, were abolished. Reflecting on this period, with the knowledge that one has a decade later, one can agree with Juffermans $(1982, p .203)$ that "... in the eve of a rapid expansion of the health care sector, central government gave away the instruments which might have been useful to control this growth ...". (translation HS).

The second half of the 1960s saw the first signs of a shift towards an increase in government control, illustrated in a Memorandum published in 1966 by the Dutch Ministry of Social Affairs and Health. Praised by some (Lamberts, 1966) and criticized by others (Vreeze, 1966), this memorandum was rather more a discussion paper than a policy statement, presenting the basic ideas which later became known as the 'health for all' strategy from the WHO (WHO, 1981). Points of discussion were equal access to health care facilities, adequate division of resources between different health care sectors, quality improvement of health care services, and future reorganization of the governmental system in dealing with future health care problems (Ministerie van Sociale Zaken en Volksgezondheid, 1966).

Following the 1966 memorandum, a model for restructuring Dutch health care services was elaborated by the Dutch Labour Party (Dr. Wiardi Beckman Stichting, 1967). In order to comply with the disadvantages of the 'old' system (1) a clear division in tiers was thought to be necessary, (2) primary health care was to be strengthened by establishing local networks of health care centres and (3) a uniform health insurance system for the entire population was recommended. Two years later the pro's and con's of both centralization and decentralization were discussed in the weekly bulletin of the Dutch Medical Association (Vreeze, 1968) and at a study conference organized by the National Hospital Board and the Dutch Association of Medical Specialists (Kortbeek, 1969). 
Plans to increase the level of governmental control in the health care planning sector did not grow beyond the level of discussion papers. Although it was admitted that "... neither for the entire country, nor on a regional level one could speak of a systematic and adequate organization of services within the health care system ..." (Ministerie van Sociale Zaken en Volksgezondheid, 1966, p.10; translation HS), this statement was not followed by proposals to restructure the health care system. The action that was taken was limited to the hospital sector. When it became clear that liberalization of the building regulations in this sector resulted in almost uncontrolled building activities, a proposal for a new act was sent to the Dutch Parliament in 1968, with the corresponding Hospital Provisions Act being accepted in 1971 .

Between the 1960 s and the early 1970 s health care policy started to undergo change. The policy statement, made at the start of a new government on 3 August 1971, announced a more coordinated and government oriented health care policy with the intention to extend the Hospital Provisions Act to the entire health care sector, in combination with the restructuring of the health care financing system (Staatscourant; 1971). However, four months later, the Minister of Health stated on the debate about the budgetary policy for 1972 that "... organization in this sector must not go too far. Governmental policy must be limited to marking the outlines of such efforts. It is absolutely necessary that there are possibilities for new developments and other coalitions of parties in the health care sector. I am an opponent of introducing a uniform system of organization and communication." (Anoniem in Medisch Contact, 1971; translation HS). A year later, during the debates on the 1973 health care budget, the main topic in the discussions was the enormous increase in health care expenditure (Anoniem in Medisch Contact, 1972). Instruments to control this growth were thought to be preventative activities " strengthening primary health care services and the restructuring of nursing and home help organizations. To limit the growth in the hospital sector, a new act was announced that would incorporate the financing, administration and utilization of hospitals. On the 3rd of May 1973, reviewing almost two years of health care policy, the then previous Minister of Health concluded that "... we started to realize that within the health care sector there are also limits to what is possible from an economical point of view .... Central government will have to take control over the implementation of all the measures taken. Today's world simply asks for more organization and planning than was necessary in the past." (Anoniem in Medisch Contact, 1973, p.571; translation HS).

\section{The period $1973-1983$}

On 11 May 1973, a central-left government gained power. Plans announced by this new government included: a restructuring of the system to control health care expenditure and a National Health Insurance system for the entire 
population. A statement from an interview with the new Minister of Health shortly after the presentation of the new cabinet illustrates these plans "... If Parliament allows us to complete a full four year period, a National Health Insurance for the entire population will be realized .... (Anoniem in Medisch Contact, 1973, p. 678; translation HS). This statement was confirmed as an official government policy statement in May 1973 (Staatscourant, 1973).

In 1974 a Memorandum on the future structure of Dutch health care services was published highlighting that both a better quality of care and cost containment could be reached by (1) more governmental influence on health care, (2) decentralization of the planning of health care facilities, combined with (3) more community influence and involvement, (4) integration of health care planning and financing, (5) substitution of care from the (expensive) hospital sector to primary care, in combination with reinforcement of the primary care sector and (6) stimulating multi-sectoral collaboration between the different health care and social services. To strengthen solidarity and equity, plans for a social health insurance system for the entire population were introduced. Such a new structure could only function adequately within a framework of new legislation and with the national government taking a more active role in health care policy. To realize the ideas about a more pronounced role of government in the planning and organizing of health care services, new legislation was announced in three different fields: (1) the planning and regulation of health care facilities, (2) the health care tariffs, and (3) the health care insurance system (Lapré, 1988) allowing central govermment to regain control over the volume of health care services as well as the pricing of these services.

One of the key features mentioned in the Memorandum on the Development of Costs in the health care sector published in 1979 was a uniform planning and financing system for health care services (Ministerie van Volksgezondheid en Milieuhygienne, 1979). Decentralization of planning activities for the primary health care sector was part of the Health Care Provisions Act accepted by the Dutch Parliament in 1982. First, this act provided the legal framework for local authorities to bestow formal approval on institutions before they could carry out their work, and make this approval dependent to the local health care plans. Secondly, local government became authorized to regulate the number of independent primary health care providers within a given district. Thirdly, the Act prescribed community involvement in health care planning procedures (Bakker, 1989). With reference to the volume of health care service, the intentions of the governmental substitution within secondary care system, from clinical to outpatient treatment and the strengthening of the primary health care sector.

Most governmental plans, however, did not grow above the level of policy intentions. Multidisciplinary cooperation between the different health care services was stimulated by the introduction of a system of financial and 
managerial support. With respect to the position of the general practitioner plans included changes in the remuneration system and income structure, experiments with special centres for diagnostic services, increasing continuing medical education and improvements in the training programme: In relation to the functioning of home help and social work, the necessity of strengthening both services and inter-cooperation, combined with integration of both services within the primary health care sector, was stressed but never realized. Regarding control over the funding of health care services and tariffs, new legislation was announced. However, it was not further developed in the period between 1974 and the start of the ANCDP in 1983. From the large number of policy intentions

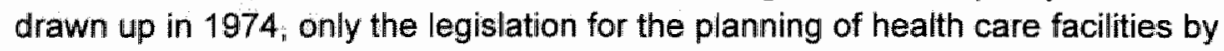
the government passed by the Dutch parliament in the form of the Health Care Provisions Act. However, this Act was only implemented, and subsequently abolished a few years later, as far as it concerned the establishment policy of general practitioners (Groenewegen, 1994). A new Health Care Insurance Act and new legislation on the price and tariff structure of health care services was not passed during that period of time.

In summary, it could be said that until the early 1970 s, no reasons to alter the status quo with regards to the planning and functioning of health care services existed. This view changed in the first half of the 1970 s, due to political and economical reasons. Politically, due to the change in the dominant vision concerning the structure and functioning of health care services. The economic reason being a long period of economic growth succeeded by a period of inflation and economic stagnation, resulting in budgetary constraints on health care expenditure. As a consequence of the declining capacity of the state to contribute indirectly to the funding of medical services and the continued growth on the demand for health care services, action was needed. Restoring the cost/effectiveness of the health care system became a sallient political issue in the Netherlands and other countries.

\subsection{Costs development in the Dutch health care sector}

After the introduction of the German Sickfund the number of publicly insured people in the Netherlands had almost doubled, from about $39 \%$ in 1940 to approximately $70 \%$ in 1945 (Centraal Bureau voor de Statistiek, 1989). Apart from being a mandatory system for employees below a certain level of income with contributions divided between employer and employee, fixed on a year-toyear basis - a voluntary system existed for those non-employees, who met the income criteria. Since 1947, services included in the mandatory and voluntary system were the same. The remaining $30 \%$ of the population could insure themselves on the private market. From the very beginning, the new Sick Fund 
covered costs for primary health care services, obstetric care, and admissions to specialized clinics and hospital admissions for a maximum of 42 days. In 1955 this period was extended to 70 days and in 1964 to 1 year (Juffermans, 1977). Other services that were included in the Sick Fund package (see Ziekenfondsraad, 1953 and further) included dental care (from 1952 onwards, conservations only), medical aids (e.g prothese, wheelchairs, from 1957 onwards), anti-conception pills (1964 onwards), transplants (1970 onwards) and hemodialysis (1971 onwards).

Provisions based on the Sick Fund legislation did not increase significantly as a result of a larger percentage of people covered by these services. However, the introduction of additional services, some of which are mentioned above, placed pressure on the Sick Fund budgets. After World War II the medical sector developed into what is sometimes known as an 'international marketplace for

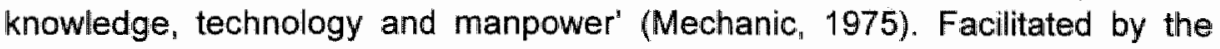
diffusion of knowledge, the growth and transfer of technologies and the mobility of highly skilled medical specialists through standardization of education and training programmes, this development lead to a shift from the model of the general practitioner to the model of the medical specialist (Starr, 1982), the development of paramedical professions and increasing specialization among nurses (Melosh, 1982). Successful new technologies and medical innovations increased the pool of eligible patients creating their own market, resulting in the reinforcement of the inflationary spiral of medical costs and adding to an overall increase in health care expenditure (Wilsford, 1991).

The combined result of (1) efforts to control the developments in the health care sector by fixed prices and tariffs and a restrictive building policy especially in the hospital sector, and (2) the diversification or application of new technologies, resulted in a steady growth in the number of health care professionals but a limited growth in the number of hospital beds. Over a 20-year period the total number of physicians increased from approximately 7,000 in 1945 to almost 14,000 in 1965 (CBS, 1989). Over the same period, the number of dentists almost doubled from around 1,500 to around 2,800 , the number of pharmacists increased slightly from about 800 to approximately 950 , while the number of midwives decreased from around 1,200 to about 750 (CBS, 1989). The total number of hospital beds increased from almost 37,000 to more than 65,000 (CBS, 1989).

There was a steady shift from primary health care to hospital care. In 1940 there were approximately 1,400 medical specialists and 3,150 GPs (Knook, 1991; CBS, 1989). Between 1940 and 1965, both professions have increased in numbers, but the increasing trend for medical specialists was more pronounced than for general practitioners. On the 31st of December 1964 there were approximately $4,400 \mathrm{GPs}$ and approximately 4,730 specialists practising their 
profession (CBS, 1989). Over a 25 year period the GP-specialist ratio changed from 2.2 in 1940 to 0.9 in 1965. Looking at the available hospitals and hospital beds, the picture that emerges is different. The absolute number of hospitals remained almost the same with 267 hospitals in 1945 and 260 in 1965 . The number of acute hospital beds available increased from almost 4 per 1000 inhabitants in 1945 to 5.3 beds per 1000 inhabitants in 1965 (CBS, 1989).

The shift from general to a more specialist oriented medicine continued after 1965 and between 1965 and 1980 the number of general practitioners gradually increased with approximately 24 per cent, from 4416 in 1965 to 5468 in 1980. Over this same period of time the number of medical specialists increased from 4729 to 8939 , resulting in an increase of almost 90 per cent. With an increase of 88 per cent, the growth in the number of dentists resembles the growth in the hospital sector. When the restrictions on building activities in the hospital sector were abolished, the number of new hospital beds increased from less than 1000 per year in the period between 1955 and 1965 to an average of about 2500 new beds per year in the period between 1965 and 1970 . For the five year period between 1970 and 1974, with the implementation of the Hospital Provisions Act in 1971, the number of new beds dropped from about 3250 in 1970 and 1971 to less than 2000 in subsequent years (Nationaal Ziekenhuisinstituut, 1976). Over the same period, the number of hospital beds per 1000 inhabitants increased from 5.3 in 1965 to 5.7 in 1970. In 1980 the number of hospital beds per 1000 inhabitants decreased to 5.3. (CBS, 1989). Examining the number of hospital admissions per 1000 inhabitants, the admission rate was about 86 per 1000 persons in 1965 , while corresponding figures for 1970 and 1974 are 98 and 105 admissions per 1000 inhabitants, and in 1980 the admission rate turned out to be 113 per 1000 inhabitants. However, the average period these persons spent in hospital gradually decreased from 20.4 days in 1965 and 18.8 days in 1970 to 16.6 days in 1974 and 14.0 days in 1980 . Over this 10 year period the total number of hospitals decreased from 268 in 1965 to 254 in 1974 (CBS, 1989).

The restrictive policy towards increasing costs in the health care sector in the years between 1945 and 1965 is reflected in the annual Sickness Funds premiums as set by the Dutch Minister of Health. Although the package of insurance benefits substantially increased premiums were kept on a level as low as possible. Between 1950 and 1965 the percentage of the salary that each publicly insured person had to pay increased (employee part) from $3.6 \%$ in 1950 to $4.6 \%$ in 1963 (Ziekenfondsraad, 1950-1965). Due to this restrictive policy, the Sick Fund's reserves gradually decreased from approximately $130 \%$ of all health care expenditure in 1949 to the point that all financial reserves of the Sickness Funds were spent in 1963, and resulted in debit (Juffermans, 1982). After 1963 Sick Fund premiums increased rapidly from $4.6 \%$ in 1963 to $7.5 \%$ in 1970 and $9.7 \%$ in 1974 . Other contributory factors leading to an increase of health care 
expenditure was a sharp increase in the allowances GPs received for each Sick Fund patient and increasing wages of the entire hospital sector.

Health care expenditure as percentage of the Gross Domestic Product (GDP) in the Netherlands increased from $3.5 \%$ in 1953 to $4.2 \%$ in 1964 (OECD, 1993). Reliable data on health care expenditure in the period before 1953 are not available. A detailed picture of Dutch health care expenditure over the period between 1960 and 1985 is presented in Graph 2.3.

Graph 2.3 Health care expenditure as a percentage of gross domestic product in the Netherlands between 1960 and 1983 (Source: OECD, 1996)

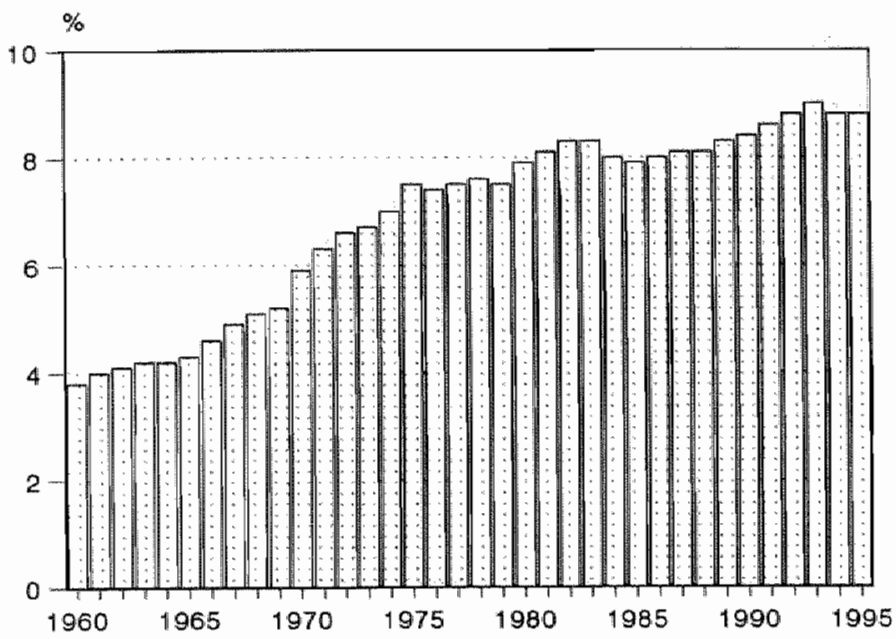

Graph 2.3 shows total health care expenditure as percentages of the GPD, as well as the average health care expenditure for all OECD countries. Total health care expenditure in the Netherlands increased sharply during the period between 1960 and 1975 . In 1960 about 3.8 percent of the GDP was spent on health care services. In 1975 this percentage had almost doubled to 7.4 percent. After 1975, the percentage continued to grow to almost 7.9 percent in 1980 and $8.3 \%$ in 1983. Over the same period, the OECD-total increased from 3.9 in 1960 to 7.5 in 1983, illustrating that the average growth in the Netherlands was somewhat more than for all 24 OECD countries in total.

The steepest increase in total health care expenditure took place during the late 1960 s and early 1970 s. Calculated over 5 -year periods, the average growth in total health expenditure as part of the GDP between 1960 and 1965 was 2.5 per cent per year. For subsequent 5-year periods, the average growth percentages on a yearly basis was: $6.5 \%(1966-1970), 4.9 \%(1971-1975)$ and $1,0 \%$ (19761980 ). On a year-to-year basis, the steepest rise can be noticed in 1970 , when total health expenditure increased from $5.3 \%$ of the GDP to $6.0 \%$. Figures for the 
Netherlands in the period between 1975 and 1980 are somewhat above the OECD averages which range from $5.0 \%$ in 1975 to $5.7 \%$ in 1980 .

The rapid increase in health care expenditure in the 1960-1980 period was common for industrialized societies. In 1960 the share of total health spending in GDP ranged from 1.5 percent in Spain to 5.5 percent in Canada, with an OECD average (excluding Turkey, Japan and Luxembourg) of 3.9 percent of the gross domestic product. In 1980, the OECD average for all 24 countries totals 7.1 percent. A sharp increase in the period between 1960 and 1975 , was followed by a slower increase in the decade after 1975. Countries which had doubled their percentage GDP for health care expenditure between 1960 and 1980 were the Netherlands, Norway. Spain, Sweden and Switzerland. A relatively slow increase of about $55 \%$ was shown by Australia, Canada, New Zealand and the United Kingdiom.

In general, the share of the gross domestic product spent on health care showed an upward trend. A more pronounced upward trend can be noticed in the years before 1975 than in the period between 1975 and 1985 . This can be shown by means of elasticity coefficients, which is the rate of growth in nominal per capita health spending relative to the rate of growth in nominal per capita GDP. In this instance it refers to two periods of time (1960 - 1975 and 1975 - 1985). The average nominal elasticity for 20 OECD countries (excluded are Turkey, Japan Luxembourg and Portugal) in the first period is 2.0. This indicates that during this period nominal per capita health spending increased some 20 percent faster than the nominal GDP. The corresponding coefficient for the years between 1975 and 1980 is 1.2 , indicating a 12 percent growth per capita health expenditure. The elasticity coefficient for the years between 1960 and 1975 for the Netherlands was 2.2, indicating that a 10-percent increase in nominal per

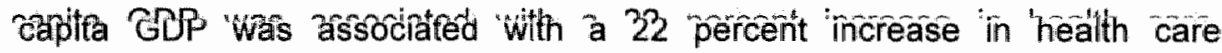
expenditure, which was slightly above the OECD-average. For the period between 1975 and 1985, the elasticity coefficient for the Netherlands was 1.1, which was slightly below the OECD average.

\subsection{Conclusions}

The aim of this chapter was to describe the policy context in which the AHCDP was developed from a national perspective. Regarding national health policy between 1945 and 1980, the combination of political and economic developments were included.

At the national level, both from a political and an economic point of view, the period during 1945 and 1983 can be roughly divided in three parts. Between 
1945 and 1958 the political theatre was dominated by a central-left coalition. Efforts concentrated on rebuilding and strengthening society by means of strong governmental influence in all sectors, including the health care sector. At the end of this 13-year period, the country as a whole as well as its system of health care services was standing on the eve of a rapid expansion facilitated by prosperous economic prospects. In the following period between 1958 and 1973 , with political power in the hands of a central-right coalition, governmental influence on the structuring and functioning of health care services diminished. During this period of continuous economic growth, increase of health care expenditure, as a result of a process in which more people could make use of more health care services, did not cause any problems.

In 1973 when also the Netherlands was confronted with a period of economic recession this resulted in budgetary restrictions ${ }_{n}$ in order to face the economic problems and to restore the weak financial position of the central government, with the health care sector being an important area in which the costeffectiveness balance no longer existed. In order to restore this balance, the central-left government decided to concentrate on a shift towards more governmental influence in the health care sector, in combination with efforts to strengthen primary health care services. At the national levell, the demonstration project in Almere can be seen as an attempt to implement governmental policy on a small scale under almost ideal circumstances. 
Chapter 3 provides the conceptual framework for evaluating the Almere Health Care Demonstration Project (AHCDP) as a policy programme'. In section 3.1 the general framework for evaluating the Almere project will be presented. Next, the three research questions formulated in chapter 1 referring to the AHCDP as a policy programme are linked to the general framework and are further evaluated in section 3.2 (Q2: Was it realistic to expect that, given the instruments chosen and the conditions expected, the Almere Health Care Demonstration Project would be successful in reaching its goals of substitution, quality and costs?; Q3: Was the experimental heaith care setting in Almere successfully implemented and were the goals formulated in 1983 actually achieved?; Q4: Are the results of the Almere Health Care Demonstration Project empirically related to the way the health care system in Almere was shaped?). These three research questions will be answered by a series of studies that were conducted in Almere between 1983 and 1992. In section 3.3 an overview of these studies and the methods used will be presented. Research question Q2, specifying the relationship between the different elements of the programme to be evaluated, will be answered in section 3.4. The chapter will end with a short summary.

\subsection{The conceptual framework}

In its basic form the Almere project can be described as a set of relations between instruments, conditions and goals. Described in these terms it can be seen as a policy programme (Rotem and Bandaranayake, 1983; Suchman, 1970). Whether or not such a policy programme was successful in reaching its goals, can be decided on the basis of evaluation studies.

A conceptual framework for the evaluation of policy programmes was developed by Stake (1967). Originally developed for the evaluation of educational programmes, Stake distinguished between intents (or the intended programme) and observations (or the observed programme). In his terminology, 'intents' refer to the desired effects. A distinction is made between antecedents, intended transactions, and the intended outcomes. Observations - the observed antecedents, transactions, and outcomes - include descriptions gathered during and after the process of implementation, using interviews, check lists,

Abma (1996) describes the evaluation of the AHCDP as a system analytical approach. 
questionnaires, psychometric tests, administrative and observational data.

Antecedents, transactions, and outcomes are related by means of 'theoretical' and/or empirical relationships. Here, theoretical relationships refer to empirical generalizations from previous research in the same or related fields of interest as well as arguments based on common sense. With respect to the observed antecedents, transactions and outcomes, the evaluator has to establish an empirical relationship based on these three elements. Intended and observed antecedents, transactions and outcomes are related to each other by the question, whether there is congruence between the intended or expected programme and the way the programme is observed by the evaluator.

The 'Stake model' has been successfully applied in the evaluation of health care programmes (Donker, 1990). Because of its elegant simplicity and the fact that the framework allows different combinations of data collection methods, the 'Stake model' was adopted as the conceptual framework for our evaluation study of the AHCDP.

Figure 3.1 Framework for the policy programme evaluation of the Almere Health Care Demonstration Project, derived from Stake (1967)

PLANNED

PROGRAMME

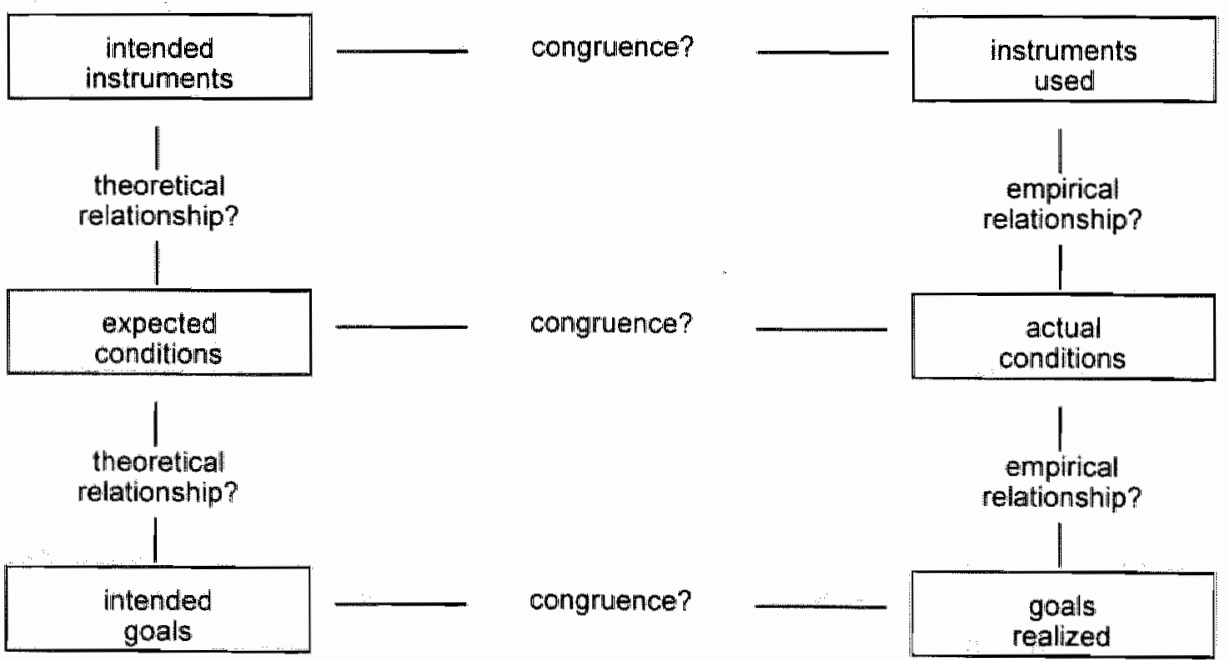

The conceptual framework presented in Figure 3.1, shows the relationships between antecedents, transactions and outcomes as formulated by Stake. These were rephrased as relationships between instruments, conditions and objectives; instruments to the means to reach the expected goals, conditions to intervening variables that disturb and/or modify the relationship between instruments and goals. Objectives or goals of the AHCDP are desired targets. 


\subsection{Research questions and their elaboration}

The three basic research questions to evaluate the project as a policy programme (see Chapter 1) can be re-formulated in terms of Stake's conceptual framework.

Q2 Is there a (theoretical) relationship between the selected instruments, expected conditions and desired goals of the Almere Health Care Demonstration Project?

Q3 Is there congruence between the selected instruments, expected conditions and desired goals of the Almere Health Care Demonstration Project and the instruments used ${ }_{1}$ and conditions and goals achieved at the end of the project?

Q4 Is there an empirical relationship between the instruments used, and conditions and goals achieved during the period the Almere Health Care Demonstration Project was implemented?

More simple: (1) Were the basic ideas behind the AHCDP in line with the 'state of the art' literature and common sense logics when the project was developed? (2) Was the Almere Health Care Demonstration Project realized the way it was anticipated, and (3) Did the Almere Health Care Demonstration Project work as anticipated? The second and third research question derived from Figure 3.1 can also be re-phrased in terms of the three-part categorization (motives, opportunities and instruments) described in chapter 1 . The motive behind the AHCDP is directly related to the following goals of the project: to improve the cost-effectiveness of the health care system, in terms of cost containment, substitution of care and an increase in quality of care.

The means or instruments identified in Figure 3.1 are consistent with the instruments introduced in section 1.3. In general, one might refer to these instruments as a primary care oriented health care system based on governmental planning and steering. The opportunities described in section 1.2 refer to the conditions mentioned in Figure 3.1., the most significant one being the non-existing infrastructure in Almere. with a clean sheet,

The observation that the objectives of most health care policy programmes are complex and unclear (Leighton, 1982; Ringeling, 1985) also holds for the Almere Health Care Demonstration Project. Published plans at the start of the experiment in 1983 (Stuurgroep Gezondheidszorg Almere, 1983), in addition to their revised versions (Stuurgroep Gezondheidszorg Almere, 1985; Stuurgroep Gezondheidszorg Almere, 1986), showed the desired future structure of the 
health care system in Almere. They do not, however, provide information about the relationships between instruments, goals and conditions.

Combining the detailed blue-prints for the future health care system in Almere with the results from a series of interviews with key-persons of the AHCDP (see Sixma \& Voort, 1984), resulted in the selection of three overall goals. These were: substitution of care and cost containment (and, if possible, a reduction of the costs involved in the use of health care facilities compared to the remainder of the Netherlands), and quality improvement. Compared with the Netherlands, the demonstration project in Almere was to result in (1) better quality of care against the same costs, or (2) equal quality of care against llower costs. To be successful, the new health care system in Almere had to achieve a better costeffectiveness than the prevalent national system.

In the following three sections the goals and instruments directed towards quality of care, substitution of care, and cost containment will be described in more detail. A distinction will be made between the 'general goals' and 'operational goals'. General goals refer to the different objectives formulated in broad and unspecified terms. To find out whether or not these objectives were achieved, the 'general goals' were reformulated in more specific terms: the operational goals. Intended instruments to reach these goals are numerous and were divided in two broad categories: (1) those directed towards the structure of health care facilities, and (2) those that focus on the health care process itself. A third category of instruments, referring to the outcome of the health care services (see Donabedian, 1966), is not separately specified. Instruments sometimes refer to different (operational) objectives. Instruments aiming at cost containment (e.g. a reduced capacity of the hospital sector) are also related to substitution of care. Furthermore, conditions were specified in terms of the way the Almere health care system and building up an entire new town could go hand-in-hand, and continuity in health care policy at the national level.

\subsubsection{Goals and instruments directed towards quality of care}

With respect to the 'quality of care' concept, Table 3.1 distinguishes between the organization and/or the organizational structure of health care services, the quality of health care workers, and the quality of the process of health care delivery (see also Nationale Raad voor de Volksgezondheid, 1990).

Objectives and instruments shown in Table 3.1 vary in their degree of specificity. The Objectives and instruments that refer to the quality of the organization(s) or the organizational structure are of a higher level of specificity than the objectives and instruments that refer to the quality of health care providers and the health care process. 
Table 3.1 Detailed goals and instruments related to the quality of care concept of the Almere Health Care Demonstration Project

\begin{tabular}{|c|c|c|}
\hline Goals & Operational goals & instruments to be used \\
\hline $\begin{array}{l}\text { good quality of } \\
\text { organizations } \\
\text { and/or } \\
\text { organizational } \\
\text { structure }\end{array}$ & $\begin{array}{l}\text { - coherent network of (health) } \\
\text { care services } \\
\text { - strengthened primary care } \\
\text { - secondary care facilities } \\
\text { supportive to primary care } \\
\text { - coordination between the } \\
\text { echelons } \\
\text { - strong patient participation } \\
\text { - good accessibility of } \\
\text { services and facilities } \\
\text { - clear procedures for the } \\
\text { filing and handling of } \\
\text { complaints by the users of } \\
\text { health care services } \\
\text { - good privacy protection for } \\
\text { clients and patients }\end{array}$ & 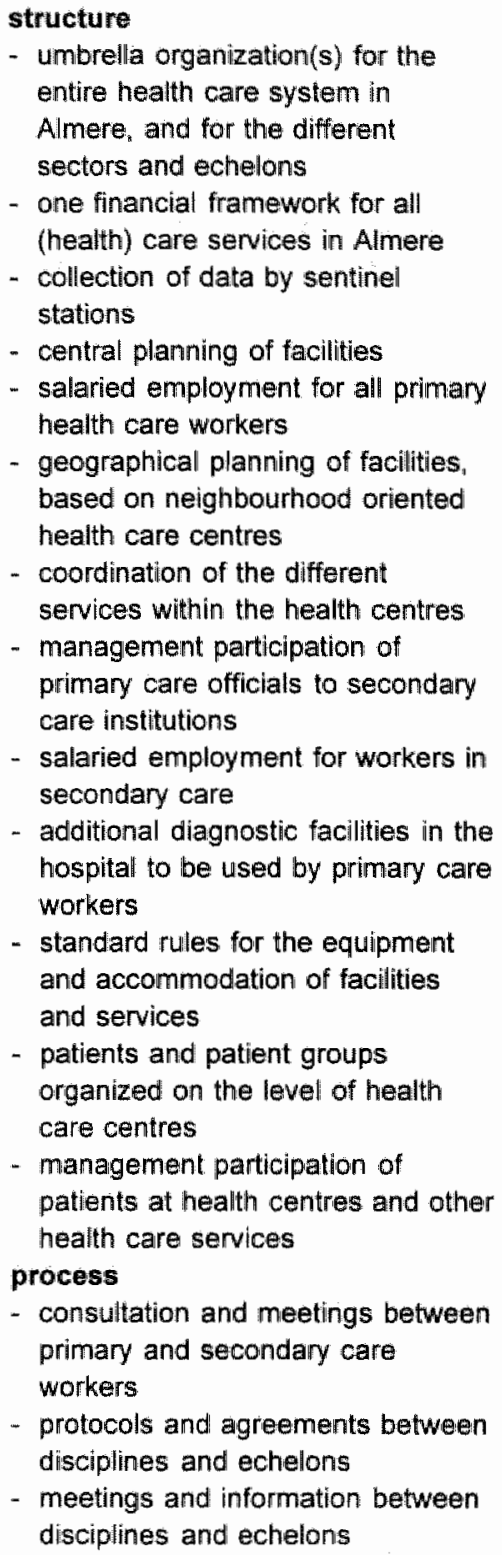 \\
\hline
\end{tabular}




\begin{tabular}{|c|c|c|}
\hline $\begin{array}{l}\text { good quality of } \\
\text { health care } \\
\text { workers }\end{array}$ & $\begin{array}{l}\text { - Uniformity in care provision } \\
\text { and tasks } \\
\text { - professional qualities in } \\
\text { relation to tasks and tasik } \\
\text { definitions } \\
\text { - number of health care } \\
\text { providers in accordance to } \\
\text { ideas about strengthening } \\
\text { primary health care }\end{array}$ & $\begin{array}{l}\text { structure } \\
\text { - specific recruitment and } \\
\text { appointment procedures of health } \\
\text { care providers } \\
\text { - salaried employment of all health } \\
\text { care providers } \\
\text { - peer review } \\
\text { - continuing medical education } \\
\text { - reduced list size of practices }\end{array}$ \\
\hline $\begin{array}{l}\text { good quality of } \\
\text { the process of } \\
\text { health care } \\
\text { delivery }\end{array}$ & $\begin{array}{l}\text { - task performance in relation } \\
\text { to professional standards } \\
\text { and values } \\
\text { - multidisciplinary cooperation } \\
\text { belween disciplines and } \\
\text { services } \\
\text { - continuity of care } \\
\text { - task definitions between } \\
\text { disciplines and echelons } \\
\text { - functional relationship } \\
\text { between disciplines } \\
\text { - care in accordance to needs } \\
\text { of the Almere population }\end{array}$ & $\begin{array}{l}\text { structure } \\
\text { - establishment of health care } \\
\text { providers restricted to rules } \\
\text { - salaried employment of all health } \\
\text { care providers } \\
\text { - specific appointment policy for } \\
\text { health care providers } \\
\text { - formalized procedures for the filing } \\
\text { and handling of complaints } \\
\text { - patient consultation and population } \\
\text { surveys on a regular basis } \\
\text { - patient meetings in health care } \\
\text { centres and other institutions } \\
\text { process } \\
\text { - agreements/protocols concerning } \\
\text { consultation } \\
\text { - peer review } \\
\text { - providing health care by protocols } \\
\text { and professional standards } \\
\text { - (muttidisciplinary) treatment plans }\end{array}$ \\
\hline
\end{tabular}

Table 3.1 illustrates that the same instruments can refer to different operational objectives (e.g. the salaried employment status for all health care providers offers the opportunity to employ professionals that subscribe the basic ideas of the demonstration project, can therefore be seen as an instrument towards good quality health care workers). At the same time, the employment status of health care professionals offers the opportunity to steer and improve the quality of care from i.e. the patients" perspective as part of a process of continuing medical education and can therefore be seen as an instrument to improve quality of care.

\subsubsection{Goals and instruments directed towards substitution of care}

In combination with decentralization of planning authority, regionalization and the hierarchical division of health care services in four echelons, substitution of care was seen as a key instrument towards better quality of care and cost containment (Bakker, 1989). 
Regionalization was desired not only to establish a common geographic division for health care providers, but also to bring about a coherent network of health services attuned to the needs of the population within that region. The decentralization of planning authorities resulted in the delegation of the responsibilities for the functioning and planning of health care facilities to regional centres. Substitution of care fits in these ideas, not only as a target in itself to render health care services at the most adequate level which will improve the quality of care, but also as an instrument to reach a more costeffective health care system.

Substitution of care implies a formal relationships between the different echelons and the different health care services in one echelon. Also implied is that access to the different health care services can be regulated to a certain extend. With respect to (in- or outpatient) hospital services, the general practitioner functions as gate keeper for the use of these services. To gain access to these services, patients need to be referred by a $\mathrm{GP}^{2}$. Within hospital, patients can be referred from one medical specialist to another. With respect to nursing homes and old people's homes, patients needs will have to meet the criteria specified. The criteria, as well as the authority by which they are applied, depend on the region of residence. Primary health care facilities are generally accessible without further than occasional fee payment. To see a physiotherapists, patients need a referral from their GP. In case of substitution of care, the general practitioner is in a central position and acting as gate keeper.

In this section of chapter 3 , and the following chapters, four different forms of substitution will be examined. (1) Substitution within the hospital sector and othersectors with institutionalized patients, from inpatient to outpatient care. (2) Substitution from the hospital sector to the primary health care sector. (3) Substitution from health care professionals to informal care, self help and self care groups. And (4) substitution from curative to preventive care.

Goals, operational goals and instruments to be used to reach these goals are specified in Table 3.2. Regarding the instruments to be implemented, a difference is made beween instruments aiming at the structure of health care services and instruments directed towards to process of health care delivery.

For medical specialists, working in hospitals and outpatient clinics as self employed professionals, the same referral charts contribute to their income. For each referral the medicall specialist receives a standard fee. 
Table 3.2 Detailed goals and instruments related to substitution of care concept of the Almere Health Care Demonstration Project

\begin{tabular}{|c|c|c|}
\hline Goals & Operational goals & Instruments to be used \\
\hline $\begin{array}{l}\text { substitution } \\
\text { within the } \\
\text { intramural } \\
\text { sector and from } \\
\text { inpatient to } \\
\text { outpatient care }\end{array}$ & $\begin{array}{l}\text { - shift from inpatient to } \\
\text { outpatient care within the } \\
\text { hospital } \\
\text { - shift from inpatient care to } \\
\text { day time surgery } \\
\text { - shift from nursing home to } \\
\text { old peoples home } \\
\text { - relatively low referral rate } \\
\text { from specialist to specialist } \\
\text { - relatively low admission } \\
\text { rates } \\
\text { - protocols and agreements } \\
\text { within hospitals and other } \\
\text { inpatient services }\end{array}$ & $\begin{array}{l}\text { structure } \\
\text { - increasing outpatient facilities in } \\
\text { the hospital } \\
\text { - increasing hospitall facilities for day } \\
\text { time surgery } \\
\text { - salaried employment status for all } \\
\text { workers in intramural care } \\
\text { - decreased bed capacity } \\
\text { process } \\
\text { - standard procedures and protocols } \\
\text { for the intake and referral of } \\
\text { patients } \\
\text { - standard procedures and protocols } \\
\text { for referrals between institutions }\end{array}$ \\
\hline $\begin{array}{l}\text { Substituition } \\
\text { from secondary } \\
\text { to primary care }\end{array}$ & $\begin{array}{l}\text { - relatively low admission } \\
\text { rates for hospitals and } \\
\text { nursing homes } \\
\text { - strengthened primary health } \\
\text { care services } \\
\text { - restriction of number of } \\
\text { procedures in secondary } \\
\text { care } \\
\text { - reduced length of stay in } \\
\text { hospital compared to the } \\
\text { national figures } \\
\text { - emergency care in primary } \\
\text { health care centres instead } \\
\text { of the hospital } \\
\text { - reinforcement of nursing } \\
\text { and treatment functions in } \\
\text { primary care } \\
\text { - reinforcement of the task } \\
\text { profile for primary care } \\
\text { workers } \\
\text { - standard intake, referral and } \\
\text { discharge procedures }\end{array}$ & $\begin{array}{l}\text { structure } \\
\text { - relatively small hospital } \\
\text { - support of primary care through } \\
\text { adequate diagnostic facilities and } \\
\text { expertise } \\
\text { - estabilishing and supporting of } \\
\text { health care centres } \\
\text { - continuing medical education } \\
\text { - recruitment of additional personnel } \\
\text { - combined nursing and old people's } \\
\text { home } \\
\text { process } \\
\text { - protocols on the different } \\
\text { specialisms } \\
\text { - protocols and procedures for the } \\
\text { admission end discharge of } \\
\text { patients } \\
\text { - regular meetings between health } \\
\text { care workers to discuss patients } \\
\text { and procedures }\end{array}$ \\
\hline $\begin{array}{l}\text { substitution } \\
\text { from } \\
\text { professional } \\
\text { care to } \\
\text { informal care } \\
\text { and self help }\end{array}$ & $\begin{array}{l}\text { - reinforcement of the home } \\
\text { care function } \\
\text { - integration of home care } \\
\text { and nursing care } \\
\text { - establishing and the support } \\
\text { of self help groups in the } \\
\text { health care centres } \\
\text { - demedicallization of the } \\
\text { Almere population } \\
\text { - stimulation of prevention } \\
\text { programs }\end{array}$ & $\begin{array}{l}\text { structure } \\
\text { - stimulating information campaigns } \\
\text { - gathering epidemiological } \\
\text { information } \\
\text { - creating networks of information on } \\
\text { services for the elderly } \\
\text { - semi-detached facilities at old } \\
\text { peoples homes } \\
\text { - offering financial support to self } \\
\text { help groups }\end{array}$ \\
\hline
\end{tabular}




\subsubsection{Cost related goals and instruments}

One of the major goals within health care policy is to provide good quality of care at the lowest possible costs, and it is genuinely believed that efforts to control costs are possible without impairing the quality of medical care (Mechanic, 1995). Instruments that can be used to reach a higher degree of cost-effectiveness are under more debate (for an overview: see Abel-Smith, 1984; Abel-Smith, 1992).

Table 3.3 Goals and instruments related to cost containment, in detail

\begin{tabular}{|c|c|c|}
\hline Objectives & Operational abjectives & Envisaged instruments \\
\hline $\begin{array}{l}\text { cost } \\
\text { containment }\end{array}$ & $\begin{array}{l}\text { - restriction of initial expenses } \\
\text { of health care services } \\
\text { - restriction of overhead costs } \\
\text { - discouragement of outflow } \\
\text { of pattients } \\
\text { - one financial framework for } \\
\text { all different health care } \\
\text { services } \\
\text { - periodical information }\end{array}$ & $\begin{array}{l}\text { structure } \\
\text { - planned development of health } \\
\text { care services } \\
\text { - limited capacity of the hospital } \\
\text { sector } \\
\text { - cooperation within disciplines } \\
\text { - cooperation within and between the } \\
\text { different echelons } \\
\text { - salaried employment for all health } \\
\text { care workers } \\
\text { process } \\
\text { - agreements and protocols } \\
\text { regarding referrals of patients }\end{array}$ \\
\hline cost restriction & $\begin{array}{l}\text { - substitution of care within } \\
\text { the echelons } \\
\text { - substitution of care between } \\
\text { the echelons } \\
\text { - restriction with regard to } \\
\text { cost generating procedures }\end{array}$ & $\begin{array}{l}\text { structure } \\
\text { - limited capacity of the hospital } \\
\text { sector } \\
\text { - salaried employment of all health } \\
\text { care workers } \\
\text { - coordination within and between } \\
\text { the different services } \\
\text { process } \\
\text { - continuing medical education, } \\
\text { stimulated by umbrella } \\
\text { organizations } \\
\text { - peer review meetings }\end{array}$ \\
\hline
\end{tabular}

A key argument underlying the AHCDP is that an experimental health care system, which is based on structuralization, coordination and regionalization, can function more adequately than the traditional health care system in the Netherlands. Instruments to reach cost containment related to the AHCDP are (1) employee-status for health care professionals, (2) limited supply of hospital services in combination with the strengthening of primary care facilities through health centres, and (3) integration of financial and structural planning of health 
care facilities under the command of local authorities. A detailed overview of cost related objectives and instruments is presented in Table 3.3 .

Table 3.3 illustrates a distinction made between cost containment and cost restriction. Where cost containment refers to a policy to limit the increase in health care expenditure cost restriction is aiming at bringing down the actual costs within the sector. It would be possible to extend the overview presented in Table 3.3 with most of the substitution of care related objectives and instruments which were presented in Figure 3.2. To avoid overlap between these figures, substitution of care related aspects were omitted in Table 3.3.

\subsection{Relationships between goals, instruments and conditions}

The first question derived from the conceptual model for the evaluation of the AHCDP as policy programme, focuses on the relationship between goals, instruments, and conditions. Question Q2 was formulated as follows: "Is there a (theoretical) relationship between the intended instruments, expected conditions and intended goals of the Almere Health Care Demonstration Project?" Initially, the relationship between goals and instruments will be looked at. Second, a further examination of the three main conditions for the AHCDP will be undertaken.

\subsubsection{The relationship between instruments and goals}

Regarding the objectives on quality of care a distinction was made between the quality of the organizational structure, the quality of the health care workers and the quality of the health care process. The most important instruments to achieve the operational objectives in these three areas were: umbrella organizations for the entire health care system in Almere as well as within the different echelons, centralization of the planning and financing of health care services, a salaried employment status for all health care workers, concentration of primary care services in multidisciplinary health centres, management and patient participation in health care services and a formalized set of rules, standards and protocols for the delivery of health care services.

From an organizational point of view, umbrella organizations that co-operate in the field of financing. planning and the functioning of health care services can be seen as adequate instruments leading towards good quality of care. Mutual consultation and cooperation on the level of different health care services and echelons may result in concerted actions towards the formulated goals. The proposed networks and umbrella organizations provide the platforms for consultation and reaching agreement, therefore, contribute in reaching the 
desired goals. Problems which occur when such planning instruments are introduced on a large scale in a complex environment (see Saltman and Otter; 1992; Saltman and Otter, 1995), are less likely to occur in a new, geographically isolated and relatively small towm. Therefore, the objective in creating a highly qualified system of health care facilities by founding umbrella organizations in Almere would appear to be realistic and feasible ${ }^{3}$.

Following the same line of argument, the use of instruments such as protocols, standards and agreements about the admission, treatment and discharge of patients, peer-review, continuous medical education and the use of interdisciplinary plans for treatment and care-coordinators can improve quality of care, as well as lead to substitution of care. The effectiveness of such instruments has been empirically established (Cromme, 1980; Feen, 1984). A setting where all health care workers are salaried professionals within one organization will facilitate professional standard setting (Heesters, 1981). This will also allow for the development of rules for cooperation between health care professionals in the different sectors, and makes it possible to select them on the basis of specific characteristics, such as task profiles. These instruments may subsequently result in a better quality of care from the management perspective (Grol, 1981; Boots and Zutphen, 1981; Dopheide, 1982).

The expected relationship between the employment status of health care professionals in general and the extend of services and interventions performed, is also one of the underlying ideas formulated in the AHCDP. This is based on the theoretical assumption that in a mixed system or a fee-for-service system health care professionals will attempt to maximize their own income by performing more services. For health care workers, who held the employee status, such an incentive is lacking. At the commencement of the AHCDP, empirical studies concerning the relationship between employment status and cost effectiveness of health care services, were limited and focused on problems associated with the financial aspects in setting up a practice (Jaspers et al, 1980; Heesters, 1983) or the employment status of medical specialists (Groef, 1985). Support for this supposed relationship can be found in more recent studies from Denmark (Flierman, 1991). Sweden and Canada (Culyer et al, 1991 ) as well as a comparative study in Europe (Delnoij, 1995). Based on this argument the probable best solution for Almere would be a combination of the employee status of all hospital based medical specialists in the hospital and GPs working as independent entrepreneurs. This free entrepreneurship, however, is in conflict with a number of other central ideas of the AHCDP (e.g. the planning

3 At the same time, the realisation of an organisation structure, based on carefully planned and controlled system of health care services, with umbrella organisation(s) on top of that organisational structure, could easily lead to bureaucracy with patients and clients merely seen as numbers than as people in need of care. 
of services, quality control and quality improvement). Therefore an employee status for all health care workers might be the most appropriate solution.

Patient participation, both with respect to the management structures as well as participation in population surveys, was meant to secure the quality of care within the new system from the patient's perspective. At that time little was known about the effects of patient participation on the quality of the actual structure of health care services and the care giving process.

One of the most important instruments of the AHCDP was the concentration of primary care services in multidisciplinary health centres. Stimulated by policy discussions concerning cooperation in the primary health care sector and examples of these 'new' developments in the United Kingdom and the Nordic countries, the number of health centres in the Netherlands increased from three in 1970 to 34 in 1975. The initial development period (see Ros et al, 1996) was followed by a ten-year period in which the number of health care centres continued to increase from 34 to about 140 . This period of rapid growth coincided with the founding activities of the AHCDP, and not surprisingly health centres were selected as one of the instruments of paramount importance for the AHCDP. With reference to the effects of the concentration of health care services in multidisciplinary health centres, a number of studies had shown that GPs working in health care centres had lower referral rates towards medical specialists (Ziekenfondsraad, 1979; Duuren and Hupkens, 1981; Wijkel, 1983; Wijkel, 1986) and lower prescription rates (Brunschot, 1984). General practitioners in health centres were found to more frequently request $X$-ray and other diagnostic facilities than single-handed working GPs (Crebolder, 1977). Also in other services it had been shown that cooperation in multidisciplinary health centres resulted in more cost-effectiveness with regard to prescribing behaviour (Paes, 1982) and ease of access for social workers (Crebolder, 1976; Biewenga et al, 1978). In general it was established that, with regard to the functioning of multidisciplinary health centres, the additional costs were outweighed by the incoming revenues (Beljaars et al, 1982; Duuren and Hupkens, 1981). Concentration of health care services in multidisciplinary health centres did not result in less patient satisfaction with respect to service quality (Boom-Van Duin, 1975; Huige and Leenen, 1979; Hofstede, 1981), somewhat higher satisfaction scores in terms of the GP's social attitude (Crebolder, 1977).

With respect to the two other goals - substitution of care and cost containment and/or cost restrictions - structural instruments play the most important role. In general, the combination of limited hospital services with additional facilities in Primary Health Care as proposed in the AHCDP, can be regarded as being more cost-effective than a health care system with a larger, and therefore more expensive, hospital sector. In had been shown that referral rates were positively associated with the supply of hospital facilities, such as the number of medical 
specialists working in a particular area (Gaag, 1978; Rutten, 1978) or the number of hospital beds (Posthuma and Zee, 1977). Also it had been shown that geographical distance between GP and the hospital was negatively associated with the referral rate (Kruidenier, 1977; Wijkel, 1983). These empirical results indicate that the availability of secondary care facilities is positively associated with cost-generating factors such as referral rates. It is therefore concluded that limiting the capacity of the hospital sector by the building a of relatively small hospital could result in (1) relatively low admission rates and lengths of stay, and (2) less cost generating interventions, such as GP referrals. The relationship between instruments (=limited hospital capacity, in combination with special facilities in the hospital for day surgery and a set of rules to influence patient flows) and goals (substitution within the hospital and between hospital care and outpatient care) is generally supported by the existing literature.

\subsubsection{The expected conditions}

Three conditions (or, in terms of the phrasing used in chapter 1, opportunities) were mentioned for the Almere project in order to become successful. These conditions were: (1) a 'tabula rasa' situation, (2) support by central and regional authorities, and (3) the possibility to combine the development of the new health care system with the development of the entire new town. The first condition suggests that vested interests are minimized and that one could start with a 'clean slate'. The second condition concerns the anticipated role of governmental bodies, its influence on the legislation system and possibilities to support the AHCDP with adequate financial means. The third condition specifies the difficulty of simultaneously development of a new system of health care services in a town that rose from to over 100,000 inhabitants less than 20 years.

Of these three conditions, the 'tabula rasa' situation in Almere is probably the most important. However, at the commencement of the AHCDP in 1983, such a situation no longer existed. In the seven years since the first inhabitants moved to Almere in 1976, it had grown with an annual average rate of about 4000 people. Together with the first 27,000 inhabitants, all primary health care services were firmly established in Almere. Although most of these services tried to function in line with the basic ideas of the demonstration project, there was not a fresh start in 1983. A number of decisions had already been taken prior to the commencement of the project. These were the intention to move an existing hospital from Amsterdam to Almere, and to join an existing regional health insurance company rather than instigating their "own Polder insurance fund". Therefore, the 'tabula rasa' condition, which provided the opportunity for the AHCDP (see Chapter 1, section 1.1) was no longer realistic when the AHCDP commenced in 1983.

The second condition refers to continuity in health care policy at the national 
level, as well as the local level during the implementation of the project. This continuity was expected on the level of the centrall government, so that priorities and (financial) support would continue and remain unchanged over a prolonged period of time. Continuity was also expected with regards to the legislation and plans for new legislation that would facilitate implementation of the experimental health care setting. When the AHCDP started in January 1983, there were no actual signs of a coming change in policy, and therefore we consider this condition at that time as being realistic.

The third and final condition, or intervening variable, refers to the assumption that the development of new system of health care facilities can go hand in hand with the development in the population and a new town. It was expected that the population of Almere would grow from approximately 27,000 to about 100,000 inhabitants between 1983 and 1993. This would influence the planning and functioning of health care facilities. It was anticipated that, while the population of Almere would be relatively young and healthy, the effects of their migration to Almere would have to be faced. Given the relatively high birth rate in Almere as compared to the national situation, special emphasis was needed for mother and child care. The specific population structure in Almere must be taken into account when the AHCDP is evaluated in terms of success or failure.

\subsection{The different evaluation studies conducted as part of the Almere Health Care Demonstration Project}

At the start of the Almere health care demonstration project in 1983 it was agreed that a series of evaluation studies would take place. Firstly, these studies would provide the cornerstone for the evaluation study planned at the end of the project in order to explore the project's success. Secondly, these studies would provide the Almere policy makers with information to determine whether the demonstration project was still on schedule and/or whether additionall measures were needed to be taken. Nineteen different studies were carried out as part of this evaluation programme.

Table 3.4 presents an overview of the 19 separate studies in terms of abjectives, methodologies, and main conclusions. A more detailed overview of these studies, especially regarding the general framework of these studies and the methodology involved, is presented in Appendix A. Included in this methodological appendix is a section about the different weighing procedures that can be (and were) followed in some of these studies, in order to compare the results for Almere with national figures. 


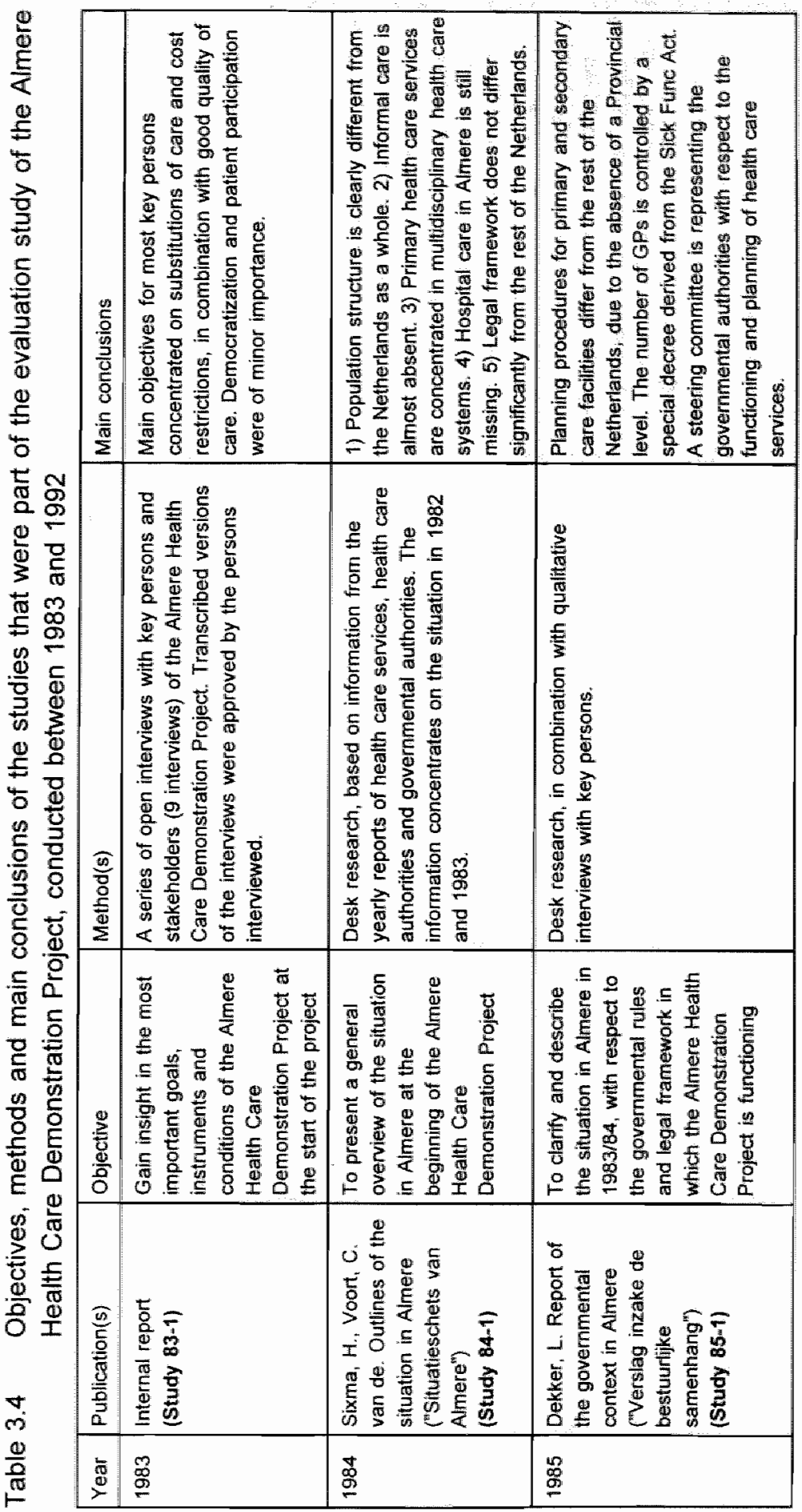




\begin{tabular}{|c|c|c|}
\hline 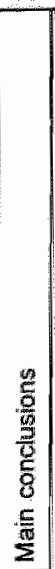 & 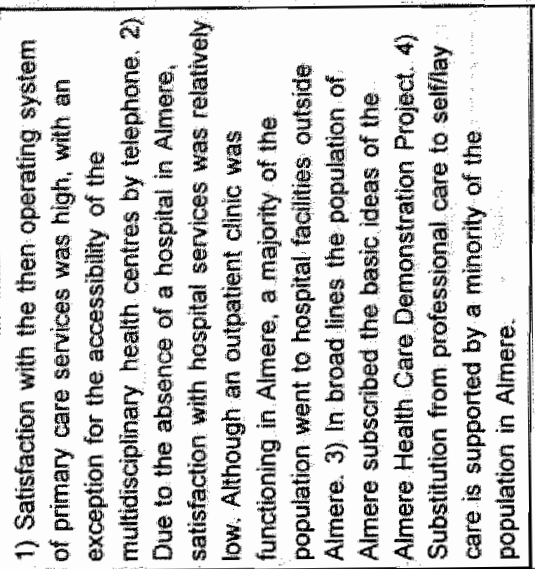 & 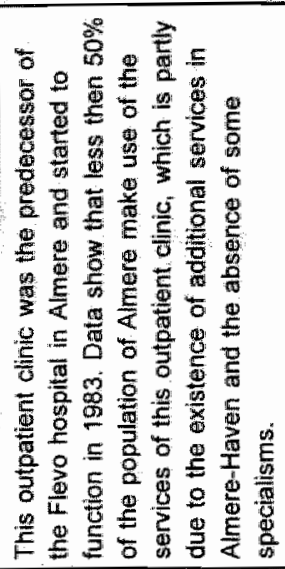 \\
\hline $\begin{array}{l}\overline{0} \\
\overline{0} \\
\frac{\vec{D}}{0} \\
\Sigma\end{array}$ & 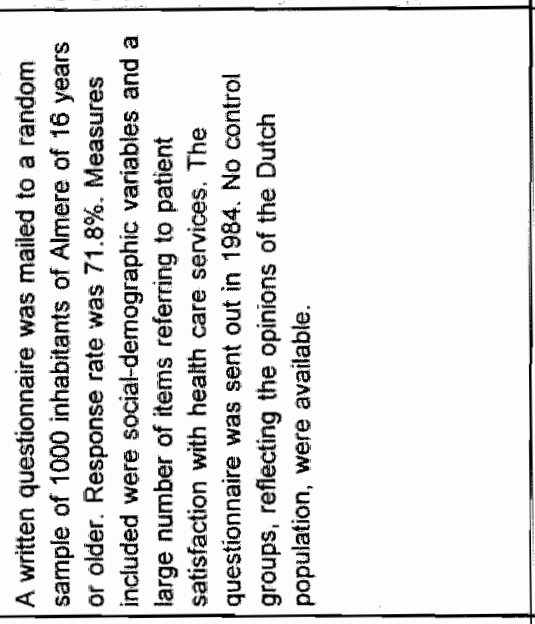 & 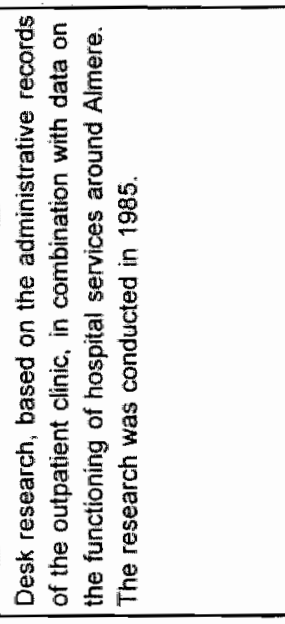 \\
\hline 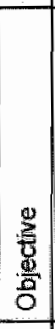 & 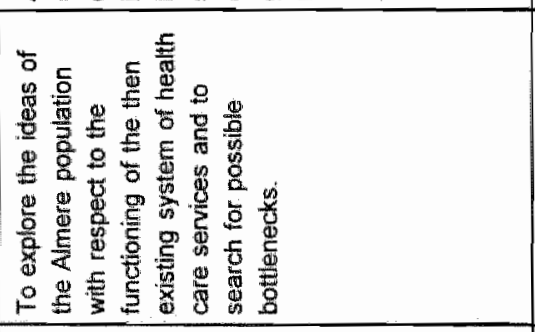 & 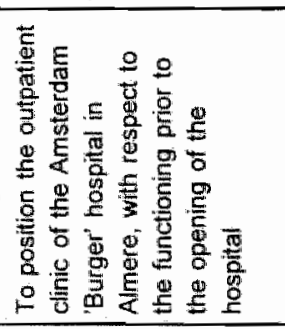 \\
\hline \begin{tabular}{|}
$\frac{5}{5}$ \\
$\frac{9}{3}$ \\
$\frac{3}{3}$ \\
$a$
\end{tabular} & 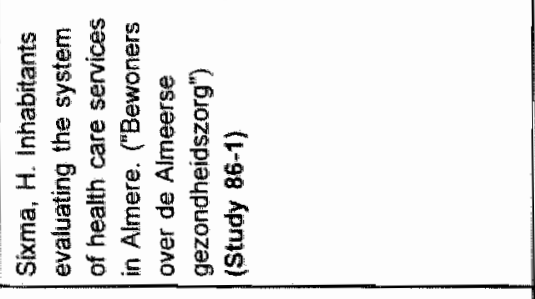 & 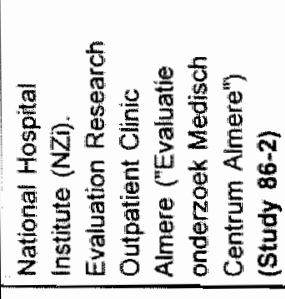 \\
\hline 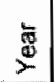 & $\begin{array}{l}\mathscr{8} \\
\stackrel{8}{*} \\
\end{array}$ & $\frac{\partial}{2}$ \\
\hline
\end{tabular}




\begin{tabular}{|c|c|c|c|}
\hline 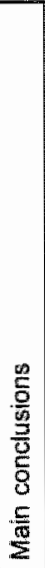 & 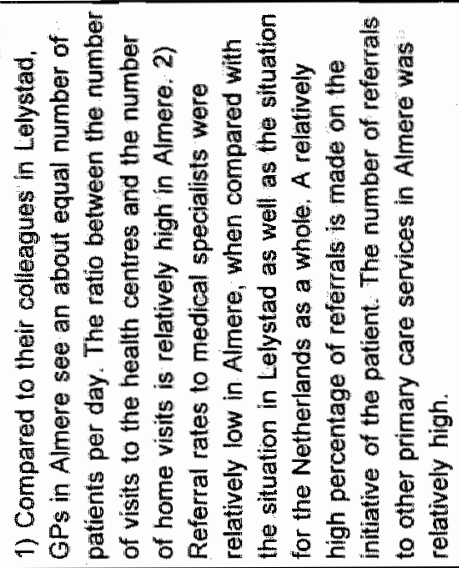 & 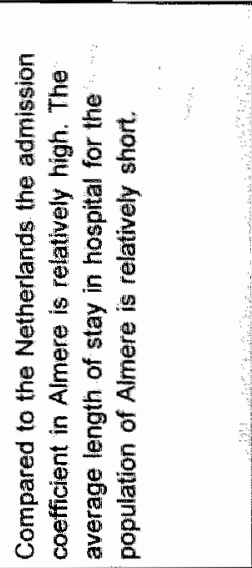 & 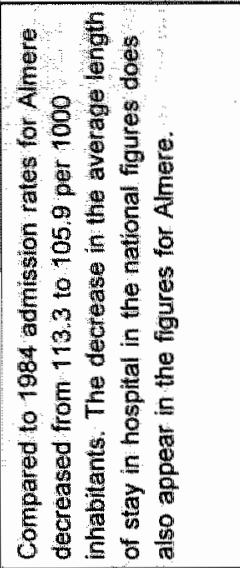 \\
\hline $\begin{array}{l}\frac{\pi}{n} \\
\frac{0}{D} \\
\frac{D}{0} \\
\frac{0}{2}\end{array}$ & 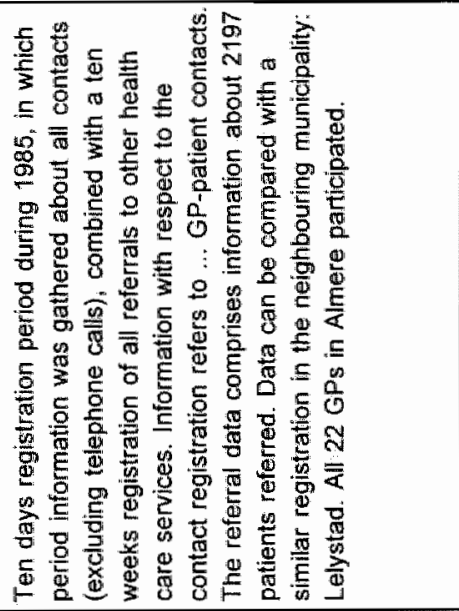 & 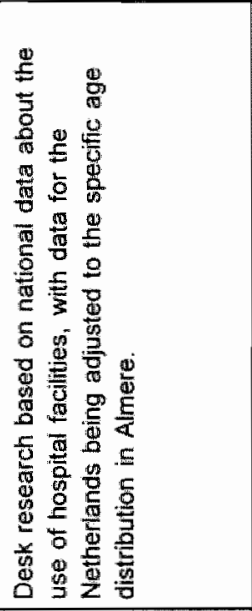 & 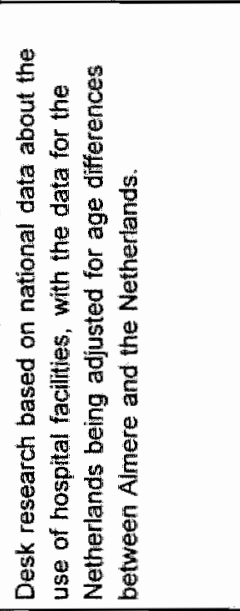 \\
\hline & 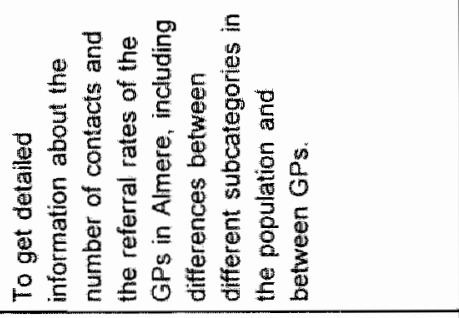 & 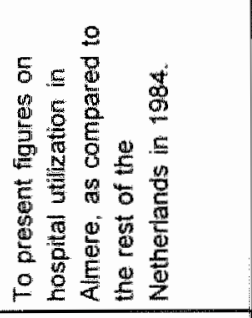 & 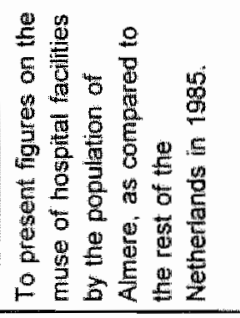 \\
\hline $\begin{array}{l}\frac{10}{5} \\
\frac{0}{9} \\
\frac{0}{0} \\
\frac{9}{3} \\
0\end{array}$ & 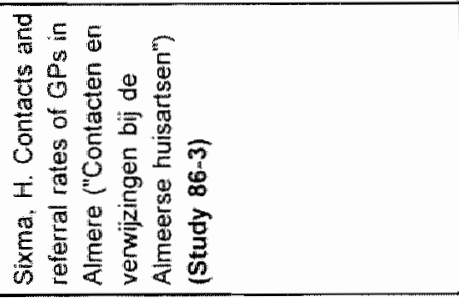 & 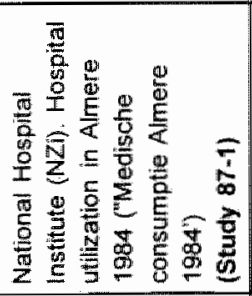 & 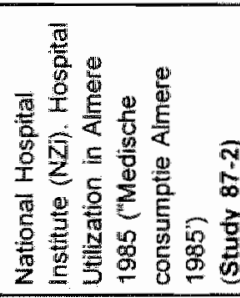 \\
\hline$\underset{\circlearrowright}{\stackrel{\mathbb{\Phi}}{\leftrightarrows}}$ & $\begin{array}{l}\text { 邑 } \\
\stackrel{2}{2}\end{array}$ & $\stackrel{5}{\stackrel{5}{g}}$ & 点 \\
\hline
\end{tabular}




\begin{tabular}{|c|c|c|c|}
\hline & 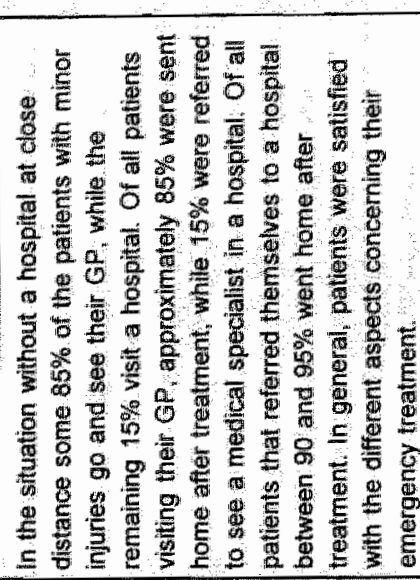 & 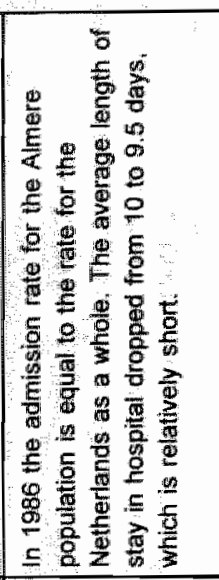 & 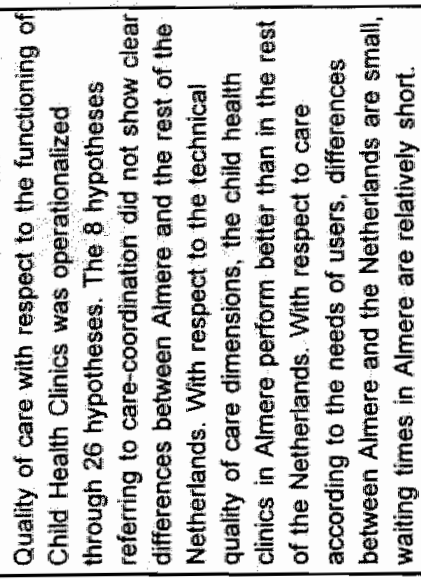 \\
\hline & 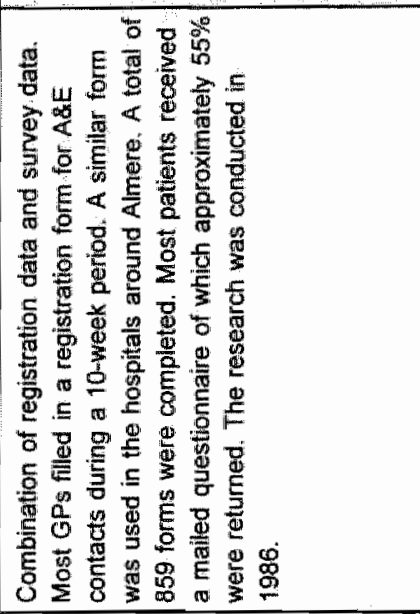 & 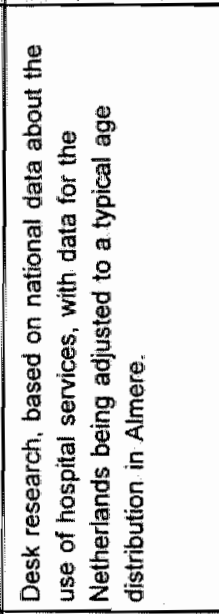 & 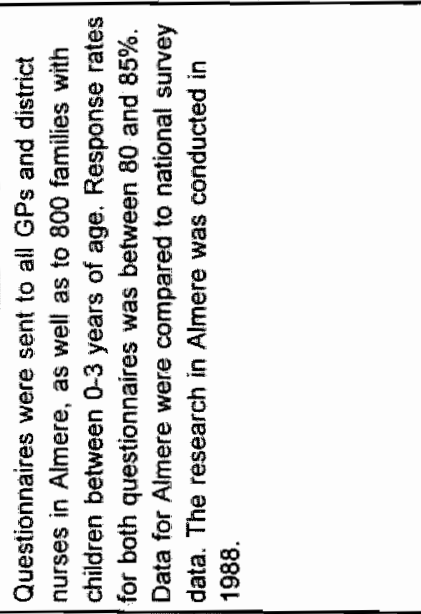 \\
\hline & 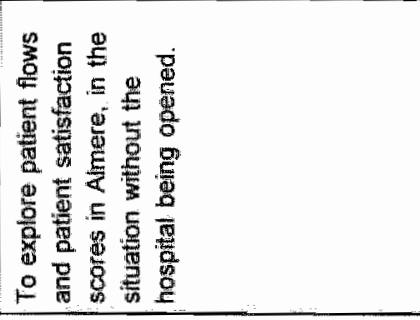 & 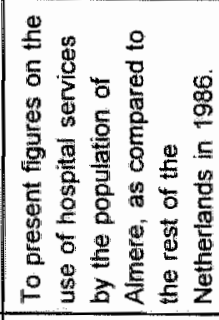 & 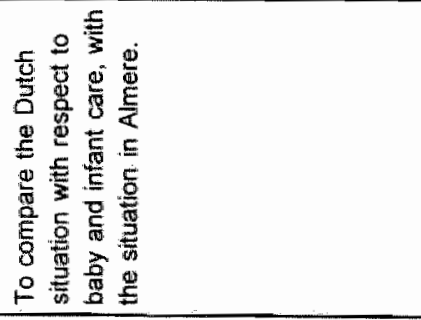 \\
\hline & 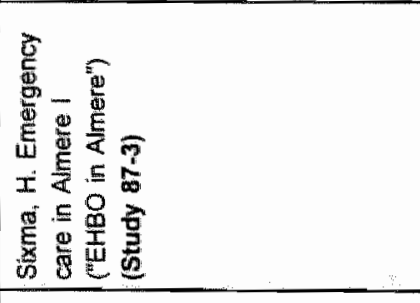 & 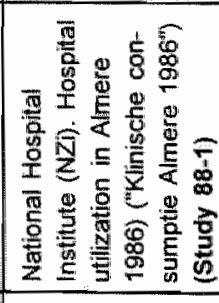 & 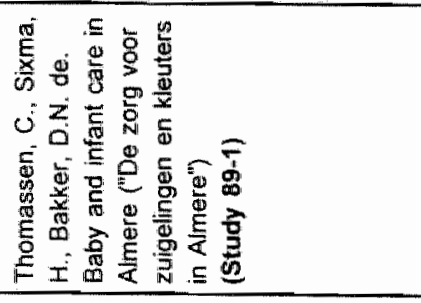 \\
\hline$\stackrel{\tilde{J}}{2}$ & $\stackrel{\Phi}{\Phi}$ & 总 & 总 \\
\hline
\end{tabular}




\begin{tabular}{|c|c|c|}
\hline & 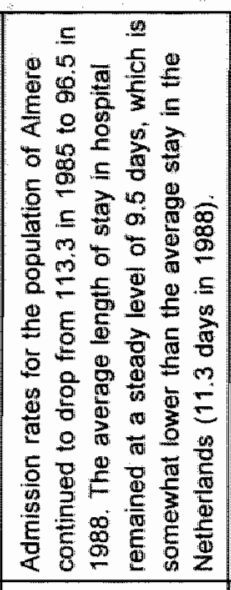 & 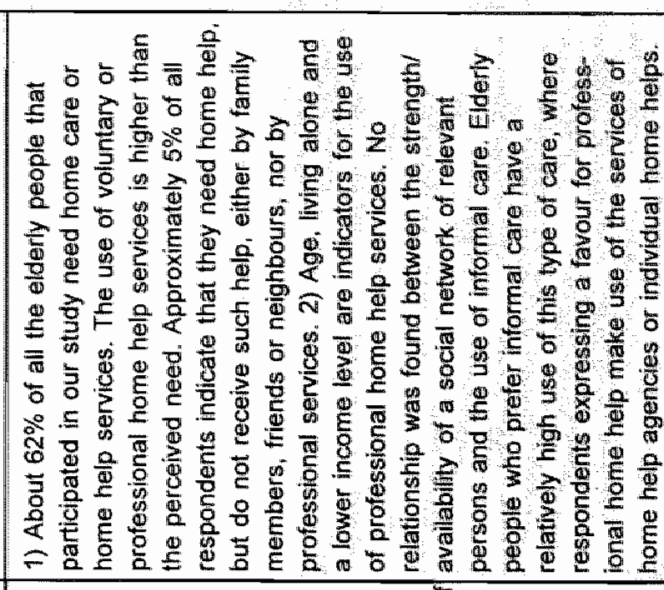 \\
\hline & 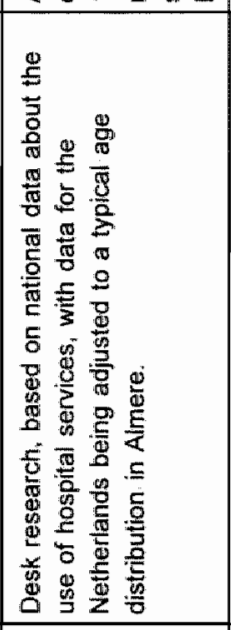 & 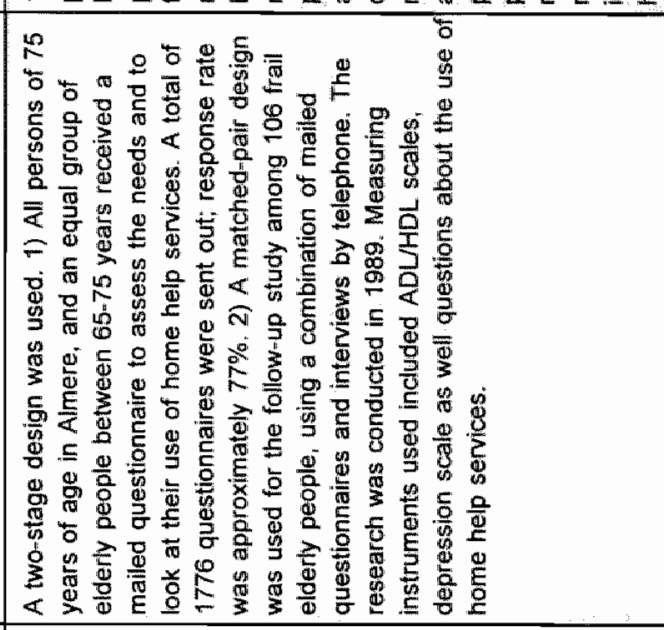 \\
\hline & 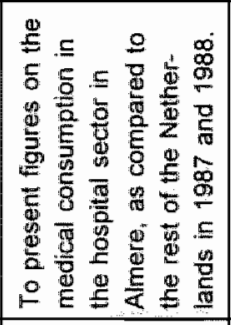 & 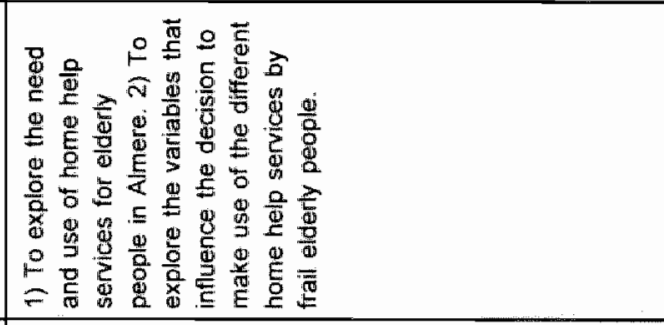 \\
\hline & 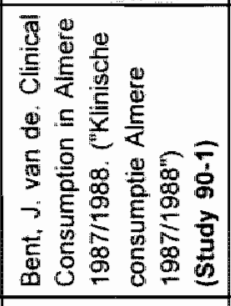 & 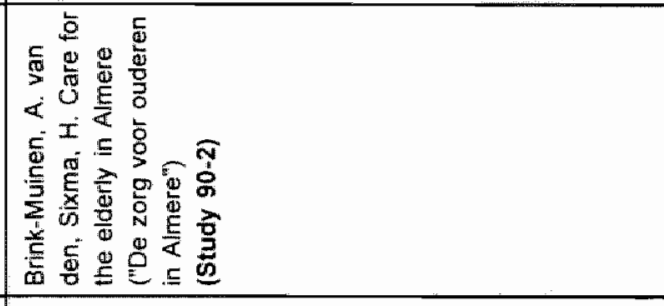 \\
\hline$\stackrel{\sqrt[5]{\mathbb{3}}}{\stackrel{2}{2}}$ & 学 & 号 \\
\hline
\end{tabular}




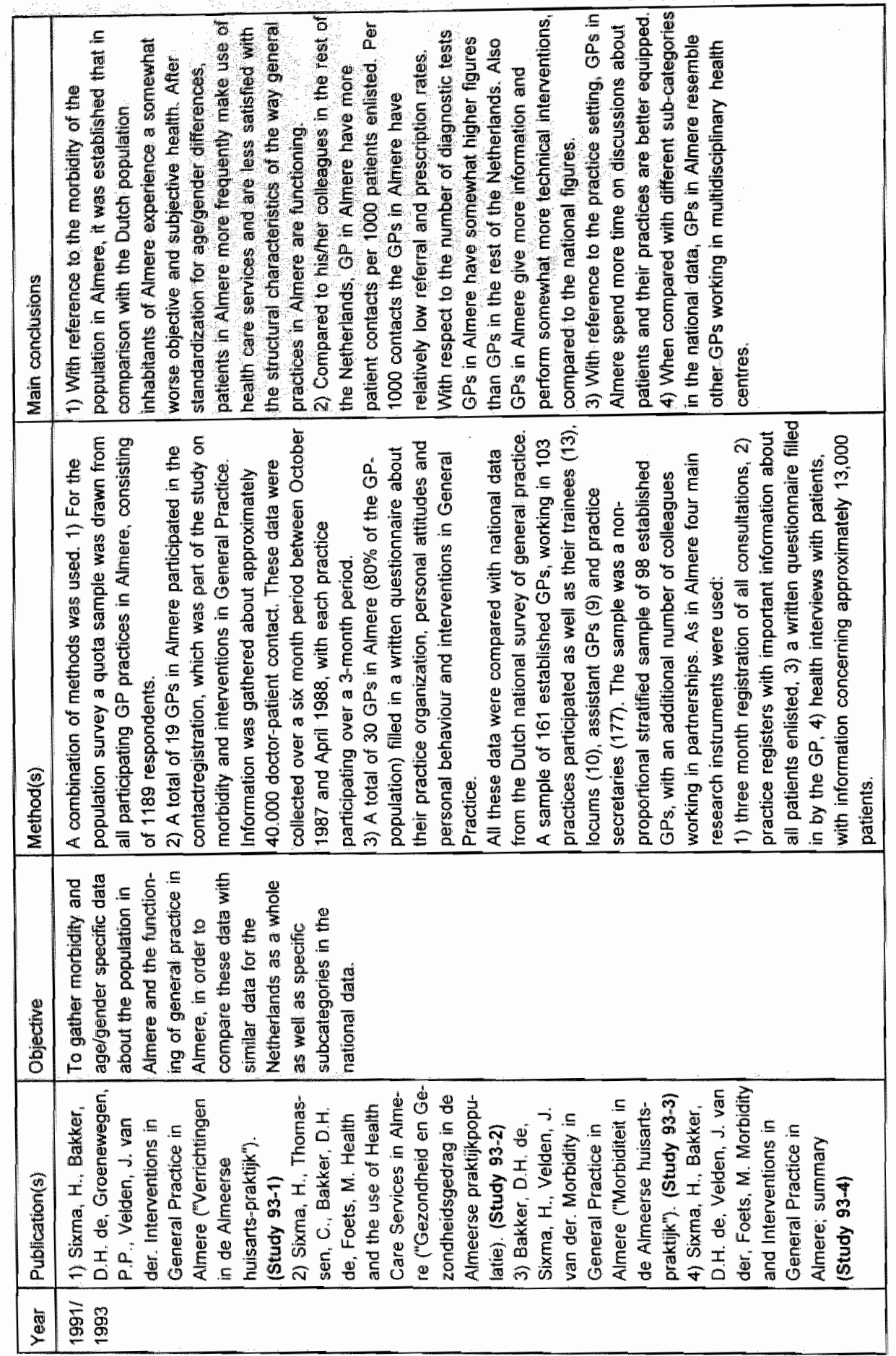




\begin{tabular}{|c|c|c|c|c|}
\hline 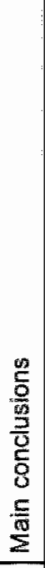 & 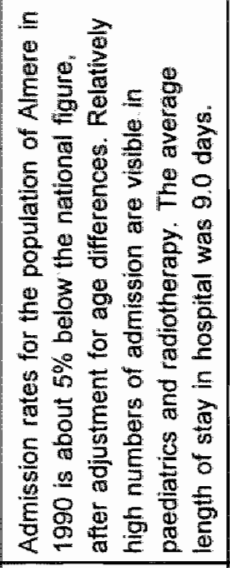 & 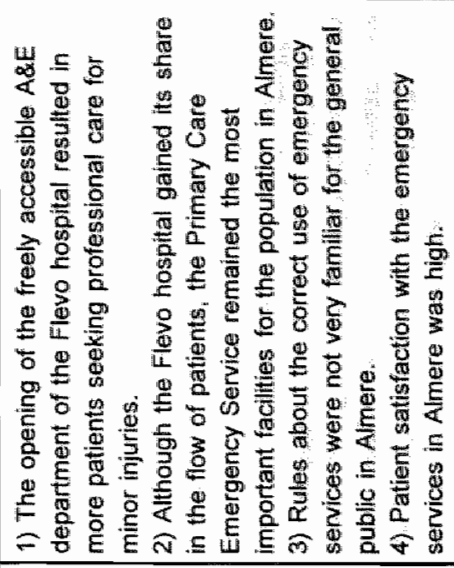 & 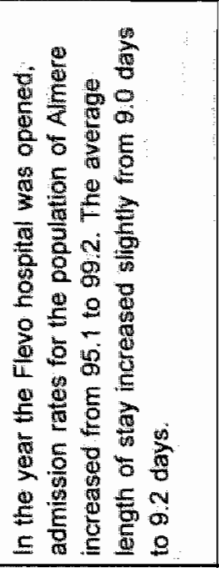 & 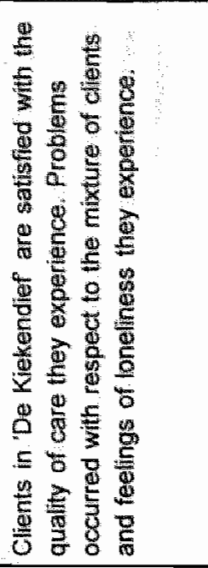 \\
\hline $\begin{array}{l}\frac{0}{0} \\
\frac{0}{0} \\
\frac{5}{5} \\
\frac{0}{2}\end{array}$ & 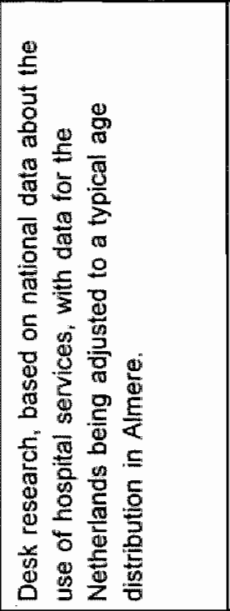 & 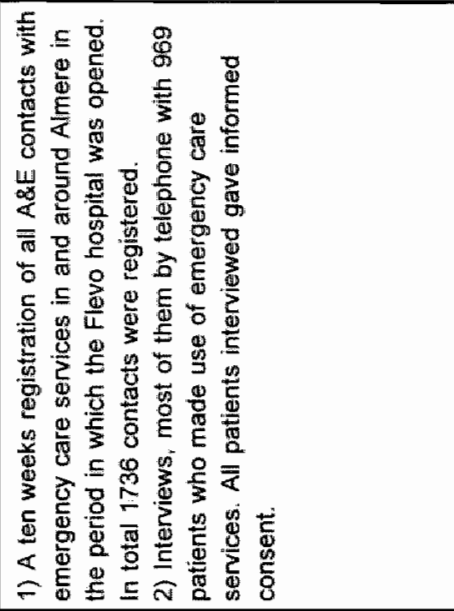 & 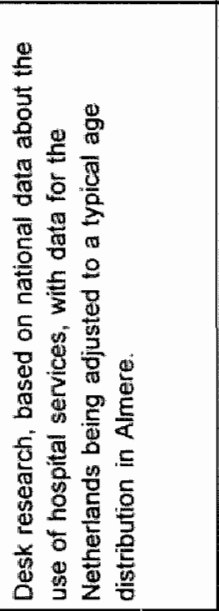 & 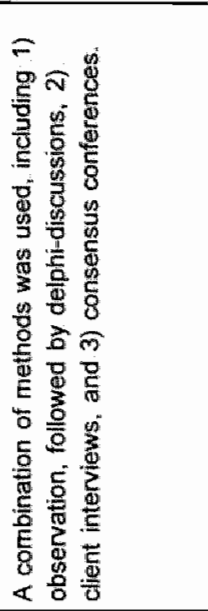 \\
\hline & 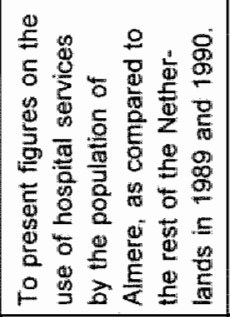 & 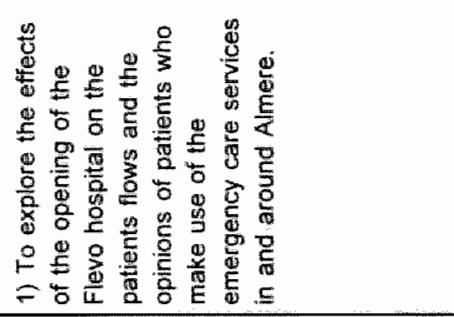 & 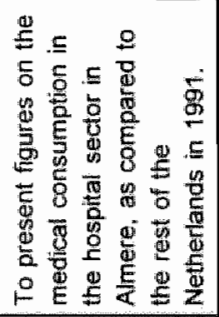 & 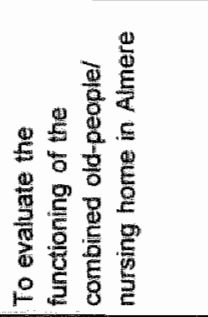 \\
\hline $\begin{array}{l}\frac{0}{2} \\
\frac{5}{7} \\
\frac{3}{3} \\
\frac{3}{2} \\
\end{array}$ & 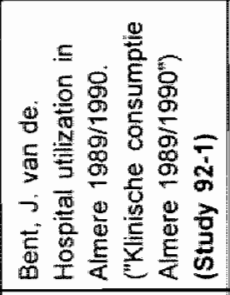 & 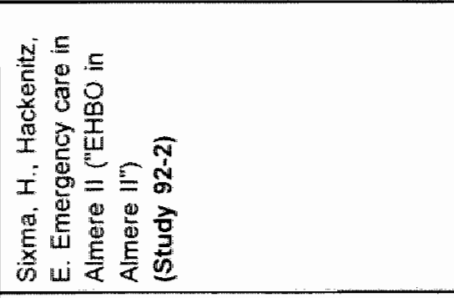 & 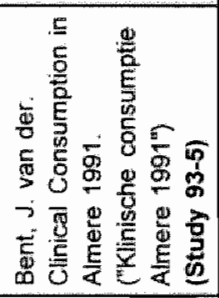 & 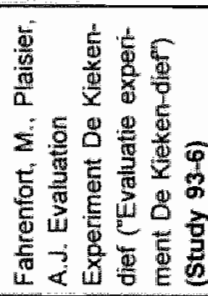 \\
\hline $\begin{array}{l}\text { 垔 } \\
\text { 㐘 }\end{array}$ & 茵 & $\stackrel{\mathrm{W}}{\mathrm{S}}$ & $\stackrel{g}{\stackrel{g}{g}}$ & 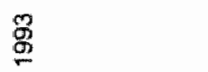 \\
\hline
\end{tabular}




\begin{tabular}{|c|c|}
\hline 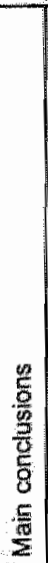 & 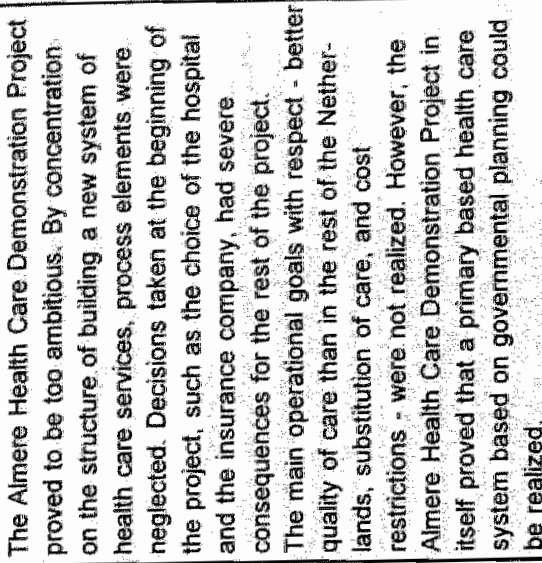 \\
\hline & 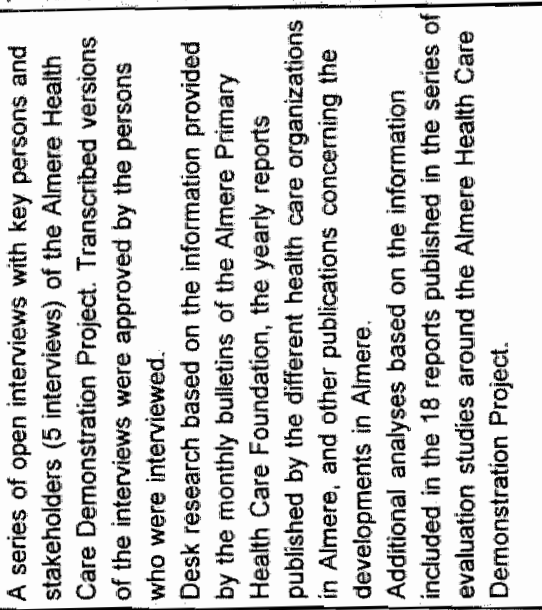 \\
\hline & 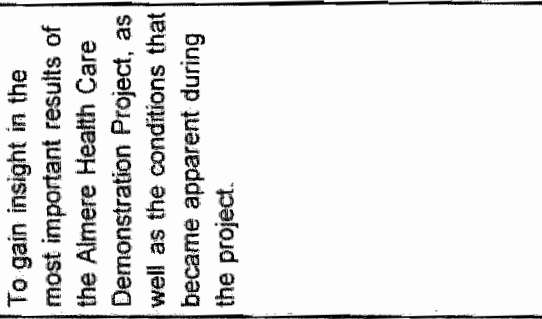 \\
\hline & 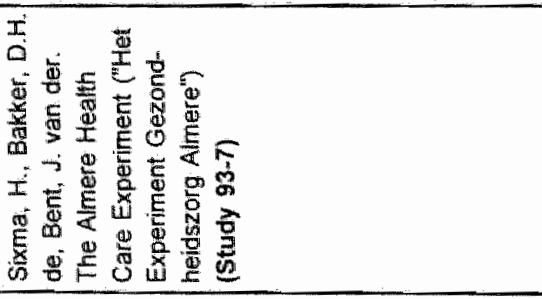 \\
\hline$\stackrel{\mathbb{g}}{y^{\prime}}$ & $\frac{8}{2}$ \\
\hline
\end{tabular}


Table 3.4 includes a series of studies carried out by the National Hospital institute (Nationaal Ziekenhuisinstituat or NZi) about the use of hospital facilities by the population of Almere on a yearly basis. Two other important studies, in which Amere was compared with the Netherlands, were carried out in $1987 / 1988$ and in 1989. In 1987/1988 a non-proportional stratified sample of 161 GPs participated in the Dutch national survey of general practice. As part of this study information was gathered about almost 400,000 doctor-patient contacts, while health interviews were conducted with over 13,000 patients. Although not being included in the national sample, $19 \mathrm{GPs}$ in Almere joined this study on a voluntary basis and provided information comparable to the national data. Secondly, in 1989 the resutts of a study on baby and infant care in Almere made it possible to compare Almere with the rest of Netherlands.

The studies described in Table 3.4 provided the backbone of data which will be presented in the chapters 6 through 8 , when we will try to establish wether the (operationalized) goals of the AHCDP were actually realized. Whenever necessary we will refer to these 19 studies by means of the identification numbers as they are presented in the first column of Table 3.4 .

\subsection{Summary and conclusions}

Having introduced the 'Stake model' as the conceptual framework for examining and evaluating the results of the experimental health care system in Almere, the AHCDP was formulated as a set of relationships between goals, instruments and conditions. The three research questions referring to the demonstration project as a policy programme, which were presented as Q2, Q3 and Q4 in Chapter 1, were linked to this conceptual framework and further elaborated. Fields of interest were: quality of care, substitution of care, and cost containment. On the basis of the existing literature, published as part of the AHCDP, general goals, more operational goals and instruments were specified.

In section 3.3 the (theoretical) relationship between instruments, conditions and goals of the AHCDP, were the main focus in order to answer the first research question as part of the policy programme evaluation. (Q2: Is there a (theoretical) relationship between the intended instruments, expected conditions and intended goals of the Aimere Health Care Demonstration Project?). In summary, it can be concluded that the anticipated relationships between the (intended) instruments "the expected conditions and the intended goals of the AHCDP are supported by the literature and common sense arguments. Due to the AHCDP starting seven years after the first inhabitants had moved to Almere and the first health care facilities had been functioning, the 'tabula rasa' situation was no longer realistic. For a better understanding of the results, attention has to be 
paid to the differences in the population structure of Almere, compared to the situation found in the rest of the Netherlands.

Section 3.4 provided an overview of the different studies carried out as part of the AHCDP. Whillst not dealing with the methodological issues, it provides the reader with basic information regarding the general aims of the different studies, the methods used and the main conclusions. Much of the results that will be presented in chapter 5,6 and 7 are based on these 19 studies.

In the following chapter the implementation process of the AHCDP will be described and a closer look will be taken at the conclusion regarding the 'tabula rasa' situation. In doing so a distinction will be made between the preexperimental, implementation and post-experimental phases. 


\section{IMPLEMENTATION OF THE ALMERE HEALTH CARE DEMONSTRATION PROJECT}

The tables presented in chapter 3 provided an overview of the (operational) goals of the Almere project and the instruments to reach these. It was also argued on the basis of the existing literature and common sense that assumptions concerning a (theoretical) relationship between goals, instruments and conditions were realistic. Chapter 4 concentrates on the implementation process of the Almere Health Care Demonstration Project (AHCDP). The questions that will be answered refer to the selected instruments and whether these instruments were actually implemented as part of the demonstration project. Formulated in this way, this question refers to the first part of the second research question, regarding the evaluation of the Almere project as a policy programme. (Q3: "What is the relationship between the intended instruments, expected conditions and intended goals of the Almere Health Care Demonstration Project and the actual instruments, existing conditions and goals realized at the end of the Experiment?"). The other two parts of research question Q3, which are related to the experienced conditions and the achievement of the most important goals of the demonstration project, will be addressed in chapter $5,6,7$ and 8 .

Section 4.2 will focus on the process of implementing the experimental health care structure. In this section a distinction will be made between the preexperimental (1976-1983), the actual implementation (1983-1992), and the postexperimental phase (1993-....). This time frame differs from the schedule applied in chapter 2, in order to comply with the specific situation in Almere. The period prior 1976, briefly described in chapter 1 , is excluded from the description. The year 1983 marked the start of the Almere project, officially coming to an end in 1992. The post-experimental phase will be described in section 4.2.3. Section 4.3 establishes whether the instruments aimed at the three main goals of the project were actually achieved. Sub-section 4.3 .1 concentrates on the instruments aimed at achieving good quality of care. This will be followed by a similar description concerning the substitution of care and the cost containment instruments in the sub-sections 4.3 .2 and 4.3 .3 respectively. The chapter concludes with a brief summary. Prior to the description of the implementation phase of AHCDP, a brief overview of the organization of the health care system in the Netherlands will be given.

Information presented in this chapter is based on a series of interviews with key persons within the AHCDP, conducted at both the commencement and the completion of the project. Extensive use was made of literature, such as the 
(bi)monthly newsletters of the Almere Health care Demonstration Project, published annual reports by the different services and facilities in Almere, and minutes from meetings of the Steering Committee and sub-committees of the project. A more detailed review of these information sources is presented in section 4.3 .

\subsection{The organization of health care in the Netherlands}

For a better understanding of the place and function of the Almere Health Care Demonstration Project (AHCDP), we will present a brief overview of the organization and functioning of the health care system in the Netherlands around $1993^{1}$ will be presented.

\section{Statistical key figures Population \\ population in $\mathrm{min}$. \\ per sq. $\mathrm{km}$. \\ $\%$ ann.growth $80-91$ \\ $\%$ urban \\ $\%$ under 15 \\ $\%$ over 65 \\ $\%$ over 75}

Development and economy human development index compuls education (yrs)

TV sets per 1000 pop.

GDP per head in $\$(p p p)$

\begin{tabular}{rlr}
\multicolumn{3}{c}{ Natality, mortality and heallth } \\
15.0 births per 1000 & 13.2 \\
365 & fertility rate/ child. p.woman & 1.7 \\
0.6 & $\%$ ann fert. reduction 1980-91 & -1.1 \\
89 & $\%$ contracept.preval. & 76 \\
18.2 & deaths per 1000 & 8.6 \\
12.9 & $\%$ infant mortality (under 1) & 0.65 \\
5.3 & $\%$ under 5 mortality (U5M) & 0.8 \\
& $\%$ ann. reduction U5M 1980-91 & 2.9 \\
& $\%$ DPT immunised at age 1 & 97 \\
98 & life expectancy (men) & 73.8 \\
11 & life expectancy (women) & 80.1
\end{tabular}

16,351

\section{The country}

The Netherlands is a small densely populated country situated near the North Sea. Large parts of the country are bellow sea levell. Formal head of the state is the queen. Executive powers, however, are with the government. The parliamentary democracy has two chambers; the First Chamber of 75 members is elected for six years by the 12 provincial councils. The Second Chamber is directly elected for four years. Extensive regulation is an important feature of the Dutch society. No Dutch town has more than one million inhabitants. Parts of the country"s extensive welfare system, developed in the 60 s and 70 s, are presently scrutinised in order to reduce its financial implications.

\section{Organization of health care}

The provision of health services is structured in four layers. Collective disease prevention, the so-called basic echelon, includes immunization, school health care, 
mother and child care and health education. The basic echelon is organised separately from primary health care, also called the first echelon, which is dominated by private initiative. Primary care is a kind of archipelago of individual independent providers and organizations: general practitioners, district nurses, physiotherapists; midwives, pharmacists, home helps and general social workers. Generalistic primary care is, in most cases, direct accessible. Usually, patients need a referral from their GP to obtain specialist or (acute) hospital care (the second echelon). A third echelon consists of long term care in psychiatric hospitals, convalescent centres and nursing homes. Nationall policy making and overall financilal supervision is the responsibility of the Secretary of State under the Minister of Welfare, Health and Culture. Since interest groups are strong, in The Netherlands policy making, and even more its implementation, is a process of negotiating and finding consensus or compromise. Planning of hospitals and nursing homes, which are non-profil private initiatives, is a duty of the twelve provinces. The well over 700 municipalities are in charge of public health (the basic echelon). The need for cost containment and improvement of efficiency in health care has resulted in proposals for a new structure and financing system. During the second half of the 1980 s government tends to retreat and there is a shift from planning to self regulation, relying on market principles. Some parts of the plans introduced in 1986 have been implemented, others were postponed.

\section{Health financing and insurance}

There is a two-ply health insurance system: a public system, run by "sick funds", for those below a certain income level (about $60 \%$ of the population) and private insurance for the other $40 \%$. In addition there is a catastrophic illiness scheme for the whole population. This last scheme, the so-called General Act on Exceptional Medical Expenses (AWBZ), is for psychiatric hospital care, out-patient mental care, community nursing and nursing home care. It is financed from tax revenues. As a part of the health care reform, there is a tendency now to increase the scope of this Act. Sick Funds, the financiers of the public scheme (covering some $60 \%$ of the population), are non-governmental organizations, still working mainly at regional level (although this is also subject to change). Premiums are deducted from wages and salaries by the employers and paid on a fifty-fifty basis by both employees and employers. The national umbrella organization of the sick funds, the Sick Fund Council, is an independent multi-party body advising the Minister on coverage and premium levels. The private scheme is financed by commercial and non-commercial insurance companies. Premiums depend an age, choice of package, optional cost sharing conditions etc. There are plans to make one tax financed health insurance system for the whole population, covering $85 \%$ of health care costs and leaving $15 \%$ to be privately insured. Early in 1992 a first step has been made by bringing pharmaceutical prescriptions under the 'AWBZ' scheme; a first step which was abolished again in 1996. Further implementation has been postponed.

\section{Secondary care}

For secondlary care there are 120 general hospitals, 9 university hospitals and 36 categorial hospitals (1990). Not included in these numbers are psychiatric hospitals, institutes for mentally handicapped and nursing homes. Bed supply and admission rate in acute hospitals is 11.4 (in-patient beds in acute hospitals), 4.3 acute hospital beds per 1000 population, and 10.3 admissions per 100 population in aculte hospitals. All figures refer to 1993 . 
Since the early 1980 s there has been an up-scaling among hospitals and a general reduction of beds. This has been compensated by promoting short stay facilities and day care and providing more diagnostic facilities to GPs on the one hand and by enforcing primary care on the other. The number of teaching hospitals for specialist training is 50 . As a rule medical specialists work exclusively hospital based. Yet most of them, almost two-thirds, are not employed. Often working in partnerships, they are free entrepreneurs, employing their allied staff and with contracts for use of hospital facilities and space. In 1990 the total number of medical specialists in 1990 was 10,955, which equals to 1350 inhabitants per specialist. In addition to these consultants a limited number of general physicians is working in hospitals, mainly while waiting for entering a specialist training programme. For publicly as well as privately insured patients medical specialists receive fees for items of service (although differently specified). Since there are waiting times for some specialisms, there is a circuit now of some 40 private clinics. These relatively small facilities are mainly offering non-clinical treatments in plastic surgery, ophthalmology, dermatology, flebology and orthopaedics.

\section{Primary care}

There is a well developed system of primary care, provided by GPS, district nurses and home helps, midwives, physiotherapists, dentists, pharmacists and general social workers. Community nurses, their number being about 7000 , are employed by 60 so called 'Cross Associations', independent foundations of private initiative and mainly tax financed. In addition to community nursing the Cross Associations provide maternity care, mother and child clinics and intensive home care. Although a lot of clients are referred by a GP, community nursing services are direct accessible. There are co-payments in the form of membership fees. A process of integrating community nursing and home help services in the same organizations is now underway. Home help services have already been brought under the same financing system as community nursing. Home help is direct accessible; use is regulated by rules and criteria and there are income dependent co-payments. Primary care obstetrics is mainly in the hands of midwives. Well over one-thirds of the deliveries are home deliveries; most of them attended by a midwife. There are 1116 midwives in The Netherlands; and $71 \%$ is independent (1991). Single handed practice is diminishing: in $198075 \%$ still worked alone, while in 1991 this was $34 \%$. Sixty percent is under 40 years of age. They are paid on a fee-for-service basis. Belonging to primary care, but only accessible on referral, are physiotherapists. Their number has increased considerably over the last two decades; there are some 13,000 now, of which threequarters work in primary care. Most of the physiotherapists work in independent private physlotherapy practices: $38 \%$ single handed, $21 \%$ in partnerships and $41 \%$ in larger groups. Treatment of publicly insured patients is only paid after authorization by the Sick Fund. Privately insured also pay fees for service. Due to the fragmented structure of primary care, co-operation and co-ordination may be a problem, especially where different providers are dealing with the same patient. Since the seventies the government has tried to improve cohesion by stimulating teamwork. This policy has been partial successful. Nowadays there are 160 health centres, in which on average of three to four GPs, an equal number of district nurses, one or two social workers and some physiotherapists are working together with allied staff in shared premises. Apart from this, there are well ower 400 multidisciplinary teams, however working on their own premises. More recent policy aims have resulted in a large number of 
substitution experiments in home care for the elderly, for terminally ill and early discharged patients. But whatever the policy, success will depend on voluntary participation of the health care field.

\section{General practice}

Usually, the first contact with health care, in a broad sense, is the contact with the general practitioner. Although there is freedom of choice of a doctor, people are registered with a GP. A typical Dutch GP is independent "owner of the premises and assisted by a receptionist or practice assistant. For most diagnostic procedures many GPs rely on external facilities. A diminishing proportion of GPs, now $11 \%$, has practice pharmacy of his own. A GP is responsible for $7 \times 24$ hours availability of services. This is usually achieved on a rota basis in locum tenancy groups with other GPS in the area. Making home visits belongs to the normal tasks. Although GPs are not involved in hospital treatment, admitted patients are visited, but not as a rule. The number of GPs is 6471 " or one per 2319 inhabitants (1991); the majority (54\%) still works in single handed practice, $31 \%$ has a partnership and $16 \%$ is in a group practice. For well over $8 \%$ of the GPs the practice is part of a health centre, which is mostly run by a private foundation or association. The proportion of female GPs is increasing from $4.7 \%$ ten years ago, until $13.2 \%$ now. It is also a relatively young population: twothirds of all GPs are younger than 45. At national level there are two organizations of GPs. The LHV, the National Association of GPS, is an interest organization, involved in megotiating tariffs and incomes, provision of practical services and the organization of continuing medical education. About $95 \%$ of all GPs is member of the LHV. The Dutch College of General Practitioners, the $\mathbb{N H G}_{4}$ is the organization for professional development, e.g. the development of criteria for treatment of frequently occurring conditions. Two-thirds of the GPS are members of the NHG.

\section{Payment and income of GPs}

For their publicly insured patients GPs have contracts with the sick funds, which pay a yearly flat capitation fee (the full tariff for 1600 publicly insured patients on the list and a lower tariff for those exceeding this number). The fee is an addition of several elements: net income ${ }_{n}$ pension contributions and practice costs. Tariffs are negotiated between the LHV and the Association of Sick Funds (VNZ) and need approval of the Ministry. With respect to tariffs for privately insured patients there is an analogous procedure with the Co-ordinating Office of the insurance companies (KLOZ). Privately insured patients pay their GP a fee-for-service " which is reimbursed by their insurance company if GP services have been chosen in the package and possible deductibles are taken into account. The proportions publicly and privately insured patients on the list differ per GP, dependent on the level of prosperity of the practice area.

\section{Training and educiation of GPs}

The obligatory registration as a GP can only take place after the fulfilment of a twoyear special training programme. Registration has to be renewed every five year. GP training programmes are organised and carried out by the eight university departments of general practice that are also involved in undergraduate medical education. Vocational training is spent largelly in the practice of an experienced GP trainer. In 1991492 doctors were in training, of which $39 \%$ was female. The average waiting time between finisithing the undergraduate programme and starting the GP vocational programme is 32 months now. 
In the above description special attention is paid to the position of the general practitioner and the way general practice functions in the Dutch health care system. This is in line with the important role the GP fulfils in the health care system in the Netherlands, and with the central position of the GP in the AHCDP. Schrijvers (1997) and Boot and Knapen (1993) provide a more extensive overyiew of the Dutch health care policy, the manner in which the health care system is functioning and the main topics in health care and policy.

\subsection{The implementation process}

In 1976 the first group of inhabitants, consisting mainly of young families formerly living in Amsterdam, moved to Almere. At the same time the first health care workers and health care institutions established themselves in this new town. This section describes the development process between 1976 and 1992.

\subsubsection{The pre-experimental period}

In 1977 a series of informal, mainly ideological discussions started. These discussions were initiated by a group of interested inhabitants, newly established primary health care workers and civil servants working in the town of Lelystad. As part of this series of discussions a conference on the future developments of the health care system in Almere was organized on 1 March 1978, on which representatives of the central, regional and local governments, health care organizations, health insurance institutions, inhabitants, and local health care workers reached agreement on the statement that the new town of Almere presents an excellent opportunity to establish a health care system different from the rest of the Netherlands. This was based on the ideas of the Memorandum on the Structure of Health Care Services published in 1974 (see chapter 1. section 1.4). However, each of the participating parties had different motives for supporting the idea for an experimental health care setting. For the central government, and despite of the change in government that took place in 1977 , Almere could become an experimental setting for future developments in the health care sector. For the local government the experimental status was thought to be an instrument for much quicker realization of health care facilities without the restriction of existing planning procedures. For representatives of the local inhabitants and health care workers, a demonstration project based on the ideas formulated in the governmental plans published after 1974 would be the realization of an up-to-date system of health care facilities. Finally, for the regional health insurance organization, the project would be a test case on how to manage ongoing cost developments. 
From 1978 onwards, initiatives towards a planned development of the health care structure in Almere were supported by the National Council for Public Health ("Nationale Raad voor de Volksgezondheid"). In 1980 the Social Health Care Foundation Almere ("Stichting Maatschappelijke Gezondheidszorg Almere") was established, and started to function as a predecessor of the future organization which would unite all primary health care services. In 1981, local government in Almere commissioned the S-1 organization - in which the Netherlands institute of general practitioners, the National Organisation of Social welfare and the National Cross Federation ${ }^{2}$ co-operated in support of the primary health care concept - and prepared a statement on the future organization of health care services in Almere. The ideas formulated by the S-1 organization (Samenwerkingsproject Eerste Lijn, 1981a-d) were accepted and subsequently published in a memorandum published in 1982 (Kommissie van Advies Gezondheidszorg Zuiderzeepoiders, 1982). The central themes of this memorandum provided the backbone of the projectplan for the AHCDP. The general idea being that, in order to reach these goals, local government would take the leading role in (1) the development of the structure and organization of primary health care services, (2) the development of the financial structure in which these services had to function, and (3) the geographical and organizational planning of all health care services. Local government in Almere was to become the driving force behind the organization and planning for the entire system of social work and health care services.

At the start of the Almere project, basic care was provided by the District Health Organization (District Gezondheids Dienst or DGD) which was situated in Lelystad (see Map 2) and had a small local office established in Almere.

With respect to primary care facilities, inhabitants of Almere could make use of the facilities of standard package in (at that time) five multidisciplinary health care centres. Three of these centres, were situated in the 'oldest' part of Almere and served 6,000 to 7,500 people. Two centres, situated in Almere-Stad "were still involved in a building-up process. Each centre served its own local area, and comprised general practitioners, physiotherapists, social workers, district nurses dentists, midwives and support staff. Four out of five centres were managed by the local Social Health Care Foundation, within these all professionals (except the social workers) were salaried employees of this organization. Social work was provided by the public authorities in Lelystad.

2. In the Netherlands social work is organised at the level of communities or districts. The National Organisation of Social welfare represents these different social work organisations as an umbrella organisation. A similar function with respect to home help services and community nursing is performed by the National Cross Federation. 
Map 2 Almere, and its surrounding area

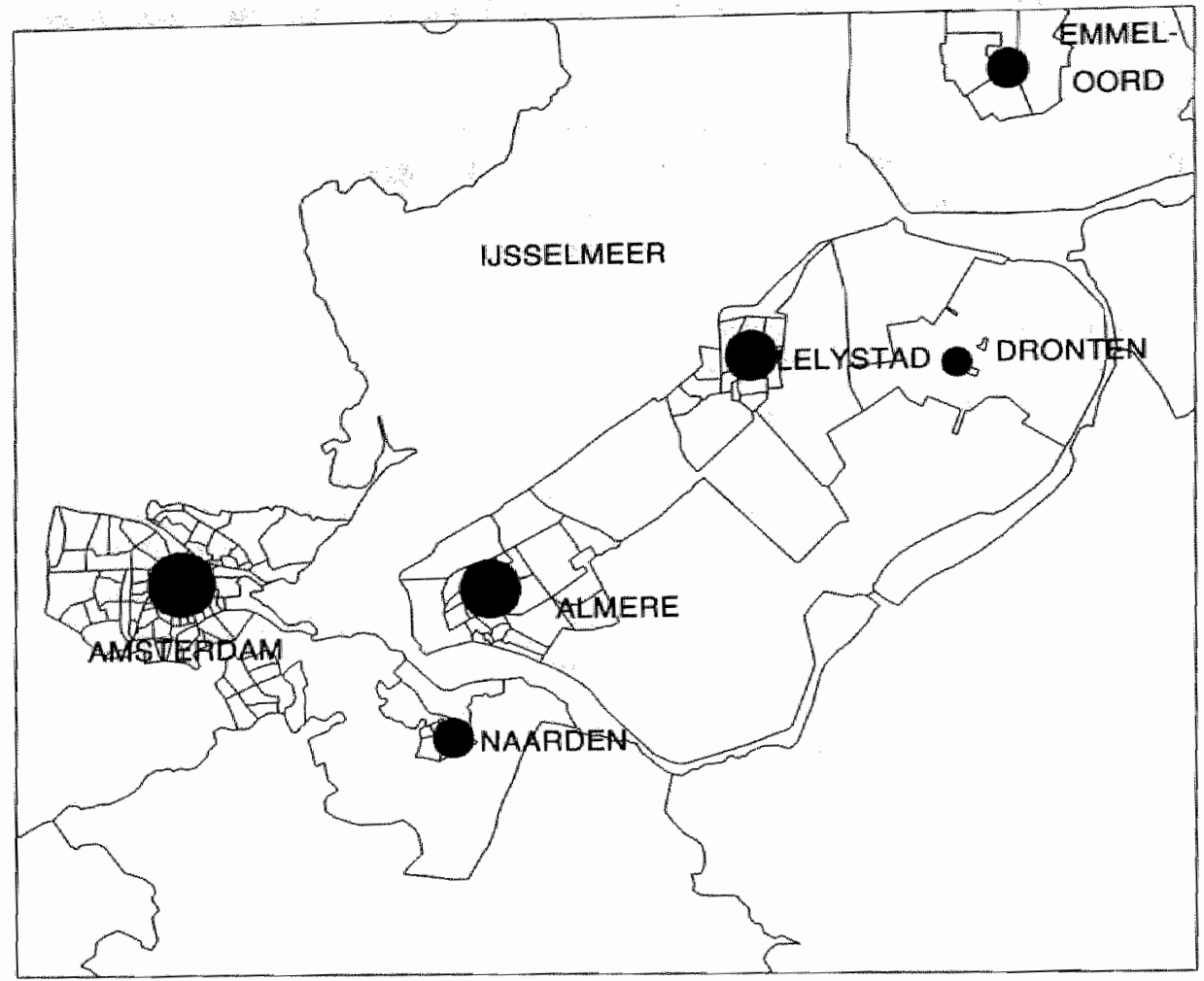

The fifth and oldest health centre - Gezondheidscentrum 'de Haak' - was managed by the regional Cross organization, located in Lelystad. All health care workers in this centre were at that moment self employed professionals. Apart from the provision of primary care in the five health care centres, a small number of physiotherapists and midwives ran an independent group practice in AlmereHaven. Also located in Almere-Haven was an independent pharmacist. Map 3 shows the three residential areas of Almere: Almere-Stad, Almere-Haven, and Almere-Buiten. 
Map 3 Almere, with its three residential areas (Source: Gemeente Almere)

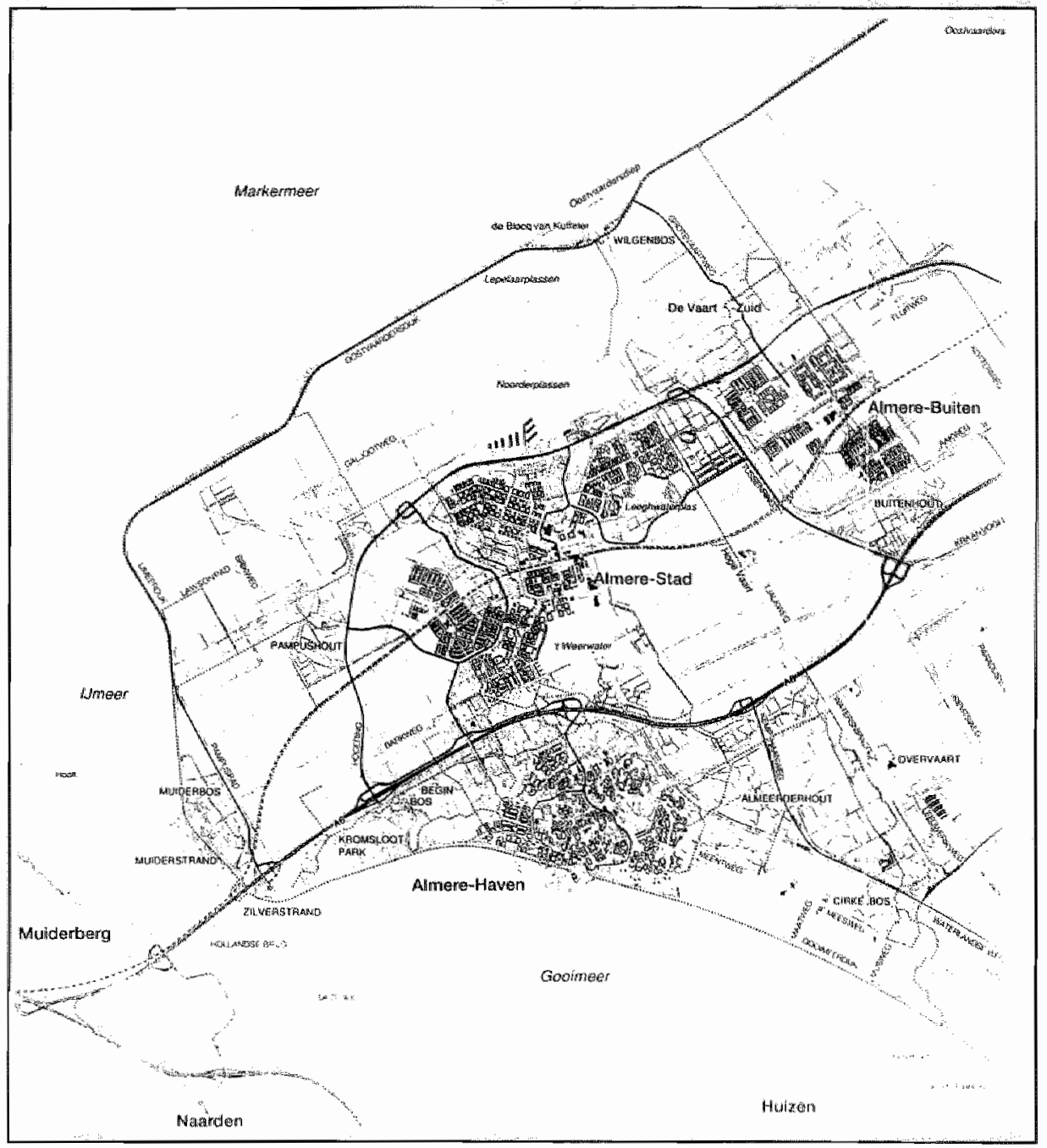

In 1983, hospital care was only available in neighbouring cities. One of the health care centres served as an outpatient clinic, with a limited number of specialists having a weekly consultation period. Other inpatient (health) care facilities, such as nursing homes, psychiatric services, convalescent centres and old people's homes did not yet exist. Emergency care was provided by each of the health care centres during office hours. People had to make use of the local 'doctor-on-call' service during out of office hours. 


\subsubsection{The implementation phase}

The start of the AHCDP was marked with the official installation of the project structure in Almere and the publication of a four-year project plan (Stuurgroep Project Gezondheidszorg Almere, 1983). This project concentrated on three main issues. (1) The realization of secondary care facilities in Almere, including a combined nursing/old people's home ${ }^{3}$ and a relatively small hospital. (2) Further structural development of the primary care sector, including the establishment of new health care centres and developing a feasibie management structure for all PHC-services. (3) Formal recognition of the experimental status of the project, including the acquisition of additional financial support. (4) Establishing an overall organizational structure for all health care facilities, based on unity in planning and financing procedures and managed by local government.

\section{(1) Realization of secondary care facilities}

In 1983 agreement was reached between the public authorities of Flevoland ${ }^{4}$ and the management board of the Burger Ziekenhuis in Amsterdam, to transfer this hospital to the new town of Almere. Following a prolonged period with discussions about the size and the organizational structure of the hospital, as well as the different departments within the hospital ${ }_{\text {. Almere's new hospital }}$ reached its operational status on 6 March 1991. This was three years behind schedule.

It is important to note that of the originally planned 325 beds, given a population size of approximately 100,000 in 1994, was limited to 180 beds, ten cradies and 15 beds for day surgery. The hospital had outpatient facilities that would fit a hospital with 240 beds. Given the fact that there always will be a limited outflow of hospital patients to more specialized clinics and facilities, the capacity of the Almere hospital was in line with the intentions to limit the clinical consumption of the population.

With reference to the employment status of the medical specialists working in the Almere hospital, a central theme of the experiment was the salaried

3 In 1983 nursing homes and old people homes were strictly separated from each ather, and therefore the idea to integrate both facilities was quite revolutionary. Since the establishment of the first combined nursing/old people home in Almere, the idea to combine both services developed rapidly and in 1997 the number of such combined services is $20+$.

Flevoland was officially established as the 12 th province on 1 January 1984 . On this date the Openbaar Lichaam Zuidelijke IJsselmeerpolders (0.1. ZJJP) was officially disbanded. The balliff of the o.I. ZIJP, appointed by the central authorities, became the first Commissaris van de Koningin of Flevoland. 
employment status for the complete medical staff. This, however, was strongly opposed by medical specialists and staff of the Burger Ziekenhuis in Amsterdam. Long and difficult negotiations between the board of the Burger Ziekenhuis and representatives of the Steering Committee of the AHCDP, resulted in non-agreement regarding the employee-status for all medical specialists. A majority of the specialists working in the Flevo ziekenhuis remained self employed. This decision was clearly not foreseen by the policy makers in Almere, and weakened the fragile relationships between the primary health care sector and the new hospital.

Problems also occurred with the plans in realizing a combined nursing- and old people's home. The experimental setting of this combined home - no formal distinction was made between both institutions and residents - was a new concept within the Netherlands and did not fit in the common national planning procedures ${ }^{5}$, in which such a combination of different services was simply not foreseen. Difficulties in finding a feasible solution for these problems resulted in considerable delay. However, the opening of the combined home in 1990 , with 100 places for frail elderly people and 30 nursing places, was an important step towards an integrated provision of health care facilities.

\section{(2) Organization of Primary Health Care services}

A notable event was the establishment of the Almere Primary Health Care Foundation (Stichting Eerstelijns Voorzieningen Almere or EVA) as an umbrella organization for all primary health care facilities. The Almere Primary Health Care Foundation (APHCF), which was officially established on 1 January 1987 , also functioned as employing organization for all primary health care professionals. The APHCF took over all organizational activities from the Social Health Care Foundation in Almere. Four years after the start of the demonstration project, the establishment of the APHCF was reached after a series of long and difficult discussions. The realization of the new organizational structure within the primary health care sector can be regarded as one the most successful elements of the demonstration project. For Almere it meant a major step towards more cohesion and organizational co-operation within the primary health care sector. This way it served as an example for other umbrella organizations that were established between 1988 and 1992 for the 'care for the elderly' sector and the 'mental health care' sector.

Strengthening primary health care by the establishment of geographically dispersed multidisciplinary health care centres was successfully implemented in

5 Nursing thomes and old people homes are built according to different planning procedures and are financed from different sources. Therefore special arrangements had to be taken to make a combination of both facilities possible from the planning point of view. 
the years after 1983. In 1992 the primary health care provision in Almere was almost exclusive to 13 health centres. Each of these health centres serviced 6000 to 8000 inhabitants and functioned under the regime of the APHCF. The number of primary health care workers not practising in health centres and not related to the APHCF at the end of the demonstration project was small. There was one general practitioner practising in Almere-Haven ${ }^{6}{ }^{6}$, while maternity care ${ }^{7}$ was given by regional organization for community care ("Stichting Kruiswerk Provincie Flevoland"). About 15 physiotherapist, two pharmacists and one midwife were not officially employed by the APHCF, but had nevertheless strong links with this foundation. Health care workers functioning independently from the APHCF were some occupational therapists, speech therapists, and $1 / 3$ of all the dentists practising in Almere. All health centres have additional diagnostic facilities, such as instruments for audiometry and electrocardiograms. In order to compete with the freely accessible Accident \& Emergency (A\&E) Department of the Flevo ziekenhuis in Almere, two health centres provided additional facilities to patients with injuries. Both primary health care emergency centres were open daily from 17.00 to 22.00 hours.

Patient participation groups were established in each of the 13 health care centres and were organized in one common structure, while patient despite the groups participated in most health care governing councils. Yet, board (Stichting Informatie patients were not represented within the hospital (1994).

\section{(3) The experimental status of the Demonstration Project}

At the start of the AHCDP, the experiment did not match with formal legislation. However, there was an agreement with the regional Sick Fund in support of the Almere policy, to exclude from the health care structure those health care

\footnotetext{
Together with two colleagues, this general practitioner was originally working in the oldest
health care centre in Almere-Haven, as independent entrepreneur. When this health centre
was taken over from the Cross organization in Lelystad (see section 4.1 .1 ), all three GPs had
the choice to join the Social Health Care Foundation and accept the salaried employment
status, or to leave the centre and continue practising outside this umbrella organisation. Two
GPs opted for the first aption. The third GP continued his practice on a different location in
Almere-Haven. working single-handed. Other GPs, who applied for a similar status, were
refused contracts by the regional health insurance organisation. This situation wauld last till
the end of the Allmere Health Care Demonstration Project in 1992.
} Maternity care, or mother

born babies and advices for the parents available in the form of preventive care for all new During the first year, mother (or father) and during regular visits to the mother-and-child clinic. having reached the age of 4 , services continue on are seen on a month-to-month basis. After 
professionals working independently by not contracting them into the Sick Fund $^{\mathrm{B}}$. On 4 November 1988 - more than five years after the start of the experiment and three-and-a-half years after publication of the first draft of this agreement on 9 May 1985, a formal decision to give Almere the (governmental) benefits of being a health care experiment was taken (Staatscourant, 1985; Staatsblad van het Koninkrijk der Nederlanden, 1988).

The experimental status was granted for a four-year period, with an option for an additional four years, which was not taken up. The experimental status itself was based on the Health Care Provisions Act, which was adopted as a framework by the Dutch parliament in 1982 (Ministerie van WVC, 1982). This act, however, was never fully implemented. As a consequence Almere can be described as the only region in which the most important elements of the Health Care Provision Act were implemented on an experimental basis.

\section{(4) Organizational structure of health care services}

Between 1983 and 1989 all activities fitting into the framework of the Almere project were organized and controlled by a Steering Committee ("Stuurgroep Gezondheidszorg Almere"), supported by funds from the central government. This steering group functioned as a platform where all parties and organizations, were setting out the rules for a common health care policy. As part of the process, in which local authorities and health care organizations were to take over the role of central government, this project structure ceased to exist in 1989 and all activities and organizational responsibilities of the steering group were transferred to the Almere Health Care Cooperation ("Samenwerkingsverband Almeerse Gezondheidszorg"). Rather than developing into a large-scale umbrella organization for the Almere health care system, the Almere Health Care Cooperation (AHCC) resulted in being a small, administrative body without the necessary power to set a (new) course for the experiment and the means to control the financial budgets of all the individual organizations.

When the plans for the experimental health care setting in Almere were developed, it was anticipated that uniformity in planning and financing procedures was possible. This was based on new legislation in the field of cost developments. The existing legislation did not provide the instruments necessary to realize such uniformity. However, a new legislation was needed that would

Until 1980 there were no possibilities to control the number of primary health care workers other than through training and education facilities. In 1980, based on article 47 (part 3) of the Sick Fund Law, it was agreed that Sick. Funds were obliged to grant all PHC workers formal permission to practise in a certain area. General dispensation was granted for physiotherapists (February 1982) and dentists (January 1983), while in November 1983 local government in Almere received permission to use this article to keep other GPs than those working in the APHCF health centres outside the municipality (see also: Dopheide, 1985). 
allow local authorities to control health care expenditure and planning procedures was considered necessary for the 'Almere model' to be formally implemented. However, this never reached official status. Consequently, plans for uniformity in the planning and financing of health care services, as mentioned in the blue-prints for the future health care system of Almere, never reached the status of an official proposal. Therefore, unity in geographical and financial planning of health care facilities, by placing this power in the hands of local authorities or local government, could not be achieved. Documents, in which the financing of all health care services in Almere could be compared with each other, were the financial paragraphs, published from 1985 onwards as supplements to the annual report which were published first by the steering group and after 1989 by the AHCC. These paragraphs had no legal status, other than a necessity to make use of additional financial means provided by central government in support of the demonstration project. They also served as a indication of the cooperation between the different organizations.

The anticipated financial support from governmental bodies as well as support on the managerial level with bureaucratic procedures was partly realized. Additional financial support to strengthen the new structure of health care facilities in Almere was received from 1985 onwards. This financial support increased from DFL 2 million in 1985 to almost DFL 5 million in 1992. However, transferred sums reached only $80 \%$ of the money that was available. This was due to inability to develop plans for future health care services and consequently obtain financial support for such additional plans.

\subsubsection{The post-experimental phase}

With the AHCDP officially ending in November 1992, the health care system built up in Almere did not significantly change. This section briefly describes the mast important changes that were implemented in the years between the end of 1993 and 1997.

Following the expiry of the terms of the Decree concerning the AHCDP, negotiations were undertaken between the APHCF and the ANOZ Gooi Apeldoorn Groep Health Insurance Association to continue the supplementary financial support. These negotiations resulted in the structural allocation of approximately half a million guilders per year for the care of the elderly. However, the remainder of the additional money that went to Almere on a yearly basis was no longer available. In 1993 one million guilders were reserved for this and the supplementary support ceased at the beginning of 1994. No additional funds were available for Almere after 1994.

Shortly after the formal end of the experiment in 1993 the Almere Health Care Foundation was officially disbanded. In contrast to the predictions, local 
government did not take on the leading role that previously had been fulfilled by the Steering Committee and subsequently by the AHCC.

As will be shown in chapter 6, patient satisfaction scores with health care facilities in Almere generally do not exceed the national level, in some instances they were lower. Ad hoc explanations for these lower scores are: (1) a limited choice between different GPs, (2) a tendency towards bureaucratization with individual GPs feeling less responsible for activities, such as the accessibility of primary care services, and (3) a more critical attitude of the population of Almere due to its high expectations or previous experiences in the town it originated from. To make the system less bureaucratic, a re-organization of the management structure of the APHCF, which started in 1991, was continued in the post-experimental phase. Management was decentralized again, with additional budget responsibilities becoming part of the four holding corporations within the APHCF.

In 1993 only a limited number of single-handed general practitioners was allowed to practise in Almere. This decision was taken in order to comply with requests from the population of Almere but also typifies the new postexperimental situation with health care workers being allowed to establish themselves in Almere without special permission from the local Sick Fund. From the end of 1992, employment status for primary health care workers under one umbrella organization was no longer mandatory and the monopoly position for the APHCF during the implementation phase of the demonstration project was exchanged for a more competitive situation. Also it was decided that clients were no longer restricted to use the health care centre within their neighbourhood. Health care centres themselves started to function more independently from each other, each responsible for its own budget and personnel management. Finally, all dentists employed by the APHCF left the organization, with the employer function taken over by the new EVADent corporation. In the postexperimental phase the APHCF gradually became a more 'open' organization already anticipated in 1991 (Helsloot, 1991).

\subsection{Implementation of the instruments}

The next three sections will summarize, in detail, those instruments specified in table 3.1 to 3.3 intended to be implemented which were realized in the period between 1983 and 1993. With respect to the organization and functioning of primary health care services use was made of the (1) bi-monthly bulletins published by the APHCF, (2) yearly reports by the APHCF, (3) yearly reports of the public health authorities in Almere, (4) yearly reports of the Social Work organization in Almere, (5) yearly reports of the Foundation of patients 
organization SIOP ("Stichting Informatie en Ondersteuning Patientengroepen"), (6) the AHCC quarterlies published since $1989,(7)$ yearly reports published by the AHCC, and (B) information bulletins published by the primary health care services in Almere. With respect to the organization of hospital services in Almere, as well as the functioning of nursing- and old people's homes, similar publications were used. These included the yearly reports of the Flevo hospital, Delta Foundation, the combined nursinglold people's home De Kiekendief as well as regular old people's homes in Almere, and reports and newsletters published by the AHCC.

\subsubsection{Implementation of the instruments directed towards quality of care}

The extent to which the instruments selected to achieve good quality of care in Almere is summarized in diagram 4.1. This diagram provides an overview of all instruments described earlier in table 3.1 , and the extent to which they were capable of being uilized at the end of the AHCDP. Operational goals have been omitted. An indication is also given as to whether the instruments was completely or partly realized, or not realized at all.

The final picture regarding the manner in which Almere health care was organized in 1993, resulted in both a positive and negative experiences. The organization of primary care through district-directed health care centres, extra diagnostic facilities for primary care and the participation of the population were all achieved. In theory, there were opportunities for participation by local inhabitants. However, management and the implementation of plans, remained in the hand of a few active people, selected through ca-optation, but functioning without consulting the people they were supposed to represent (Hermans, 1985).

The general rule of salaried employment applies to most health care workers in Almere. Three groups of employees are not paid in salaries. These three groups are: a number of the initially employed primary care providers, some care providers whose establishment in practice did not depend on the Health msurance Associations and a majority of the medical specialists. Not, or partly realized was the contribution of the involvement of primary care disciplines on the hospital's managerial board and other secondary care provisions, institutionalized opportunities for consultation, uniform admittance procedures for home care and intramural care, and agreements regarding the planning and financing of health care provisions. Some of these points need further explanation. 
Diagram 4.1 Goals, instruments and the degree to which these instruments have been directed towards quality of care

\begin{tabular}{|c|c|c|}
\hline Goals & Envisaged instruments & $\begin{array}{l}\text { Degree of realization of } \\
\text { instruments }\end{array}$ \\
\hline $\begin{array}{l}\text { good quallity of } \\
\text { organizations } \\
\text { and/or } \\
\text { organizational } \\
\text { structure }\end{array}$ & $\begin{array}{l}\text { structure } \\
\text { - one organizational body for all health } \\
\text { care services (AHCC) Almere care } \\
\text { department } \\
\text { - one financial framework } \\
\text { - epidemiological collection of data by } \\
\text { sentinel stations } \\
\text { - central planning of facilities } \\
\text { - uniform assessment of indications } \\
\text { - umbrella organizations for the } \\
\text { different sectors } \\
\text { - salaried employment for all PHC } \\
\text { workers in one organization } \\
\text { - multidisciplinary health centres with } \\
\text { coordination between the disciplines } \\
\text { - management participation primary } \\
\text { care sector in secondary care } \\
\text { - salaried employment for workers in } \\
\text { secondary care } \\
\text { - additional diagnostic facilities by } \\
\text { secondary care to primary care } \\
\text { - organization of patients and patient } \\
\text { groups on a central level } \\
\text { - health care centres and other } \\
\text { facilities } \\
\text { process }\end{array}$ & $\begin{array}{l}\text { realized } \\
\text { not realized } \\
\text { partly realized } \\
\text { realized } \\
\text { partly realized } \\
\text { realized by primary care, } \\
\text { care of the elderly and } \\
\text { mental health care } \\
\text { realized } \\
\text { realized } \\
\text { not realized } \\
\text { partly realized } \\
\text { realized } \\
\text { realized } \\
\text { realized } \\
\text { partly realized } \\
\text { partly realized } \\
\text { partly realized } \\
\text { pal }\end{array}$ \\
\hline $\begin{array}{l}\text { good quality of } \\
\text { health care } \\
\text { workers }\end{array}$ & $\begin{array}{l}\text { structure } \\
\text { - specific recruitment and appointment } \\
\text { - salaried emplloyment of all health } \\
\text { care workers } \\
\text { - peer review } \\
\text { - continuing medical education } \\
\text { - reducing the size of practices }\end{array}$ & $\begin{array}{l}\text { partly realized } \\
\text { partly realized } \\
\text { realized } \\
\text { realized } \\
\text { partly realized }\end{array}$ \\
\hline
\end{tabular}




\begin{tabular}{|c|c|c|}
\hline $\begin{array}{l}\text { good quality with } \\
\text { regards to the } \\
\text { structure of health } \\
\text { care services }\end{array}$ & $\begin{array}{l}\text { structure } \\
\text { - geographical planning of facilities } \\
\text { - patient participationi on the level of } \\
\text { facilities } \\
\text { - rules for arrangement of facilities } \\
\text { process } \\
\text { - rules and protocols for use of } \\
\text { facilities }\end{array}$ & $\begin{array}{l}\text { realized } \\
\text { partly realized } \\
\text { realized } \\
\text { partly realized }\end{array}$ \\
\hline $\begin{array}{l}\text { good quality of the } \\
\text { process of health } \\
\text { care delivery }\end{array}$ & $\begin{array}{l}\text { structure } \\
\text { - establishment of help providers } \\
\text { restricted to rules } \\
\text { - salaried employment of all health } \\
\text { care workers } \\
\text { - specific appointment policy for help } \\
\text { providers } \\
\text { - official complaints procedure } \\
\text { - regular examination of needs and } \\
\text { patient consultation of inhabitants } \\
\text { - patient meetings in health care } \\
\text { centres and other instifutions } \\
\text { process } \\
\text { - agreements/protocols concerning } \\
\text { consultation } \\
\text { - peer review } \\
\text { - providing health care by protocols } \\
\text { and professional standards } \\
\text { - (multidisciplinary) treatment plans }\end{array}$ & $\begin{array}{l}\text { realized and released } \\
\text { partly realized } \\
\text { partly realized } \\
\text { realized } \\
\text { partly realized } \\
\text { realized } \\
\text { partly realized } \\
\text { reallized } \\
\text { partly realized } \\
\text { partly realized }\end{array}$ \\
\hline
\end{tabular}

Consultation takes place mostly on an 'ad hoc' basis. Case meetings, stimulated by the "primary/secondary care" network take place: however, these cannot be considered as regular consultations. Uniform indication procedures have been successfully implemented for home care and were under development for the care for frail elderly people.

An important feature in the organizational structure of the health care system in Almere, was the founding of several umbrella organizations, such as the Almere Primary Health Care Foundation, the Delta Foundation (organising all care for the elderly people) and the umbrella organizations in the area of mental health and care of the physically handicapped. This structure, in which organizations in different sectors work closely together in the Almere Health Care Cooperation, provides the opportunity for an integrated, efficient care policy.

Regarding the quality of the structure of health care services, most instruments were realized or partly realized. In respect of the quality of care process, those partly realized included the salaried employment status, regular surveys among patients, protocols for consultations and multidisciplinary treatment plans. Following the expiry of the Decree on the AHCDP, the "Besluit Experiment 
Gezondheidszorg Almere", rules restricting health care workers from establishing themselves in Almere no longer existed after 1992. Finally, an official complaints procedure in Almere has been implemented for primary care patients in Almere. In general, instruments directed towards the structure of health care services were realized. On the process side, the results are more ambiguous. Much work remains to be done here.

\subsubsection{Implementation of the instruments directed towards substitution of care}

The relationship between instruments and goals in the area of care substitution was discussed in section 3.2.2. Instruments already discussed in the previous section (e.g. the employment status of health care professionals), are left out of the discussion. In diagram 4.2 an indication is given as to whether the instruments were completely or partly implemented, or not implemented at all.

A distinction can be made between instruments aimed at structural components and instruments aimed at process elements. An example of a beneficial implementation of instruments aimed at the structure of facilities can be seen in the Flevo hospital. This hospital has the intended additional outpatient facilities, extra beds for day surgery and additional cradles, sufficient for a hospital with 240 beds "instead of the 180 beds (plus 10 cradles and 15 beds for day surgery). These facilities compare favourably with the capacity considered usual for a standard hospital of 180 beds, and with the size of the population of Almere. However, because of the delay in opening the Flevo hospitall, these facilities resulting in implementation of this instrument became available in March 1991. This was three years behind schedule and less than two years before the end of the AHCDP.

Between 1985 and the opening of the Flevo hospital in 1991 an outpatient department existed, the Medical Centre Almere ("Medisch Centrum Almere" or MCA). During this period minor day care surgery was carried by medical specialists of the Burger hospital on a small scale basis. However, streamlining the intake and referral policy within the provisions of the hospital sector using protocols and agreements has only been realized to a limited extent (EVA, 1995). This also applies to medical specialists in the Flevo hospital receiving salaries. Most medicall specialists working in the hospital have been able to ensure that they remain exceptions to this rule, despite the fact that salaried employment was an urgent requirement in moving the hospital to Almere. After a new management board for the Flevo hospital was appointed in 1991, patient representation was no longer available. 
Diagram 4.2 Goals, planned instruments and the degree in which these instruments are realized, regarding substitution of care in Almere

\begin{tabular}{|c|c|c|}
\hline General goals & enwsaged instruments & $\begin{array}{l}\text { degree af realization of } \\
\text { instruments }\end{array}$ \\
\hline $\begin{array}{l}\text { substitution within } \\
\text { intramural sector } \\
\text { and from } \\
\text { intramufal care to } \\
\text { outpatient care }\end{array}$ & $\begin{array}{l}\text { structure } \\
\text { - increasing outpatient facilities } \\
\text { hospital } \\
\text { - increasing day treatment } \\
\text { - salaried employment contracts for all } \\
\text { workers in intramural care } \\
\text { - lower bed capacity } \\
\text { process } \\
\text { - streamlining the intake and referral } \\
\text { policy } \\
\text { - protocols and agreements within the } \\
\text { intramural provisions }\end{array}$ & $\begin{array}{l}\text { realized } \\
\text { realized } \\
\text { partly realized } \\
\text { realized } \\
\text { partly realized } \\
\text { partly realized }\end{array}$ \\
\hline $\begin{array}{l}\text { substitution from } \\
\text { secondary to } \\
\text { primary care }\end{array}$ & $\begin{array}{l}\text { structure } \\
\text { - relatively small hospital } \\
\text { - support of primary care through } \\
\text { adequate diagnostic facilities and } \\
\text { expertise } \\
\text { - continuing medical education } \\
\text { - recruitment of extra personnel } \\
\text { - combined nursing and oid people's } \\
\text { home } \\
\text { process } \\
\text { - protocols on the different specialisms } \\
\text { - agreements concerning discharge of } \\
\text { patients } \\
\text { - broadening the task package for } \\
\text { primary care } \\
\text { - agreement between primary and } \\
\text { secondary care an intake and } \\
\text { transferring policy }\end{array}$ & $\begin{array}{l}\text { realized } \\
\text { partly realized } \\
\text { realized } \\
\text { partly realized } \\
\text { realized }\end{array}$ \\
\hline $\begin{array}{l}\text { substitution from } \\
\text { professional care } \\
\text { to } \\
\text { informal care and } \\
\text { self help } \\
\text { substitution from } \\
\text { curative to } \\
\text { preventive care } \\
\text { and }\end{array}$ & $\begin{array}{l}\text { structure } \\
\text { - stimulating information campaignis } \\
\text { - gathering epidemiological information } \\
\text { - creating networks of information on } \\
\text { services for the elderly } \\
\text { - semi-detached facilities at retirement } \\
\text { homes } \\
\text { - supporting volunteer groups }\end{array}$ & $\begin{array}{l}\text { partly realized } \\
\text { partly realized } \\
\text { realized } \\
\text { realized } \\
\text { partly realized }\end{array}$ \\
\hline
\end{tabular}


Diagram 4.2 shows that substitution from secondary to primary care was in many cases realized. Most of the selected instruments were implemented, even though there were some delays in their realization.

In accordance with the original design the Flevo hospital was relatively small although with adequate diagnostic facilities and satisfactory support for primary care services. Of the 205 beds available (180 regular beds, 10 cradles and 15 beds for day surgery), the number of beds per 1000 inhabitants was 2.3 on 1 January 1993.

Primary and secondary care networks enabled agreements to be drawn up for the discharge policy, after care of day-treatment patients, transfer of diabetics, COPD and decubitus patients from hospital treatment to nursing supervision, and treatment of oncology and diabetic patients. Working agreements were also set up between the Flevo hospital and dieticians, midwives and social workers. A general protocol for emergency services also existed, with rules being formalized concerning the referral and treatment of emergency treatment of patients between the primary health care emergency centres and the Accident \& Emergency Department of the Flevo hospital. However, similar protocols for other specialisms in the Flevo hospital were not in place by the end of 1992. Particular attention is paid to broadening the task package for primary care for example by continuing medical education.

At the end of the Almere project the majority of the instruments to substitute professional care by informal care had been implemented. This, however, was not the case for instruments intended to substitute curative by preventive care. Information campaigns took place, although their number was small. The network of information services (APHCF-partners, Flevo hospital, Delta Association for elderly people) would provide an opportunity for computerized information exchange between primary and secondary care, but this facility was not in place until the end of 1992. The same can be said for the process of automatization of all health care centres in Almere. In 1992, the conditions for gathering large scale epidemiological data sets were favourable. However, it would be premature to claim that these instruments were in place.

\subsubsection{Implementation of the instruments with respect to cost contain- ment}

With respect to cost containment, diagram 4.3 gives an overview of the goals, the instruments to be put in place and the extent to which they were realized during the Almere project. The instruments of care substitution working towards the cost containment goal are not included in the diagram. For these, we refer to diagram 4.2 . 
Diagram 4.3 Goals, planned means and the degree to which these goals have been realized, in order to reach the goal of cost containment

\begin{tabular}{|c|c|c|}
\hline Goaks & Erwisged inswuments & $\begin{array}{l}\text { Degree of realization of } \\
\text { nstruments }\end{array}$ \\
\hline cost conainment & 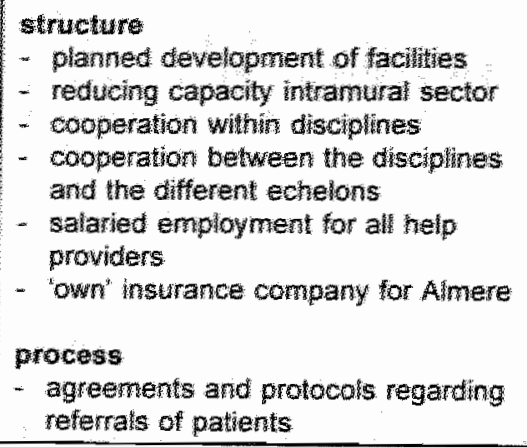 & $\begin{array}{l}\text { realized } \\
\text { realized } \\
\text { realized } \\
\text { partly reaized } \\
\text { party realized } \\
\text { not realized } \\
\text { partly realized }\end{array}$ \\
\hline cost containment & $\begin{array}{l}\text { structure } \\
\text { - management through infomation } \\
\text { and teed back } \\
\text { - offering foms of continung medicat } \\
\text { education } \\
\text { process } \\
\text { - meetings directed for peer review }\end{array}$ & $\begin{array}{l}\text { party realized } \\
\text { realized } \\
\text { partly realized }\end{array}$ \\
\hline
\end{tabular}

The overall picture that arises from diagram 4.3 (see next page) is, that in the course of the Almere experiment some of the instruments directed to cost containment were put in place, albeit sometime later than had originally been planned. Cooperation within disciplines was faciltated through bringing together all aspects of primary care in the health centres and forming the EVA as a coordinating institution for the primary care disciplines. In other areas of heath care provision, for example in the care of the elderly and the handicapped, coordination and coordinating organizations are in place.

Agreements and protocols regarding referrals within and between the echelons and cooperation between echelons were partly realized. Supplementary to the section focusing on substitution, only types of continuing medical education (CME) were successful. Management of care provider's work through information and feed back differs at this time from discipline to discipline. This also applies to peer review meetings. General practitioners and pharmacists in Almere have drawn up agreements aiming to control costs in the prescription of medicines.

From an early stage the idea of a "polder insurance fund" was superseded, with Almere's becoming part of the working area of the "Het Gooi \& Omstreken" Health Insurance Association. 


\subsection{Conclusions with respect to the implementation process and the instruments realized}

Looking at the process to implement a new and experimental structure of health care facilities in Almere, the first conclusion must be that the 'tabula rasa' situation in Almere no longer existed. After the official start of the Almere project, some seven years after the first inhabitants moved to Almere, the idea that one can develop a new health care system from the very beginning proved to be unrealistic. Building such a new system, existing parties play important roles based on their vested interests. It therefore proved easier to develop a complete new structure than to transfer an already existing organization, i.e the Flevo hospital, to Almere. This is illustrated by the prolonged discussion about the size of the hospital (which ended in favour of the original ideas of the experiment) and the discussions about the employment status of medical specialists (which, from the point of view from the policy makers in Almere, ended in a defeat by allowing specialist to work as self-employed professionals). The challenge to develop a new system, is accompanied by the necessity to render one's own independence and part of the power each organization has. This process proved to be easier in theory than in reality.

With reference to the instruments implemented and the prevailing conditions, it can be concluded that structural instruments were broadly implemented, although not achieved completely (e.g.: the employment status of all health care professionals), or achieved with serious delay (e.g. the Flevo hospital). A uniform financial framework for all health care services in Almere, in combination with centralized planning authority was not realized. It can be concluded that process instruments were less extensively realized. This applies particularly to the instruments aiming at the cooperation and mutual adjustment of activities between the primary and secondary care disciplines and within the hospital sector. In the following chapters the consequences of these omissions on the realization of the different objectives will be described. 
Chapter 4 described the instruments realized during the implementation process of the Almere Health Care Demonstration Project (AHCDP). By describing these instruments a partial answer was provided to the second research question derived from the conceptual framework to evaluate the demonstration project as a policy programme. In chapter 5 , the second part of the same research question (Q3: "Is there congruence between the intended instruments, expected conditions and intended goals of the Almere Health Care Demonstration Project and the instruments that were used, the actual conditions and the goals realized at the end of the project?"), will be answered, focusing on the conditions experienced.

In chapter 3 three conditions for regarding the evaluation of the results of the experiment Almere were mentioned: (1) the 'tabula rasa' situation in Almere, (2) population growth and distribution in Almere, and (3) the policy context. The same three headings will be used in this chapter, in order to describe the conditions realized. A description of the policy context in which the demonstration project was implemented, will subsequently provide an answer to the second part of the first research question (Q1: "How does the Almere Health Care Demonstration Project fit into the increased tendency to allow more governmental influence in the organization of the Dutch health services in the mid seventies and the subsequent shift in national health policy towards the introduction of market elements in the mid eighties?"). In this respect the focus will be on political and economical developments in general, cost developments in the Dutch health care sector, and Dutch health care policy between 1983 and 1993.

\subsection{The 'tabula rasa' situation}

At the start of the AHCDP there was no real 'tabula rasa' situation. There were approximately 23.000 inhabitants, five health centres and a number of outpatient facilities operating. Nevertheless, many of the health care organizations in Almere could start from a 'clean slate'. Here, the Almere Primary Health Care Foundation (APHCF) provides a good example. After a difficult start (Stuurgroep Project Gezondheidszorg Almere, 1988), the APHCF started to function as a 'new' organization. 
For the Flevo hospital the situation differed. Taking over a new building and accepting a new name masked the fact that this consisted of no more than the transfer of the existing infrastructure and work culture. Problems appearing, such as extensive discussions concerning bed capacity and the employment status of the medical specialists, can be related to these differences in culture and workculture. That the hospital was completed in the final phase of the Almere experiment had caused complications with respect to the coordination of services between the primary health care and hospital sector. As a consequence, there were hardly any relationships between primary care services in Almere and the Burger hospital in Amsterdam before 1991, apart from the services performed in the outpatient clinic in Almere-Stad. Where the Almere population made use of hospital facilities outside Almere (e.g.: in NaardenBussum, Amsterdam, and Lelystad), this happened outside the influence sphere of the demonstration project. Therefore, with respect to the hospital, the condition of a 'tabula rasa' situation was less obvious than anticipated.

\subsection{The Almere population}

The AHCDP assumed that implementing a system of health care services could run parallel with the expected population growth. Diagram 5.1 illustrates that population of Almere increased rapidly between 1983 and 1992, although less rapidly than expected (Stuurgroep Project Gezondheidszorg Almere, 1983).

Diagram 5.1 Population growth in Almere 1976 - 1997, specified for the three residential areas (Source: Municipality of Almere, 1997)

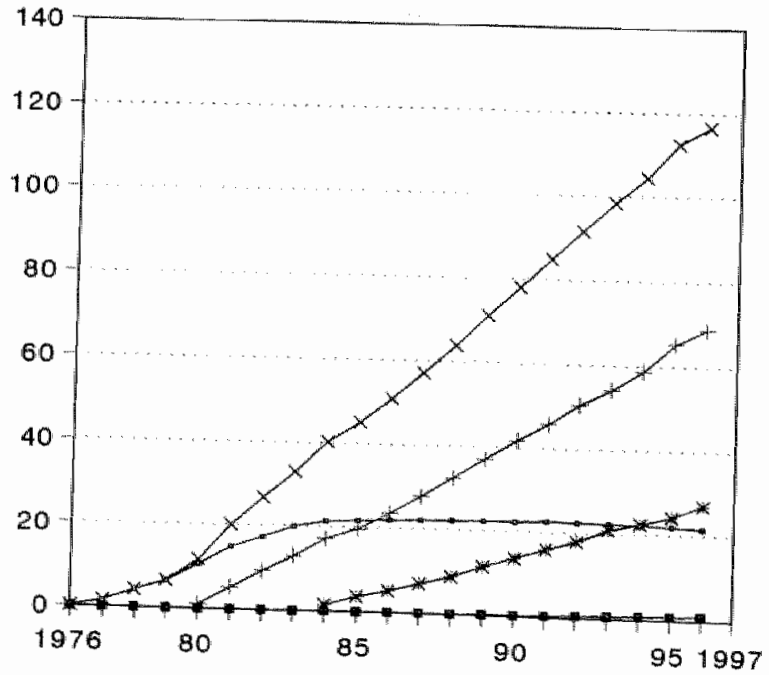

- Almere-Haven

A Almere-Stad

* Almere-Buiten

- overig Almere

* Totaal Almere 
On January 1, 1983, there were 27,483 inhabitants. Ten years later, on January 1,1993 , the number of people living in Almere was more than 93,000 . Therefore, it is obvious that the expected condition - a strong population growth setting specific demands in the building up of health care provisions - actually took place.

The age distribution of the Almere population differed from the situation in the Netherlands in general, as is illustrated in Diagram 5.2. Whilst the age groups from 0 to 10 years and from 25 and 40 years are over-represented, the groups between 15 to 24 and people aged 45 and over are under-represented. As a consequence, additional attention should be paid to services such as pre- and perinatal care, whilst care for the elderly is less important (at least in numbers). Also, morbidity data and data on the use of health services, should therefore be standardized for age and gender differences. Social class differences between Almere and the Netherlands (not shown in Diagram 5.2) were eminent. However, with lower and upper classes in Almere both being under-represented, effects on the use of health care services in general were minimal.

Diagram 5.2 Population structure of Almere and the Netherlands by age and gender on the 1st January 1993, in percentages of the total population of Almere and the Netherlands (Source: Community of Almere, 1993; CBS, 1993)

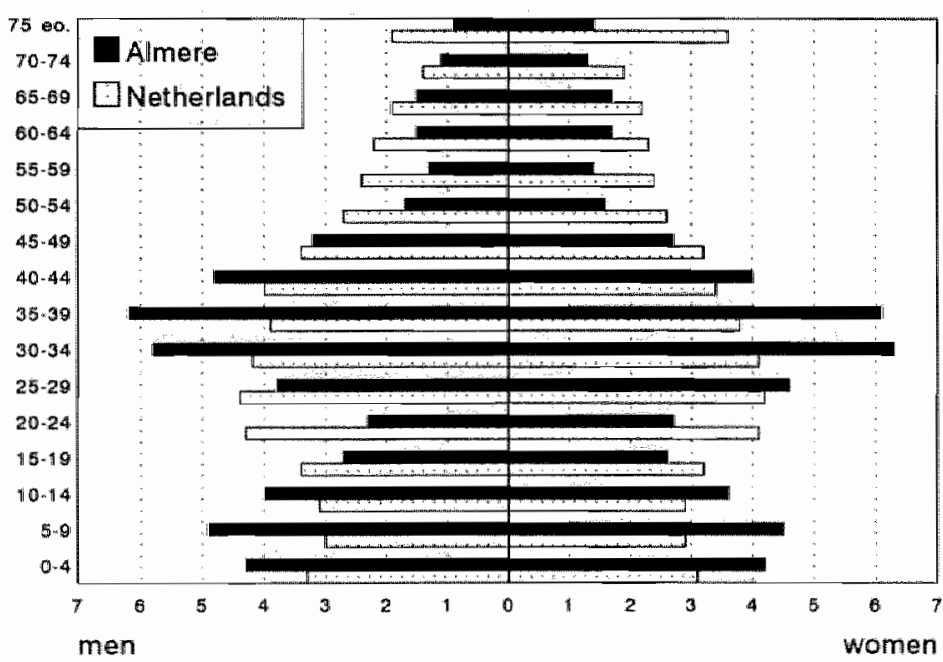

percentages 
Table 5.1 Morbidity data in Almere (standardized for genderlage differences) and the Netherlands, in 1987/1988 (Source: Study 93/2)

\% respondents

Almere

Netherlands

subjective health

$\%$ (very) good

$818^{* *}$

85.4

$\%$ not good, not bad

$14.5^{*}$

12.5

$\%$ (very) bad

$3.6^{\star *}$

2.1

number of acute complaints

$\%$ no complaints

$17.1^{\text {** }}$

27.2

21.8

$\% 1-2$ complaints

$22.9^{*}$

28.0

\% 3-5 complaints

$32.9^{* *}$

25.6

$\% 6$ or more complaints

24.6

number of chronic complaints

$\%$ no complaints

49.2

50.5

$\% 1$ complaint

25.0

26.1

$\% 2$ complaints

13.3

12.9

$\% 3$ or more complaints

$12.5^{*}$

10.5

number of limitations/restrictions

$\%$ no limitations

$\% 1$ limitation

63. 6

18.3

64.1

$\% 2$ limitations

$3.5^{*}$

16.5

$\% 3$ or more limitations

14.7

5.2

1.4 .2

\section{GHQ-score}

$\% 0$ symptom

\% 1-2 symptoms

$50.9^{* * *}$

$26.9^{* * *}$

58.6

$\%$ 3-4 symptoms

$\%$ 5-9 symptoms

$\% 10$ of more symptoms

7.4

20.8

7.4

7.2

7.4

6.9

6.2

psycho-sociall problems

$\%$ no problems

$\%$ 1-2 problems

$40.0^{* *}$

34.9

46.4

\% 3.5 problems

$19.3^{\text {** }}$

32.0

$\% 6$ or more problems

5.7

\section{absenteeism}

$\%$ taking things more quietly

$\%$ absence

16. $1^{*}$

$266^{* * *}$

$\%$ bed rest

* = significant by $p<.05$

** = significant by $\mathrm{p}<.01$ 
The use of health care services is related to differences in morbidity and health behaviour of the population. An assumption was that, given the atypical age distribution of Almere, there should be no differences in morbidity and health behaviour, in comparison with the remainder of the Netherlands. However, as is shown in Table 5.1, this hypothesis has to be rejected. After standardization for age- and gender differences, the population of Almere reported more acute, somatic, psychiatric and psycho-social complaints. Also, perceived health was less often "(very) good" and the percentages of the population who reported that they had to take things more quietly for a while, or had suspended their usual daily activities, was relatively high in Almere. Given that use of health services is mostly determined by illness, or a feeling of not being well, these differences in morbidity (over and above other factors) result in the Almere population's higher medical consumption.

\subsection{The policy context in the years between 1983 and 1993}

Formal legislation and a favourable policy context were important conditions for implementation of the instruments and the subsequent achievement of goals of the AHCDP. In chapter 2 it was already briefly mentioned that, at the start of the AHCDP, existing legislation to facilitate the experiment was missing, both with respect to the structure of health care services as well as the process of implementation of new instruments and the financial structure. Although these legal barriers were party circumvented by the special decree published in November 1988 not all problems, such as the possibility to reach unity of financing and planning authority, could be solved. Therefore, it was extremely difficult to achieve integrated health care policy, with the various disciplines, institutions and echelons no longer being in competition with each other about funding.

Continuity in governmental health care policy was another underlying assumption of the AHCDP. This continuity in health care policy, both at the governmental and the local level, was missing. During the demonstration project, attention shifted from governmental planning towards a more prominent role for market elements. With respect to funding authorities, during the same period attention shifted towards more cost-effectiveness. Both developments are somewhat further explained, by taking into account the international developments in health care policy in the years between 1983 and 1993 .

National and international health care policy in the 1970 s and early 1980 s was dominated by a shift towards an increase in governmental influence. However, at the time the AHCDP started, a (second) shift in Dutch health care policy away from government influence in health care planning and functioning and towards 
government retrenchment and the introduction of market elements and competition was about to take place. And, just as in the early 1970s, at the same time in other countries comparable changes were initiated. Sometimes, like in the former communist countries of Eastern Europe, as a direct consequence of the political revolutions and a subsequent change in ideology towards the health care system following the fall of the Berlin Wall in 1989 (Marree \& Groenewegen, 1997). Sometimes, like in Sweden and other Scandinavian countries, after a change of Government following democratic elections (Diderichsen; 1995; Ham, 1992: Lindgren, 1995; Linnakko \& Bade, 1995; Pekurinen \& Vohlonen, 1991; Saltman, 1992). Also the American efforts to reorganize the existing health care system fit into the large scale introduction of health care reform programmes, although the direction towards more instead of less governmental control differed and the efforts were unsuccessful so far. These developments may have served as examples for local policy-makers in Almere how to proceed in a situation that develops away from the structure that was foreseen and/or partially realized.

\subsubsection{The general policy context; political and economical developments in the $1983-1993$ period}

Privatisation became the official government policy in the Netherlands from 1983 onwards (Janssen and Made, 1990). Based on three arguments, privatisation was seen as the remedy against the in-effectiveness of governmental interference in the public sector, including the health care sector. (1) The economic argument, that private enterprises functioning in a competitive environment produce their services in a more cost/effective way and more tailored to the wishes of the general public. (2) The administrative argument, that privatisation reduces the overload of public administration and improves the administrative efficiently. (3) The political argument, that privatisation reduces government spending. The proposals of the Dekker committee published in 1987, to reorganize the Dutch health care system (Dekker Committee, 1987) fit in these developments.

In the period between 1983 and 1989 government was in the hands of a coalition cabinet consisting of the Christian Democratic Appeal (CDA) and the conservative People's Party for Freedom and Democracy (WVD). In November 1989 a change in cabinet took place. The centre/right coalition was succeeded by a central-left coalition, consisting of the Christian Democratic Appeal and the Dutch Labour party (PvdA), under the same prime minister as in the four preceding years and with a Labour secretary of state for health taking control over the health care department.

Regarding the economic situation in the Netherlands the percentage of unemployed people reached its peak in 1984. In that year $17.3 \%$ of the potential work force in the Netherlands was officially unemployed. Between 1984 and 
1988 , this percentage decreased slowly from 17.3 in 1984 to $13.7 \%$ in 1988 . In 1988 there was a redefinition of the 'unemployed' concept, and as a consequence the percentage of 13.7 changed to $8.7 \%$ of the total amount of all job dependent people (CBS, 1989). Since 1988, the percentage of unemployed people has been fluctuating between $5.9 \%$ (in 1990) and $7.5 \%$ in 1994. In general, economic policy in the Netherlands between the second half of the 1980 s and the first half of the 1990 s can be characterized as a policy in which economic growth is not translated into higher wages but was used to bring back the expenditure level of governmental expenses and to create jobs. The success of this 'Dutch' solution is illustrated by the amount of interest that exists in other countries for what became the Dutch 'Polder Model'.

\subsubsection{Health care policy in the Netherlands between 1983 and 1993}

Also in the health care sector the introduction of market elements became a central topic in the years after 1983. For various reasons (see e.g. Lapre, 1988) instruments based on governmental planning did not bring about the changes that were anticipated in the late 1970 s and first half of the 1980s. As a consequence, a reorientation of health policy from a planning-oriented approach to a market-oriented approach was seen as the most appropriate alternative (Schut et al, 1991). In August 1986 an external advisory body was implemented to develop a blue-print to restructure the Dutch health care system in correspondence with this new ideology. The committee, which was chaired by the former President of Phillips Electronics, Wisse Dekker - and became subsequently known as the Dekker Committee - had six months to formulate its recommendations. In March 1987, the Dekker Committee published its report entitled "Willingness to Change", containing a series of proposals towards a more market-oriented approach and more freedom of operation. Other topics were solidarity and social justice. The 'Dekker proposals' were accepted by the Dutch Ministry of Welfare, Health and Cultural Affairs in 1988 (Ministerie van WVC, 1988) and proved to be the fundament for Dutch health care policy from 1987 onwards.

An important element of the Dekker proposals was the intraduction of a compulsory basic insurance scheme for all citizens in the Netherlands. This basic insurance package would cover approximately $85 \%$ of the services in the field of health and social care, including costs of hospitalisation, the general practitioner, specialist care, homes for the elderly, family care, certain forms of home care etc. This basic insurance package was to be financed mainly by an income-related premium plus a small flat rate (nominal) premium. Insurance for the $15 \%$ of services not included in the basic insurance package was to be paid directly by the insured to the insurer. This flat premium varies between insurers, depending on cost-management abilities and contracts with efficient health care providers. By introducing the possibility of negotiations between health care 
providers and health care insurers about the most beneficial terms of contracts, the Dekker proposals would make it possible to establish limited provider plans comparable to the American Health Maintenance Organizations (HMOs) and Preferred Provider Organizations (PPOs). Consumers are free to buy basic insurance from any insurer with procompetitive rules, such as open enrolment and quality assurance standards (Schut et al, 1991; Lapré, 1988). Two basic elements of the Dekker proposals - a compulsory comprehensive "basic insurance' system for all citizens and regulated competition among health care providers and health insurers, with money following the patients - would improve the efficiency of the prevailing system, while the controlling elements of the 'old' system remained in force.

On March the 7th, 1987, the policy paper 'Change Assured' was published by the Dutch Cabinet presented as a reaction to the 'Dekker Report'. In this White Paper, the ideas of the Dekker Committee were accepted as the basis for future health policy in the Netherlands. According to this White Paper, the insurance systems would be changed from 1988 onwards, as part of a step-by-step strategy towards the abolishment of distinctions between health insurance funds and private insurance companies, and with freedom of choice for all insured. Market elements would include the (1) freedom for insurance companies to contract different health care providers in order to bring about competition between providers, and (2) freedom to establish the level of the nominal premium charged to the insured, which would result into competition between insurance companies. However, at the same time it was established that the health care sector could not function adequately without governmental regulations. Such regulations would still be needed in important areas such as the quality of health care services, the provision of the basic insurance plan and the planning of large-scale intramural provisions such as hospitals and nursing homes. In June 1988, the full parliamentary debate on the Government's future policy document took place and with the acceptance of the plans the implementation process of the Dekker proposals officially started.

After the change of Government in November 1989, the new central-left coalition decided to continue with the health care reform process. However, some elements were revised and more emphasis was put on creating universal social health insurance. In these revised plans, the compulsory basic insurance package increased from about $85 \%$ to about $95 \%$ of the total health care expenditure, and the income related share of health care expenditure increased from $75 \%$ to $85 \%$. Other differences included the possibility to give discounts in case of group insurances and the commitment that basic insurance would be provided by non-profit insurers. Regarding the convergence of public and private insurance schemes, plans were to expand the existing catastrophic illness scheme (Exceptional Medical Expenses Act) by transferring specific items from the public and private schemes to this scheme (Groenewegen, 1994). Finally, 
the original time schedule for the reforms was changed by setting the date for full implementation at the end of 1995 (Schut et al, 1991).

In the period between 1988 and 1997 a series of steps was taken to introduce changes along the lines of the Dekker plan (e.g. the introduction of a mix of income-related and flat premiums, the transfer of drug prescription from the public and private insurance schemes to the catastrophic illness scheme (and back again), abolition of contracting obligations for insurers and more freedom in the insurer-insured relationship). However, large-scale changes with respect to the key elements of the health care reform programme were not carried out. Legislation changed only marginally, while other plans (e.g. the costs of pharmaceuticals) were cancelled after first being implemented. In general, 'health care reforms' did not vanish entirely from the political agenda of the new coalition government that came into power in 1994. This new 'purple' coalition consisted of the labour party (PvdA), the liberal democrats (D66) and the conservatives (VD). Following this change in government, more emphasis was placed on items directly linked to cost-effectiveness instead of changing the entire health care system.

In conclusion one might say that the report of the Dekker Committee set the stage for a series of new views on the structure and functioning of health care services in the Netherlands, characterized by less government interference and the introduction of market elements. However, as in 1974, this new health care reform did not grow far beyond the 'paper tiger' status. Following the results of a report by Parliamentary Committee known as the Willems Subcommittee $(1994)^{1}$ "Van Raak and Mur-Veeman (1996) conclude that as long as goals are general - like reforming the health care system - they are supported by many. Yet, when concrete measures are taken to realize this goal, clashes appear between decision-makers and decision-making parties pursuing competing interests. Since the existing system of decision-making blocked change, steering capacity was minimal and that every effort to steer the process evoked new interdependences and counter-activities that went in different directions, farreaching changes were not accomplished (Raak and Mur-Veeman, 1996, p.49). This explanation is in line with the conclusions from Groenewegen (1994, p. 146) that when the power base of the govern-ment is relatively weak, the amount of actual policy implementation by the government is rather small. Although farreaching changes so far only appeared on paper, the change in ideology that took place between 1983 and 1993 when the AHCDP was implemented, did affect the demonstration project. As a consequence, Almere lost its position as show-case for future changes in the national health care system. For policy

The Willems Subcommittee which was established in 1993 to describe and analyse the decision-making process on reforms of prevailing national structure of health care services on the basis of a "stakeholders analysis". 
makers in Almere financial and political support from central government for the demonstration project started to fade away as the years proceeded. Therefore, the expected condition of 'stability and continuity in health care policy during the years of implementation' was not satisfied.

\subsubsection{Cost developments in the Dutch health care sector between 1983 and 1993}

Between 1983 and 1993, health care expenditure in the Netherlands increased from $8.3 \%$ of the Gross Domestic Product (GDP) in 1983 to $9.0 \%$ in 1993 (OECD, 1996), as is shown in Diagram 5.3. For 1994 and 1995, the percentage decreased slightly to $8.8 \%$ in both years. With this percentage, the Netherlands was still to be found in the top 10 of OECD countries ranked according to the percentage of the GDP spent on health care expenditure.

Diagram 5.3 Trends in the percentage of the Gross Domestic Product used for health care expenditure for the Netherlands and 24 OECD countries, between 1980 and 1994 (Source: OECD, 1996)

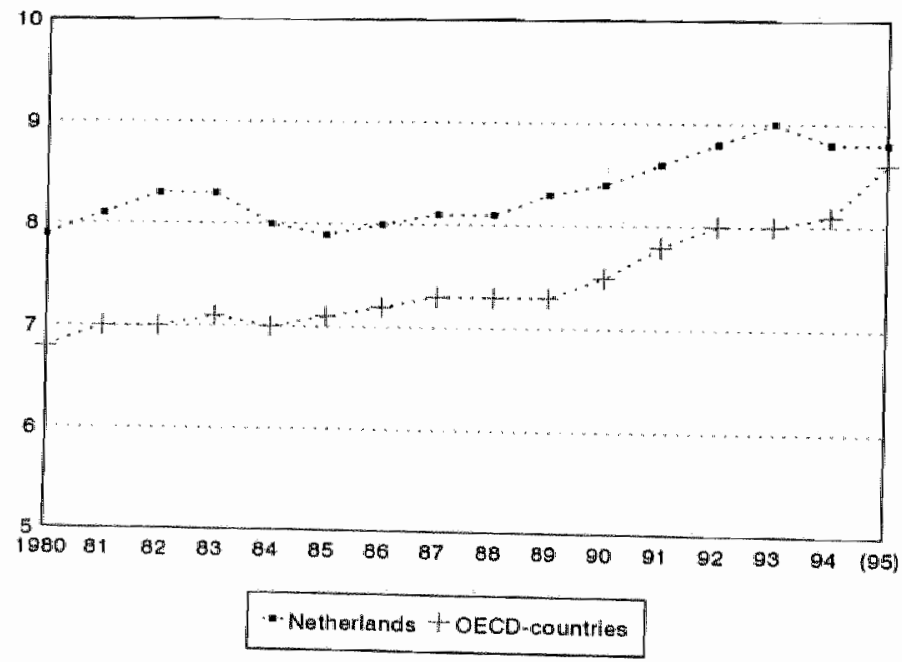

With $14.5 \%$ of the GDP spent on health care in 1995 , the leading position in this top 10 was still firmly in the hands of the United States. Other countries with a relatively high level of their national budget spent on health care were Canada $(9.8 \%)$, Belgium $(9.7 \%)$, France $(9.7 \%)$, Switzerland $(9.6 \%)$ and Germany $(9.5 \%)$. In Diagram 5.3 the OECD average is calculated for the same 21 countries as in the Graph 2.3 presented in chapter 2, section 2.4. Apart from Turkey, Japan and Luxembourg, also the new OECD countries: Czech Republic, Hungary and
Mexico were excluded from this comparison. 
Diagram 5.3 illustrates that during the AHCDP the health care expenditure level in the Netherlands continued to grow and remained above the average OECD level. However, the gap between the Netherlands and the rest of the OECD countries is slowly diminishing.

\subsection{Conclusions with respect to the conditions experienced}

In chapter 3 three conditions were mentioned that require attention in the evaluation of the results of the experiment Almere: (1) the 'tabula rasa' situation in Almere, (2) population growth and the population distribution in Almere, and (3) the policy context in which the demonstration project was implemented. This chapter focused on what happened with respect to these conditions during the implementation of the AHCDP and provided an answer to the part of the research question Q1, that referred to the policy context in which the project was conducted and the shift in national policy towards the introduction of market elements.

First, it was established that the "tabula rasa' situation that was supposed to facilitate the process of implementing a differently organized system of health care services in Almere did not exist in 1983. At the start of the AHCDP several health care organizations were already functioning in Almere, serving a population well over 20,000 inhabitants. With respect to the fast population growth it was noticed that implementing a new organizational structure parallel with a fast growing population took a lot of energy. Building up the organizational structure gained priority above activities directed at the care giving process and to bring about cohesion within and between health care institutions (Stichting EVA, 1996). In addition, the decision to transfer the Burgerziekenhuis to Almere was not the most favourable one and in this respect was less successful than anticipated.

With respect to the population in Almere it was shown that, apart from the atypical age distribution, the morbidity level of the population of Almere was rellatively high. These findings have to be taken into account when interpreting statistics about the use of health care services and the interventions that take place in health care institutions.

Finally, changes in government policy took place which effected the implementation process of the AHCDP. Because the new structure of health care services had to be implemented in an environment, which gradually changed from being focused on governmental planning to a more market oriented approach serious problems were encountered. During the first phase of the implementation process, existing legislation did not permit implementation of the 
anticipated structure of health care services. Sometimes this hurdle was taken successfully (e.g. the realization of the combined old people/nursing home, the acquirement of additional funds to compensate the relative low number of hospital beds, the experimental status of the demonstration project). However, with respect to unity of planning and financing of all health care services in Almere no solution were available.

Having described the level of congruence between the instruments to be implemented and instruments realized (chapter 4) and the congruence between the anticipated and experienced conditions (this chapter 5), the next step will be to look at the achieved goals. The next chapter will therefore deal with one of these the goals: to achieve good quality of care. 
Probably the most important question with respect to the Almere Health Care demonstration Project (AHCDP) is whether or not the goals of the project were actually realized. Or, in terms of research question Q3: Is there congruence between the intended goals of the Almere Health Care Demonstration Project and the goals as they were achieved at the end of the project? Three main goals were derived from the blue-prints for the future structure and functioning of health care services in Almere (Stuurgroep Project Gezondheidszorg Almere, 1983; Stuurgroep Project Gezondheidszorg Almere, 1986). These three goals were: (1) good quality of care, (2) substitution of care, and (3) cost containment. Quality of care was subsequently categorized as (1) quality of the organization and/or organizational structure of health care services, (2) quality of the health care workers, and (3) quality of the care giving process. Following this categorization, an overview was presented of the operational goals and the instruments to achieve these goals. Whether or not these instruments were implemented during the course of the AHCDP was reviewed in Chapter 4.

This chapter reviews whether or not the operational goals, referring to 'quality of care', were actually achieved between 1983 and 1993. A distinction is made between 1) the process of care provision and 2) the Almere population's perceptions of the quality of the care provided. The process part will focus on (1) cooperation between the disciplines and echelons, (2) possible overlap in and continuity between in the care giving process, and (3) the amount of success in bringing about professional agreements and guidelines. Regarding the care giving process itself, the focus will be on patients' evaluations. Here, the quality of the process affords a particularly good yardstick for determining the quality of institutions (Nationale Raad voor de Volksgezondheid, 1990). 'Structure', 'process' and 'outcome' form the three traditional aspects from which quality criteria are generally derived (Donabedian, 1980; Loeffler, 1992).

\subsection{Structure of the care provision}

The focus in this section, describing the structure of care provision in Almere, is on the numbers of care providers, staff turnover, qualifications and medical training and continuing medical education, staff perceptions of their tasks, and the equipment of the facilities. Each section starts with an hypothesis concerning the operational goal to be achieved as part of the AHCDP. 


\subsubsection{The Numbers of Care Providers in Almere}

In Almere, in comparison with the Netherlands as a whole, there is a relatively high number of providers of primary care. This number conforms better than elsewhere with guidelines formulated in the Mernorandum on Primary Care. (Hypothesis H6.1)

The answer on hypothesis H6.1 will be answered on yearly reports of the APHF published in 1993/1994. These data will be compared with national data on the availability of health care services and professionals.

A relatively high number of care providers as compared to the population size means that more attention can be paid to the quality of the care process. An operational goal of the AHDCP was to have the numbers of care providers in line with the prognoses for the capacity of primary care services published in 1983 (Ministerie van Welzijn, Volksgezondheid en Cultuur, 1983a; Ministerie van Welzijn, Volksgezondheid en Cultuur, 1983b). During the implementation process of the demonstration project these target numbers were adjusted to the latest figures, to meet developments in society to increase the number of general practitioners per 10,000 inhabitants. Table 6.1 presents the target numbers, or the number of health care workers the AHCDP aimed for, and the actual situation in Almere around the end of the project on 1-1-1993". In this table care providers are given in full time equivalents (FTEs).

With respect to the practice size of GPs in the Netherlands, the density (the average number of patients per independently established care provider) was 2295 on 1-1-1993 (Hingstman \& Pool, 1993). Almere fell well below this average. Regarding midwifery, the number of independently established midwives on 1-11992 was 832 . For a population of 15 million, that is one midwife per 18,000 inhabitants. For the physiotherapists the density was about 1750 on 1-1-1991 (Pool \& Hingstman, 1993). As can be seen in Table 6.1, densities in Almere were lower for all professional groups mentioned.

Efforts to increase the proportion of female general practitioners, in respect of the supposed wishes of a part of the population, were successful (Brink-Muinen et al, 1993). About $30 \%$ of the general practitioners in Almere were women, in comparison with $13 \%$ for the Netherlands in general (Hingstman \& Pool, 1992).

\footnotetext{
The Almere Health Care Demonstration Project officially came to an end on 3 November 1992. At this date the special decree for Almere, which was accepted by the Dutch parliament four years earlier, expired and was not prolonged for an additional period of 4 years. The date of 1-1-1993 is chosen because this is close to this official expiring date.
} 
Table 6.1 Capacity of disciplines in primary health care; prognoses of terms of reference and realized capacity in Almere on 1-1-1993

$\begin{array}{rr}\text { Number of inhabitants } & \text { Target } \\ \text { per discipline } & \text { numbers } \\ \text { Almere } 1-1-1993 & \end{array}$

\begin{tabular}{lrr} 
general practitioner** & 1,815 & $2,200-2,400$ \\
dentist & 3,500 & 3,000 \\
midwives & 7,500 & 20,000 \\
maternity nurse & 1,800 & 2,000 \\
district nurse & - & 2,500 \\
dietician & unknown & 50,000 \\
physical therapist**** & 1,900 & 2,400 \\
pharmacist & 7,400 & 10,000 \\
social worker*****⿲二丨匕 & 5,250 & 8,000 \\
\hline
\end{tabular}

* In the year 1983 the norm of $(2,600-17,5 \%) 2,150$ patients was used for general practitioners in health centres.

* Separate information on the discipline of district nurses, are not available. In Almere the distinction is made between home care $(13,55$ fte), home nursing $(49,92$ fte $)$ and home help $(86,24$ fte) at a population of 91,700 on 1 January 1993.

*** The norms for physical therapy is 1 on 3,000 inhabitants.

***** For social workers no target figures were given; the objective was to maintain the situation on 31 December 1982 being $1: 8,000$.

In summary, the operational goal of arriving at a density of primary care disciplines equal to or below the target figures as they were formulated in 1983 at the start of the Almere Health Care Demonstration Project was realized. The hypothesis cannot be rejected.

\subsubsection{Characteristics of the care providers}

In Almere, in comparison with the Netherlands as a whole, health care providers are better trained and received more continuing (medical) education. (Hypothesis H6.2)

Hypothesis $\mathrm{H} 6.2$ will be answered on the basis of the results from the study 'Morbidity and Interventions in General Practice in Almere' conducted in $1987 / 1988$ (Study 93-4), with data from the survey among GPs in Almere being compared with corresponding data for the $161 \mathrm{GPs}$ in the national sample (Foets et al ${ }_{1}$ 1991; Foets et al, 1993). Additional data are coming from Study 89-1 (see Table 3.4), the study on the functioning of child health clinics in Almere (BrinkMuinen and Sixma, 1990) 
Provided there is no shortage on the labour market with respect to the amount of qualified personnel, the employee status enables an employer to select according to education and specific characteristics. Further, certain groups of potential employees may prefer to work as salaried professionals because of job-security or to avoid bureaucracy associated with being an independent entrepreneur. Whether or not health care providers in Almere differ from their colleagues in the rest of the country regarding their background and practice experience, can be found out for district nurses and general practitioners.

A study in which child health clinics in Almere were compared with similar clinics in the rest of the Netherlands revealed, that the training undergone by district nurses in Almere differed very littie from those working in the Netherlands in general (Thomassen et al, 1989). This also holds for the continuing educational programmes and on-the-job training. For the general practitioners working in these clinics, differences between Almere and the Netherlands were eminent. In the Netherlands a majority of GPs report only having followed their normal professionall training, sometimes with a child health clinic application course. In Almere, the majority of GPs (over $70 \%$ ) report having followed a child health clinic application course in addition to their general practitioner's training. Also the number of GPs, who reported having followed a specific continuing education course fitted to the child health clinics, was significantly higher in Almere than in the remainder of the Netherlands.

The same study of the function of the child health clinics in Almere revealed that, compared to the Netherlands, there was more agreement among general practitioners about the way in which the child health clinics should operate. This should result in a more easily identifiable service. For district nurses the findings are less unidimensional. Some elements in the task profile showed more agreement among the nurses in Almere, whereas for other elements the situation was reverse.

More general characteristics of Almere general practitioners can be derived from the study 'Diseases and interventions in general practice in Almere' (Sixma et al, 1991). Apart from questions about general practitioners' initial training and continuing medical education, information about a number of their sociodemographic characteristics was also gathered. General practitioners in Almere have relatively few years of practice experience, and graduated relatively often from the Catholic University of Nijmegen "the Free University of Amsterdam or the University of Amsterdam, as is shown in Table 6.2. However, they do not spend any more time reading professional literature or following continuing medical education. 
Table 6.2 Quality of general practitioners in Almere and the Netherlands; continuing medical education and university of graduation. (Source: Study 93-4)

$\begin{array}{lc}\text { Almere }(\mathrm{N}=28) & \text { Netherlands }(\mathrm{N}=161) \\ \text { mean std.dev } & \text { mean std.dev }\end{array}$

\section{Continuing medical education and practice experience}

- number of years practice experience

- hours per week reading professional literature

- hours per year medical education

$\begin{array}{rrrr}3.4 & 2.1 & 2.6 & 1.4 \\ 52.3 & 19.0 & 56.3 & 47.1\end{array}$

\section{University of graduation}

- Groningen

$\begin{array}{rr}- & 24.7 \% \\ 6.9 \% & 14.8 \% \\ 31.0 \% & 20.4 \% \\ 6.9 \% & 5.6 \% \\ 20.7 \% & 12.3 \% \\ 24.1 \% & 5.6 \% \\ - & 1.9 \% \\ 3.4 \% & 12.1 \% \\ 6.9 \% & 3.3 \%\end{array}$

In summary, it is not possible to establish whether care providers in Almere have had a distinctly better suited medical training or can draw on more experience on the basis of the relatively few research results available. An exception is the general practitioners' child health clinic function. Our hypothesis $\mathrm{H} 6.2$ cannot be confirmed.

\subsubsection{Attitudes of the care providers}

In Almere, in comparison with the Netherlands as a whole, the care providers have better and more suitable attitudes for the achievement of the goals formulated in the project plan Health Care in Almere (Hypothesis H5.3)

Like in the previous sub-section, hypothesis $\mathrm{H} 6.3$ will be answered on the basis of the results from the study 'Morbidity and Interventions in General Practice in Almere' conducted in 1987/1988 (Study 93-4), with data from the survey among GPs in Almere being compared with corresponding data for the 161 GPs in the national sample (Foets et al, 1992).

Salaried service provides employers not only with the opportunity to select staff members according to the preferred education and background characteristics, 
but also according to their attitudes. That is especially important for health care professionals such as general practitioners, who perform a key function in the achievement of the goals related to substitution of care, costs containment and quality of care. In other words, the AHCDP will be facilitated by general practitioners, and other health care providers, who perceive their tasks in accordance with the assumptions underlying the experiment. Table 6.3 illustrates that the opportunity to employ physicians with opinions differ from those of general practitioners elsewhere in the Netherlands has not been maximized. Differences between GPs in Almere and in the rest of the country are small.

Table 6.3 Quality of general practitioners in Almere and the Netherlands; attitudes towards the profession. (Source: Study 93-4)

\begin{tabular}{|c|c|c|c|c|}
\hline & \multicolumn{2}{|c|}{ Almere $(N=28)$} & \multicolumn{2}{|c|}{ Netherllands (161) } \\
\hline & mean & st.dev. & mean & st.dev \\
\hline \multicolumn{5}{|l|}{ Attitudes, in general } \\
\hline work style directed at reduction of uncertainty & $3.64^{*}$ & 0.48 & 2.97 & 0.78 \\
\hline inclination to take risks & $3.37^{\star}$ & 0.47 & 3.02 & 0.74 \\
\hline seeing diagnostics as task of general practitioner & $2.69^{*}$ & 0.45 & 2.92 & 0.47 \\
\hline seeing treatment as task of general practitioner & 2.07 & 0.27 & 2.04 & 0.31 \\
\hline broad task profile concerning somatization & 4.03 & 0.30 & 3.93 & 0.46 \\
\hline $\begin{array}{l}\text { feelings of competence somatic complaints } \\
\text { broad task profiles concerning }\end{array}$ & 3.49 & 0.44 & 3.51 & 0.67 \\
\hline psycho-social complaints & 3.13 & 0.44 & 3.32 & 0.49 \\
\hline feelings of competence psycho-social complaints & 3.14 & 0.45 & 3.20 & 0.50 \\
\hline broad task profiles, in general & 3.23 & 0.46 & 3.38 & 0.66 \\
\hline broad performance profile, in general & 3.05 & 0.47 & 3.15 & 0.52 \\
\hline democratic attitude towards patient & 3.28 & 0.33 & 3.30 & 0.56 \\
\hline 'locus of contral' & 3.04 & 0.22 & 3.12 & 0.38 \\
\hline \multicolumn{5}{|l|}{ Attitudes, specific } \\
\hline role psycho-social factors in complaints & 3.04 & 0.44 & 2.92 & 0.57 \\
\hline inclination to prescription & 2.30 & 0.38 & 2.60 & 0.51 \\
\hline
\end{tabular}

* = significant difference $(p<.05)$ campared to the Netherlands

There are some significant differences that refer to the work style of the Almere general practitioners. Compared to the national sample of 161 Dutch GPs, the working style of the general practitioner in Almere was somewhat more directed to the reduction of uncertainty. The Almere general practitioner seemed to be more inclined to consult with a colleague general practitioner in problem cases. However, at the same time Almere's GPs were somewhat more inclined to take risks when it comes to the actual (non)treatment of patients, which is in contrast to his/her risk taking behaviour. Compared to the average Dutch GP, GPs in Almere are somewhat less inclined to consider every complaint as the start of 
a serious episode of illness. When in doubt the Almere general practitioner referred patients less often and works under the assumption that many complaints are self limiting. A defensive attitude towards the prescription of medicines, which would have been in line with the goals of the demonstration project, is not apparent in the data presented in Table 6.3. With respect to other key elements of the Almere policy (broadness of task profile, feelings of competence, task performances, relationship between primary and secondary care, and the influence assigned to patients) no significant differences were found between Almere and the remainder of the Netherlands. As a group , GPs in Almere were more homogeneous in their opinions of their tasks and their attitudes than are general practitioners in the rest of the country.

In general, the hypothesis that attitudes of care providers in Almere, in particular those of the general practitioners, differ from those in the rest of the Netherlands, and that their attitudes are more in line with the assumptions underlying the AHCDP, must be rejected.

\subsubsection{The equipment of the facilities}

In Almere, in comparison with the Netherlands as a whole, the facilities for health care provision are better equipped (Hypothesis H6.4)

The answer on hypothesis $\mathrm{H6.4}$ will be based on data from the "Morbidity and Interventions in General Practice in Almere" study, conducted in 1987/1988 (Study 93-4). Data for GPs in Almere are compared with corresponding data for the $161 \mathrm{GPs}$ in the national sample (Foets et al, 1992).

Better equipment of the multidisciplinary health centres allows for more treatments in primary care and treatment close to a patient's home. With respect to the equipment of the health care centres in Almere a comparison can be made between the instruments used by general practitioners in Almere and those in the rest of the Netherlands. Information refers to the availability of 14 instruments. As is shown in Table 6.4 general practices in Almere were somewhat better equipped than the average practice in the Netherlands. Regarding the availability of audio meters, ECG equipment, hygracators and bulletdrawers general practices in Almere show significantly higher percentages than the average general practice in the Netherlands. For Eyeball meters and tonometers scores in Almere are significantly lower than in the Netherlands. For the other eight instruments differences between Almere and the Netherlands were non significant. 
Table 6.4 Instruments avallable in general practice in Almere and the rest of the Netherlands (Source: Study 93-4)

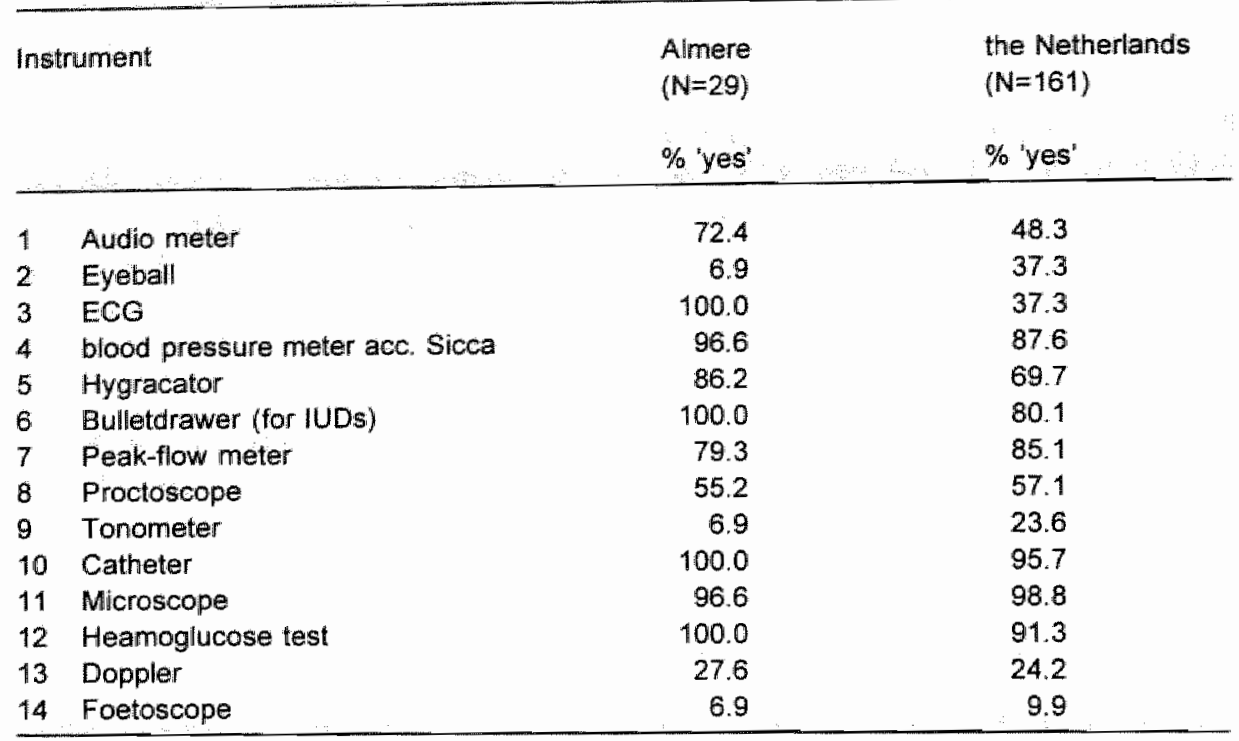

On the basis of the scarce information available, our hypothesis, stated at the beginning of this sub-section, is confirmed.

\subsection{The process of health care provision}

Regarding the quality of the health care process this section will describe differences between Almere and the remainder of the Netherlands focusing on information and counselling (subsection 6.2.1), care-coordination within and between echelons (subsection 6.2.2), interventions and professional guidelines (sub-section 6.2.3), and continuity of care (sub-section 6.2.4).

\subsubsection{Information and counselling}

In Almere, in comparison with the Netherlands, patients and clients receive much information and recommendations (Hypothesis H6.5)

The study 'Interventions in General Practice in Almere' conducted in 1987/1988 (Study 93-1), with contact registration data over a three-month period for 19 GPs in Almere were compared with corresponding data for the 102 practices in the national sample (Van der Velden et al, 1992), provides a partial answer on hypothesis H6.5. Additional data were derived from the community nursing study conducted in 1989 (Study 90-2). 
The fact, that attitudes of general practitioners and other health care professionals in Almere did not differ from colleagues in the remainder of the Netherlands; does not necessarily mean that there are no differences in the provision of care. Data on the amount of information given and counselling activities are available for district nurses and general practitioners.

Table 6.5 Number of therapeutic procedures per 1.000 patients and per 1.000 contacts at general practices in Almere (age/sex standardized) and the Netherlands. (Source: Study 93-1)

\begin{tabular}{|c|c|c|c|c|}
\hline & $\begin{array}{r}\text { Almere, st } \\
\text { per } 1.000 \\
\text { patients }\end{array}$ & $\begin{array}{l}\text { ardized } \\
\text { per } 1.000 \\
\text { contacts }\end{array}$ & $\begin{array}{l}\text { Netherlands } \\
\text { per } 1.000 \\
\text { patients }\end{array}$ & $\begin{array}{l}\text { per } 1.000 \\
\text { contacts }\end{array}$ \\
\hline treatment, total & 924.4 & 723.1 & 692.1 & 591.5 \\
\hline counselling & 372.7 & 291.5 & 287.9 & 246.1 \\
\hline information + recommendations & 619.2 & 484.3 & 450.7 & 385.2 \\
\hline watchful waiting & 51.4 & 40.3 & 51.9 & 44.3 \\
\hline life style advices & 44.2 & 34.6 & 32.8 & 28.0 \\
\hline medication without prescription & 46.9 & 36.7 & 25.9 & 21.3 \\
\hline change in medication & 22.2 & 17.4 & 20.4 & 17.4 \\
\hline
\end{tabular}

Table 6.4 indicates that in general more information and advice is given to patients in general practice in Almere than in the average practice in the Netherlands. However, figures presented in Table 6.5 must be treated with caution, since what one doctor may consider to be 'a serious conversation' or "giving information" might be interpreted differently by another doctor. Consultation length in Almere was somewhat longer, whereas the number of complaints per consultation in Almere and the Netherlands was the same. In Almere more contacts were initiated by patients.

Looking at community nursing, it was shown that district nurses in Almere gave more courses for parents and parents-to-be than nurses in the remainder of the Netherlands (Brink-Muinen and Sixma, 1990).

In summary, the hypothesis about information and counselling in Almere is confirmed by the available data.

\subsubsection{Coordination of work within and between the echelons}

In Almere, in comparison with the Netherlands as a whole, the activities of the various disciplines are better coordinated with each other and there is more structured and ad hoc consultation within and between the various disciplines. (Hypothesis H6.6) 
Hypothesis $H 6.6$ will be answered on the basis of the results from the study 'Morbidity and Interventions in General Practice in Almere' conducted in $1987 / 1988$ (Study 93-4) and the study 'Interventions in General Practice in Almere $1987 / 1988$ (Study 93-1). Based on the study $93-4$ data from a survey among 30 GPs in Almere can be compared with corresponding data for the 161 GPs in the national sample (Foets et al, 1992). In the second study contact registration data over a three month period for 19 GPs in Almere were compared with similar data from a national sample of $161 \mathrm{GPs}$.

With respect to the task profile of general practitioners and district nurses concerning child health clinics, activities of both professional groups were categorized into 17 activities. In Almere agreement between representatives of both disciplines is significantly greater for seven of these tasks than the remainder of the Netherlands. For eight activities differences were not significant, and for two aspects agreement in the Netherlands was more than in Almere. Furthermore, general agreement within both professional groups concerning the role of the child health clinics is greater in Almere than elsewhere in the country. Differences between Almere and the rest of the Netheriands regarding mutual coordination of the existing task distribution and the desired task distribution in a child health clinic are not significant.

Another possibility is to look at regular and informal consultation sessions within echelons and between echelons. Here, consultation can be conceived as a necessary condition for the coordination of tasks and interventions. In the study of morbidity and interventions in general practice in Almere (Sixma et al, 1992) general practitioners in Almere as well as the rest of the country were asked to indicate with which institutions they had regular and/or informal consultation and the amount of time spent on these consultations.

Table 6.6 Consultation in number of hours a week between health care disciplines in Almere and the Netherlands in which general practitioners participate. (Source: Study 93-4)

\begin{tabular}{lcc}
\hline regular consultation primary care & $\begin{array}{c}\text { Allmere } \\
(\mathrm{N}=29)\end{array}$ & $\begin{array}{r}\text { Netherlands } \\
(\mathrm{N}=161)\end{array}$ \\
informal consultation primary care & $2.5^{*}$ & 1.3 \\
regular consultation secondary care & 0.8 & 0.4 \\
informal consultation secondary care & 0.2 & 0.2 \\
regular consultation mental health care & 0.0 & $0.1^{*}$ \\
informal consultation mental heaith care & 0.1 & 0.1 \\
total consultation time & 0.1 & 0.1
\end{tabular}

* significant difference $(p<05)$ between Almere and the Netherlands 
Table 6.6, illustrates that, in total, the number of hours spent on consultation was significantly higher in Almere that in the remainder of the Netherlands. Regarding the time spent on consultations with medical specialists (institutionalized and ad hoc consultations), the situation refers to the years before the opening of the Flevo hospital. Following the opening of the Flevo ziekenhuis hospital in 1991 the figure may have risen, as a result of the monthly meetings and the case discussions. However, no data were available to test this hypothesis.

The results in Table 6.6 are supported by the results of the study in which general practitioners indicated for a large number of patient contacts whether following that contact there was any consultation with anyone other than the patient. In Almere, consultation between GPs took place for 24 of 1000 patient contacts, whereas in the Netherlands such consultations refer to 15 per 1000 contacts $(p<0.05)$.

In general, hypothesis $\mathrm{H} 6.6$ is supported by the research findings. However, there are indications (see chapter 9) that the differences between Almere and the Netherlands are not exclusive to Almere but are probably valid for all general practitioners working in health centres.

\subsubsection{Professional guidelines}

In Almere, in comparison with the Netherlands as a whole, the care provided by general practitioners is more in line with the guidelines published by the Netherlands General Practitioners Society (NHG) guidelines. (Hypothesis H6.7)

Hypothesis $\mathrm{H} 6.7$ will be answered on the basis of the results from the study 'Interventions in General Practice in Almere' conducted in 1987/1988 (Study 931, see Table 3.4). In this study contact registration data over a three-month period for $19 \mathrm{GPs}$ in Almere are compared with corresponding data for the 102 practices in the national sample (Van der Velden et al, 1992).

From a professional point of view, it is important that interventions are carried out in accordance with professional guidelines. Examples of such guidelines are the standards of the Netherlands Society of General Practitioners (NHG), to promote autonomous expertise and further professionalization. NHG guidelines are based on literature surveys and consensus discussions within the profession and provide a yardstick for the prevalent 'state-of-the-art- situation. However, they do not provide absolute rules how to practise. The first NHG guidelines were published in 1989, one year after the study on interventions in general practice in Almere was conducted. Between 1989 and 1997, approximately 70 NHG guidelines were published at a frequency of 6 to 10 per year. Interventions referring to eight of these guidelines are presented in table 6.7. 
Table 6.7 Interventions of general practitioners in Almere and the Netherlands according to eight NHG guidelines. (Source: Study 93-1)

\begin{tabular}{|c|c|c|c|c|}
\hline & $\begin{array}{l}\text { Almere } \\
\% \text { "Correct" }\end{array}$ & $\mathbb{N}$ & \multicolumn{2}{|c|}{$\begin{array}{l}\text { Netherlands } \\
\% \text { "Correct" N }\end{array}$} \\
\hline \multicolumn{5}{|l|}{ Acne Vulgaris: } \\
\hline No dietary advice & 99.5 & 207 & 99.5 & 1927 \\
\hline Term ( 3 mth.) prescription local antibiotics & $0.0^{*}$ & 2 & 71.2 & 66 \\
\hline Prescription obsolete preparations & 88.5 & 192 & 86.6 & 1727 \\
\hline Prescription tetracyclines & 100.0 & 16 & 93.2 & 338 \\
\hline Follow-up appointments & $3.5^{* *}$ & 202 & 9.0 & 1746 \\
\hline No referrals & 97.6 & 207 & 96.2 & 1927 \\
\hline \multicolumn{5}{|l|}{ Diabetes Mellitus Type II } \\
\hline Diagnosis with reference & & & & \\
\hline to blood glucose value & 64.3 & 14 & 42.6 & 94 \\
\hline \multicolumn{5}{|l|}{2 Diagnosis not with reference } \\
\hline to urine glucose value & $83.3^{*}$ & 336 & 78.8 & 4558 \\
\hline Prescription tolbutamide & 21.4 & 14 & 6.4 & 94 \\
\hline \multicolumn{5}{|l|}{ Migraine } \\
\hline Prescription paracetamol, NSAID & 37.9 & 29 & 52.5 & 284 \\
\hline Prescription of ergotamine (tel. consultation) & $43.3^{\text {*** }}$ & 30 & 90.3 & 383 \\
\hline \multicolumn{5}{|l|}{ Acute sore throat } \\
\hline No check of appointments & 96.0 & 100 & 91.6 & 1324 \\
\hline \multicolumn{5}{|l|}{2 Prescription feneticiline/ } \\
\hline fenoxymathy/penicillime & 63.6 & 184 & 89.9 & 2058 \\
\hline \multicolumn{5}{|l|}{ Ankle distortion } \\
\hline$X$-ray in case of fracture & 88.6 & 184 & 89.8 & 2058 \\
\hline No referrals & 97.3 & 1184 & 95.8 & 2044 \\
\hline \multicolumn{5}{|l|}{ Otitis media acuta } \\
\hline Child ( $<6 \mathrm{mth}$ ) ) referral or antibiotics & 0.0 & 4 & 34.6 & 26 \\
\hline Child $(>6$ mth $)$ no antibiotics & $91.5^{* *}$ & 402 & 75.8 & 2135 \\
\hline Prescription amoxocilline & $94.4^{*}$ & 36 & 78.8 & 245 \\
\hline No prescription of lidocaine & $68.4^{* * *}$ & 626 & 82.6 & 3525 \\
\hline \multicolumn{5}{|l|}{ Infection of urinary system } \\
\hline Examination with nitrite-strips & $54.7^{* *}$ & 289 & 32.9 & 3268 \\
\hline Right medication & 77.2 & 92 & 76.4 & 1904 \\
\hline Duration of cure & $42.5^{* *}$ & 40 & 10.8 & 1487 \\
\hline Check appointment & $38.3^{* *}$ & 115 & 26.1 & 2299 \\
\hline No reterral & 97.4 & 386 & 96.3 & 4487 \\
\hline \multicolumn{5}{|l|}{$\begin{array}{l}\text { COPD } \\
1 \text { Prescriotion salbutamol }\end{array}$} \\
\hline Prescription salbutamol & $75.1^{*}$ & 342 & 69.3 & 2916 \\
\hline Prescription corticasteroids & 61.5 & 74 & 56.1 & 1779 \\
\hline Vaccination against influenza & $14.5^{*}$ & 345 & 19.8 & 2157 \\
\hline Peak-flow measuring & 1.1 & 545 & 1.6 & 6750 \\
\hline Measurement of prescription & 36.2 & 47 & 34.6 & 714 \\
\hline Treatment asthma attack with antibiotics & 66.2 & 426 & 62.6 & 5425 \\
\hline Treatment asthma attack with predniso(10) in & $3.8^{* * *}$ & 426 & 8.7 & 5425 \\
\hline
\end{tabular}

$*=p<0.5 \quad * *=p<0.1$ 
Information about interventions by general practitioners in Almere and the Netherlands, covered by some of the later published NHG guidelines, was gathered in 1987/1988. If concerns the period prior to the publication of the first guidelines ${ }_{n}$ and can therefore be used to 'measure' quality of care prior to the implementation of the NHG guidelines. However, there are no objections to use the GPs performances on the NHG guidelines in a more relative way, by comparing the situation in Almere with the rest of the Netherlands.

For eight NHG guidelines scores ${ }^{2}$ were calculated to indicate the extent to which each general practitioner's treatment conforms in a number of precisely described indications with the relevant standard. The results of this exercise are given in Table 6.7. In this table, the ' $N$ ' indicates the number of times the particular situation arises. It can indicate the number of patients, or the number of contacts, or the number of episodes of contacts.

The Almere general practitioners treated patients more in accordance with the (later published) guidelines in three out of eight NHG-standards: 'diabetes', 'acute otitis media' and 'urinary tract infections'. For these standards the diagnostic activities, prescriptions and follow-up appointments by the Almere general practitioners were more in line with the (later published) NHG guidelines, than activities and interventions by GPs in the remainder of the Netherlands. Compared to GPs in the remainder of the Netherlands, general practitioners in Almere performed 'less well' on the guidelines about 'acne vulgaris', 'migraine' and 'acute sore throat'. In the treatment of acne patients, less frequently followup appointments were made. When migraine patients are treated, ergotamine is more often prescribed by telephone. Regarding acute sore throat patients, general practitioners in Almere, less often followed the NHG guideline about medication. For the COPD standard the picture is uneven. For some aspects, such as the prescription of salbutamol, interventions of the Almere general practitioners were more in line with the guidelines, whereas for other aspects (e.g. vaccination against influenza, the treatment of an asthma attack with prednisone or prednisolon) the opposite was found.

In summary, hypothesis $H 6.7$ regarding quality of care from the perspective of general practitioners is confirmed for three NHG guidelines and rejected for four NHG guidelines. In general ${ }_{\text {, }}$ our hypothesis is rejected.

2 De eight NHG-guidellines, were selected on the basis of three criteria: (1) the date of publication, which had to be relatively close to the period in which the National Study data were gathered, (2) the possibility to 'translate' the guidelines into variables which were part of the study concerning interventions in general practice in Almere, and (3) a relatively high incidence and prevalence of the morbidily category the guidelines were referring to. 


\subsubsection{Continuity of care}

In Almere, in comparison with the Netherlands as a whole, the inhabitants are less likely to encounter different health care providers. (Hypothesis H6.8)

Hypothesis $\mathrm{H} 6.8$ will be answered on the basis of the study on baby- and infant care in Almere (Study 89-1), yearly reports of the APHCF, in combination with national data on the number of GPs established in the Netherlands, and results from the study 'Morbidity and Interventions in General Practice in Almere' conducted in 1987/1988 (Study 93-4).

One of the possible indicators for continuity of care is the extent to which people meet different health care providers. With respect to the child health clinics it was established that in Almere, when children moved on from one phase in the clinic to the next phase, most of the time the care provider remained the same. Here, continuity of care was better in Almere than in the rest of the Netherlands.

A more general picture can be derived from the relationship between the number of care providers per discipline and the staff-turnover. In this respect, data for general practitioners in Almere were compared with similar data for the Netherlands as a whole, based on the NIVEL (Netherlands Institute for Primary Care Research) registration system for primary care provisions. Data regarding the year of entry/departure and changes in practice location were compared with the data of health centres in the rest of the Netherlands and with GPs practising in other settings. These data are shown in Table 6.8.

The picture of Almere as a New Town is clear in the numbers of general practitioners entering each year. In 1983 fifteen general practitioners were practising in Almere. On 1 January 1993 the number of GPs had increased to 61. The national growth percentages for general practitioners in health centres outside Almere $(+51 \%)$ and for doctors in other sorts of general practices $(+15 \%)$ fell far behind. The average rate of departure for the period 1983 to 1993 was almost $6 \%$ in Almere. Comparative figures for general practitioners working in health centres outside Almere and GPs practising in other settings - singlehanded, partnership or group practices - were $4.3 \%$ and $3.1 \%$.

For $94 \%$ of the doctors practising single-handed, in partnership or in group practices 'departure' usually means 'retirement from general practice'. The remaining $6 \%$ moved to health centres. From the GPs that leave health centres approximately $62 \%$ does so because retirement. From the 20 general practitioners in Almere, who gave up practising between 1983 and 1993, 10 dropped out to start another job or study and 10 others moved to a practice location elsewhere in the Netherlands. 
Table 6.8 In- and outflow of General Practitioners in Almere and the rest of the Netherlands between 1983 and 1993 , in absolute numbers: (Sources: NIVEL-registration system on primary health care professionals, 1983 - 1993; yearly reports APHCF, 1983 - 1993.)

\begin{tabular}{|c|c|c|c|}
\hline & $\begin{array}{r}\text { Almere } \\
\text { health centre }\end{array}$ & $\begin{array}{l}\text { health centre } \\
\text { other places }\end{array}$ & $\begin{array}{l}\text { other } \\
\text { GPS }\end{array}$ \\
\hline \multicolumn{4}{|l|}{$1983-1984$} \\
\hline present & 15 & 339 & 5244 \\
\hline entry & 4 & 54 & 295 \\
\hline departure & - & 16 & 189 \\
\hline transfer & 4 & 4 & 27 \\
\hline \multicolumn{4}{|l|}{$1984-1985$} \\
\hline entry & 4 & 39 & 301 \\
\hline departure & - & 12 & 6 \\
\hline transfer & - & 6 & 41 \\
\hline \multicolumn{4}{|l|}{$1985-1986$} \\
\hline entry & 3 & 36 & 433 \\
\hline departure & 2 & 17 & 183 \\
\hline transfer & 2 & 4 & 40 \\
\hline \multicolumn{4}{|l|}{$1986-1987$} \\
\hline entry & 5 & 26 & 152 \\
\hline departure & - & 21 & 121 \\
\hline transfer & - & 7 & 32 \\
\hline \multicolumn{4}{|l|}{$1987-1988$} \\
\hline entry & 6 & 31 & 198 \\
\hline departure & 3 & 20 & 144 \\
\hline transfer & - & 5 & 42 \\
\hline \multicolumn{4}{|l|}{$1988-1989$} \\
\hline entry & 8 & 29 & 194 \\
\hline departure & - & 16 & 171 \\
\hline transfer & 5 & 1 & 48 \\
\hline \multicolumn{4}{|l|}{$1989-1990$} \\
\hline entry & 5 & 35 & 188 \\
\hline departure & 1 & 10 & 159 \\
\hline transfer & - & 2 & 32 \\
\hline \multicolumn{4}{|l|}{$1990-1991$} \\
\hline entry & 15 & 36. & 294 \\
\hline departure & 4 & 14 & 252 \\
\hline transfer & 1 & - & 50 \\
\hline \multicolumn{4}{|l|}{1991 - 1992} \\
\hline entry & 10 & 43 & 258 \\
\hline departure & 6 & 35 & 208 \\
\hline transfer & 1 & 1 & 38 \\
\hline \multicolumn{4}{|l|}{$1992-1993$} \\
\hline entry & 6 & 32 & 252 \\
\hline departure & 4 & 26 & 191 \\
\hline transfer & - & 2 & 50 \\
\hline present & 61 & 512 & 6022 \\
\hline
\end{tabular}


The number changing practice lacation in Almere was relatively high. By combining departures and transfers (in both circumstances there is discontinuity of care from the patients point of view), about $10 \%$ of the GPs in Almere experienced such a change, compared with $5 \%$ and less than $4 \%$ for GPs practising in health centres outside Almere "or single-handed, in partnership or in group practices respectively.

Another measure for continuity of care is the extent to which patients encounter different care providers during follow-up consultations or cannot consult the health care profession they are enlisted with. Data from the study 'Morbidity and interventions in general practice' show that in Almere, when consulting their GP, in $20 \%$ of a series of consultations (measured over a three months period) there was discontinuity of care. In the remainder of the Netherlands the corresponding percentage was $10 \%$. When the analysis is limited to practice settings with more than one GP, differences between Almere and the Netherlands are not significant.

In summary, hypothesis $\mathrm{H} 6.8$ regarding contacts with different health care providers during a series of consultations, is rejected.

\subsection{Quality of care from the patients perspective}

This section concentrates on the judgments of the users of the care facillities regarding the organization of health care services (sub-section 6.3.1), the functioning of child health clinics (sub-section 6.3.2), the accessibility of health care services (sub-section 6.3.3), waiting times (sub-section 6.3.4), the personal attitude or humaneness of health care providers (sub-section 6.3.5), and the expectations of the users of health care services (sub-section 6.3.6).

\subsubsection{Opinions about the organization of Health Care in Almere}

In Almere, in comparison with the Netherlands as a whole, the inhabitants are more satisfied with the organization of health care and its constituent elements. (Hypothesis H6.9)

Data to answer hypothesis $\mathrm{H6.9}$ are provided by the study in which inhabitants of Allmere evaluated the system of health care services (Study 86-1), the followup study on emergency care in Almere (Study 92-2), and the study on baby- and infant care in Almere (Study 89-1).

Value judgments, as part of patient satisfaction studies, are important indicators of the quality of care of health care services from the user's perspective. These 
value judgments can apply to different provisions or services, care coordination between services, or the assumptions underlying the AHCDP.In this sub-section attention is paid to (1) the organization of the emergency care (2) the organization of midwifery and obstetrics, and (3) the comcentration of primary health care in health centres.

With respect to emergency care, it was decided that after the opening of the Flevo hospital the best solution would be to follow a two track policy, instead of the original idea to close the Accident and Emergency Department of the hospital completely for 'self-referrals' (see Sixma and Bakker, 1996). The first track was (1) to discourage patients from going directly to the hospital, and (2) to refer patients, with injuries caused more than 24 hours before the time of presentation, to their general practitioners. The second track was that in the evening hours Primary Health Care emergency centres ran in parallel with the Emergency \& Accident (A\&E) department of the Flevo hospital.

Patients satisfaction judgments, regarding waiting times, routes to follow and clarity of the procedures to be followed, were part of a study to evaluate the effects of the opening of an A\&E Department in the Flevo hospital. Results from these studies show that waiting times were valued as 'good', both by patients using the PHC emergency centres as well as the visitors of the A\&E department of the Flevo hospital. People also expressed satisfaction with the opening hours of the PHC-emergency centres ${ }^{3}$ and the distance to the institutions. Relatively low satisfaction scores were given to aspects such as finding your way to the emergency care centre and how to use the emergency treatment posts and the A\&E Department of the Hospital. Also, many of the visitors of the PHCemergency centres were not aware of the specific regulations which applied to the proper use of both services (see also Sixma and Hackenitz, 1992).

In the context of the research project about cooperation between midwives and gynaecologists, 200 women in Almere answered questions about the organization of obstetric care in Almere. Since there are no figures currently available to permit comparison a report of the main results will have to suffice. Most of the women encountered various care providers during pregnancy with the median of 4 and with $15 \%$ of the women having had more than 5 different care providers. About $35 \%$ of the respondents were not satisfied with this. Immediate help after childbirth became imminent, the cooperation between the different disciplines, the information provided at the different stages of pregnancy and childbirth and the maternity care after having given birth were all found to

PHC emergency centres were established in the multidisciplinary health centres 'De Driehoek' (Almere-Stad) and 'De Haak' (Almere-Haven). At the start the PHC-centre in Almere-Stad was open 24 hours per day; since then opening hours have been standardized at 22.00 hours. 
be satisfactory. With respect to maternify care at home, between 10 and $15 \%$ reported that it came too late or sometimes not at all.

With emergency services and obstetric care being important components of Almere"s system of health care services, concentration of primary care in the multidisciplinary health centres is considered as one of the key elements of the philosophy underlying the AHCDP. The opinion of the Almere population regarding the concentration of primary care in health centres was assessed on two occasions. First at the beginning of 1985 , as part of a population study on the use of and opinion about health care provision in Almere (Sixma 1986). Secondly, in 1991 as part of the study on emergency care. Data for the population of Almere can be compared with those of residents of Lelystad (Dopheide \& Nijhout, 1983; Dopheide et al, 1986). In Lelystad there are health centres, group practices and single-handed GPs, and with less emphasis on achieving strong primary care as there is in Almere.

Table 6.9 shows that the majority of the inhabitants of Almere preferred an organization with primary care organized in multidisciplinary health centres.

Table 6.9 Preference of inhabitants of Almere and Lelystad for the concentration of primary care disciplines in health centres; percentages. (Sources: Study 86-1 and Study 92-2)

\begin{tabular}{lrrr}
\hline & $\begin{array}{r}\text { Almere 1985 } \\
(\mathrm{N}=706)\end{array}$ & $\begin{array}{r}\text { Almere 1991 } \\
(\mathrm{N}=927)\end{array}$ & 56 \\
\hline preference for primary care in health care centres & 67 & 1984 \\
cooperation yes, but not necessarily under one roof & 13 & 13 & 43 \\
preference for care providers working singlehandedly & 4 & 13 & 23 \\
il makes no difference & 16 & 18 & 4 \\
\hline
\end{tabular}

Patents preference for heath care workers in multidisciplinary health centres was more pronounced in 1985 than in 1991. The percentage of inhabitants that preferred single-handed health care providers rose from $4 \%$ in 1985 to $13 \%$ in 1991. Compared with the population of Lelystad, the population of Amere more strongly supports the idea of concentrating primary care services in mutidisciplinary heath centres. In Lelystad the percentage of the population who prefer single handed health care professionals is similar to the 1985 percentage for Almere.

In summary, hypothesis H6.9 that the Amere population is more satisfied with the organization of health care in Amere cannot be tested through the lack of avaluble data for the Netherlands. The resuts for Almere indicate that the majority of people are satisfed with the organization of health care, and that 10 


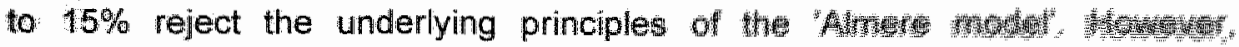
resistance against concentrating primary heath car in muthes centres increased between 1985 and 1991.

\subsubsection{Opinions about the child health clinics}

In Almere, in comparison with the Nethertands as a

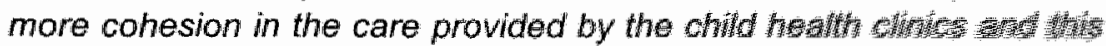

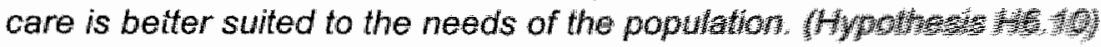

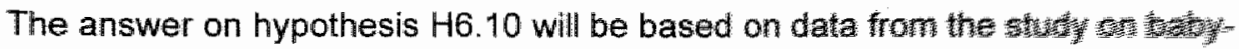

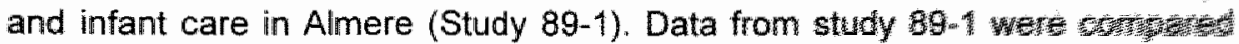
with data coming from a national sample (Vorst-Thijsen, 1987 .

Coordination of care for infants and toddlers was an explicit goal of whe fhore. Table 6.10 shows the most important results of the study conducted 落

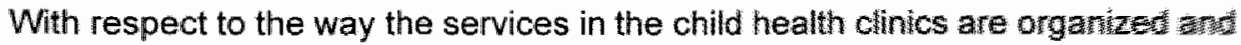
the activities carried out, the differences between Amere and the resit of Netherlands were small. There was somewhat more uniformity in Amere regarding the existing task distribution. No differences were noticed with respect to the perceived task profile of the professionals working in these clinics and the responsibilities associated with these tasks. With respect to consultations carried out, the differences were restricted to ad hoc consultations. The assumption that the child health clinics' in Almere put more efforts to achieve a degree of population participation in their mother-and-child care programmes was confirmed with respect to telephonic and written reminders, and rejected with regard to additional home visits. The testing of the assumptions 7 to 16 , yield a uneven picture. For four assumptions ( $\mathrm{nr} .11, \mathrm{nr} .12, \mathrm{nr} .14, \mathrm{nr}$. 16) no differences were found between Almere and the rest of the Netherlands, and therefore these hypotheses had to be rejected. Assumption 8 is confirmed in part and rejected in part; in Almere more courses were offered to parents-to-be and babies, but not to parents of toddlers.

The transfer from the bureau the child is visiting below the age of 1 and the bureau one is visiting being 1 to 4 years of age was better arranged in Almere than in the rest of the Netherlands. In Almere general practitioners and district nurses usually remain the same persons after such a transfer. In Almere more information was received by the visiting parents of the child health clinics about the professional on duty and waiting times were relatively short. Clients of the child health clinics in Almere had a less marked preference for the professional in the child health clinic they would like to see. 
Table 6.10 Comparison of the function of child health clinics in Almere and the Netherlands. Assumptions and testing results (Source: Study 89-1).

testing results

1 Almere offers a more complete care for infants and toddlers

2 The staff of the child health clinic works more independently in Almere, in which present and desired task distribution are closer to each other

3 In Almere there is more structural consultation at the child health clinic both inside as outside primary care

4 In Almere there is more incidental consultation at the child health clinic between the staff of the clinic and other disciplines

5 In Almere there is more consultation between the staff of the child health clinic

6 In Almere there are more activities to have non-participants participate in the child health clinic

7 In Almere there are more home visits as part of the child health clinic

8. In Almere more courses are offered for parents and parents to be

9 In Almere there are fewer changes in care providers when transfer takes place from the infant to the toddlers bureau

10 In Almere there is better information over who one consults

11 In Almere more children go to the child health clinic and the clinics are visited more frequently

rejected

confirmed

rejected

confirmed

rejected

partly confirmed, partly rejected

confirmed

confirmed

rejected

rejected child health clinic is bigger

13 In Almere the waiting times are shorter and the judgement of the users about the waiting times is more positive

confirmed

14 In Almere the coordination of duties between care prowiders is better organized concerning the needs of the population

15 In Almere clients have a less marked preference for the person in the clinic they would like to see

(probably)

rejected

confirmed

16 In Almere the clients are more satisfied in the child health climic than in the rest of the Netherlands

(probably)

rejected 
The overall picture based on table 6.10 suggests that the coordination of mother and child care within the child health clinics was clearly better organized in Almere on a number of aspects (involvement of non-participants in the child health clinics, fewer changes of care provider, shorter waiting times, better information over who one consults) than in the rest of the Netherlands. For the other aspects, differences with the rest of the Netherlands are small. Nowhere do the results of the research indicate that the organization of the child health clinics in Almere is observably inferior than elsewhere in the Netherlands. Summarizing these results hypothesis $\mathrm{H} 6.10$ is provisionally confirmed.

\subsubsection{Opinions about the accessibility of health care facilities in Almere}

In Almere, in comparison with the Netherlands as a whole, the inhabitants are more satisfied with the accessibility of health care facilities. (Hypothesis H6.11)

Hypothesis $\mathrm{H} 6.11$ will be answered on the basis of data from various studies. With respect to the Almere data these studies are: 'Health and the use of Health Care Services in Almere' (Study 93-2), 'Morbidity and Interventions in General Practice in Almere' (Study 93-4) and the study about contacts and referral rates of GPs in Almere (Study 86-3). Data for Almere are compared with national data coming from the National Survey on General Practice (Velden et al, 1992; Foets et al, 1991). Other sources are survey results gathered in Almere by the APHCF (Stichting EVA, 1995), data from a study in which new measuring instruments for quality of care from the patients perspective were developed (Sixma et al; 1996) and a study about the existence of waiting lists for community nursing and home help services (Groenewegen et al, 1993).

Accessibility of health care services can be subdivided into geographical access - or the place where the care provisions are situated - and the possibilities to get in touch with health care providers in person or by telephone. Regarding geographical access, efforts have been made in Almere to spread the care provision over the various districts of the town, which is illustrated by the distribution of health centres over the three parts of the town. Efforts have also been made to spread the nursing and old people's homes evenly over the town districts, while in support of Almere's policy of arranging emergency services under primary care, emergency treatment posts have been established in Almere-Haven and Almere-Stad and the setting up of a similar emergency treatment post in Almere-Buiten is under discussion. Still another aspect of accessibility is the possibility to reach the different health centres by telephone and the procedures to call for help outside the usual opening hours of these centres. Outside the opening times of the health centres - all centres are occupied during the working days between 08.00 and 17.00 , with some of them having a lunch-break between 12.30 and 13.00 hours - this procedure was 
coordinated by one central doctor's telephone. On reporting, the patient is called back by the GP on call and decisions concerning action to be taken are decided in this (telephonic) consultation.

Geographical access is crucially important at the moment emergency help is needed. The opinions of the Almere population concerning the geographical accessibility of the health centres, the primary care emergency posts and the Flevo hospital revealed only a few points of criticism. This criticism concerned the clarity of the rules about where and when people should go to with different types of complaints or injuries and the way routes towards the PHC emergency centres were indicated (Sixma \& Hackenitz, 1992).

Survey results indicate that patients who tried to reach their GP by telephone outside the office hours experienced uncertainty ("I was told that someone would "phone me back, but when?"). This uncertainty has undoubtedly influenced the opinions concerning the accessibility of the general practitioner outside surgery hours. While $95 \%$ of a randomly selected group of patients from the rest of the Netherlands reported good accessibility outside the office hours - in the evening, at night, during the weekends and in holiday periods - the corresponding percentage in Almere was $85 \%$. Even when account is taken of the special distribution of age and gender of the population in Almere, as has been done in Table 6.11, or with the differences in morbidity, these differences remain.

Table 6.11 Satisfaction with the GP's accessibility as perceived by persons of 15 years and older in Almere and the Netherlands. (Source: Study 93-2)

$\%$ 'seldom/never'

Almere

Netherlands

standardized

experlences concerning accessibility

visit refused

$88.2^{\text {*** }}$

93.1

worried about accessibility in weekends

worried about accessibility at night

$78.3^{* *}$

89.9

$78.2^{* *}$

92.3

satisfaction with accessibility

well accessible in weekends and holiday periods

$15.2^{\text {** }}$

weil accessible in evening and at night

$14.8^{* *}$

5.7

*** = significant with $p<.01$

Considering what actually happened when people call their general practitioners for help outside the usual hours, the percentage of people in Aimere who actually speak to the GP-on-call over the telephone is relatively low (Sixma et at, 1991). The time between the first telephone call and the moment one actually 
speaks to the GP or the GP's assistant over the telephone is on average 25 minutes, both in Almere and in the Netherlands as a whole (Sixma et al "1991), although this conclusion was based on a small sample of respondents.

With regard to the functioning of emergency services in Almere, it was found that ${ }_{n}$ as soon as an actual telephone call was made on services about $75 \%$ of all people calling were immediately put in contact with the institution of their choice. About $13 \%$ of these people reported that contact was made after some lapse of time, about $6 \%$ reported waiting for a long time and for $5 \%$ the waiting time was too long, or no telephone contact was made at all. Subsequently, people decided to telephone again or to take some other action (Sixma and Hackenitz, 1992).

The accessibility of the provisions is determined on the one hand by situation and hours of opening and on the other by physical barriers which have to be overcome before one arrives in the consulting room of the care provider concerned. In an optimum situation the call made on provisions should match the capacity and the organization of the facilities. To test the hypothesis at the beginning of the section in this respect, information about the accessibility came from different sources.

A study about the existence of waiting lists by the organizations for community nursing and home help services conducted in 1992 indicated that Almere did not report problems with respect to district nurses, whereas at that time no information was available for home help services (Groenewegen et al, 1993).

Making an appointment to see a general practitioner in his or her practice room on the very same day, was somewhat more difficult in Almere than in the remainder of the Netherlands. About $70 \%$ of the Almere population report that such an appointment is possible, with the corresponding figure for the remainder of the Netherlands of $88 \%$. A request for a home visit invariably takes place the same day "both in Almere as in the rest of the Netherlands. In Almere $75 \%$ of the general practitioners reported that their practice is open at some time in the weekend. Given the corresponding figure for the Netherlands of $50 \%$, it must be remembered that in Almere the answers probably refer to the health care centre in which the practice is established and not to the practice itself. Finally in Allmere a visit for consulting the GP at the health centre are usually arranged by appointment, while in the rest of the country patients can usually visit their GP at certain times without a prior appointment.

Findings for Almere, that the population was relatively dissatisfied with arrangements made for the weekends and nights for seeing a GP and the accessibility of general practice by telephone (see Table 6.11), are supported by the results from other studies among the population of Almere conducted by the 
APHCF between 1992 and 1994 (EVA, 1995). These studies concentrated on patient satisfaction with the various services offered in the health care centres. When the average percentage of satisfied patients dropped below $80 \%$ patient satisfaction was defined as 'low', scores between $81 \%$ and $90 \%$ were specified as "moderate". Also scores of $99 \%$ or $100 \%$ "(very) satisfied" were mentioned in the text. With respect to the work of general practitioners and the functioning of general practice less than or about $80 \%$ of the patients $(\mathrm{N}=2175)$ were satisfied with the time between making an appointment and the actual consultation ( $75 \%$ 'satisfied'), services offered during the night or weekends $(80 \%$ "satisfied'), waiting times ( $80 \%$ 'satisfied') and the services offered in case of emergencies at night $(80 \%$ 'satisfied'). Other areas with relatively large numbers of dissatisfied people were continuity of care with respect to seeing the same GP during every visit and the accessibility by telephone during the office hours.

As part of the development process towards a series of instruments for measuring quality of (home)care from the patients perspective, the opinions of about 200 elderly and disabled people from Almere can be compared with the same number and groups of people living in a neighbouring region. Again, the accessibility by telephone, the possibility to see own's own GP and opportunities to make an appointment for the very same day were aspects where GPs in Almere scored (significantly) lower than their counterparts in the neighbouring region. GPs in Almere scored better on the process dimensions such as 'perceived autonomy' and the amount of information given during consultations (Sixma et al, in press).

In summary, to the extent that the data is available, it was found that the accessibility of care provision in Almere is better on certain aspects (accessibility of the practice locations) than in the Netherlands as a whole and worse on other aspects (the possibility to reach health care services by telephone). In general terms hypothesis $H 6.12$ has to be rejected.

\subsubsection{Opinions about waiting times for health care providers in Almere}

In Almere, in comparison with the Netherlands as a whole, the inhabitants are more satisfied with the waiting times when visiting institutions and providers of health care (Hypothesis H6.12)

Hypothesis $\mathrm{H} 6.12$ will be answered on the basis of data from the study "Emergency care in Almere, part II" (Study 92-2), the study about baby- and infant care in Almere (Study 89-1), the study about the use of home help services and community nursing by frail elderly people in Almere (Study 90-2). the (unpublished) results from a study among midwives and gynaecologists in Almere, and the study among inhabitants evaluating health care services in Almere (Study 86-1). 
Waiting times on visiting an institution concerned with health care is a relatively simple indicator to use for obtaining an impression of the quality of the various care provisions. Waiting times should be short. From the patients' perspective, the importance of short waiting times increases with the urgency of the case. Information about the (perceived) length of waiting times in Almere is available for general practitioners, medical specialists, child health clinics and home help services.

Table 6.12 Waiting times at general practices in Almere and the Netherlands in percentages (Source: Study 93-2)

\begin{tabular}{rrr} 
& Almere $(N=511)$ & Netherlands $(N=4777)$ \\
\hline $0-10$ minutes & $32.6^{*}$ & 42.2 \\
$11-20$ minutes & $49.2^{*}$ & 40.2 \\
$21-30$ minutes & $12.9^{*}$ & 10.0 \\
$31-45$ minutes & 4.3 & 4.1 \\
$>45$ minutes & $0.8^{*}$ & 3.5 \\
\hline
\end{tabular}

* = significant $(p<.05)$

On average, patients in Almere reported somewhat longer waiting times when visiting a GP than patients in the remainder of the Netherlands. However, extremely long waiting times of 45 minutes or more occurred in Almere less frequently than elsewhere. The average time which people have to spend in the waiting room was more readily considered 'too long' in Almere than in the rest of the country.

For the child health clinic function in Almere the reverse can be noticed. Here, waiting times in Almere were slightly shorter in Almere than in the rest of the Netherlands. In Almere approximately $3 / 4$ of the clients reported waiting times of 15 minutes or less. For the rest of the country the comparable proportion was $58 \%$. Of those visiting the child health clinic in Almere $13 \%$ judged the waiting time rather long and $3 \%$ found it inconveniently long. These percentages are significantly lower than the comparable percentages in the rest of the Netherlands (Thomassen et al, 1989).

With respect to home help services, information is available concerning the average waiting time in Almere (in 1990) for the period between a request is filled and the time the home help makes her first visit. In Almere the waiting time was about two weeks. None of the respondents taking part in the study concerned commented on the length of time between approval of the request and the actual commencement of help in the family as being too long (BrinkMuinen and Sixma, 1990). A national survey among home help agencies in the Netherlands, conducted two years later, showed that the average waiting time 
between the moment the patients receives an indication for home help and the first visit is 45 days (Groenewegen et al, 1993).

More recent information about dissatisfaction about waiting times can be derived from the APHCF-studies about patient satisfaction and the NIVEL-studies on quality of care (Stichting EVA, 1995; Sixma et al, submitted). The APHCFstudies show that in the period between 1992 and 1994 about $80 \%$ of the people in Almere are satisfied with waiting times when visiting a GP. Corresponding figures are $90 \%$ for mother-and-child care, $85 \%$ for the visitors of dentists $(\mathrm{N}=261)$ and $86 \%$ of the visitors of pharmacies $(\mathrm{N}=941)$. Corresponding data for the rest of the Netherlands are missing. The NIVEL-study allowed us to compare the opinions of patients in Almere with patients in a neighbouring region with respect to waiting times in general practice and medical specialists. About $45 \%$ of both groups of respondents experienced waiting times which were frequently longer than 15 minutes, both for GPs as well as medical specialists. Differences between the two populations were not significant (Sixma et al, unpublished).

Finally, information is available about the waiting times at medical specialists, without figures for the Netherlands to compare with. These figures for Almere refer to medical specialists in general, including the waiting times in the A\&E Department in the Flevo hospital. Ratings for the time spent in the specialist's waiting room were 'moderate to good', even though these ratings are lower than the high satisfaction scores usually encountered in health care research. Opinions from the population of Almere with respect to specialists working in Almere did not differ significantly from opinions expressed about specialists working outside Almere (Sixma, 1987; Sixma and Hackenitz, 1992). The 1991 study about emergency care in Almere (see Sixma and Hackenitz, 1992) information is available about the (perceived) the number of minutes between arrival in the emergency care facility and the moment treatment started. Table 6.13 illustrates that most of the people making use of the emergency services in the PHC centres during the office or the PHC emergency centres in Almere almost received treatment within 5 to 10 minutes. Patient satisfaction scores on a scale ranging from 1 (extremely bad) to 10 (excellent) was an average ' 8 '. Visitors to the Flevo hospital had to wait a little longer than those patients that made use of the primary care emergency centres in Almere. Waiting time in A\&E department of the Flevo hospital was about 11 minutes. Waiting times in the two hospitals outside Almere who cooperated in the research into emergency services - the AMC and the Gooi-Noord hospital - were about half an hour. 
Table 6.13 Waiting times and judgements about the speed of care at the emergency services in and around Almere. (Source: Study 92-2)

waiting time

(in minutes)
Judgement

(mean score

between $1-10$ )

Almere health care centres

6.1

7.8

Emergency services in Almere

7.5

7.9

Flevo hospital

11.4

7.4

Hospitalls outside Almere

30.9

7.1

In summary, with respect to waiting times when visiting health care institutions, hypothesis $\mathrm{H} 6.12$ was partly confirmed and rejected. It was rejected with respect to the GP's waiting times, and confirmed for the child health clinics and the emergency services in the hospital.

\subsubsection{Opinions about the providers of health care and the care provided in Almere}

In Almere, in comparison with the Netherlands as a whole, the inhabitants are more satisfied with the quality of health care providers and the care they provide. (Hypothesis H6.13)

Hypothesis H6.13 will be answered on the basis of data from the study on health and the use of health care services (Study 93-2), the study about the use of home help services and community nursing by frail elderly people in Almere (Study 90-2), the two studies on the functioning of emergency services in Almere (Study 87-3, Study 92-2), the study about baby- and infant care in Almere (Study 89-1), and the evaluation study focusing on the combined nursing/old peoples home 'de Kiekendief' (Study 93-6).

Research into the field of patient satisfaction with health care services experienced need to be interpreted with caution. Usually such studies on patient satisfaction show that the majority of people questioned respond with 'satisfied' or 'very satisfied' (Sixma et al, in press). Secondly, it can be shown (Sixma et $\mathrm{al}_{i}$ in press) that variance in satisfaction scores can be attributed to a small extent to differences between care providers, or circumstances of care delivery. Most variance in patient satisfaction scores is usually on the level of the individual patients and only a small part of this variance can be explained by socio-demographic variables or variables measuring the health status of the respondent. Although these conclusions cast some doubts on the usefulness of such studies in quality improvement programmes, they do not effect the validity of value judgments as possible indicators for quality of care from the perspective of the users of health care services. 
Although patient satisfaction with respect to the communication and informative skills of the general practitioners is generally high. general practitioners in Almere receive significantly lower scores than their colleagues in the remainder of the Netherlands, as is shown in Table 6.14.

Table 6.14 Appreciation for the general practitioners by persons of 15 years and older in Almere and the Netherlands (Source: Study 93-2)

\section{$\%$ "seldom, never"}

Aimere, standardized

Netherlands

Satisfaction with the GP's social attitudes

- GP explains my situation

$10.4^{\text {*** }}$

6.3

OP keeps patients at a distance

$79.1^{*}$

82.4

- GP explains what to do in case of illness

$8.9^{* *}$

6.2

- GP treats me as a number

$89.6^{*}$

92.1

- GP is open to all my problems

$14.9^{* * *}$

- GP spends enough time to me

$6.3^{* *}$

- GP informs me about the seriousness

$11.6^{\text {** }}$

6.4

- GP takes me seriously

$19.8^{*}$

16.5

Satisfaction with the GP's technical skills

- GP refers too quickly

- GP refers unnecessarily

- unnecessary prescription of medicines

- GP refuses prescription

${ }^{*}=$ significant with $p<.05$

$* *$ significant with $p<.01$

With respect to the technical skills of the GPs, differences in opinion between the population of Almere and the Dutch population in general are minimal. When the opinions of disabled and frail elderly people in Almere with respect to the humaneness of the general practitioner are compared with the opinions of the same groups of respondents in the neighbouring Gooi/Eemland/ Apeldoorn region, data show that approximately 5 to $10 \%$ of the respondents are dissatisfied. There are no significant differences between Almere and the other region (Brink-Muinen and Sixma, 1990; Sixma, in preparation).

With respect to the functioning of the emergency services, patient opinions on the friendliness were predominantly positive, with differences between the general practices and hospitals in and outside Almere being small (Sixma, 1987 " Sixma and Hackenitz, 1992; Sixma and Bakker, 1996). Regarding midwifery and obstetrics "again the dominant opinion was positive, although small differences between the disciplines could be observed. Midwives and the district nurses were slightly more positively judged than the gynaecologists and the maternity care provider (Sixma, unpublished report). 
For the child health clinic in Almere data are availablle on a number of content related aspects (information about growth and development, diseases of infancy. vaccinations, hearing test and use of medicines). According to the users of these services, expectations were met and supply and demand were in line with each other (Thomassen et al, 1989).

A specific group in Almere consists of the people resident in one of the nursing/old people"s homes. That is particularly the case for "De Kiekendief", where the nursing and old people's home functions are integrated. 'De Kiekendief' was opened in 1990, and offers living facilities for elderly people. Residents have their own room, which could mean single rooms or rooms for a couple who is living together. Evaluation research conducted in 'De Kiekendief' was directed to clients satisfied with the facilities, such as living conditions, nursing aspects, social relationships inside and outside the home, privacy, loneliness and the extent to which it is possible to continue to live independently. Data show that, with regard to the integration of nursing and old people's home care and the associated continuity of care, the experiment was judged by the residents to be a success. Satisfaction with medical care was good. Those allocated to the nursing home said that they have found their stay in 'De Kiekendief' pleasant. However, residents of the old people's home department were less satisfied especially when confronted by people in a worse state than one is oneself and the problems are psycho-geriatric clients (Fahrenfort and Plaisier, 1993). Meals ( $70 \%$ positive), nursing care ( $76 \%$ positive), and living accommodation ( $87 \%$ positive) were listed spontaneously by the residents as the core of the evaluation. The friendliness of approach of the personnel was not put forward by any of the respondents as a positive point, and for some it was a negative point. Although comparative studies to put these figures in a broader perspective are missing, the general picture of the satisfaction of the residents of 'De Kiekendief' can best be described as fairly good to good.

Finally, results from a research study conducted in 1985 with a random sample of the Almere population involved show high percentages of satisfied clients of midwives and dentists, and moderate to high satisfaction scores for GPs, district nurses, social workers and physiotherapists.

In summary, the inhabitants of Almere convey a global positive judgment with respect to their care providers, but this feeling cannot be said to be more positive than elsewhere. Hypothesis $\mathrm{H} 6,13$ is therefore rejected. 


\subsubsection{Care according to needs}

In Almere, in comparison with the Netherlands as a whole, from the patients' perspectives needs are better fulfilled. (Hypothesis H6.14)

Hypothesis $\mathrm{H} 6.14$ will be answered using data from the study "inhabitants evaluating the functioning of health care services in Aimere (Study 86-1), the study about contacts and referrals in general practice in Almere (Study 86-3), the study about the use of home help services and community nursing by frail elderly people in Almere (Study 90-2), and the study interventions and morbidity in general practice in Almere (Study 93/4).

With respect to the professional group of general practitioners the inhabitants of Almere were more likely to encounter a doctor who reported being more reluctant to prescribe medicines or to write out a referral letter than does the average inhabitant of the Netherlands (see Table 6.3). This policy is in line with the goals directed to substitution of care and achieving cost containment.

Data from a population study in Almere, conducted in 1985 and shown in Table 6.15 , show that between $62 \%$ and $78 \%$ of the inhabitants of Almere who consulted their GP exactly received the help they expected. Percentages were relatively low for the categories 'referral to specialist' and 'examination' and high for 'prescription'. Answering the question whether people actually received the treatment they expected ${ }_{2}$ the greatest discrepancies can be found in the categories 'counselling' and 'prescription', while most agreement can be found in the category 'check up' visits.

Table 6.15 The relationship between the demand of care and the supply of care during a visit to the general practitioner in Almere, in numbers (Source: Study 86-1)

\begin{tabular}{|c|c|c|c|c|c|c|c|c|c|c|}
\hline \multirow{2}{*}{\multicolumn{2}{|c|}{$\begin{array}{l}\text { help asked of the } \\
\text { general practitioner }\end{array}$}} & \multicolumn{9}{|c|}{ help given by the gemeral practitioner } \\
\hline & & \multirow{2}{*}{$\frac{1}{141}$} & \multirow{2}{*}{$\frac{2}{15}$} & \multirow{2}{*}{$\frac{3}{9}$} & \multirow{2}{*}{$\frac{4}{14}$} & \multirow{2}{*}{$\frac{5}{3}$} & \multirow{2}{*}{$\frac{6}{5}$} & \multirow{2}{*}{7} & \multirow{2}{*}{ none } & \multirow{2}{*}{$\frac{\text { total }}{188}$} \\
\hline 1 & check-up & & & & & & & & & \\
\hline 2 & examination & 13 & 220 & 19 & 39 & 31 & 20 & 8 & 4 & 354 \\
\hline 3 & counselling & 2 & 5 & 54 & 3 & 2 & 5 & 3 & 1 & 75 \\
\hline 4 & prescription & - & 10 & 5 & 122 & 3 & 10 & 2 & 5 & 157 \\
\hline 5 & referral & 2 & 25 & 8 & 4 & 89 & 1 & 6 & 2 & 137 \\
\hline \multirow[t]{2}{*}{6} & information and & & & & & & & & & \\
\hline & reassurance & 2 & 9 & 7 & 6 & 3 & 81 & - & 1 & 109 \\
\hline \multirow[t]{2}{*}{7} & other & - & 2 & 1 & 1 & 2 & $\mathbb{1}$ & 22 & - & 29 \\
\hline & total & 160 & 286 & 103 & 189 & 133 & 123 & 41 & 14 & 1049 \\
\hline
\end{tabular}


With respect to the care provided at the child health clinic and the services performed by midwives, no indications were found for discrepancies between the needs of clients and the care received (Thomassen et al, 1989 ; Sixma, unpublished). Regarding the functioning of home help services and the home care provided by family helpers and district nurses "data were available from a survey among inhabitants of Almere of 65 years and over living at home. Supply and demand for home help services in Almere were well matched. Where the fit was less optimal it usually concerned unusual events such as moving furniture, taking care of the central heating system, etc. Home care was directed, in accordance with the task description for the discipline, predominantly to housekeeping tasks. District nurses are brought in where there are restrictions in the area of personal care. There was hardly any overlap between these, so that it can be concluded that the work of the two disciplines was tuned not only to needs of the patients but also to each other (Brink-Muinen and Sixma, 1990).

Finally, the number of home visits a general practitioner makes in Almere is relatively low in comparison with the Netherlands as a whole and is roughly the same as the numbers of visits made by doctors working in other health centres. The practice/home visit ratio is about 7 for Almere. The comparative ratios for general practitioners are 4.2 for the Netherlands, 6.6 for the large cities and 6.9 for general practitioners in other health centres.

In summary, supply and demand of care provision in Almere are fairly well or well matched. However, where comparison with national figures is possible, the situation in Almere is not superior to the rest of the Netherlands. Therefore, hypothesis H6.14 has to be rejected.

\subsection{Conclusions with respect to the quality of care}

This chapter focused at different operationalizations of quality of care, and whether or not the quality of care in Almere is better than in the remainder of the Netherlands. First the structure of health care services was examined (H6.1), followed by the health care process (H6.2) and the value judgments of the users of health care services (H6.3).

Implementation of a system of health care facilities that matched the expectations of central and local policy makers, local health care workers and the population of Almere was one of the most important goals of the AHCDP. However, conclusions whether or not the operational goals derived from this overall goal were actually achieved is not easy. Research data that refer to the structure of health care services and the care delivery process frequently refer to only one or two categories of health care providers, whereas control groups 
were often missing. Also, results do not always point in one straight direction, which is illustrated in Table 6.16.

Table 6.16 Overview of the degree in which the operational goals of the Experiment Health care Almere, concerning quality of care, were achieved as compared to the rest of the Netherlands

Hypotheses Operational gaal Result

H6.1

H6.2

H6.3

$\mathrm{H} 6.4$

H6.5

H6.6

H6.7

H6.8

H6.9

H6.10

H6. 11

H6. 12

H6. 13

H6. 14 more primary care providers per

100.000 inhabitants

care providers with better and more

suitable education

attitudes of care provides in accordance to the goals of the Almere Health Care Demonstration Project

better equipped facilities for care provision

specific work style, with much information and advice

specific work style, with much coordination

and consultation

work style general practitioners anticipating

on NHG guidelines

patients are less likely to encounter different

care providers; continuity of care

more satisfaction with inhabitants about

arganization of the Almere health care

care by child health clinics better tuned

to the needs of the clients

good accessibility of health care services

from the user's perspective

relatively short waiting times when visiting

institutions and providers of health care

relatively good quality of the health care process

as perceived by the clients

partly realized, not for the GPs

not realized

realized to a restricted degree

realized to a restricted degree

realized

realized

realized

partly realized,

nat realized

not realized

mainly realized

partly realized

partly realized,

care is more suited to needs of clients 
Regarding the number of health care workers established in Almere (or the density of health care providers) a conclusion is that figures for Almere are in line with the target figures stated at the start of the Almere demonstration project.

Secondly " on the level of the individual health care workers only a few differences were found when the situation in Almere was compared to the remainder of the Netherlands. The attitudes and workstyles of the general practitioners in Almere differed slightly from their colleagues in the Netherlands. Practice settings in Almere were somewhat better equipped, and both GPs and district nurses in Almere reported somewhat higher levels of information, counselling and advices given to patients or clients during consultation sessions. With good quality of care from the perspective of general practitioners being operationalized as practising according to the (later published) professional NHG guidelines, general practitioners in Almere acted somewhat more in accordance with these professional guidelines, although this conclusion did not apply to all eight guidelines investigated. The concentration of primary care services in multidisciplinary health centres resulted in a relatively high level of discussion and consultation between the different care providers in Almere. This can be described as a more cohesive form of care. Regarding continuity of care, positive points included for instance the integration of nursing care and old people's home in 'De Kiekendief'; negative points included the relative high percentage of GPs in Almere who ceased practising or moved from managers. Finally, in respect of the opinions and value judgments of the inhabitants of Almere about the functioning of health care services and health care providers, the picture which emerged from the research regarding patient satisfaction was that the majority of patients and clients was satisfied. Furthermore, on a number of services Almere's inhabitants were more satisfied than their counterparts elsewhere, including the accessibility of health care services during office hours, the functioning of the emergency services, and waiting times in child health clinics. For other aspects, however, satisfaction was significantly lower than for the remainder of the Netherlands (e.g. the accessibility of the health care services outside the office hours other than emergency care, waiting times while visiting the GP).

This chapter concentrated on quality of care from the organizational and providers' perspective, and the perspective of the user of different health care services. The next chapter will be looking at one of the two other goals of the demonstration project in Almere: substitution of care. 
Substitution of care could be an instrument for reaching higher goals, such as: cost containment or and cost reduction. Substitution of care can also be considered as an important goal on itself. Here, instruments to achieve this goal can be found in the structure of health care services and the way the health care process is functioning. Chapter 7 considers substitution as a goal to be achieved, with goals operationalized as presented in chapter 3 (Table 3.2). A distinction is made between substitution (1) within hospital and nursing home sector and from inpatient care to outpatient care, 2) from secondary to primary care, and 3) from professional to informal and from curative to preventive care. As in chapter 6 , subsections start with a hypothesis concerning differences between Almere and the Netherlands with respect to the relevant substitution of care area are stated, which statement is 'tested' against the research data presented.

With regard to some of the data presented in this chapter, account is taken for the atypical age- and gender distribution of the Almere population. For most of these data, this is done by indirect standardization. Wherever possible, data referring to the situation in Almere are adjusted in accordance with the same distribution on the national level. Such data are referred to as 'Almere standardized'. However, with respect to the utilization of hospital services another way of standardization is used. Data for the Netherlands were adjusted as if the national situation with respect to age and gender was identical to the situation in Almere. This direct standardization is referred to as 'Netherlands standardized'. Most tables and graphs will show data with Almere being compared to the Netherlands. A comparison between Almere and sub-categories of the Dutch population are presented in chapter 9 .

\subsection{Substitution in the hospital and nursing home sector}

With respect to the institutionalized care sector, six subsidiary goals were operationalized. These goals refer to (1) substitution from inpatient to outpatient care, (2) substitution from inpatient to day care, (3) shortening the length of hospital stay, (4) reduction of the number of referrals within the hospital sector, (5) protocols and agreements within hospitals and other inpatient services, and (6) substitution from nursing homes to old people's home care. Goals (1) to (5) refer to the way the hospital function is fulfilled for the population of Almere. The first two operational goals would result in relatively low admission rates for the hospital in Almere. 
Before March 1991, when the Flevo hospital in Almere was opened, people in Almere were referred to hospitals outside the municipality. Approximately $80 \%$ of these admissions concerned five different hospitals, as is shown in Table 7.1.

Table 7.1 Number of admissions in the different hospitals in and around Allmere between 1983 and 1995 , in percentages (Source: Studies $86-3,87-1,87-2,88-1,90-1,92-1,93-5)$

\begin{tabular}{lrrrrrrrrrrrr}
\hline & 1983 & 1984 & 1985 & 1986 & 1987 & 1988 & 1989 & 1990 & 1991 & 1992 & 1995 \\
\hline Hospital & & & & & & & & & & & \\
Gooi-Noord, Bussum & 55 & 48 & 43 & 38 & 34 & 31 & 29 & 26 & 10 & 6 & 5 \\
AMC, Amsterdam & 9 & 16 & 19 & 21 & 23 & 24 & 27 & 25 & 17 & 12 & 10 \\
VU, Amsterdam & 5 & 6 & 5 & 5 & 6 & 6 & 5 & 5 & 4 & 4 & 3 \\
OLVG, Amsterdam & 5 & 4 & 5 & 3 & 4 & 4 & 5 & 4 & 3 & 2 & 2 \\
Burger, Amsterdam & 4 & 9 & 12 & 13 & 15 & 16 & 17 & 22 & 6 & - & - \\
Flevo, Almere & - & - & - & - & - & - & - & - & 48 & 66 & 69 \\
Other, Amsterdam & 14 & 9 & 10 & 13 & 10 & 10 & 7 & 8 & 5 & 4 & 3 \\
Other, elsewhere & 8 & 7 & 6 & 7 & 8 & 9 & 10 & 10 & 7 & 7 & 7 \\
& $100 \%$ & $100 \%$ & $100 \%$ & $100 \%$ & $100 \%$ & $100 \%$ & $100 \%$ & $100 \%$ & $100 \%$ & $100 \%$ & $100 \%$ \\
Total & 3,527 & 4,343 & 4,833 & 5,082 & 5,542 & 5,837 & 6,458 & 7,091 & 8,089 & 9,052 & 11,027 \\
Absolute & & & & & & & & & & & &
\end{tabular}

In the period between 1983 and 1991 most inhabitants of Almere were admitted to the Gooi-Noord hospital in Naarden-Bussum and the Academic Medical Centre (AMC) in Amsterdam. Over this period, admission rates for the GooiNoord hospitals showed a steady decrease, whereas the share for the AMC increased till 1989. Also the percentage of patients admitted to the Burger hospital increased from $4 \%$ in 1983 to $22 \%$ in the year preceding the opening of the Flevo hospital in Almere. On 6 March 1991, the Burger hospital was officially closed, and at the same date the Flevo hospital in Almere took over its function. In the opening year almost half of all the admissions from the Almere population went to this hospital.

Until 1991 admissions from the Almere population were related to numerous hospitals outside Almere, which hampered the possibilities to establish a specific admission policy attuned to the goals of the AHCDP. Here, 1991 can be seen as the turning point, but also as a year of transition and a rather unstable situation. In the subsequent year, $66 \%$ of all 9052 admissions from the Almere population ' went to the Flevo hospital. Hospitals that remained important for the

For the years between 1992 and 1995 data were available about the number of discharges from the all hospitals to which inhabitants of Almere were admitted, instead of admission data. Although there might be small differences in the yearly figures between the number of admissions and discharges we included the data for 1992 until 1995 in table 7.1 without corrections. In 1992 the number of people living in Almere who were discharged from hospital was 9052 (or 106.61 per 1000 inhabitants), while in 1995 this figure was 11027 (105.48 per 1000 inhabitants). 
population of Almere in 1992 were the AMC hospital $(12.4 \%)$, the Goo-Noord hospitall $(5.8 \%)$ and the VU hospital $(3.6 \%)$. Other hospitals with more that 100 inhabitants of Almere admitted over 1992 were located in Hilversum (1.2\%), Amsterdam (OLVG hospital: $1.7 \%$, St. Lucas hospital: $1.3 \%$ ) and Lelystad $(1.3 \%)$. The picture that can be derived from the data for 1995 is almost equal to 1992 . Of all the admissions from the population of Almere, some $69 \%$ went to the Flevo hospital. Other hospitals with more than $1 \%$ of the total number of admissions from Almere were: the AMC hospital (10.4\%), Gool-Noord hospital $(5.2 \%)$, VU hospital $(2.9 \%)$, St.Lucas hospital $(1.6 \%)$, OLVG hospital (1.5\%), the IJsselmeer hospital in Lelystad (1.1\%) and the hospital in Hilversum (1.0\%). An important conclusion is therefore that, in the relative stable situation after the opening year of the Flevo hospital, some 30 to $35 \%$ of all admissions from the Almere population refer to hospitals outside Almere.

\subsubsection{Substitution from inpatient to outpatient care}

In Almere, in comparison with other hospitals in the Netherlands, a relatively high number of interventions are carried out in the hospital outpatient department (Hypothesis HT.1)

Hypothesis H7.1 will be answered on the basis of the yearly reports of the Flevo hospital in Almere, and reports from three hospitals in cities comparable to Almere.

Prior to 1991 no data were available permitting the comparison of the numbers of clinical and outpatient procedures for inhabitants of Almere carried out in hospitals outside Almere. Data for 1991 and 1993 refer to the Flevo hospital and three hospitals in cities comparative to Almere. As in Almere, these hospitals are situated in fast-growing 'new' satellite towns for the cities of Amsterdam (Purmerend), Utrecht (Nieuwegein) and The Hague (Zoetermeer). Health care services in these three towns resembled the national situation and did not match the experimental situation in Almere. Population structures closely resembled Almere with respect to the size and age/gender distribution. Also because of the lack of relevant information, no attempts were made to correct for differences in population structures with respect to age and gender. Also, the fact that admissions in each of the hospitals included in Table 7.2 were not limited to the population in that particular town was neglected.

Table 7.2 shows the relationship between the total number of visits to the hospital's outpatients departments and the number of hospital admissions for twelve departments. To obtain the inpatient/outpatient ratio, the number of admissions is divided by the number of visits to outpatients departments. A shift from inpatient to outpatient care must result in a relatively high number of visits 
to outpatient departments, fewer admissions, and as a consequence to a relatively low ratio between these two variables.

Table 7.2 Relation between the number of admissions and visits to outpatient departments in the Flevo hospital (Almere) and some hospitals in similar municipalities, ratios per specialism. (Source: annual reports Flevo hospital, St. Antonius hospital, Waterland hospital, and 't Lange Land hospital, 1991/1993)

\begin{tabular}{|c|c|c|c|c|c|c|c|c|}
\hline & \multicolumn{2}{|c|}{$\begin{array}{l}\text { Flevo } \\
\text { Almere }\end{array}$} & \multicolumn{2}{|c|}{$\begin{array}{l}\text { Sit. Antonius } \\
\text { Nieuwegein }\end{array}$} & \multicolumn{2}{|c|}{$\begin{array}{l}\text { Waterland } \\
\text { Purmerend }\end{array}$} & \multicolumn{2}{|c|}{$\begin{array}{l}\text { "Lange Land } \\
\text { Zoetermeer }\end{array}$} \\
\hline & 1991 & 1993 & 1991 & 1993 & 1991 & 1993 & 1991 & 1993 \\
\hline cardiology & .23 & .18 & .23 & .17 & .10 & .13 & - & .15 \\
\hline surgery & .09 & .10 & .10 & .10 & .10 & .09 & .11 & .09 \\
\hline dermatalogy & .00 & .00 & .00 & .00 & .02 & .01 & .00 & .00 \\
\hline gynaecology & .13 & .12 & .20 & .13 & .18 & .12 & .12 & .10 \\
\hline internal medicine & 11 & .12 & .06 & .06 & .07 & .07 & .10 & .09 \\
\hline otorhinolaryngology & .02 & .03 & .05 & .03 & .03 & .04 & .02 & .02 \\
\hline paediatrics & .16 & 14 & .17 & .13 & .12 & .11 & .15 & .16 \\
\hline pulmonary & .12 & .09 & .17 & .12 & .09 & .11 & - & - \\
\hline neurology & .08 & .07 & .11 & .08 & .08 & .09 & .07 & .06 \\
\hline ophthaimology & .02 & .02 & .03 & .03 & .01 & .02 & .02 & .02 \\
\hline orthopaedics & .10 & .07 & .06 & .07 & .09 & .07 & - & .04 \\
\hline urology & .06 & .07 & .09 & .08 & .08 & .08 & - & \\
\hline total & .086 & .078 & .092 & .075 & .078 & .069 & .068 & .067 \\
\hline
\end{tabular}

The ratio between the admission rate and the number of visits to outpatient departments of the Flevo hospital was 0.086 in 1991 and 0.078 in 1993 . For every 1000 visits to outpatient departments in 199 there were 86 persons admitted to the Flevo hospital. This was less than the 92 admissions per 1000 outpatient visits in the St. Antonius hospital. Compared to the outpatient/admission ratio for the hospitals in Purmerend and Zoetermeer, the ratio for the Flevo hospital was relatively high. Between 1991 and 1993 the relative share of visits to outpatient departments increased for all four hospitals in 1993, illustrating a more general tendency towards substitution of inpatient to outpatient care. This increase was the largest in the St. Antonius hospital and of minor importance in 't Lange Land hospital. Compared to the three other hospitals, the Flevo hospital had the highest admittance/visits to outpatient departrnents ratio in 1993, where the lowest ratio was to be expected. In this respect, no indications were found for substitution of care from inpatient to outpatient services. 
With respect to the number of first visits to outpatient departments and follow-up appointments, data for the Flevo hospital show that in 1991 approximately $39 \%$ of all contacts with outpatient departments referred to first contacts, albeit the three other hospitals showed percentages between $25 \%$ and $30 \%$. For subsequent years the percentage of first contacts with outpatient departments in Almere remained high, being $34.7 \%$ in 1993 and $37.1 \%$ in 1995 (Flevo Hospital, 1994/1996), whereas the three other hospital showed corresponding figures for 1993 of $26.1 \%$ (St. Antonius Hospital), $29.1 \%$ ("t Lange land Hospital), and $24.8 \%$ (Waterland Hospital). A relatively high percentage of first contacts to outpatient departments could indicate that the Flevo hospital is maintaining a policy of referring patients back to the GP in an early stage, which is in line with the original goal of limiting the use of hospital facilities.

In addition to the admission/visits to outpatient departments ratios, Table 7.3 presents information about the share of outpatient care in the various function departments. In the Flevo hospital, the relatively high number of births in the short stay delivery room(s) and a small share of outpatient procedures in the physiotherapy department, in combination with a relatively small number of patients visiting the physiotherapy department of the Flevo hospital, are remarkable. Both findings are in line with the agreements made in Almere between the PHC-sector and the hospital sector, as part of the AHCDP. Where in other hospitais situations vary from immediate referrals to the PHC sector as soon as the situation allows to all follow-up sessions in the hospital itself, in Almere patients are usually referred to the physiotherapists in the health centres for physiotherapy following hospital admission. In 1992 the share of outpatient treatment for physiotherapy in the Flevo hospital increased to $26 \%$, so that the functioning of the agreements in the somewhat longer term has to be called into question.

With respect to the relatively high number of births in the delivery rooms of the Flevo hospital, cooperation between the obstetrics/gynaecology department of the hospital and the midwives in Almere has been characterized as 'extremely good' (Stichting EVA, 1994). Although detailed information is missing, probably most of these births in the Flevo hospital took place with midwives involved in the actual deliverance of the baby. Another possible explanation is that the percentage of home deliveries in the three towns is relatively high when compared to Almere, although the absolute numbers of hospital deliveries in the three hospitals do not support this hypothesis. In a way, the situation in Almere reflects the unique situation in the Netherlands of a large percentage of home births of approximately $30 \%$, while somewhat less than $70 \%$ of all births take place in hospital (Wiegers and Berghs, 1994; Wiegers, 1997). When the decision is made for a home delivery, over $70 \%$ of these deliveries are done by midwives and less than $30 \%$ by general practitioners. In hospital, between 30 and $35 \%$ of all short-stay deliveries take place under the responsibility of a midwife (CBS, 1994). 
Table 7.3 The use of different function departments in the Flevo hospital and three other hospitals in 1991. (Source: Annual reports Flevo hospital, St. Antonius hospital, Waterland hospital and 't Lange Land hospital, 1991)

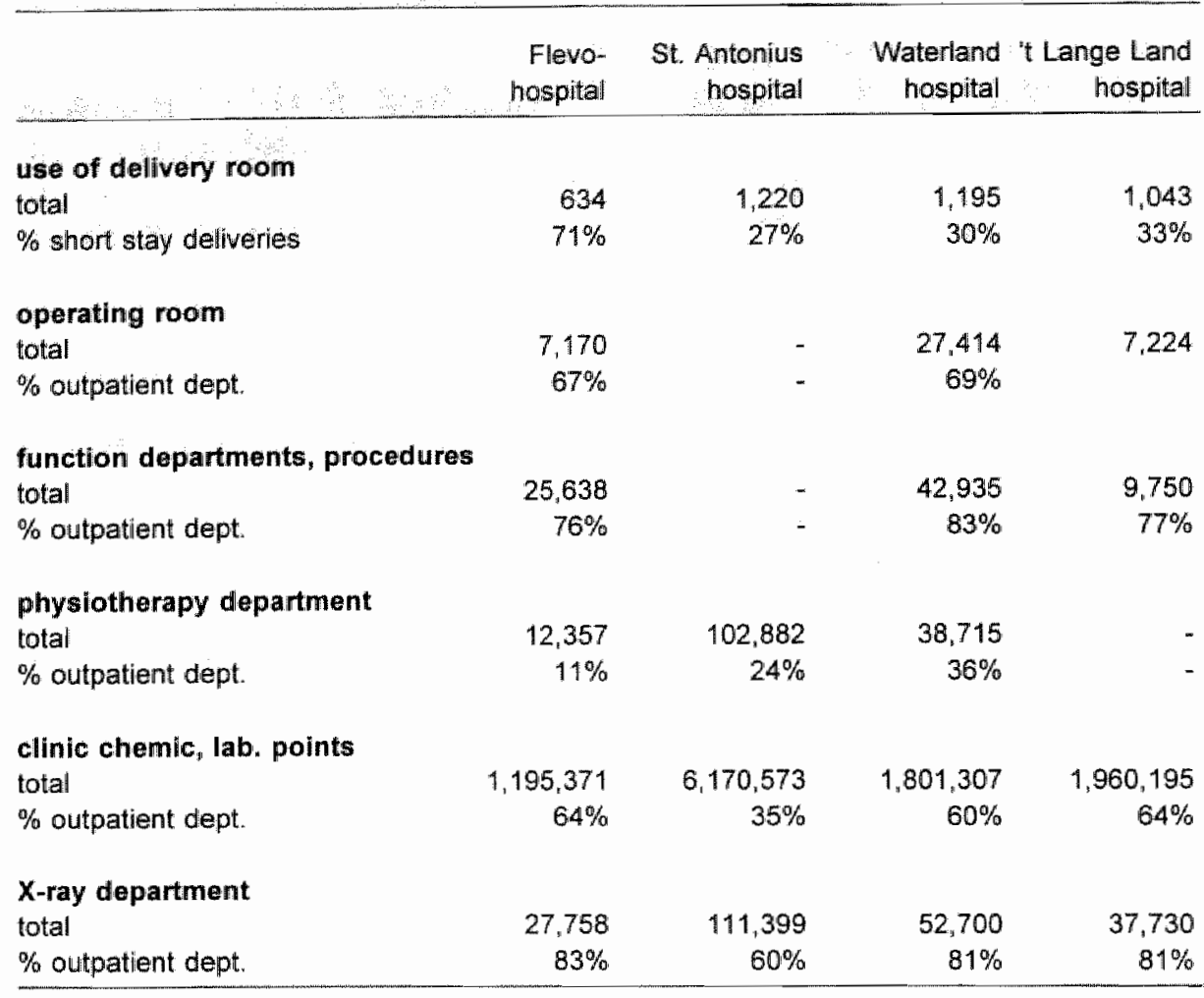

Due to the fact that not all the hospitals present their figures in a similar way, a more detailed comparison between Almere and the three other towns was not possible, and some cells in Table 7.3 were left blank.

Although some departments in the Flevo hospital in Almere, such as the gynaecology and physiotherapy department, were successfull in reaching a shift from in- to outpatient care, the Flevo hospital did not succeed in profiling itself during its first years after the opening as an institution in which inpatient care was replaced by outpatient care.

On the basis of the data presented in this sub-section, hypothesis $H 7.1$ has to be rejected. 


\subsubsection{Substitution from clinical care to day treatment}

In Almere, in comparison with other hospitals in the Netherlands, day treatment instead of hospital admission is used relatively frequently. (Hypothesis H7.2)

The answer on hypothesis $\mathrm{H} 7.2$ will de based on the yearly reports of the Flevo hospital in Almere, and on similar reports from three other hospitals in cities comparable to Almere.

The Flevo hospital was especially designed to facilitate substitution of care by having a relatively large number of outpatient and day treatment facilities. To answer the question whether the 15 day care beds were used optimally, the same restrictions are applicable as in sub-section 7.1.1.

Table 7.4 The use of day treatment facilities in the Flevo hospital and three other hospitals in 1992 and 1995, in percentages. (Source: Annual reports Flevo hospital, St. Antonius hospital, Waterland hospital and 't Lange Land hospital, 1992/1995)

\begin{tabular}{rrrr}
$\begin{array}{r}\text { Flevo- } \\
\text { hospital }\end{array}$ & $\begin{array}{r}\text { St. Antonius } \\
\text { hospital }\end{array}$ & $\begin{array}{r}\text { Waterland 't Lange Land } \\
\text { hospital } \\
\text { hospital }\end{array}$ \\
\hline
\end{tabular}

day treatment,

as \% of total number of admissions

\begin{tabular}{lllll}
1992 & 30 & 43 & 34 & 60 \\
1995 & 38 & 36 & 41 & $? ?$ \\
\hline
\end{tabular}

Table 7.4 illustrates that in 1992 the total number of admissions for day care treatment in the Flevo hospital ( 1882 admissions) was approximately $30 \%$ of the total number of hospital. In 1995 the number of hospital admissions for the Flevo hospital had increased to 7993 , while 2986 patients $(38 \%)$ visited the hospital for day-time surgery. Compared to the three other hospitals the share of day treatments in the Flevo hospital in 1992 was relatively low. In 1995, the relative share of day-time surgery in Almere was almost equal to the St. Antonius hospital, but remained low compared to the hospitals in Lelystad and Purmerend. For all hospitals in the Netherlands, the admission rate for day time surgery between 1990 and 1994 increased from $27 \%$ to $37 \%$ (CBS, 1996). Figures for Almere were almost equal to these national figures.

Hypothesis 7.2 , referring to a relatively high share of day care treatment within the Flevo hospital as compared to other hospitals in the Netherlands, has to be rejected. 


\subsubsection{Substitution from Nursing Home to Old People's home}

In Almere, in comparison with the situation in the rest of the Netherlands, a relatively high number of the people needing care use the services of an Old People's home and relatively few use a nursing home. (Hypothesis H7.3)

Due to the scarcity of data hypothesis $\mathrm{H} 7.3$ cannot be tested. Research on the functioning of the combined nursing and old people's home 'De Kiekendief' showed that the perceived health care status of the residents of the old people's home department was somewhat better compared to the average old people's home resident in the Netherlands (Fahrenfort and Plaisier, 1993). However, with respect to the inhabitants of the nursing home section of 'De Kiekendief' differences with national figures were insignificant.

\subsubsection{Referral within the intramural sector}

In Almere, in comparison with other hospitals in the Netherlands, relatively few patients are referred from one medical specialist to another. (Hypothesis H7.4)

A preliminary answer on hypothesis $\mathrm{H} 7.4$ is based on the study on the number of contacts and referrals in general practice in Almere (Study 86-3).

Recent data on the number of referrals within the hospital sector are missing, both for Almere as well as for the Netherlands. Some information about the number of referrals from one medical specialist to another can be derived from the 1985 studly on the referral policy of general practitioners in Almere. When classified, approximately $3 \%$ of all registered referrais were categorized as 'from specialist A to specialist B.' In Lelystad the corresponding percentage in 1982 was $2 \%$ (Dopheide and Nijhout, 1984).

On the basis of this limited amount of information, hypothesis $\mathrm{H} 7.4$ cannot be confirmed.

\subsubsection{Shortening the duration of stay in intramural facilities}

In Almere, in comparison with other hospitals in the Netherlands, the length of the period people stay in hospital is relatively short. (Hypothesis H7.5)

Hypothesis $\mathrm{H} 7.5$ will be tested against data from the series of studies about the utilization of hospital services by the Almere population (Study 87-1, 87-2, 88-1, $90-1,92-1,93-5)$, with additional information coming from yearly reports 
published by the Flevo hospital and five hospitals in towns comparable to Almere.

One of the goals of the AHCDP explicitly stated at the start of the project was to bring down the utilization of in-patient hospital facilities by the population of Almere. Planned instruments to achieve this goal, aside substitution from in- to outpatient care, were (1) a relatively small hospital, resulting in the availability of 3 beds per 1,000 inhabitants in 1993, (2) an adequate referral policy, and (3) shortening the length of hospital stay. In this subsection we focus on length of stay, using data that cover the period between 1986 and 1995.

With figures for the Netherlands standardized for age/gender differences, the average length of stay per hospital admission in 1991 for the population of Almere was slightly lower than these standardized national figures. This difference, however, was consistent over the period between 1985 and 1991 (Sixma et al, 1993), as shown in figure 7.1.

Figure 7.1 Length of stay in hospital during the period 1986-1991 in Almere and the Netherlands (standardized), average number of days per admission (Source: Studies 87-1, 87-2, 88-1, 90-1, 92-1, 93-5)

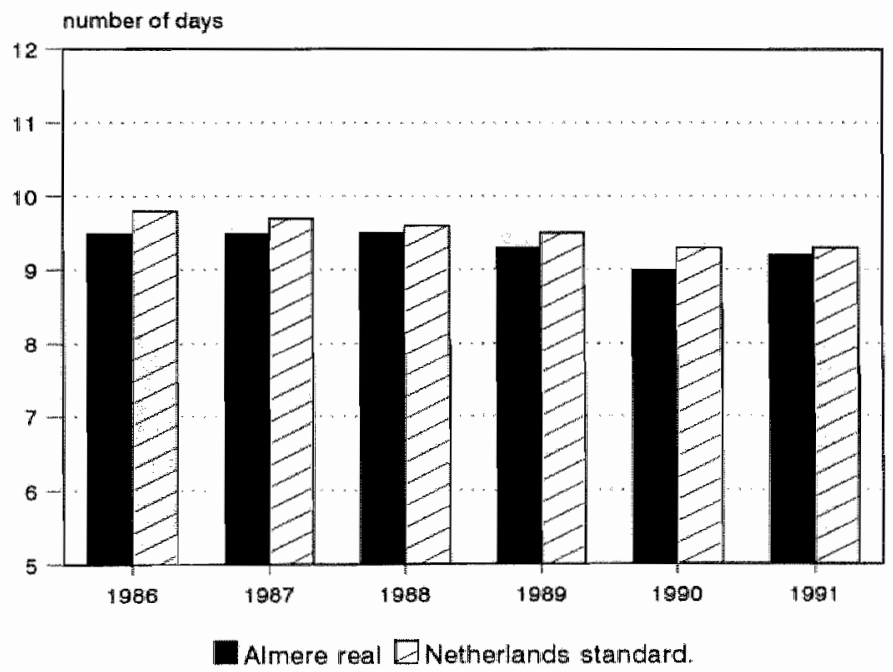

For the period since 1991 comparative data are missing. The average length of stay in hospital for inhabitants of Almere, which made use of facilities outside Almere, are not part of the census data collected at the national level. Also, information for the Netherlands is only available in an unstandardized way. Information that is available is, either at the level of individual hospitals (e.g the hospitals in Almere, Nieuwegein, Purmerend, Zoetermeer and Lelystad) or refers 
to the unstandardized situation in the Netherlands. In comparing data about the average length of stay in hospital on the basis of individual hospitals, possible differences with respect to patient populations, case mix and the facilities offered had to be neglected.

The average length of stay in the Flevo hospital was 9.0 days in 1991 and 8.7 days in 1992. For the IJsselmeer hospitals in Lelystad and Dronten, the Waterland hospital in Purmerend, the 't Lange Land hospital in Zoetermeer and the St. Antonius hospital in Nieuwegein the 1991 figures were 9.4 days, 8.7 days, 9.3 days and 10.6 days respectively. Between 1991 and 1995 all hospitals managed to bring down the average stay in hospital. This decrease was strongest in 't Lange Land hospital in Zoetermeer and the Flevo hospital in Almere. Also on the national level the average length of stay in hospital over the 1992 - 1995 period showed a constant decrease from 10.7 days in 1992 to 10.0 days in 1994 (CBS, 1996).

Figure 7.2 Length of stay in hospital between 1991 and 1995, in the Flevo hospital in Almere and the Netherlands (unstandardized), average number of days per admission (Source: annual reports Flevo hospital; CBS, 1993-1996)

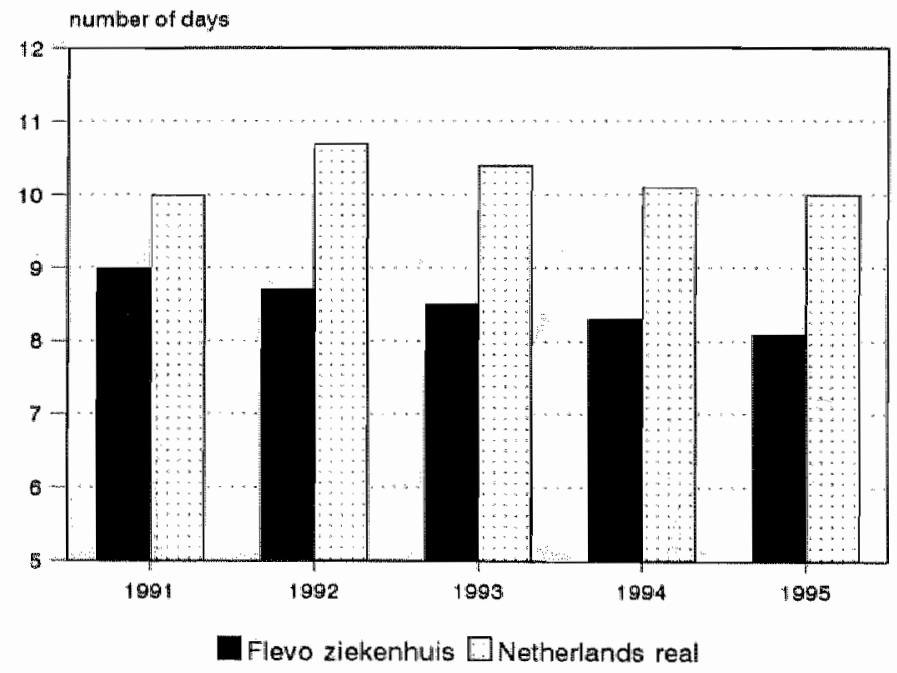

For the Flevo hospital in Almere more detailed information concerning the average length of stay per specialism are available for 1991 and 1992 (see Table 7.5). These figures for this particular hospital can be compared with the situation for the Netherlands as a whole. 
Table 7.5 Length of stay in hospital in the Flevo hospital and the Netherlands in 1991; average number of days per specialism (Source: Annual reports Flevo hospital 1991/1992; Study 93-5)

\begin{tabular}{lrrr}
\hline & \multicolumn{2}{c}{ Flevo hospital } & Netherlands \\
Specialism & 1991 & 1992 & 1991 \\
\hline Internal medicine & 14.5 & 14.7 & 14.2 \\
Lung disease and tuberculoses & 13.5 & 14.5 & 15.2 \\
Cardiology & 9.8 & 8.8 & 8.6 \\
Paediatrics & 7.9 & 6.8 & 9.9 \\
Surgery & 8.2 & 8.4 & 11.0 \\
Orthopaedics & 10.7 & 10.5 & 11.2 \\
Urology & 8.0 & 6.9 & 8.7 \\
Plastic surgery & - & - & 5.8 \\
Neurosurgery & - & - & 12.6 \\
Cardiopulmonic surgery & - & - & 13.8 \\
Ophthalmology & 3.6 & 3.2 & 5.2 \\
Otorhinolaryngology & 5.2 & 5.1 & 4.6 \\
Dentistry & - & 3.5 & 5.0 \\
Obstetrics/gynaecology & 5.5 & 5.8 & 5.8 \\
Neurology & 13.8 & 13.7 & 15.1 \\
Psychiatry &.- & - & 39.7 \\
\hline
\end{tabular}

Compared to national data, the average length of stay in the Fllevo hospital was relatively long for cardiology and otorhinolaryngology patients. Relatively short lengths of stay can be noticed for patients of the Flevo hospital admitted to the departments of lung disease, paediatrics, general surgery, ophthalmology and neurology.

In summary, hypothesis $\mathrm{H} 7.5$ was confirmed on the basis of the available data. Although differences between Almere and (standardized) national data are small, they are in line with the ideas formulated at the start of the AHCDP.

\subsection{Substitution from secondary to primary care}

Substitution of care activities in hospital are related to the functioning of primary care services. This relationship is a two-edged sword. A limited supply of hospital facilities will facilitate PHC-services to retain some of the ground that was lost due to the more general trend towards hospitalization (e.g. emergency care, diagnostic services). The complement, that a broader task profile of primary care might result in a decrease in the use of hospital services, is just as true. In this section both hospital admissions and the functioning of primary care services in Almere are discussed. The focus will be on (1) the number of hospital admissions of inhabitants of Almere, (2) the number of interventions carried out in the hospital sector, (3) referral rates of general practitioners, (4) the number of interventions carried out in primary care, (5) the emergency care 
function in Almere, and (6) the functioning of the nursing-and old people's home.

\subsubsection{Hospital admissions}

In Almere, in comparison with the Netherlands as a whole, the number of hospital admissions is relatively low. (Hypothesis H7.6)

Hypothesis $\mathrm{H} 7.6$ will be answered on the basis of the series of studies about the utilization of hospital services by the population of Almere (Study 87-1, 87-2, 88$1,90-1,92-1,93-5)$. Additionally, yearly reports by the Flevo hospital and the Central Bureau of Statistics (CBS, 1996) will be used.

Probably one of the most effective ways of achieving substitution of care is by restricting the number of non-acute hospital admissions. The instrument to achieve this goal - a hospital with limited bed capacity - was actually implemented when the Flevo hospital opened in 1991. However, even with the hospital realized, a certain outflow of patients (e.g. to specialized hospitals of specific departments that are not available in a general hospital) can always be expected, and actually did occur (see Table 7.1). Figure 7.3 illustrates that the admissions coefficient for inhabitants of Almere, with data for the Netherlands being standardized, remained relatively high over the entire 1982 - 1991 period.

Figure 7.3 Number of admissions in hospitals of inhabitants of Almere between 1982 and 1992 , numbers per 1000 inhabitants

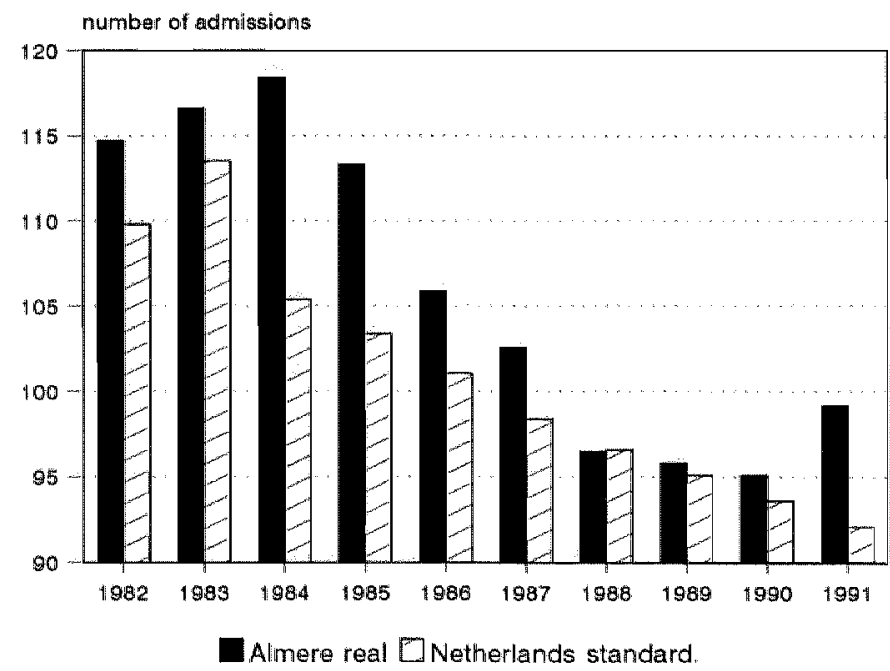


Between 1984 - one year after the start of the AHCDP - and 1990, the number of hospital admissions per 1000 inhabitants gradually decreased in Almere as well as in the Netherlands. However, the decline in Almere was more pronounced than in the rest of the Netherlands. In Almere, the number of hospital admissions per 100,000 inhabitants in 1990 was $80 \%$ of the admission rate in 1984. The corresponding figure for the Netherlands during the same period - after adjustment for differences between the two populations in age and sex distributions - was $89 \%$. At the beginning of the health care experiment in Almere, the hospital admission rate for the population of the town was about $12 \%$ higher than the adjusted admission rate in the Netherlands. In 1990, the difference between Almere and the Netherlands was much smaller and less than $1 \%$. In 1991, however, which was the year that the hospital in Almere was opened, there was a $4 \%$ increase in the number of hospital admissions.

No systematic research on the use of hospital facilities by the population of Almere was conducted after 1991, following the decision to end the demonstration project. Therefore, corresponding data for 1992 and subsequent years, with standardized figures for the Netherlands, were not available. However, unstandardized (=real) data for the period between 1982 and 1995 , were available and are shown in figure 7.4.

Figure 7.4 Number of admissions in hospitals of inhabitants of Almere and the Netherlands (unstandardized figures) between 1982 and 1995; numbers per 1000 inhabitants (Source: NZI, 1992-1996; CBS, 1996)

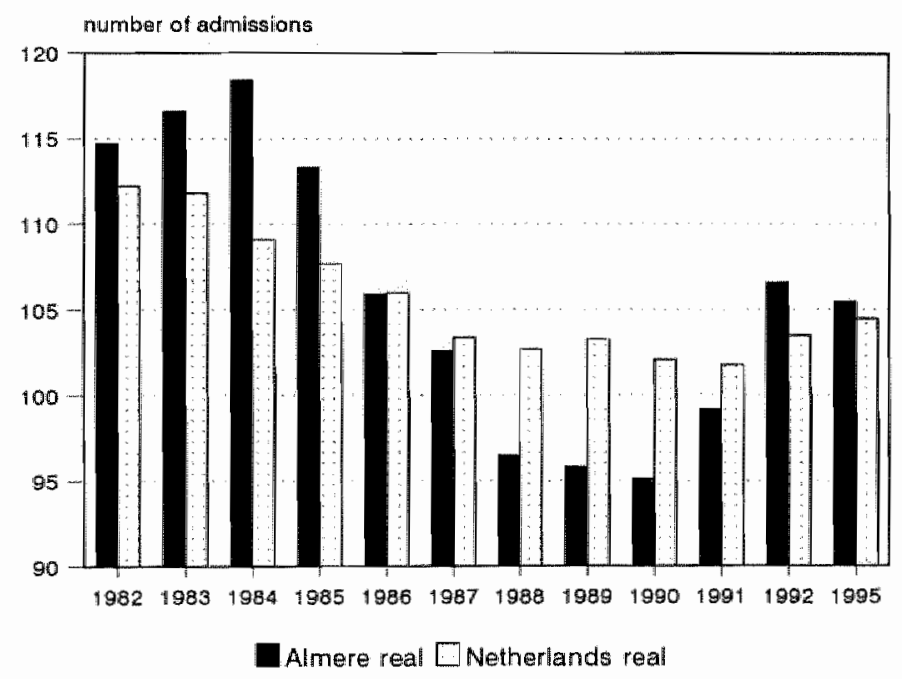


Also available are figures per specialism for the admissions to the Flevo hospital (1991 and 1993), admissions of all Almere patients (1991) and the (standardized) number of admissions per specialism in the Netherlands (1991). Table 7.6 shows significant differences between the different specialisms.

Table 7.6 Number of hospital admissions for the Flevo hospital (1991 and 1993), all inhabitants of Almere (1991) and the Netherlands (standardized, 1991), per specialism. (Source: Study 93-5).

\begin{tabular}{lrrrr}
\hline & $\begin{array}{r}\text { Flevo ziekenhuis } \\
\text { realized }\end{array}$ & $\begin{array}{r}\text { Almere total } \\
\text { realized } \\
1993\end{array}$ & $\begin{array}{r}\text { Netherlands } \\
\text { standardized } \\
1991\end{array}$ \\
\hline Internal medicine & 1991 & 1993 & 995 & 775 \\
Lung disease & 490 & 727 & 226 & 206 \\
Cardiology & 141 & 222 & 801 & 503 \\
Paediatrics & 581 & 1,139 & 945 & 735 \\
Surgery & 687 & 768 & 1,174 & 1,177 \\
Orthopaedics & 713 & 1,287 & 549 & 471 \\
Urology & 270 & 414 & 279 & 270 \\
Plastic surgery & 151 & 265 & 142 & 147 \\
Neuro surgery & - & - & 136 & 96 \\
Ophthalmology & 138 & 236 & 222 & 193 \\
Otorhinolaryngology & 80 & 192 & 300 & 414 \\
Obstetrics/gynaecology & 915 & 1,388 & 1,647 & 1,755 \\
Neurology & 262 & 283 & 434 & 449 \\
Other specialisms & 6 & 58 & 239 & 316 \\
& & & & \\
Total & 4,434 & 6,979 & 8,089 & 7,507 \\
\hline
\end{tabular}

For internal medicine $(+28 \%)$, cardiology $(+60 \%)$, paediatrics $(+29 \%)$, orthopaedics $(+17 \%)$, and neuro surgery $(+42 \%)$ the actual numbers of admissions were significantly higher than the (standardized) admission for the Netherlands. For Almere, the numbers of admissions for the otorhinolaryngology department were relatively low as compared to the rest of the Netherlands. Regarding other specialisms, differences between Almere and other hospitals in the Netherlands were small.

After the opening of the Flevo hospital on 6 March 1991, this hospital accounted for approximately $2 / 3$ of all hospital admissions of the Almere population. During 1991, there were relatively high referral rates to hospitals outside Almere for the departments of internal medicine $(+48 \%)$ orthopaedics $(+40 \%)$ and otorhinolaryngology $(+68 \%)$. For cardiology and paediatrics there was an above average flow of patients to the Flevo ziekenhuis hospital. Trends in admission rates for the years between 1984 and 1991, with respect to five important specialisms, are presented in figure 7.5 . 
Figure 7.5 Number of admissions per 1000 inhabitants of Almere and the Netherlands (standardized) concerning five of the largest specialisms, between 1984 and 1991. (Source: Study 93-5)

Obstetries/gynaecollogy'

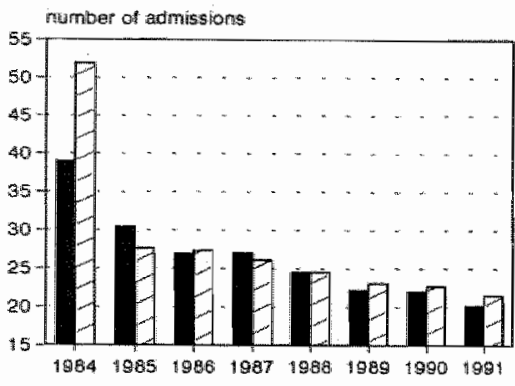

Internal medicine

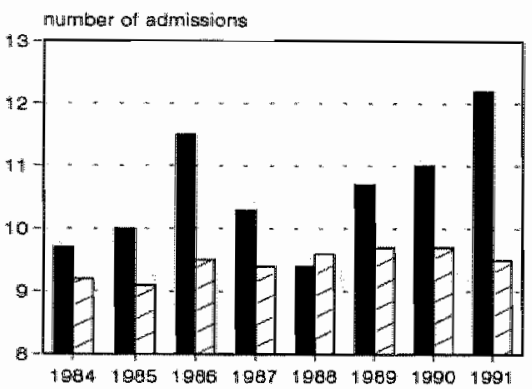

Cardiology

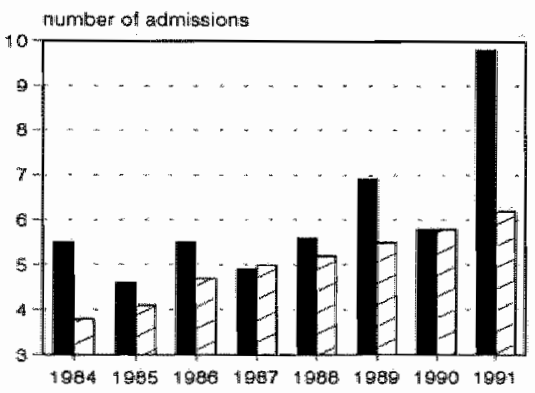

Surgery
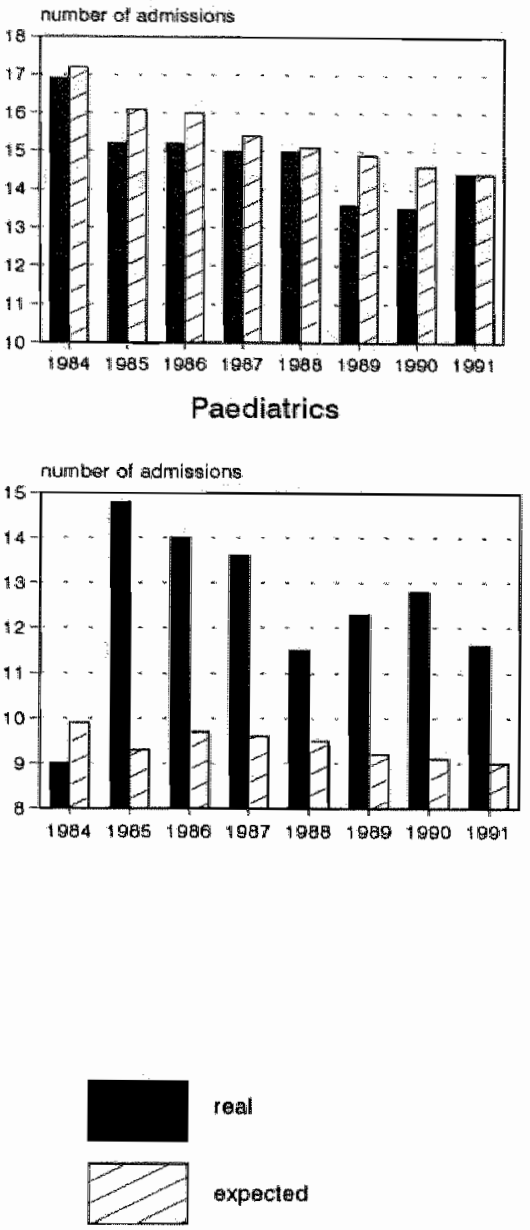

real

expected

Obstetrics shows, both in the numbers anticipated and the actual admissions, a decreasing trend with anticipated and actual figures closely in line. For surgery, the step-wise falling trend in the actual numbers of admissions was broken in 1991, while the expected numbers decreased more smoothly. The admissions coefficient for internal medicine and paediatrics fluctuated, with figures for Almere being considerably higher than the (age standardized) figures for the Netherlands. Finally, for cardiology a rising trend in the standardized 
figures for the Netherlands can be noticed. The actual number of admissions from the inhabitants of Almere varied from year to year, with a trend towards a somewhat higher admission rate.

In summary, data that refer to the number of hospital admissions per 1,000 inhabitants and that take into account the atypical population distribution in Almere, suggest that hypothesis H7.7 has to be rejected. Hospital admission rates for Almere, as compared to the remainder of the Netherlands, were relatively high during the entire period between 1993 and 1993, where relatively low admission rates were assumed.

\subsubsection{Restriction of the number of interventions in hospital}

In Almere, in comparison with the Netherlands as a whole, relatively few interventions take place in hospital and outpatient clinics. (Hypothesis 47.7)

Because relevant data with respect to hypothesis $\mathrm{H} 7.7$ are missing, this hypothesis could not be tested.

\subsubsection{Increasing the number of interventions in primary care}

In Almere, in comparison with the rest of Netherlands, the number of interventions carried out in primary care is relatively high. (Hypothesis H7. 8)

Hypothesis $\mathrm{H} 7.8$ will be answered on the basis of data from the study about morbidity and interventions in general practice in Almere (Study 92-4). These data will be supplemented with the data from the yearly reports on social work in Almere (Brouwer, 1993-1995).

To achieve substitution of care, the position of the general practitioner is of paramount importance, both with respect to the number of interventions carried out in daily practice and his/her position as gatekeeper for the use of hospital and other intramural services. In Table 7.7 the number of contacts and interventions carried out in general practice in Almere are compared with the average Dutch GPs. Information about the numbers of interventions per 1,000 patients provides an overview of the differences in absolute numbers and is in line with the common way data about interventions in general practice are published. The number of interventions per 1,000 contacts offers more insight into differences in the working style of general practitioners since account is taken of the differences in the number of contacts. 
Table 7.7 Number of contacts and interventions per 1,000 patients and 1,000 contacts in general practices in Almere and the Netherlands (Source: Study 93/4)

\section{Per 1,000 registered patients}

\section{Number of contacts}

- total

- with GP

\section{$1,278.4$}

915.9

kind of contact

- consultation

- home visit

- between appointments

- by telephone

- other and unknown

- $>10$ minutes

\section{interventions}

- diagnostics, in the practice

- diagnostics, external

- treatment in practice

- prescription of medicine

- referral secondary care

- referral primary care

- follow-up appointment

\section{Per 1,000 contacts}

\section{Niumber of contacts}

- total

- with GP

Kind of encounter

- consultation

- home visit

- between appointments

- by telephone

- other

$\rightarrow 10$ minutes*

\section{interventions}

- diagnostics, in the practice

- diagnostic external

- treatment in practice

- prescription medicine

- referral secondary care

- referral primary care

- follow-up appointiment
748.2

106.2

146.5

239.3

38.2

236.4

762.3

91.6

924.4

743.8

70.1

48.0

29.9
$1,000.0$

716.5

585.4

83.1

114.6

187.2

29.9

184.8

596.3

71.7

723.1

581.9

54.9

37.5

22.6
$1,170.0$

813.7

689.6

135.7

126.8

174.3

43.5

199.5

658.8

66.4

692.1

750.6

71.8

36.4

16.2
$1,000.0$

695.4

589.4

116.0

108.4

148.9

37.2

170.6

563,1

56.8

591.5

641.5

61.4

31.1

13.8

* only GP contacts 
Per 1,000 contacts, as compared to average general practitioner in the Netherlands, general practitioners in Almere performed more diagnostic services, had less patients being helped by other members of the staff, had higher referral rates to other primary care disciplines, consulted more frequently with other care providers, prescribed less medication and referred less frequently to medical specialists. These data are in line with the profile that can be derived from the goals of the AHCDP. However, at the same time there are more contacts per 1,000 patients, and as a consequence the absolute number of prescriptions and referrals to medical specialists (per 1,000 patients) did not differ significantly from the numbers for the average Dutch GP.

Also, information is available about the way social work (Algemeen Maatschappelijk Werk) was functioning in Almere and in the Netherlands in general. Data, that refer to the $1991-1994$ period, are shown in Table 7.8. Due to a change in the way interventions were categorized and the absence of a uniform registration form for both populations, some "?' are included.

Table 7.8 Number of contacts, issues and care disciplines of social work in Almere and the Netherlands. (Source: AMW-Almere, 1991-1994)

\begin{tabular}{|c|c|c|c|c|c|c|}
\hline & \multicolumn{4}{|c|}{$\begin{array}{l}\text { social work } \\
\text { Almere }\end{array}$} & \multicolumn{2}{|c|}{$\begin{array}{l}\text { socilal work } \\
\text { Netherlands }\end{array}$} \\
\hline & 1991 & 1992 & 1993 & 1994 & $1991 / 92$ & $1993 / 94$ \\
\hline \multicolumn{7}{|l|}{ Number of contacts } \\
\hline clients per fte & 239 & 228 & 225 & 242 & 209 & $?$ \\
\hline clients, $\%$ of population & 3.8 & 3.5 & 3.7 & 3.5 & 3.1 & 3.2 \\
\hline \multicolumn{7}{|l|}{ Kind of issues } \\
\hline$\%$ relational complaints & 41 & 42 & 35 & 31 & 31 & 27 \\
\hline$\%$ material complaints & 14 & 12 & 11 & 11 & 33 & 26 \\
\hline$\%$ cultural complaints & 2 & 1 & 2 & 2 & 3 & 1 \\
\hline \multicolumn{7}{|c|}{$\%$ complaints concerning health } \\
\hline and individual problems & 43 & 45 & 53 & 56 & 33 & 46 \\
\hline \multicolumn{7}{|l|}{ Kind of intervention } \\
\hline$\%$ counselling & 76 & 64 & 48 & 45 & 50 & 47 \\
\hline$\%$ support & $?$ & 13 & 15 & 17 & $?$ & 10 \\
\hline$\%$ information + advice & 11 & 11 & 10 & 10 & 17 & 13 \\
\hline$\%$ clarification & 4 & 4 & 17 & 19 & 12 & 15 \\
\hline$\%$ other & $?$ & 8 & 10 & 9 & $?$ & 15 \\
\hline
\end{tabular}

The utilization of the social work function in Almere was relatively high, especially with regard to relational problems and perceived psycho-social health/individual problems. In Almere relatively many social work contacts were initiated by the GP (an estimated $50 \%$ in 1991, and $54 \%$ in 1992), which can be 
regarded as a result of the concentration of $\mathrm{PHC}$ services in multidisciplinary health centres.

In summary, hypothesis H7.6, that in Almere the number of services supplied by primary health care workers, is confirmed with respect to general practitioners and social workers.

\subsubsection{Emergency care in Almere}

In Almere, in comparison with the Netherlands as a whole, relatively many First Aid procedures are carried out within primary care. (Hypothesis H7.9)

The answer on hypothesis $\mathrm{H} 7.9$ will be based on data from the studies about the emergency care function in Almere (Study $87-3$ and Study 92-2). Additional information was provided by the PHC emergency centres in Almere and by the A\&E department of the Flevo hospital.

Substitution of care between hospital and the PHC-sector, includes the actual transfer of functions and services from hospital to the PHC-sector, like the treatment of emergency patients. The results of a study regarding the emergency care function in Almere, before and after the opening of the Flevo hospitall with additional information from both the hospital's A\&E department and the $\mathrm{PHC}$-emergency centres, are presented in figure 7.6 , figure 7.7 and figure 7.8 .

Data shown in figure 7.6 and 7.7 illustrate that after the opening of the Flevo hospital Almere primary care institutions continued to treat the largest share of trauma patients, in total (figure 7.6) as well as for emergency treatment outside office hours (figure 7.7 ) only. The number of patients reporting to the health centres before and after opening of the hospital, remained about the same. However, the number of patients going directly to the new $A$ \& E Department, without consulting their GP first, increases from an average of 18.8 patients per week before 6 March 1991 to 71.8 after opening of the hospital. Before March 1991, about $85 \%$ of all doctor-patient contacts recorded in general practice could adequately be handled by the GP. After opening of the hospital in Almere, this percentage increased to about 90 per cent. The number of patients treated in hospital for (minor) injuries increases from 38 to 84.6 on a weekly basis (Sixma and Hackenitz, 1992).

Figure 7.7 illustrates that, before March 1991, outside the office hours approximately 83 per cent of all patients that needed emergency care for minor injuries attended one of the two specialized health centres, while the remaining 17 per cent went directly to the A \& E Department of a hospital outside Allmere. 
After opening of the Flevo hospital, the percentage of people going to primary care emergency centres dropped from 83 to 65 per cent. The remaining 35 per cent focused almost entirely on the new hospital in Almere, although about $10 \%$ of the 'self-referrals' still went to hospitals outside Almere, mostly because they were not aware there was free access to the hospital in Almere.

Figure 7.6 Patient flows of emergency care patients before and after the opening of the Flevo hospital in Almere, total number of patients on a weekly basis. (Source: 92-2)

Health care centre/First Ald

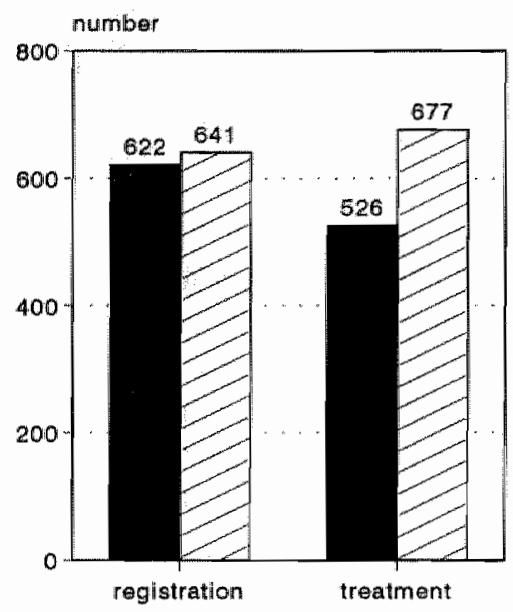

Hospital

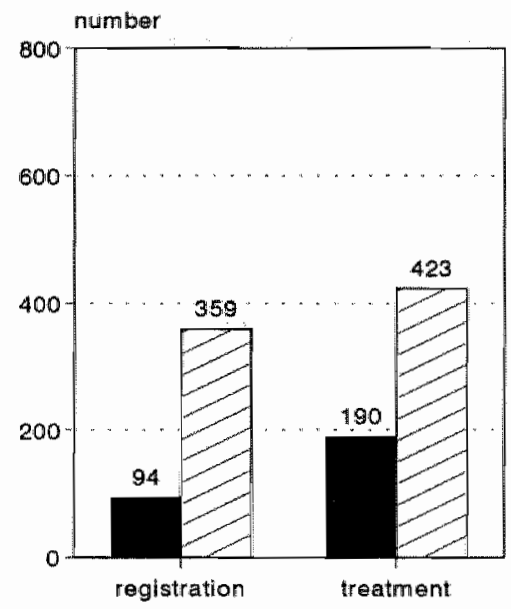

belon G March 7991

1091

Figure 7.6 and 7.7 also show that there is a large difference in the absolute number of doctor-patient contacts for emergency before and after the opening of the hospital. Maybe extra facilities such as a nearby A \& E Department in a hospital setting resulted in more people looking for professional help with minor injuries. Partial support for this hypothesis is found in the comparison between the type of complaints presented under both conditions (Sixma \& de Bakker, 1996). For the period between January 1991 and July 1992 the percentage of people going directly to the A\&E Department of the Flevo hospital slightly increased, which is shown in figure 7.8. Due to differences in the registration systems of both types of services a comparison in absolute numbers is, however, problematic. 
Figure 7.7 Patients reporting to the A\&E department of the Flevo hospital and PHC-emergency centres outside the office hours, absolute numbers on a weekly basis. (Source: $92-2$ )

First Aid

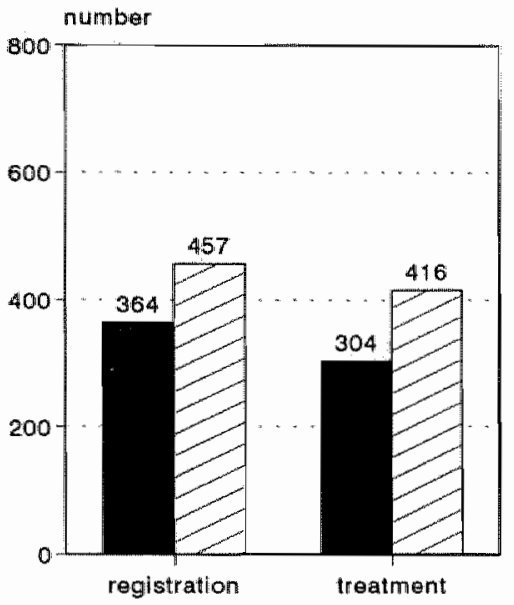

Hospital

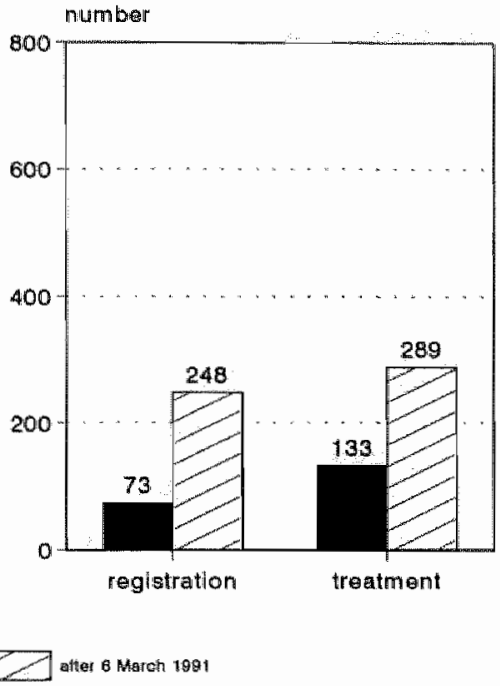

Figure 7.8 Emergency care contacts with PHC-emergency centres and the Flevo hospital between January 1991 and June 1992; absolute numbers (Source: Study 1992/5; APHCF, 1992-1993; Flevo hospital, 1992)

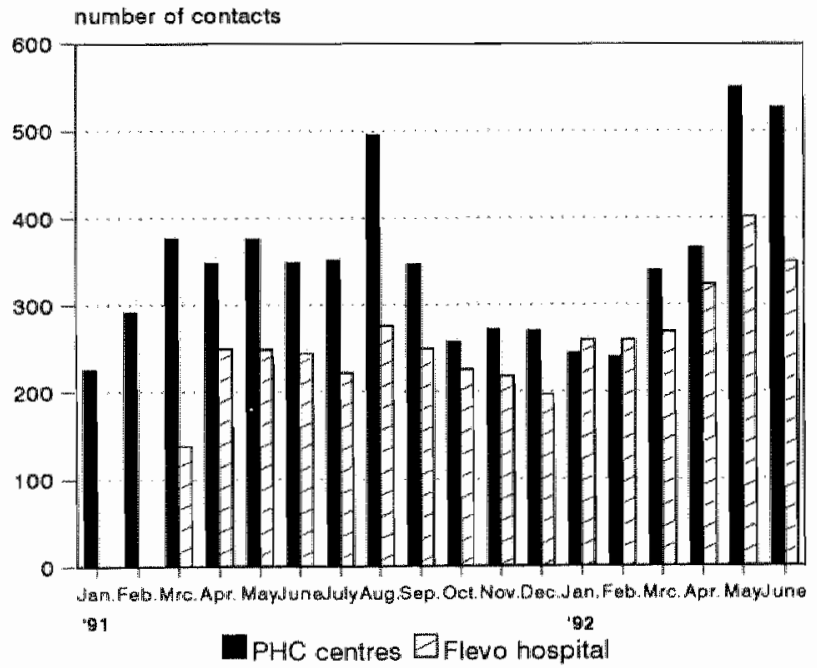


With regard to the emergency care function in Almere, comparable figures of the emergency treatment function in the Netherlands are not available. However, results from other studies (Montfoort, van Galen \& Harris, 1988; Ministry of Welfare, Health and Culture, 1987; Werkgroep Eerste Hulp, 1988) show that at national level approximately $50 \%$ of the emergency care patients visit their GP on the GP-on-call, with the remaining $50 \%$ going directly to the A\&E department of a hospital. However, large differences were found between cities (about $85 \%$ of all emergency patients go directly to the hospital) and rural areas (up to $90 \%$ of all emergency cases are seen in general practice).

The conclusion is therefore, that the AHCDP provided a (partly) successful example that primary care emergency centres form an alternative to the A\&E departments of a hospital. Hypothesis $\mathrm{H} 6.9$ was confirmed.

\subsubsection{Numbers of referrals to medical specialists}

In Almere, in comparison with the Netherlands as a whole, relatively few patients are referred to a medical specialist for treatment. (Hypothesis H7. 10)

Hypothesis $\mathrm{H} 7.10$ will be answered on the basis of data from the study about interventions in general practice in Almere (Study 93-4), with additional data supplied by the ANOZ Gooi Apeldoorn Insurance Group (ANOZ, 1991/1995)

Referral rates to medical specialists can be considered as important indicators for substitution of secondary to primary care. A strengthened system of primary care services, with GPs taking over some of the functions of medical specialists, will result in a relatively low referral rate (and a less frequent use of secondary services).

As was shown in section 7.2 .3 , referral rates per 1,000 contact of general practices in Almere per 1000 contacts were relatively low, while referral rates per 1,000 patients differed slightly from corresponding rates in the Netherlands. In Almere fewer referrals were initiated by the general practitioner, while the percentage of referrals initiated by patients or medical specialists was relatively high. With respect to publicly insured patients longitudinal data on the number of referrals are available for the period between 1984 and 1991. These figures were derived from publications of the ANOZ Gool Apeldoorn Insurance Group, with national data (until 1986) and data referring to the entire working area of the Group being presented as a contrast. Reliable national data for the period between 1987 and 1993 are not available. 
Figure 7.9 Number of referrals to medical specialists for publicly insured patients between 1984 and 1991 (Source: Ziekenfonds Anoz Gooi Apeldoorn groep, 1992)

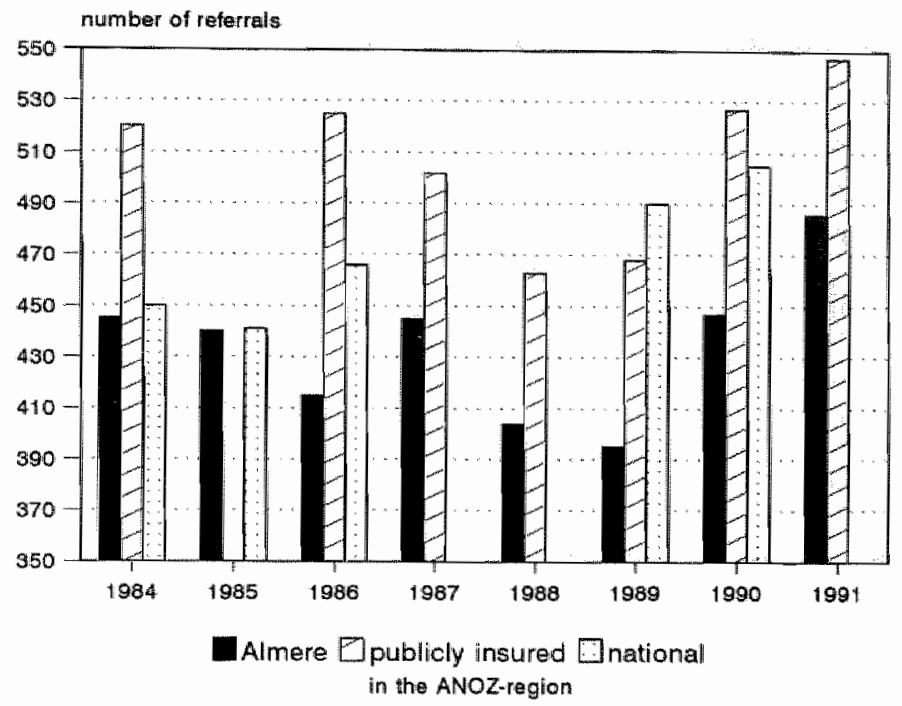

As is shown in figure 7.9 show that referral rates per 1,000 patients in Almere are relatively low when compared to rates for the entire working area of this Insurance Group. The 1991 index for Almere, after correction for the atypical age distribution of the Almere population, was 486 referrals per 1,000 publicly insured patients, where the ANOZ-figure was about 550 referrals per 1000 patients (ANOZ Gooi Apeldoorn Insurance Group, 1992). The national index for 1991, according to data from the Landelijk Informatie Systeem Ziekenfondsen (LISZ), was approximately 485 referrals per 1,000 publicly insured patients.

Regarding the number of referrals per 1,000 patients per specialism, Table 7.9 illustrates that, after standardization, referral rates to otorhinolaryngology, orthopaedics, dermatology and internal medicine are relatively low in Almere. High referral rates applied to the gynaecology and cardiology departments. Except for otorhinolaryngology, all rates in Almere increased between 1990 and 1991 , with cardiology $(+26 \%)$ gynaecology $(+26 \%)$ orthopaedics $(+20 \%)$ and urology $(+20 \%)$ showing the most pronounced increase. 
Table 7.9 Referrals of GPs to medical specialists per 1,000 publicly insured persons in 1991, in Almere (age standardized) and the entire area of the ANOZ Gooi Apeldoorn Group. (Source: Ziekenfonds Anoz Gooi Apeldoorn Groep, 1992)

\begin{tabular}{lrr} 
& $\begin{array}{r}\text { Almere } \\
\text { patients }\end{array}$ & $\begin{array}{r}\text { ANOZ-Group } \\
\text { per, o00 patients }\end{array}$ \\
\hline Ophthalmology & & 104.6 \\
Otorhinolaryngology & 96.9 & 49.0 \\
Surgery & 39.9 & 65.2 \\
Plastic surgery & 58.0 & 6.5 \\
Orthopaedics & 5.7 & 39.4 \\
Urology & 31.6 & 15.2 \\
Gynaecology & 15.7 & 47.4 \\
Neuro surgery & 50.3 & 1.9 \\
Neurrology & 2.7 & 33.5 \\
Dermatology & 28.4 & 37.3 \\
Internal Medicine & 27.7 & 56.1 \\
Paediatrics & 43.4 & 21.0 \\
Gastric complaints and metabolic disease & 16.6 & 1.9 \\
Cardiology & 2.6 & 29.3 \\
Lung disease & 32.2 & 14.8 \\
Rheumatology & 13.0 & 4.2 \\
Revalidation & 2.2 & 3.1 \\
Psychiatry & 2.6 & 9.5 \\
Mouth and dental surgery & 6.0 & 3.9 \\
Anaesthesia & 7.3 & 1.9 \\
ather & 1.7 & 1.5 \\
Total & 1.0 & 547.2 \\
\hline
\end{tabular}

More recent figures for Almere about the number of referrals, with Almere being compared to some other towns included in the working area of the ANOZ Gooi Apeldoorn Group, are available for 1994 and 1995. These data are shown in Table 7.10. In Table 7.10, data for Almere and Huizen were standardized on the basis of the age/gender distribution in that particular region (Gooi and Flevoland). Data for the three other towns were standardized towards the particular age/gender distribution in the geographical area in which they were situated, and therefore results have to be studied with caution. Table 7.10 illustrates that, compared to GPs in the neighbouring town of Huizen, GPs in Almere had relatively low referral rates in 1994 and 1995. Compared to GPs in Leeuwarden, referral rates in Almere were relatively high in both years. When Almere is compared to Apeldoorn and Leerdam, the results differed from year to year. 
Table 7.10 1994 and 1995 referral rates for GPs in Almere and four other towns per 1000 insured persons and with all figures age/gender adjusted per region. (Source: ANOZ Gooi Apeldoorn Group)

\begin{tabular}{|c|c|c|c|c|c|c|c|c|c|c|}
\hline & \multicolumn{2}{|c|}{ Almere } & \multicolumn{2}{|c|}{ Huizen } & \multicolumn{2}{|c|}{ Apeldoorn } & \multicolumn{2}{|c|}{ Leerdam } & \multicolumn{2}{|c|}{ Leeuwarden } \\
\hline & 1994 & 1995 & 1994 & 1995 & 1994 & 1995 & 1994 & 1995 & 1994 & 1995 \\
\hline Ophthalmology & 84 & 77 & 99 & 91 & 63 & 77 & 87 & 94 & 84 & 79 \\
\hline Otorhinolaryngology & 106 & 107 & 106 & 111 & 75 & 102 & 84 & 106 & 79 & 84 \\
\hline Surgery & 71 & 70 & 79 & 77 & 62 & 87 & 59 & 70 & 80 & 74 \\
\hline Plastic surgery & 4 & 4 & 6 & 5 & 6 & 8 & 7 & 7 & 6 & 6 \\
\hline Orthopaedics & 45 & 42 & 49 & 49 & 35 & 45 & 31 & 41 & 42 & 39 \\
\hline Urology & 24 & 21 & 22 & 21 & 15 & 19 & 20 & 21 & 15 & 15 \\
\hline Gynaecology & 68 & 63 & 65 & 62 & 35 & 50 & 39 & 42 & 53 & 48 \\
\hline Neuro surgery & 4 & 4 & 4 & 4 & 2 & 2 & 4 & 3 & 3 & 3 \\
\hline Mental disease & 34 & 31 & 34 & 39 & 34 & 43 & 30 & 34 & 28 & 29 \\
\hline Dermatology & 40 & 35 & 49 & 45 & 24 & 31 & 28 & 34 & 50 & 46 \\
\hline Intern Medicine & 56 & 48 & 78 & 74 & 55 & 71 & 57 & 62 & 57 & 55 \\
\hline Paediatrics & 14 & 13 & 21 & 22 & 9 & 22 & 15 & 16 & 18 & 16 \\
\hline Cardiology & 42 & 40 & 41 & 39 & 33 & 42 & 39 & 45 & 24 & 24 \\
\hline Lung disease & 19 & 17 & 21 & 20 & 17 & 23 & 17 & 20 & 20 & 19 \\
\hline Rheumatology & 6 & 7 & 7 & 7 & 10 & 13 & 10 & 11 & 7 & 8 \\
\hline Revalidation & 5 & 5 & 5 & 5 & 3 & 5 & 6 & 6 & 4 & 4 \\
\hline Psychiatry & 7 & 7 & 9 & 8 & 8 & 10 & 6 & 6 & 4 & 4 \\
\hline other & 22 & 0 & 32 & 0 & 8 & 8 & 7 & 5 & 27 & 0 \\
\hline Total & 651 & 591 & 735 & 679 & 494 & 658 & 546 & 623 & 601 & 553 \\
\hline
\end{tabular}

In summary, the assumption that referral rates in Almere were relatively low has to be rejected. Per 1000 patients there were no significant differences between GPs in Almere and the remainder of the Netherlands. Per 1000 contacts, however, GPs in Almere had relatively low referral rates.

\subsubsection{Primary care contribution in the nursing home}

In Almere, medical and paramedical care for residents of nursing homes is provided by primary care services. (Hypothesis H7.11)

Hypothesis $\mathrm{H} 7.11$ will be answered with data presented in the evaluation study focusing on the combined nursing/old people's home 'De Kiekendief' (Study 936).

According to the original plans of the AHCDP, residents of the combined nursing/old people's home 'De Kiekendief' and the nursing homes would utilize the same primary health care facilities as the non-institutionalized population of Almere. Care was to be provided by the general practitioners and ather services 
that were part of the multidisciplinary health centres, and not by a specialized nursing home doctor and nursing staff.

One of the conclusions from the evaluation study about the functioning of "De Kiekendief' was that the combined functioning of the nursing home and old people's home departments was actually achieved. Although small in numbers, clients did actually move from one department to another and the combined administration of both services functioned without problems. In 1991 six out of 97 residents from the old people's home moved to the nursing home section of 'De Kiekendief', which figure is in line with a percentage from the 2 to $5 \%$ of residents in any randomly chosen old people"s home in the rest of the Netherlands who require nursing care (Fahrenford \& Plaisier, 1993). Residents of the nursing home department of 'De Kiekendief' required less help than the average residents of these services.

The original idea that all care for the residents of 'De Kiekendief' and other nursing homes under development was to be provided by the primary health care services of the APHCF, was abandoned shortly after the opening of 'De Kiekendief in 1990. A specialized nursing home dactor was appointed in 1992. As a consequence, hypothesis $\mathrm{H} 7.11$ has to be rejected.

\subsection{Substitution of professional care to informal care, and from curative care to preventive care}

Detailed figures concerning the substitution of professional to informal care, and from curative to preventive care in Almere and the rest of the Netherlands are scarce, making it difficult to check whether the operational goals that refer to these forms of substitution have been achieved. The information available refers to (1) attitudes towards a shift from professional to informal care and the actual use of professional health care services, and (2) the role prevention and preventive activities take in the work of health care professionals.

\subsubsection{Professional and informal care}

In Almere, in comparison with the Netherlands as a whole, less frequent use is made of professional health care services whereas the use of informal care is relatively high. (Hypothesis H7.12)

Hypothesis $\mathrm{H} 7.12$ will be answered with data coming from: the study in which inhabitants evaluated the Almere health care system (Study 86-1) "the population survey conducted as part of the survey on general practice in Almere (Study 93- 
2), the study about morbidity and interventions in general practice in Alimere (Study 93-1), and the study about care for the elderly (Study 90-2).

In an early phase of the AHCDP it was established that with regard to informal care, both potential care providers and people to receive informal care were sceptic about a possible shift from professional to informal (Sixma, 1986). For a majority of the respondents, willingness to provide informal care on a voluntary basis was restricted to family or good friends in Almere, with the condition that such informal care would not take too much time. On the other hand, when care was needed, informal care would first of all be accepted when offered by family, good friends or the next-door neighbour and that people would rather not ask for help from people they did not know (Sixma, 1986).

The idea that persons are responsible for their own health and that professional health care workers function in a supportive role, was one of the key elements of the AlHCDP. In combination with the idea of demedicalization (see the original project plans published under the responsibility of the Steering Committee of the AHCDP) so a policy would, in the long run, result a less frequent use of professional health care services. Here, table 7.11 presents an overview of the use of health care services by the population of Almere as compared to the average Dutch population, for different morbidity categories. Data for Almere are standardized for age/gender differences.

The most important conclusion to be drawn from table 7.11 (see next page) is that the percentage of the population of Almere making use of professional health care services, controlling for a number of morbidity indicators and after standardization for age/gender differences, is equal or somewhat higher than in the remainder of the Netherlands. Exception was the extent to which a call is made on the services of alternative healers.

With respect to the use of informal care services, the available information is restricted to frail, non-institutionalized people living in Aimere, aged 65 years or more (Brink and Sixma, 1990). The most important conclusion from this study was that, with very few exceptions, needs for home care services were fulfilled. Informal care played an important role in the fulfilment of these needs ${ }_{\text {" }}$ and professional care was provided in an adequate way. Since comparable figures were missing, it is difficult to establish whether or not the situation in Almere differs from the situation in the remainder of the Netherlands with respect to needs assessment. 
Table 7.11 The use of a health care services in Almere and the Nether-lands, for different morbidity categories (Source: Study 93-1)

Almere

Netherlands

\section{Total population}

1 contact with general practitioner ( $2 \mathrm{mth}$.)

44. 1

37.2

2 contact with physiotherapist (1 yr)

16.0

13.3

contact with district nursing (1 yr.)

6.3

6.6

4 contact with social work (1 yr.)

3.7

2.5

17.1

16.3

contact with medical specialist ( $2 \mathrm{mth}$.)

3.5

3.5

contact with mental care institution (1 yr.)

6.4

7.6

Persons with four of more acute complaints

4 contact with general practitioner (2 mth.)

contact with physiotherapist (1 yr.)

3 contact with district nursing (1 yr.)

6.7

contact with sociall work (1 yr.)

6.6

4.6

5 contact with medical specialist (2 mth.)

6 contact with mental care institution (1 yr.)

22.7

22.0

5.3

6.1

7 contact with alternative medicine ( $1 \mathrm{yr}$ )

8.1

\section{Persons with four or more chronic complaints}

1 contact with general practitioner $2 \mathrm{mth}$.)

70.6

68.4

contact with physiotherapist $(1 \mathrm{yr}$.)

40.1

contact with district nursing (1 yr.)

6.3

contact with social work (1 yr.)

8.3

contact with medical specialist ( $2 \mathrm{mth}$.)

6 contact with mental care institution (1 yr.)

13.9

38.0

7 contact with alternative medicine (1 yr.)

48.8

11.9

6.4

18.9

\section{Persons with 3 or more psychosocial problems}

1 contact with general practitioner (2 mth.)

2 contact with physiotherapist (1 yr.)

contact with social work (1 yr.)

10.0

contact with medical specialist ( $2 \mathrm{mth}$ )

14.7

22.5

contact with mental care institution (1 yr.)

26.5

13.0

contact with alternative medicine (1 yr.)

12.1

13.8

\section{Persons with mental health problems (GHQ >4)}

1 contact with general practitioner(2 mth.)

10.1

contact with physiotherapist (1 yr.) 
Persons with subjective health "moderate-bad"

1 contact with general practitioner(2 mth.)

2 contact with physiotherapist ( 1 yr.)

66.0

64.0

contact with district nursing (1 yr.)

29.8

26.8

contact with social work (1 yr.)

10.3

contact with medical specialist ( 2 mth.)

8.4

5.8

contact with mental care institution ( $1 \mathrm{yr}$.)

35.7

35.8

contact with alternative medicine (1 yr.)

6.7

6.7

12.9

14.6

Another form of demedicalization refers to the medication which is prescribed in general practice. Less prescriptions, refer to a greater responsibilities for the individual person. In tables 7.12 and 7.13 detailed information is presented about prescription rates and the use of prescribed and non-prescribed medicines.

Table 7.12 Average number of contacts with medication, per 1000 contacts for practices in Almere and in the Netherlands. (Source: Study 93-1)

\begin{tabular}{lrrr} 
& Almere & $\begin{array}{r}\text { Netherlands } \\
\text { total } \\
(\mathrm{N}=102)\end{array}$ & $\begin{array}{r}\text { Multidisciplinary } \\
\text { health centres } \\
(\mathrm{N}=9)\end{array}$ \\
\hline medication without prescription & 32.1 & 21.9 & 21.1 \\
changes in medication & 15.2 & 17.1 & 16.8 \\
prescription of medicine & 585.9 & 651.4 & 589.9 \\
- psycholeptics & 59.6 & 65.5 & 54.5 \\
- antibiotics & 43.6 & 57.2 & 47.3 \\
- analgetics & 31.7 & 43.6 & 42.4 \\
- sex hormones & 41.4 & 39.7 & 41.0 \\
- diuretics & 24.5 & 35.7 & 27.8 \\
- cough/cold medicines & 38.8 & 38.6 & 40.1 \\
- beta-blockers & 23.1 & 26.9 & 20.3 \\
- anti-rheumatic medicines & 30.2 & 39.4 & 32.7 \\
- CoPD medicines & 18.5 & 21.9 & 17.2 \\
- medicines for nasal use & 25.4 & 22.0 & 29.6 \\
- other medication & 278.2 & 298.2 & 271.2 \\
\hline
\end{tabular}

Compared to the rest of the Netherlands, GPs in Almere prescribed less medicines per 1,000 patients. With medication divided into sub-categories, GPs in Almere show lower prescription rates in almost all of the sub-categories. Exceptions were: sex hormones (including 'the pill') and cough and cold medicines. Additional information about the use of medicines without prescription of the GP, as presented in table 7.13, illustrates that such medicines were more frequently used in Almere than in the rest of the Netherlands. 
Table 7.13 Prescribed and used medicines per fortnight by the inhabitants of Almere (standardized) and the Netherlands, in percentages. (Source: Study 93-4)

\begin{tabular}{lcr} 
& Almere & Netheriands \\
\hline gets prescriptions of medicine & 14.0 & 13.8 \\
uses prescribed medicine & 30.0 & 30.4 \\
uses medicine obtained without prescription & 27.9 & 23.9 \\
\hline
\end{tabular}

With respect to their "health locus of control' attitudes, the population of Almere is placing a somewhat greater responsibility on the individual person when it concerns everyday complaints. The perceived relationship between 'a good health" and the person's own responsibility is somewhat stronger in Almere than in the remainder of the Netherlands (Sixma et al, 1991). The fact that attitudes and actual behaviour seem to be in conflict with each other indicates that, either intentions or attitudes and actual behaviour are not in line or that people in Almere have a different perception about the seriousness of complaints.

In summary, the Almere population made more frequent use of professional health care services when compared to the average Dutch population, whereas the were no indications that informal care is used more often. With respect to demedicalization, prescription rates in Almere were relatively low and more frequent use was made of over-the-counter medicines. Apart from the prescription, hypothesis $\mathrm{H7.12}$ is rejected.

\subsubsection{Prevention and prevention programmes}

In Almere, in comparison with the Netherlands as a whole, relatively more attention is given to activities concerning the prevention of diseases. (Hypothesis H7.13)

Hypothesis $\mathrm{H} 7.13$ will be tested with data on preventive activities by GPs coming from the study on morbidity and interventions in general practice in Almere (Study 93-1) and the functioning of GPs and nursing staff in the child health clinics in Almere (Study 89-1).

Child health clinics play an important preventive role for children between 0 and 4 years of age. Children are examined on a routinely basis by specialized GPS and nurses, while immunization programmes are carried out to prevent children from a series of serious diseases. Therefore, the functioning of child health clinics can be seen as an indicator for the level of preventive activities for this specific age group. 
Table 7.14 Prevention activities of general practitioners in Amere and the Netherlands, in percentages. (Source Study 93-1)

\begin{tabular}{|c|c|c|c|c|}
\hline & \multicolumn{2}{|l|}{$\begin{array}{l}\text { Almere } \\
(\mathrm{N}=29)\end{array}$} & \multicolumn{2}{|c|}{$\begin{array}{l}\text { Netherlands } \\
(\mathrm{N}=161)\end{array}$} \\
\hline & $\begin{array}{r}\text { not } \\
\text { systema- } \\
\text { tically }\end{array}$ & $\begin{array}{l}\text { systema- } \\
\text { tically }\end{array}$ & $\begin{array}{r}\text { not } \\
\text { systema- } \\
\text { tically }\end{array}$ & $\begin{array}{r}\text { systema- } \\
\text { tically }\end{array}$ \\
\hline screening for hypertension & 82.8 & 17.2 & 78.3 & 21.7 \\
\hline screening for cervical cancer & 6.9 & 93. ** & 24.9 & 75.1 \\
\hline instructions on breast examination & 71.4 & 28.6 & 70.3 & 29.7 \\
\hline \multirow[t]{2}{*}{ screening for diabetics } & 96.4 & 3.6 & 93.2 & 6.8 \\
\hline & $\begin{array}{l}\text { always! } \\
\text { most of } \\
\text { the time }\end{array}$ & $\begin{array}{r}\text { sometimesi } \\
\text { selldom } \\
\text { never }\end{array}$ & $\begin{array}{l}\text { alwaysi } \\
\text { most of } \\
\text { the time }\end{array}$ & $\begin{array}{r}\text { sometimes/ } \\
\text { seldom } \\
\text { never }\end{array}$ \\
\hline \multicolumn{5}{|l|}{ Smoking } \\
\hline informing about smoking behaviour & 13.7 & 86.3 & 19.4 & 80.6 \\
\hline informing in case of complaints & 96.6 & 3.4 & 99.1 & 0.9 \\
\hline informing with risk patient & 93.1 & 6.9 & 95.0 & 5.0 \\
\hline \multicolumn{5}{|l|}{ Drinking alcohol } \\
\hline informing about alcohal use & 3.6 & 96.4 & 9.9 & 90.1 \\
\hline informing in case of complaints & 100.0 & 0.0 & 97.0 & 3.0 \\
\hline \multirow[t]{2}{*}{ informing with risk groups } & 82.8 & 17.2 & 85.9 & 14.1 \\
\hline & $\begin{array}{l}\text { in case of } \\
\text { complaints }\end{array}$ & always & $\begin{array}{l}\text { in case of } \\
\text { complaints }\end{array}$ & always \\
\hline advising smokers to stop & 55.2 & 44.8 & 34.6 & $65.4^{*}$ \\
\hline advising 'fatties' to lose weight & 69.0 & 31.0 & 59.7 & 40.3 \\
\hline \multirow[t]{2}{*}{ advising 'drinkers' to stop } & 27.6 & 72.4 & 29.3 & 70.7 \\
\hline & yes & no & yes & no \\
\hline \multicolumn{5}{|l|}{ Care of the elderly } \\
\hline extra care & 24.1 & 75.9 & 22.3 & 77.7 \\
\hline extra attention at consultation & 65.5 & 34.5 & 72.1 & 27.9 \\
\hline syst. examination at consultation & 0.0 & 100.0 & 6.6 & 93.4 \\
\hline \multirow[t]{2}{*}{ home visits (syst.) } & 17.2 & 82.8 & 16.2 & 83.8 \\
\hline & $\begin{array}{r}\text { per } 1000 \\
\text { patients }\end{array}$ & $\begin{array}{l}\text { per } 1000 \\
\text { contacts }\end{array}$ & $\begin{array}{r}\text { per } 9000 \\
\text { patients }\end{array}$ & $\begin{array}{l}\text { per } 1000 \\
\text { contacts }\end{array}$ \\
\hline vaccinations, total & 27.7 & 21.6 & 27.4 & 23.4 \\
\hline tetanus & 2.0 & 1.6 & 2.2 & 1.9 \\
\hline flu & 23.0 & 18.0 & 21.3 & 18.2 \\
\hline hay fever & 0.9 & 0.7 & 1.0 & 0.9 \\
\hline DTP injection (also pertussis) & 0.3 & 0.3 & 1.3 & 1.1 \\
\hline bmr & 0.2 & 0.2 & 0.3 & 0.3 \\
\hline other & 1.3 & 10 & 1.4 & 1.2 \\
\hline
\end{tabular}

* significant with $p<.05$ 
In Almere, child health clinics provided a somewhat better quality of care than in the remainder of the Netherlands. Child health clinics in Almere more frequently paid attention to the functioning of the ears and eyes of children and the involvement of non-participants in the child health clinics. Also, general practitioners involved in the functioning of child health clinics were better trained and more courses for parents and children were offered. In other aspects the differences between Almere and the rest of the Netherlands were small, while the visiting frequencies of the Almere clinics in general were somewhat lower than in the Netherlands as a whole (Thomassen et al, 1989).

Table 7.14 focuses on a series of preventive activities, such as screening programmes, vaccination programmes, informing about the patients'smoking and drinking behaviour and care for the elderly, of general practitioners in Almere as compared to their colleagues in the remainder of the Netherlands. Data presented in table 7.14 are based on the self reports.

Table 7.14 illustrates that differences between GPs in Almere and the rest of the Netherlands, regarding prevention policy, were small. In Almere more attention was given to systematic screening for cervical cancer. No significant differences were found regarding screening for hypertension or diabetes or extra care for the elderly. Also "differences with respect to paying attention to unhealthy life-styles of patients (smoking, heavy drinkingl, overweight) were small, as were differences in vaccination rates per 1,000 patients.

In surnmary, hypothesis $\mathrm{H} 7.13$ stating the level of preventive activities in Almere as compared to the remainder of the Netherlands is partly rejected and partly confirmed. Rejected, where it concerned most of the preventive activities of the GPs in Almere; confirmed with regard to the functioning of the child health clinics.

\subsection{Conclusions with respect to substitution of care}

The original project plans published as part of the Almere Health Care Demonstration Project, did not mention substitution of care as one of the main goals. The starting-point was a coherent system of care provisions, related to the needs of Almere's inhabitants, with emphasis on the primary care sector and with secondary care in a supportive role. Such a primary health care based system was ideologically in line with national health care policy of the mid 1970s. During the demonstration project, however, substitution of care was regarded by the central government and the funding bodies as an instrument towards cost containment and reduction in costs. 
Three different aspects of substitution of care have been examined: (1) substitution within the hospital and nursing home sector, (2) substitution of secondary to primary care, and (3) substitution of professional to informal care, and of curative to preventative care. Operational goals to be achieved were explicitly stated in the form of a series of hypotheses in each of the sub-section. Diagram 7.1 presents the results when these hypotheses were tested against the available data.

Diagram 7.1 Overview of the degree of realization of the operational goal concerning substitution of care during the Demonstration project Health care in Almere

Hypothesis Operational goal Result

$H 7.1$

many outpatient interventions in Almere

$\mathrm{H} 7.2$

$\mathrm{H} 7.3$

47.4

$H 7.5$

H7.6

$H 7.7$

$H 7.8$

47.9

H7. 10

H7. 11

H7. 12

H7. 13 relatively high share of day treatment

shift Nursing Home to Old People's home

fewer referrals from specialist to specialist

relatively short stay in hospital

relatively low number of hospital admissions in Almere

relatively few interventions in inpatient and outpatient departments

relatively high number of interventions in primary health care sector

Relatively large share of emergency care calried out by primary care sector

relatively low number of referrals to medical specialist

primary care is responsible for medicall and paramedical care in nursing homes

relatively low use of professional care, much woluntary and self care

many activities concerning prevention of diseases in general not realized. however on certain procedures it was realized

not realized

$?$

$?$

realized

not realized for 1991

$?$

realized

realized

realized per 1000 contacts, not realized per 1000 patients

not realized

mainly not realized

partly realized 
Data on the utilization of clinical facilities within Almere show that the operational goal to decrease the use of these facilities compared to the Netherlands was not realized. Furthermore, hospital utilization figures do not support a shift from hospital utilization to other forms of care, such as primary health care services. The average length of hospital stay per admission for the population of Almere was shown to be consequently lower than when compared to the rest of Netherlands, although differences are small.

An integrated system of primary health care services in Almere would result in a relatively low referral rate to medical specialists and lower hospital admission rates. Although the number of contacts with general practice in Almere per 1,000 patients is relatively high, GPs' referral rates to the medical specialists compared to the average Dutch GP are low, suggesting that the increased morbidity rate of the population could be dealt with by the primary health care institutions in Almere. A further success of the demonstration project are the primary health care emergency centres. Emergency care is offered in the health centres during office hours, resulting in relatively few people directly attending the hospital's emergency department.

Examining the shift from professional to informal care, and from curative to preventive care, there is little evidence to suggest that such shifts occurred. Although information on informal care was scarce. With respect to prevention activities, GPs in Almere report somewhat more screening for cervical cancer and child health clinics pay generally somewhat more attention to such activities. 
The objective of the Almere Health Care Project was to implement a cohesive system of health care services, attuned to the needs of the population, of high quality and at acceptable costs. In the original project plan, the 'acceptable costs' concept was operationalized as costs that did not exceed or were less than the costs of the traditional health care system in the Netherlands (Stuurgroep Project Gezondheidszorg Almere, 1983). With respect to the costs of the Almere health care system, the condition that had to be taken into account was Almere's 'new town' status and introductionary costs for certain facilities. From a series of interviews with key persons involved in implementing the AHCDP it was derived that substitution of care was considered as an important instrument to achieve the goals of cost containment and cost restriction. Since substitution of care is most associated with the primary, secondary and care of the elderly sectors, this chapter will focus on these three areas.

By estimating the costs of the health care system in Almere, as compared to the situation in the Netherlands, the chapter will concentrate on 1991. Because the AHCDP officially came to an end in 1992, the year 1991 was the last full year the project was implemented. Secondly, for the years after 1991 standardized information on the functioning of costs generating services (e.g. the hospital sector, hospital admission rates, number of occupied beds by the population of Almere, average length of stay in hospital, referral rates of GPs) was not available. Since figures about hospital utilization largely determine costs within the entire health care sector, it was decided to focus on 1991. Data with respect to (unstandardized) trends in the use of hospital facilities in Almere were presented in chapter 7 .

\subsection{Introduction}

Instruments to achieve a more cost effective health care system, such as a strengthened PHC-system and a hospital with limited bed capacity, were actually implemented during the AHCDP. When the Flevo hospital opened in 1991" its bed capacity of 180 was $20 \%$ below the national norm. For Almere the (unstandardized) norm was 3 beds per 1,000 inhabitants, or 2.4 beds after standardization for age differences. At that moment the national bed capacity norm was 3.7 beds per 1,000 inhabitants. In combination with a limited bed

This chapter is a translated version of chapter 7 of the concluding report on the AHCDP (Sixma et al, 1993). 
capacity, the hospital had relatively large outpatient departments and additional beds for day-time surgery.

Bed capacity restrictions of the Flevo hospital were directly related to additional financial support for the Amere Health Care Demonstration Project provided by the Dutch Ministry of Health, Welfare and Culture granted for the year 1985 and onwards. For 1991, these additional funds to strengthen the institutional sector and to improve coordination between the different echelons was set at five million guilders. In the next three sections on the costs of hospital care (section 8.2), costs of primary care (section 8.3) and costs of care for the elderly (section 8.4), these additional funds will be taken into account as much as possible.

\subsection{Costs of hospital care}

In Almere, in comparison with the Netherlands as a whole, the costs of hospital care are lower. (Hypothesis H8.1)

Hypothesis $\mathrm{H8.1}$ will be answered on the basis of figures about the use of hospital services by the population of Almere. This information is published in the Studies 87-1,87-2,88-1,90-1,92-1 and 93-5 (see Table 3.4)

With the ANOZ Gooi Apeldoorn Group being unable to provide costs for the care of their patients in Almere and with data on privately insured patients missing because of financial reasons, the necessary information to calculate the exact costs for the Almere population was lacking. However "given the importance of the hospital sector with respect to health care expenditure, the data presented refer to the population's clinical consumption in Almere expressed in the number of admissions and the number of beds occupied. This entails some overlap with the information reported in chapter 7 .

In the 10-year period between 1982 and 1992 there was an increase in the admission coefficient for the years 1982 through 1984, followed by a strong decrease from 1985 through 1988 . In 1988 the admission coefficient was almost equal to the standardized admission coefficient for the Netherlands. In 1990 the admission coefficient for the population of Almere was about $1.5 \%$ higher than the standardized coefficient for the Netherlands (95.1 versus 93.6). The increase in between 1990 and 1991 was associated with an increase of the number of admissions to the Burger hospital in Amsterdam of approximately $40 \%$. Compensation, in the form of a decline in the number of admissions in other hospitals around Almere, was missing. Between 1990 and 1991 the (standardized) admission coefficient in Almere increased from 95.1 to 99.2. 
Another important indicator for the use of hospital facilities, with data shown in Graph 8.2 , is the number of hospital beds occupied by the population of Almere on a yearly basis.

Graph 8.1 Admission coefficients per 1000 inhabitants in Almere and the Netherlands in the period 1982 through 1992 (Source: Studies 87-1, $87-2,88-1,90-1,92-1$ and $93-5)$

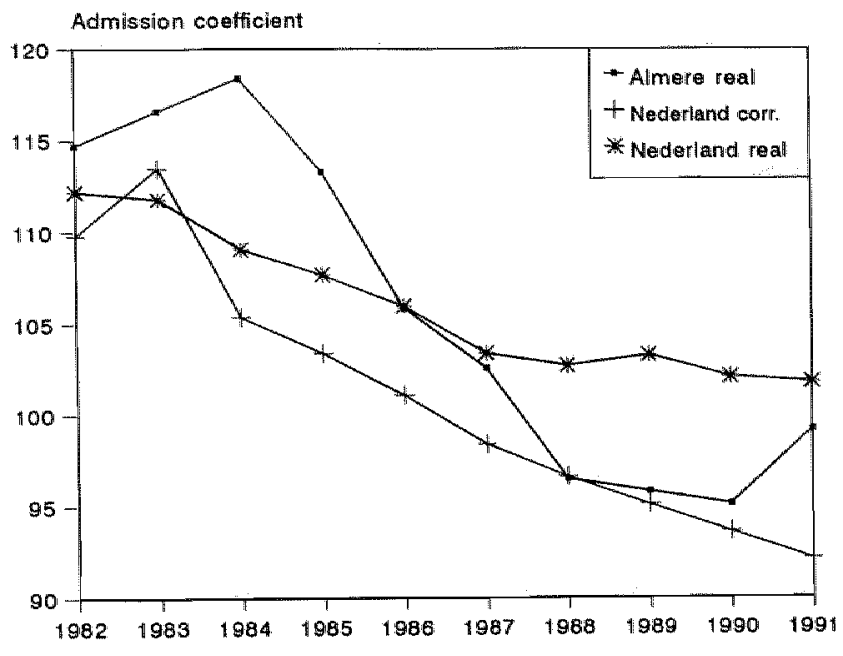

Graph 8.2 The number of occupied beds per 100.000 inhabitants in Almere and the Netherlands in the period 1982 through 1990. (Source: Studies $87-1,87-2,88-1,90-1,92-1$ and 93-5)

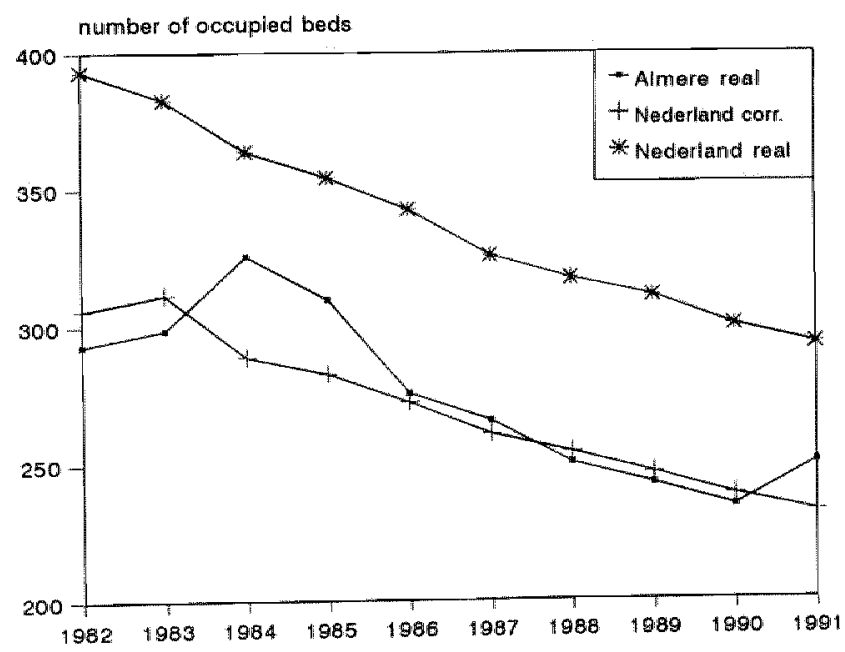


The number of occupied beds by the Almere population decreased in the period 1982 through 1990 from 293.1 to 234.4 per 100,000 inhabitants. This is indicated in Graph 8.2. A slight increase in the period between 1982 and 1984 was followed by a steady decrease, that (after standardization) ran almost parallel to and in 1988 dropped below the national average. In 1990 the Almere population occupied $1.7 \%$ fewer beds that the standardized national rate for occupied hospital beds. In 1991 this downward trend for Almere was interrupted. The number of occupied beds rose from 234.4 to 250.3 per 100,000 inhabitants. As with the admissions coefficient, in 1991 the number of occupied beds was about $8 \%$ higher than the standardized figure for the Netherlands. The increase in the admission coefficient can be attributed for the most part to the opening of the Flevo hospital. Hospital departments responsible for this increase were the departments of cardiology and internal medicine.

In 1991, there were 8089 hospital admissions generated by the Almere population, of which 4288 refer to the Flevo hospital. Taking into account that this hospital opened in March, it can be calculated that the opening date about $64 \%$ of all patients from Almere were admitted to the Flevo hospital. Subsequently, there was a large overflow of patients to other hospitals. The total occupation rate for all beds in the Flevo hospital in 1991 was $69.8 \%$ (Flevo ziekenhuis, 1992). This figure is in line with the average national rate of $69.2 \%$ for general hospitals of less than 200 beds (NZI, 1992). Data referring to the 1992 - 1995 period show that this overflow of patients continued in the subsequent period of four years, with admission rates for the Flevo hospital in Almere varying between 65\% (in 1992) and almost 70\% (in 1995).

On the basis of the information presented in Graph 8.1 and 8.2 it can be concluded that in 1991 the costs of hospital care in Almere were not lower than in the rest of the Netherlands. The $20 \%$ reduction in the number of clinical beds in the Flevo hospital in comparison with the national norm led to a considerable overflow of patients to other hospitals. In 1991 the admissions coefficient and the number of occupied beds was about $8 \%$ higher than the national average.

\subsection{Costs of primary care}

In Almere, in comparison with the Netherlands as a whole, costs of primary care are higher following the implementation of the Primary Care concept and measures to strengthen primary care facilities. (Hypothesis H8.2)

Data to test hypothesis $\mathrm{H} 8.2$ refer to the survey about morbidity and interventions in general practice in Almere (Study 93-1; Study 93-2). Additional 
information was received from the APHCF, the Municipality of Almere, the Dutch Ministry of Well-being. Health Care and Cuiture and based on yearly reports of the COTG.

In Almere primary care has been delivered almost exclusively through multidisciplinary health centres, with 14 of them being operated by the APHCF at the end of 1992. Services operating from these centres were: general practice, physiotherapy, dentistry, district nursing, midwifery, social work, pharmacy, and home care. Most personnell were employees of the APHCF. Maternity care in Almere was provided by the Province of Flevoland Community Nursing Organisation. However, a small number of independently established providers of primary care aperated in Almere outside the APHCF, including one GP and one midwife, about 20 physiotherapists, and some occupational therapists and speech therapists.

Table 8.1 and 8.2 show the expenditure for the health centres run by the APHCF in 1991, as well as estimates for the primary care workers not employed by the APHCF or the Flevoland Community Nursing Organisation. Included in Table 8.1 are special project funds in the context of the AHCDP, covering an amount of NLG 1,958,500 in 1991. NLG 908,000 was used to strengthen the different PHC services with additional personnel and equipment and NLG 1,050,000 for projects not assigned to a particular service.

Table 8.1 Expenditure in 1991 for the health centres run by the Almere Primary Health Care Association (APHCF) and for Maternity care. (Source: Stichting EVA, 1992; SAG, 1992)

costs

( $X$ NLG 1000,-)

general practitioner's care

13,605

paramedical care

4,573

obstetrical care

1,264

pharmaceutical care

15,405

dental care

6,074

social work

1,691

districs nursing

5,382

home help

5,752

maternity care

2,520

special projects

1,050

total

57,316

Estimated costs of the independently established primary thealth care givers shown in Table 8.2, were based on the number of staff personnel in full time 
equivalents and guide-lines published in the 1991 annual report of the Organisation for Tariffs in Health Care (Centraal Orgaan Tarieven Gezondheidszorg or COTG).

Table 8.2 Number of full time equivalents (fte's) and estimated costs for independently established GP's physiotherapists, remedial therapists, speech therapists and midwives in Almere in 1991. (Source: Gemeente Almere, 1992; COTG, 1992)

\begin{tabular}{lcr}
\hline & number of fte's & costs in NLG \\
\hline general practice & 1 & 265,100 \\
physiotherapy & 13.65 & $1,605,240$ \\
occupational therapy & 3.5 & 299,750 \\
speech therapy & 6.1 & 652,100 \\
midwife & 0.35 & 63,600 \\
\hline
\end{tabular}

Estimates of the costs of pharmaceutical help, shown in Table 8.3, were based on the personnel costs of the number of independent and APHCF-employed pharmacists (in full time equivalents) and the practice costs for both groups, with the assumption of equal costs for independently and APHCF-employed pharmacists.

Table 8.3 Number of full time equivalents (fte's) and estimated costs for the APHCF- and independently established pharmacists. (Source: Gemeente Almere, 1992; Stichting EVA "1992)

\begin{tabular}{lrr}
\hline & APHCF & $\begin{array}{r}\text { indepenciently } \\
\text { established }\end{array}$ \\
\hline $\begin{array}{l}\text { number of fte's } \\
\text { personnel costs (in NLG) } \\
\text { number of pharmacies } \\
\text { accommodation and practice costs (in NLG) }\end{array}$ & $3,270,000$ & 2,65 \\
total costs (in NLG) & $10,800,000$ & $1,010,000$ \\
2 \\
\hline
\end{tabular}

Costs of dentists and dental care (in full time equivalents) were also based on the number of independently established dentists and the number of dentists employed by the APHCF. Estimates for these costs are presented in Table 8.4, assuming there were no differences between independent and APHCF-employed dentists. 
Table 8.4 Number of full time equivalents (fte's) and estimated costs for APHCF and independently established dentists. (Source: Gemeente Almere, Jaarversiag EVA 1991)

\begin{tabular}{lrr}
\hline & APHCF & $\begin{array}{r}\text { independently } \\
\text { established }\end{array}$ \\
\hline number of fte's & 15.3 & 7.6 \\
costs (in NLG) & $5,860,000$ & $2,900,000$ \\
\hline
\end{tabular}

Table 8.5 and 8.6 present an overview of total costs of primary health care services in Almere, as compared to health care expenditure for the whole of the Netherlands, in total (Table 8.5) as well as in NLGs per inhabitant (Table 8.6) with national figures being standardized. Population data refer to the average number of inhabitants in 1991.

Table 8.5 Estimates of the expenditure of primary health care in 1991 in Almere and the Netherlands in NLGs (Source: FOZ 1993; Study 932)

\begin{tabular}{lrr} 
& $\begin{array}{r}\text { Almere } \\
(x f .1000,-)\end{array}$ & $\begin{array}{r}\text { Netherlands } \\
(x f .1,000,000)\end{array}$ \\
\hline general practice & 13,870 & 2,216 \\
physiotherapy & 7,130 & 1,390 \\
obstetrical care & 1,328 & 99 \\
pharmaceutical care & 19,505 & 4,390 \\
dental care & 8,974 & 2,081 \\
social work & 1,691 & 210 \\
community nursing & 5,382 & 1,011 \\
home help & 5,752 & 1,943 \\
maternity care & 2,520 & 324 \\
special projects & 1,050 & - \\
total & & 13,664 \\
\hline
\end{tabular}

This concerns subsidizing of projects regarding the Experiment gezondheidlszorg Almere, that are not part of a specific discipline. 
Table 8.6 Estimates of the expenditure per inhabitant in NLGs in primary health care in 1991 in Allmere and Netherlands (in NLGs)

\begin{tabular}{lccc}
\hline & Almere & Netherlands & $\begin{array}{r}\text { Netherlands } \\
\text { corrected }\end{array}$ \\
\hline generall practice & 170 & 147 & 147 \\
physiotherapy & 87.5 & 92 & 102.5 \\
obstetrical care & 16 & 6.5 & 9.5 \\
pharmaceutical care & 239.5 & 292 & 242.5 \\
dental care & 110 & 138 & 131.5 \\
social work & 21 & 14 & 15 \\
community nursing & 66 & 67 & 37.5 \\
home help & 70.5 & 129 & 77.5 \\
maternity care & 31 & 21.5 & 31 \\
special projects* & 13 & - & - \\
total & 824.5 & 907 & 794 \\
\hline
\end{tabular}

This concerns subsidizing of projects regarding the Experiment gezondheidszorg Almere, that are not part of a specific discipline.

Correction factors for general practice, physiotherapy, dental care, social work and pharmacy were based on data from the national survey on morbidity and interventions in general practice in Almere (Sixma et al, 1993), whereas for district nursing data from the Financieel Overzicht Zorg (FOZ = Financial Overview for Care) 1993 were used. For home help services, a correction factor was calculated on the basis of the number of hours of home help per age group. Correction factors for midwifery and maternity care were based on the number of births per 1000 inhabitants (CBS, Municipality of Almere).

Table 8.6 shows that the estimated costs of primary care per inhabitant in 1991 in Almere were about 30 guilders (or 4 per cent) higher than the standardized national average, with 26 guilders being accounted for by the additional funds of AHCDP. Costs of general practitioners, midwifery, social work and district nursing in Almere were higher than the average costs in the Netherlands. Costs for physiotherapy, pharmacy, dentistry and home help in Almere were below the national average.

Information about cost-generating interventions in general practice, such as diagnostic services, prescription of medicines, and referrals to medical specialists and physiotherapists, are presented in Table 8.7. This table illustrates that GPs in Almere more frequently requested external diagnostics than their colleagues elsewhere; for the other categories, differences in absolute numbers (per 1,000 patients) were small. 
Table 8.7 Cost generating procedures in general practice in Almere and the Netherlands, with data for Almere being standardized for age differences. (Source: Study 93-1)

\begin{tabular}{lrrrr}
\hline & \multicolumn{2}{c}{ per 1000 patients } & \multicolumn{2}{c}{ per 1000 contacts } \\
& Almere & Netherlands & Almere & Netheriands \\
\hline request external diagnostics & 91.6 & 66.4 & 71.7 & 56.8 \\
prescription medicines & 743.8 & 750.6 & 581.9 & 641.5 \\
referral medical specialist & 70.1 & 71.8 & 54.9 & 61.4 \\
refermal physiotherapist & 28.6 & 28.1 & 22.3 & 24.0 \\
\hline
\end{tabular}

Table 8.8 Costs of the prescription of medicines (in NLGs) per contact in Almere (standardized) and the Netherlands for 30 diagnostic categories. (Source: Study $93-1$ and study 93-3)

\begin{tabular}{|c|c|c|}
\hline & Almere & Netherlands \\
\hline Infection upper bronchial tubes & $9 *$ & 11 \\
\hline Simple hypertension & $44 *$ & 59 \\
\hline Contra conception pill & 43 & 42 \\
\hline Cystitis/urinary tract infection & $6 *$ & 16 \\
\hline Myalgia/fibrositis & 8 & 8 \\
\hline Neurasthenia/surmenage & 6 & 6 \\
\hline Aculte bronchi(oli)tis & 26 & 27 \\
\hline Other eczema & 18 & 17 \\
\hline Anxious/nervous & $14 *$ & 16 \\
\hline Otitis media acuta & 10 & 10 \\
\hline Coughing & 12 & 10 \\
\hline Sinusitis & $18 *$ & 25 \\
\hline Asthma bronchial & 49 & 56 \\
\hline Sleep disturbance & 19 & 18 \\
\hline Diabetes mellitus & 53 & 70 \\
\hline Lumbago & 9 & 11 \\
\hline Other infection stomach/intestines & 8 & 9 \\
\hline Warts & 7 & 10 \\
\hline No illness & 2 & 2 \\
\hline Inritable bowel syndrome & 17 & 18 \\
\hline Dermatophytosis/-mycotis & 27 & 24 \\
\hline Virusinfection NNOINEC & $3 *$ & 6 \\
\hline Pneumonia & 18 & 18 \\
\hline Deviant stomach furiction & 46 & 47 \\
\hline Allergy NNO/NEC & 43 & 38 \\
\hline Depression & 21 & 21 \\
\hline Hyperventilation & 4 & 5 \\
\hline Influenza & $5 *$ & 7 \\
\hline Allergic conjunctivitis & 15 & $10^{*}$ \\
\hline
\end{tabular}

* Statistically significant cheaper $(p<05)$ 
Detailed information about costs per prescription is presented in Table 8.8. In $1987 / 1988$, general practitioners in Almere prescribed medication at an average cost of NLG 16.00 per contact (standardized), compared to NLG 20.00 for the rest of the Netherlands. For seven out of 30 diagnostic categories prescribing costs were significantily lower in Almere; for one category (allergic conjunctivitis) prescription costs in Almere were relatively high.

In summary, hypothesis $H 8.2$, was confirmed regarding the data presented in this section. In 1992, costs involved in running a system of PHC-services in Almere the way it was implemented during the AHCDP were slightly higher as compared to the traditional (national) system.

\subsection{Costs of care for the elderly}

In Aimere, in comparison with the Netherlands as a whole, the costs of care of the elderly are lower. (Hypothesis H8.3)

Hypothesis $\mathrm{H} 8.3$ will be tested with data based on the yearly reports covering the old people's homes in Almere (e.g. 'De Sichoor' Foundation, Della Foundation, Salvation Army Almere).

In Almere in 1991, there were two old people's homes and a combined old people's home/nursing home. The capacity of the old people's homes, with two of them managed by the Delta Foundation and one by the Salvation Army, was 300 places. The nursing home capacity was 30 beds. However, many people were admitted into nursing homes outside Almere. In 1991 36,224 nursing days were initiated by the Almere population ( $\mathrm{SIG}_{\text {n }} 1992$ ). With $80 \%$ of the nursing home patients being admitted to ordinary nursing homes, estimated costs were based on the average price of NLG 235 for one nursing day in such a facility (NZI, 1992).

Table 8.9 Costs of elderly care in Almere in 1991, in NLGs. (Source: Jaarverslagen 1991 Stichting De Schoor, Stichting Delta, Leger des Heils, Stichting Informatiecentrum voor de Gezondheidszorg) 
Included in Table 8.9 are additional funds allocated to 'care-for-the-elderly' projects that were part of the AHCDP, totalling NLG 460,400 in 1991. National data show that in 1991 about $90 \%$ of the patients in the nursing homes and $98 \%$ in the old people's homes were older than 70 years of age. In 1991, costs of inpatient facilities for these age categories of elderly people were NLG 7,267 in Almere compared to NLG 7,190 in the Netherlands as a whole (FOZ, 1993). It can therefore be concluded that costs of the care of the elderly per inhabitant aged 70 years and over in Almere were about $1 \%$ higher than the national average. It should be kept in mind here that $N$ LG 137 (or approximately 2\%) per inhabitant aged 70 years or over must be ascribed to the projects in the context of the Almere Health Care Demonstration Project.

Based on the data presented in this section hypothesis $\mathrm{H} 8.4$, stating lower costs in Almere as compared to the Netherlands, has to be rejected.

\subsection{Conclusions}

Chapter 8 focused on the third important goal of the Almere demonstration project: the costs of health care expenditure in Almere as compared to the Netherlands as a whole. Three sectors were selected: the hospital sector, the primary health care sector and care of the elderly sector.

For governmental policy makers and funding bodies, cost containment gradually became one of the most important objectives of the project. A $20 \%$ reduction in bed reduced capacity of the Flevo hospital would result in substantial savings in this sector which could be used to strengthen the primary health care sector. In advance to the opening of the Flevo hospital and to cover the building-up process, additional funds for the AHCDP were made available by central government up to five million guilders per year. Because there were no apparent reasons to assume that the implemented system in Almere would cost less than the system in the rest of the Netherlands, it was assumed that total costs associated with the AHCDP in 1991 would be equal or somewhat less than in the "traditional' system.

With respect to the costs for the hospital sector an indirect approach, based on admissions and occupied beds initiated by the population of Almere, was chosen because it was impossible to compute direct costs of hospital care. In 1991, both the hospital admissions coefficient and the number of occupied beds for the population of Almere were about $8 \%$ above the (standardized) national average. On this basis the hypothesis that costs of hospital care were lower in Almere than elsewhere in the Netherlands cannot be confirmed. 
Costs of primary care in Almere in 1991 were estimated to be slightly higher than in the rest of the Netherlands. Costs per inhabitant were NLG 825 in Almere and, after standardization for age differences, NLG 794 in the rest of the Netherlands. Lower production figures for general practitioners with respect to costs generating interventions, were compensated by the high morbidity rates of the population.

With costs of care for the elderly in Almere being estimated at NLG 7267 against NLG 7190 for the Netherlands, health care expenditure for this specific category were about $1 \%$ higher in Almere than in the rest of the Netherlands. The original goal: lower costs in the care for the elderly sector, was therefore not realized. The results with respect to the three sectors are summarized in Table 8.10.

Table 8.10 Operational goals of the Almere Health Care Demonstration Project and if they were achieved

Hypotheses Operational goal Result

H8.1 lower costs for hospital care

not realized

48.2

restricted higher costs in Almere primary care

confirmed

H8.3

lower costs for elderly care

not realized

Interpreting the summary presented in Table 8.5, differences between 'confirmed' and 'not realized' were rather small. Because all costs were based on estimates and assumptions, a general conclusion that the total amount of costs generated by the use of health care services by the population of Almere are about equal to the costs in the Netherlands as a whole would probably fit the data best. A final conclusion, therefore, is that the 'Almere model' is probably no more expensive than the traditional Dutch health care system. Given the fact that a cheaper health care system was clearly not part of the original goals, it could be considered that in this respect the project was a success for the policy makers

After having presented our conceptual framework for evaluating the Almere Health Care Demonstration Project as a policy programme in chapter 3 , the first two research questions that refer to this policy programme were answered in chapter 4 to 8 . The third and final research question derived from the policy programme, referring to the empirical relationship between instruments, conditions and goals, will be answered in chapter 10 . 


\section{THE EMPIRICAL RELATIONSHIP BETWEEN GOALS, INSTRUMENTS AND CONDITIONS}

In chapter 3 the 'Stake model' was adopted as the conceptual framework for evaluating the Almere Health Care Demonstration Project as a policy programme. Subsequently, the three research questions referring to this policy programme, the theoretical relationships between the instruments, objectives and conditions of the Almere Health Care Demonstration Project were described, and an answer was given on the first policy research question. Next, in chapter 4 to 8 the second research question was answered, by looking at the correspondence between the planned programme and the programme as it was implemented between 1983 and 1993.

The third policy research question (Q4: "Is there an empirical relationship between the instruments used, the actual conditions and the goals of the Almere Health Care Demonstration Project that were realized?") is the most difficult to answer. For a partial answer, the focus will be on one of the successful elements of the Almere Health Care Demonstration Project: the strengthening of the primary health care sector, and will concentrate on the role of the general practitioner. First ${ }_{\text {n }}$ the reasons behind this decision will be described. Secondly, the way general practices in Almere are functioning with respect to quality of care and substitution, will be described in more detail in order to find out which elements of the AHCDP contributed to the success of failure of the strengthened primary care concept.

\subsection{The empirical relationships, an introduction}

At the time the research programme for the Almere Health Care Demonstration Project was developed "there was a choice between (1) a full scale experimental design, with control groups for the different elements of conceptual framework, or (2) a descriptive study of the field experimental setting of this health care experiment. The second option was chosen. Firstly, because budgetary restrictions did not allow a full scale experimental design. Secondly, because even when control groups could be found "it would have been extremely difficult to find out which element of the Almere Health Care Demonstration Project 'caused' the effect. Thirdly, the decision was made that the evaluation studies would have to serve 'three masters': (1) to facilitate a process description of the way the AHCDP was implemented, (2) to monitor and, when necessary, correct the process of implementation, and (3) to provide materials for the goal-oriented part of the evaluation. As a consequence, the structure of the different research projects conducted in Almere (for an overview of these research projects: see 
table 3.4) did not allow an univocal answer to the question whether instruments, conditions and goals are empirically related to each other. Based on these evaluation studies, with additional material coming from different sources, chapter 4 to 8 illustrated that the implementation process itself was only partly successful. Not all the selected instruments were actually implemented, some of the conditions specified at the start of the AHCDP were too optimistic, and not all of the goals were actually achieved. The remainder of this chapter concentrates on one of the successful elements of the Almere Health Care Demonstration Project: the strengthening of the primary health care sector. More in particular we will be exploring the work of the GP in relation to the costreffectiveness objective.

With respect to the goals of the Almere Health Care Demonstration Project the role of the GP was of crucial importance. As gate-keeper to second and third tier facilities to achieve substitution of care, and as an important health care service that people frequently need and of which they expect good quality of care. The way general practice is functioning - from the patients point of view, the physicians point of view and based on 'objective' data - is one of the few elements of the AHCDP that allows a direct comparison between Almere and the remainder of the Netherlands as well as different sub-groups, controlling for variables such as morbidity and the age/gender distribution. The logic behind this analysis is (1) to identify the core elements of the AHCDP, and (2) to look at differences between Almere and the rest of the Netherlands, controlling for these core elements. When differences between Almere and the Netherlands disappear after controlling for these core elements, the effects of the 'Almere model' can be attributed to these specific elements. When differences remain present, the AHCDP is 'more' that its separate elements.

One of the most important elements of the AHCDP is the way primary health care is organized. The large majority of PHC workers (including all but one general practitioners) are employees, working in multidisciplinary health centres (see chapter 4). Employment status and multidisciplinary health centres can therefore be seen as core elements of the Almere Health Care Demonstration Project. Detailed information about the relationship between employment status and the functioning of general practice on the national level is missing, and, as a consequence, it is impossible to compare the results for Almere with this particular sub-sample. However information about the relationship between practice setting and the functioning of general practice is available, both for Almere and for the Netherlands. Therefore it is possible to look at the effect of working in multidisciplinary health centres, apart from other elements of the AHCDP.

Although some of the Almere data were already presented in preceding chapters, this chapter will present these data in a more systematic way. In doing 
so, sections 9.2 and 9.3 will focus on data that refer to the quality of care concept, whereas sections 9.4 and 9.5 will put the spotlight on substitution of care and cost-containment. The chapter ends with a brief concluding section.

\subsection{Quality of care in general practice from the professional perspective}

After adjustment for the relevant conditions, better quality of care in Almere from the perspective of the GP is empirically related to important instruments of the Almere Health Care Demonstration Project. (Hypothesis H9.1)

The first part of this section will look at the characteristics of general practitioners in Almere as compared to GPs in other health centres with respect to continuing medical education and practice experience (see also section 6.1.2), the attitudes of the GPs (see also section 6.1.3), the instruments available in general practice (see also section 6.1.4). Secondly, the focus will be on quality of care from the perspective of the general practitioners themselves by taking another look at the workstyle as compared to the (later published) NHGguidelines.

With respect to practice experience and the hours per week GPs spent on reading professional literature, differences between Almere and other GPs working in health centres remain constant after introduction of the health care setting as a controlling variable (see table 9.1).

Table 9.1 Quality of general practitioners in Almere $(N=28)$ and the Netherlands $(\mathrm{N}=16)$; continuing medical education and university of graduation. (Source: Study 93-4)

\begin{tabular}{|c|c|c|c|c|}
\hline & \multicolumn{2}{|c|}{ Almere } & \multicolumn{2}{|c|}{ health centres } \\
\hline & mean & std.dev & mean & std.der \\
\hline \multicolumn{5}{|l|}{$\begin{array}{l}\text { Continuing medical education and } \\
\text { practice experience }\end{array}$} \\
\hline $\begin{array}{l}\text { - number of years practice experience } \\
\text { - hours per week reading professional }\end{array}$ & 3.9 & 3.0 & 11.5 & 6.1 \\
\hline literature & 3.4 & 2.1 & 3.2 & 2.0 \\
\hline - hours per year medical education & 52.3 & 19.0 & 45.5 & 25.6 \\
\hline
\end{tabular}

Looking at the number of hours per week spent on medical education "the GPs in Almere fall somewhere in between the average Dutch GP (approximately 56 hours) and GPs working in health centres in the rest of the Netherlands (approximately 45 hours). Due to the small numbers, differences between 
Almere and the Netherlands do not reach the level of statistical significance at the $5 \%$ level:

The attitudes of the GPs in Almere and other health centres in the rest of the Netherlands are compared in table 9.2. In this table we also include the average scores for the entire sample of $161 \mathrm{GPs}$ in the Netherlands.

Table 9.2 Quality of general practitioners in Almere, in other health centres and the Netherlands; attitudes towards the profession. (Source: Study 93-4)

\begin{tabular}{|c|c|c|c|}
\hline & $\begin{array}{c}\text { Almere } \\
\text { nean }(N=28)\end{array}$ & $\begin{array}{l}\text { Health centres } \\
\text { mean }(N=16)\end{array}$ & $\begin{array}{l}\text { Netherlands } \\
\text { mean }(N=161)\end{array}$ \\
\hline \multicolumn{4}{|l|}{ Attitudes, in general } \\
\hline work style directed at reduction of uncertainty & $3.64^{*}$ & 3.12 & 2.97 \\
\hline inclination to take risks & 3.37 & 3.40 & 3.02 \\
\hline seeing diagnostics as task of general practitioner & $2.69^{*}$ & 3.04 & 2.92 \\
\hline seeing treatment as task of general practitioner & 2.07 & 2.17 & 2.04 \\
\hline broad task profile concerning somatization & 4.03 & 3.94 & 3.93 \\
\hline $\begin{array}{l}\text { feelings of competence somatic complaints } \\
\text { broad task profiles concerning }\end{array}$ & 3.49 & 3.50 & 3.51 \\
\hline psycho-social complaints & 3.13 & 3.39 & 3.32 \\
\hline feelings of competence psycho-social complaints & s $\quad 3.14$ & 3.28 & 3.20 \\
\hline broad task profiles, in generall & 3.23 & 3.60 & 3.38 \\
\hline broad performance profile, in general & 3.05 & 3.20 & 3.15 \\
\hline democratic attitude towards patient & 3.28 & 3.57 & 3.30 \\
\hline 'locus of control' & 3.04 & 3.28 & 3.12 \\
\hline \multicolumn{4}{|l|}{ Attitudes, specific } \\
\hline role psycho-social factors in complaints & 3.04 & 3.17 & 2.92 \\
\hline inclination to prescripiton & 2.30 & 2.30 & 2.60 \\
\hline
\end{tabular}

" = significant difference $(p<.05)$ compared to the GPs working in other health centres

In general, the hypothesis that the GP's attitudes in Almere differ from those of other GPs working in multidisciplinary health centres, with attitudes in Almere being more in line with the basic assumptions of the AHCDP, has to be rejected. Also, GPs in Almere do not resemble GPs in other health centres more than the average GP in the Netheriands. The few differences between Almere and the Netherlands, remain constant after controlling for the health care setting of the Dutch GPs.

With respect to the instruments available in general practice, chapter 6 concluded that practices in Almere were slightly better equipped than the average general practice in the Netherlands (see table 6.4). If we limit our comparison to Almere and GPs in multidisciplinary health centres outside Almere, differences remained small as is shown in table 9.3. 
Table 9.3 Instruments available in general practice in Almere, in other health care centres and in practices in the rest of the Netherlands (Source: Study 93-4)

\begin{tabular}{|c|c|c|c|c|}
\hline \multicolumn{2}{|c|}{ Instrument } & \multirow{2}{*}{$\begin{array}{l}\text { Aimere } \\
(\mathrm{N}=29) \\
\text { \% 'yes" }\end{array}$} & \multirow{2}{*}{$\begin{array}{l}\text { health centres } \\
\qquad(N=16) \\
\% \text { "yes' }\end{array}$} & \multirow{2}{*}{$\begin{array}{l}\text { Netherlands } \\
(N=161) \\
\% \text { 'yes' }\end{array}$} \\
\hline & & & & \\
\hline 1 & Audio meter & 72.4 & 37.5 & 48.1 \\
\hline 2 & Eyeball & 6.9 & 43.8 & 37.3 \\
\hline 3 & ECG & 100.0 & 37.5 & 37.3 \\
\hline 4 & blood pressure meter acc. Sicca & 96.6 & 87.5 & 87.6 \\
\hline 5 & Hygracator & 86.2 & 81.3 & 69.7 \\
\hline 6 & Bulletdrawer (for IUDs) & 100.0 & 87.5 & $B 0.1$ \\
\hline 7 & Peak-flow meter & 79.3 & 100.0 & 85.1 \\
\hline 8 & Proctoscope & 55.2 & 68.8 & 57.1 \\
\hline 9 & Tonometer & 6.9 & 31.3 & 23.6 \\
\hline 10 & Catheter & 100.0 & 93.8 & 95.7 \\
\hline 11 & Microscope & 96.6 & 100.0 & 98.8 \\
\hline 12 & Heamogluciose test & 100.0 & 87.5 & 91.3 \\
\hline 13 & Doppler & 27.6 & 6.3 & 24.2 \\
\hline 14 & Foetoscope & 6.9 & 6.3 & 9.9 \\
\hline
\end{tabular}

From table 9.3 we can learn that sometimes health centres in Almere resemble the situation in other health centres (e.g the availability of hygracators), sometimes the situation in the Netherlands in general (e.g. peak-flow meters, proctoscope, doppler equipment), and sometimes remain the odd one out compared to both the Netherlands and other health care centres (e.g. audio meters, eyeball meters, ECG equipment, bulletdrawers, and tono meters). On the whole, general practices in Almere are not better equipped than the average general practice established in multidisciplinary health centres outside Almere.

Based on the results presented in chapter 6 (table 6.6), it was concluded that general practitioners in Almere treated their patients more in accordance with eight (later published) NHG guidelines than the average Dutch general practitioner. In order to establish whether or not there was an empirical relationship between this operationalization of quality of care and the "Almere model', the data presented in table 6.6 ('\% of decisions in accordance with the NHG-guideline') were included in a two-level analysis. Level-1 predictor variables included in this analysis were practice setting and GP-characteristics, whereas the eight morbidity categories were included as level-2 variables. The results of such an analysis show that practice setting and the number of years that have passed since graduation from university, had a significant effect on the quality of care from the providers' perspective. General practitioners working in health centres and relatively young general practitioners delivered better quality of care 
than older GPS and GPS working single-handed or in duo-practices. If information whether or not the GP was practising in Almere is added to the

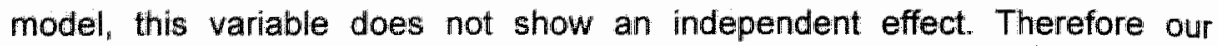
conclusion in this respect has to be that differences between Almere and the Netherlands are most related to practice setting and number of years experience. Although practice setting can be considered as an important characteristics of the 'Almere model', the "Almere model' in itself does not add a significant effect on better quality of care (Sixma et al, 1994).

Given the results from the additional analyses presented in this section, hypothesis 9.1 is not confirmed. If better quality of care from the professional point of view was found in Almere, the effect is probably more related to the concept of 'multidisciplinary health centres' than to the 'Almere model' itself.

\subsection{Quality of care in general practice from patient's perspective}

After adjustment for the relevant conditions, better quality of care in Almere from the patients perspective is empirically related to important instruments of the Almere Health Care Demonstration Project. (Hypothesis H9.2)

In this section a comparison will be made between patient satisfaction scores for the GPs in Almere and GPs in other health centres (see also section 6.3.3, 6.3 .5 , and 6.3.5)

An important GP-characteristic related to the AHCDP was practice setting. All (except one) GPs in Almere worked in multidisciplinary health centres. Other variable in which the GP-population in Almere differed from the rest of the Netherlands were: number of years working as a GP (less experienced in Almere), gender (more female GPs in Almere), and list size (smaller practices in Almere).

A negative conclusion with respect to the AHCDP was that patient satisfaction scores for the way general practice was organized were relatively low. Hypotheses with regard to the accessibility of general practice and the personal workstyle of the general practitioner, had to be rejected on the basis of a direct comparison between Almere the Netherlands, with data for Almere age/gender adjusted. Here, data concerning patient satisfaction will be further analysed, first by making a direct comparison between the average patient satisfaction scores in Almere and other health centres in the Netherlands and secondly, by including these patient satisfaction scores in a multivariate design. 
Looking at the accessibility of general practice and the availability of the GP's services in the weekends and during the night, no differences in patient satisfaction scores are found between health centres outside Almere and patients with GPs working in other health care settings. The relatively low scores on patient satisfaction with the accessibility of general practice in Almere remain constant after the introduction of the health care setting in our analyses. Table 9.4 presents the percentages of satisfied patients, with the figures for Almere not being adjusted for the atypical population distribution according to age and/or gender.

Table 9.4 Satisfaction with the GP's accessibility as perceived by persons of 15 years and older in Almere $(N=793)$, health centres outside Almere $(N=1086)$ and the Netherlands $(N=10318)$. (Source: Study 93-2)

Almere $\begin{gathered}\% \text { 'never or ' } \\ \text { Health } \\ \text { centres }\end{gathered}$ Netherlands

experiences concerning accessibility visit refused

worried about accessibility in weekends worried about accessibility at night

$\begin{array}{lll}87.1^{* *} & 92.2 & 93.1 \\ 77.6^{* *} & 91.3 & 89.9 \\ 76.9^{* *} & 92.9 & 92.3\end{array}$

satisfaction with accessibility

well accessible in weekends and holiday periods $\quad \begin{array}{llll}6.9^{* *} & 3.4 & 2.8\end{array}$ well accessible in evening and at night

$7.3^{* * *}$

3.7

2.6

** = significant $p<01$, with Almere compared to health centres outside Almere

Another indicator with regard to the accessibility of health care services is the time patients have to wait when visiting the GP (or other services). As is shown in table 9.5, waiting times in multidisciplinary health centres outside Almere are slightly shorter than waiting times in Almere and significantly shorter than waiting times in other practice settings in the Netherlands. Waiting times longer than 45 minutes, which less frequently appeared in Almere than in the rest of the Netherlands, are also very seldom experienced by visits to general practices in health centres outside Almere.

With respect to patient satisfaction with the GP's social attitude and attitude towards prescribing medicines and referrals, table 9.6 shows that general practitioners working in health centres outside Almere take a position between physicians working in other practice settings and the GPs practising in Almere. In general, differences between Almere and the Netherlands are less pronounced when we limit our comparison to GPs working in multidisciplinary health centres. However, also in this comparison differences between Almere 
and health centres outside Almere do not disappear completely.

Table 9.5 Waiting times at general practices in Almere and the Netherlands in percentages (Source: Study 93-2)

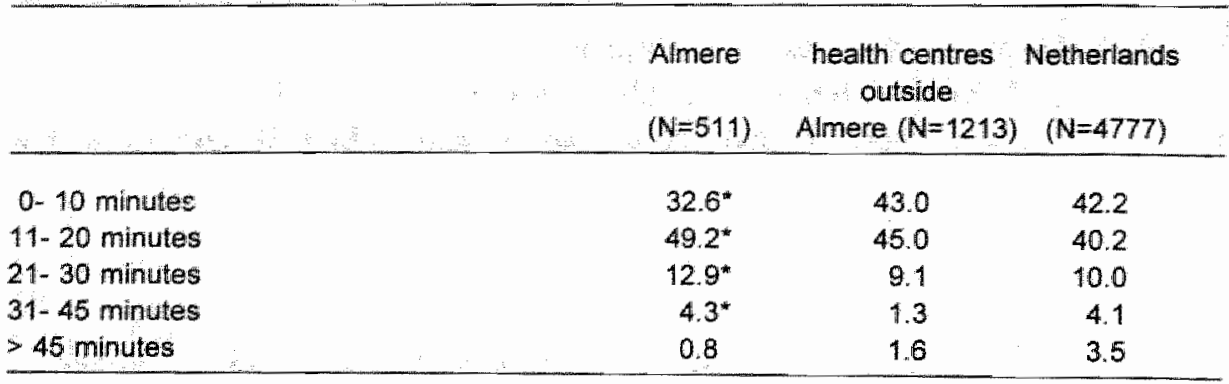

* = significant $(p<.05)$, compared to health centres outside Almere

Table 9.6 Appreciation for the general practitioners by persons of 15 years and older in Almere and the Netherlands (Source: Study 93-2)

\begin{tabular}{c} 
Almere $\quad \begin{array}{c}\% \text { 'mostly, always' } \\
\text { health centres Netherlands } \\
\text { outside Almere }\end{array}$ \\
\hline
\end{tabular}

Satisfaction with the GP's social attitudes

- GP explains my situation

- GP keeps patients at a distance

$81.2^{*}$

82.6

93.1

- GP explains what to do in case of illness

$11.5^{\text {क }}$

7.8

9.9

- GP treats me as a number

81. 8*

84.5

87.3

2.1

2.5

2.0

- GP is open to all my problems

- GP spends enough time to me

$75.8^{* *}$

82.9

83.8

- GP informs me about the seriousness

$88.2^{*}$

91.2

90.7

- GP takes me seriously

86.0

87.3

86.8

$88.8^{* *}$

94.6

95.2

Satisfaction with the GP's technical skills

- GP refers too quickly

- GP refers unnecessarily

- unnecessary prescription of medicines

- GP refuses prescription

0.9

0.7

0.3

0.6

0.9

0.2.

$3.1 *$

0.9

1.9

0.9

* significant $p<.05$, Almere compared to other health centres

* significant $p<.01$. Aimere compared to other health centres

As shown elsewhere (Sixma et al, 1994), the results from analyses at the patient (or GP) level are sometimes misinterpreted, when patients are selected from higher level variables like general practices. Here, two-level models (see 
Goldstein, 1987; Bryk and Raudenbush, 1992; Woodhouse et al, 1993; Snyders and Bosker, 1994) should be used, with patients characteristics (level 1) and GP/practice characteristics (level 2) included predictor variables. Differences between patient populations in Almere and the rest of the Netherlands, as well as specific characteristics of the "Almere model" on the GP-level, could be included in such an analysis. A dummy-variable whether or not it concerns a patient or a GP from Almere can be included in the fixed part of the model.

Patient satisfaction data with regard to the GPs in Almere were subsequently reanalyzed using two-level models. Dependent variables were the three different patient satisfaction scores based on scaled Likert-type items covering the accessibility of general practice, the social attitude (or humaneness) of the GP. and the amount of information given by the GP. Level- 1 variables were centred (see Raudenbush, 1989) before estimating the model ${ }_{\text {"with scores calculated as }}$ the deviation from the group (= level-2 unit) mean. Group means were added to the model as level-2 (GP-patient) variables. Patient level variables included in our analyses refer to specific characteristics of the Almere population, such as: age ( $P$ AGE), gender ( $P$ SEX), the number of psycho-social problems reported (P SOCPROB) the number of chronical diseases reported (P CHROPROB), the number of children at home (P CHILDFAM) and the frequency of visits to general practice (P FREQGP). At the GP-level, again, a series of predictor variables in which the GPs in Almere differed from their colleagues in the rest of the Netherlands were selected. These level-2 variables include: GP's attitude toward psycho-social problems (G PSYATT), GP's democratic attitude (G DEMOATT), attitude toward technical interventions (G TECHATT), number of contacts in which information is given to patients ( $G$ INFORATE), personal list size (G LISTSIZE), time between a telephone call and consultation ( $G$ CONSSP), number of instruments available (G INSTRU), degree of urbanization (G UIRBAN) and type of practice setting (G PRACTYPE). Not all variables were included in each of the three analyses, with selections being based on the results of earlier findings their relevance for explaining differences in the dependent variables. Table 9.7 shows the results of this two-level analysis.

Based on the parameters presented in table 9.7 " the conclusion is that differences in patient satisfaction scores were partly associated with characteristics of the situation in Almere. On the patient level, differences in the age-structure of the population and higher morbidity rates had an independent effect on patient satisfaction. At the GP-level, some personal characteristics of the general practitioner showed independent effects on patient satisfaction scores, but their relevance was limited. 
Table 9.7 Multi-level analysis of differences in patient satisfaction with the accessibility, humaneness and information given by the general practitioner between Almere and the Netherlands; coefficients and t-values (Source: Study 1992/1, Study 1992/3)

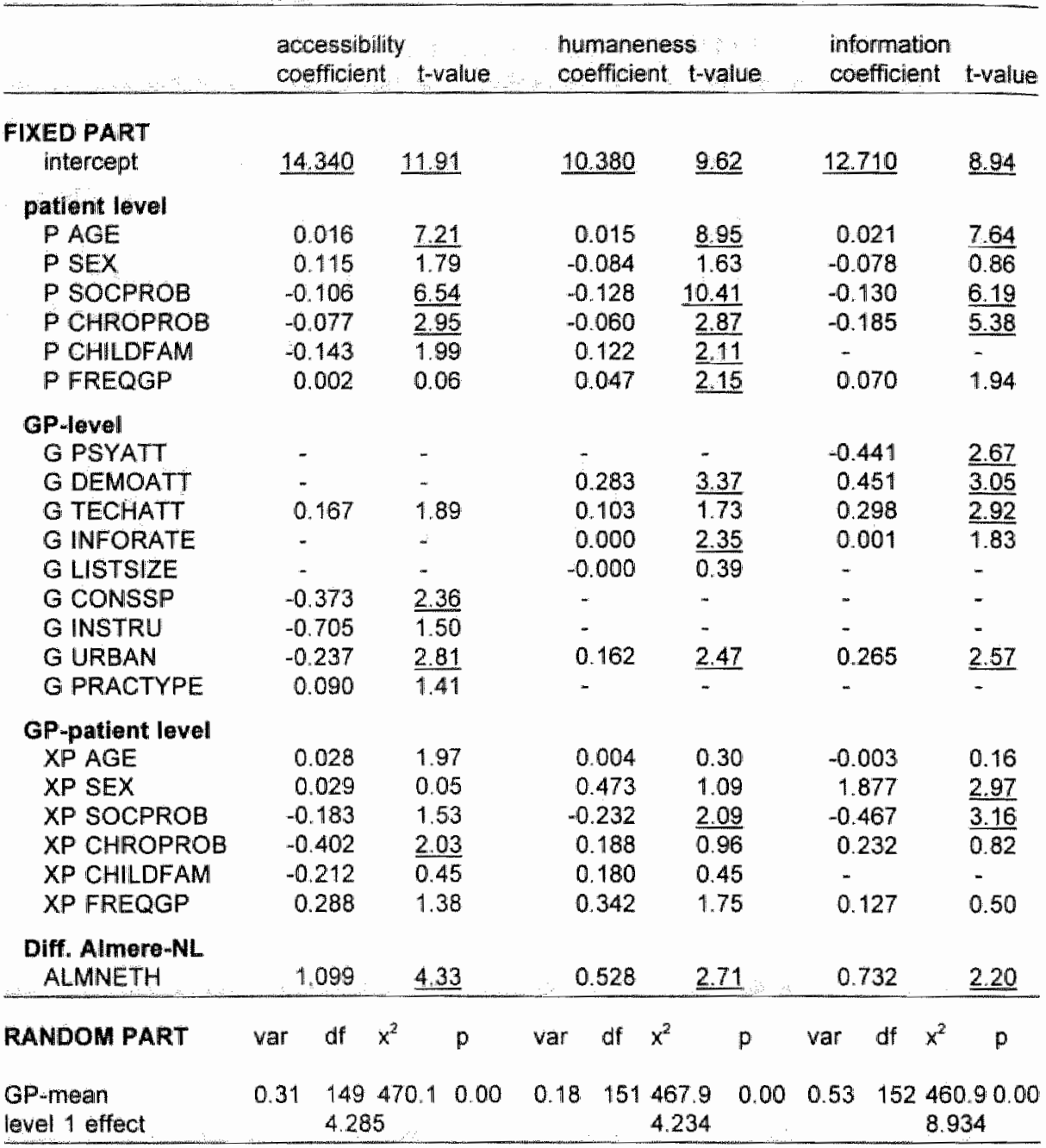

At the patient level, patients' age and morbidity status had the strongest effect on the level of the satisfaction scores. Satisfaction scores increase with age and with an increasing levell of morbidity. Level-2 (GP) variables like workstyle and attitudes of the general practitioner did have an independent effect on patients satisfaction, but only on the patients' opinion about a respectful treatment and the openness of the GP in giving information. Other level- 2 variables that represent the way general practice was organized, like whether or not one could 
make an appointment for the very same day, had an independent effect on patient satisfaction with the accessibility of general practice. Better opportunities to make an appointment for the same day, corresponded with higher satisfaction scores. Patients in rural areas were, generally speaking, more satisfied with the accessibility of the GP than patients in large cities. On the other hand, patient satisfaction scores with the humaneness of the GP and with the information which was received during a consultation were higher for general practitioners in the city than for GPs that are located in more rural areas.

Apart from these effects, information whether or not the patient is living or the GP is practising in Almere did show an independent effect on patient satisfaction scores. Apart from other patient and GP-characteristics, patients in Almere reported lower satisfaction scores on each of the three dimensions of the quality of care, than patients in the rest of the Netherlands. This effect was strongest for the accessibility of general practice, and somewhat less pronounced for the social attitude of the general practitioner and the amount of information which was given during consultation.

On the basis of the analyses presented in this section it can be established that differences in patients satisfaction scores are partly related to the 'Almere model' in general and partly to concentrating PHC-services in Almere in multidisciplinary health centres. Hypothesis $\mathrm{H} 9.2$ can therefore not be rejected.

\subsection{Substitution of care and cost containment at the level of the population of Almere}

After adjustment for relevant conditions, utilization of health care services in Almere is empirically related to important instruments of the Almere Health Care Demonstration Project. (Hypothesis H9.3)

One of the main conclusions from chapter 5 was that, compared to the average situation in the Netherlands, morbidity in Almere was relatively high. Also it was found in chapter 7 that, compared to the rest of the Netherlands and taking into account the higher morbidity figures for Almere, the utilization of the different health care services in Almere was relatively high (see table 7.11). The question to be answered in this section is whether these findings are empirically related to the fact that health care services in Almere are concentrated in multidisciplinary health centres. In order to do so, the use of health care services in Almere and patients enlisted with GPs practising in similar settings outside Almere, will be compared. The results of this comparison are shown in table 9.8 . 
Table 9.8 Utilization of health care services by the population of Almere compared to subsamples from the Dutch population (Source: Study 93-2)

Almere Health centres Netherlands

$(N=1013) \quad(N=1289) \quad(N=13016)$

$\%$ of the population having contact with

- general practice (2 months)

- physiotherapist (1 year)

- community nursing (1 year)

- social work (1 year)

- speech therapist (1 year)

- dietician (1 year)

- home help services (1 year)

- dentist (11 year)

- medical specialist (2 months)

- hospital admission (11 year)

- hospital admission (5 years)

- mental health services (1 year)

- mental health services (5 year)

- alternative medicine (1 year)

- alternative medicine (5 year)

- prescription of medicines (14 days)

- use of prescribed medicines (14 days)

- use of other medicines ( 14 days)
$42.9^{*}$

15.9

6.9

3.6

$2.6^{*}$

$3.5^{*}$

$1.7^{*}$

76.4

15.1

7.0

23.1

3.6

75

$7.0^{*}$

$12.3^{*}$

13.7

$26.2^{*}$

$29.3^{*}$
39.7

16.2

6.5

3.4

1.6

2.9

2.2

74.5

15.8

8.1

24.2

3.5

7.5

8.2

15.1

13.9

30.1

25.8
37.2

13.3

6.6

25

1.3

2.1

2.0

68.3

16.3

8.0

24.1

3.5

7.4

7.6

13.8

13.8

30.4

23.9

* = significant difference $(p<.05)$, Almere compared to health centres in the rest of the Netherlands

Table 9.8 shows that, in general, the use of health care services in Almere resembles the pattern for other patients of multidisciplinary health centres in the Netherlands. Especially when it concerns services which are generally represented in such health centres (e.g. physiotherapists, social work, community nursing and dentists) differences between the population of Almere and patients of other health centres are small and non-significant. With respect to the utilization of hospital services and alternative medicine the differences between Almere and the rest of the Netherlands remained constant after controlling for the health care setting in the rest of the Netherlands. On the basis of the results presented in table 9.8 we consider hypothesis $\mathrm{H} 9.3$ as partly confirmed. 


\subsection{Substitution of care and cost containment in general practice}

After adjustment for the relevant conditions, the way general practitioners in Almere are practising their profession, with respect to substitution of care and cost-containment is empinically related to important instruments of the Almere Health Care Demonstration Project. (Hypothesis H9.4)

In section 5.1.1 (table 5.1) and section 6.3.1 (table 6.12) it was shown that in Almere morbidity is higher than in the rest of the Netherlands, and that inhabitants of Almere more often called on professional care. Also it was shown see figure 5.1 - that during the demonstration project the population of Almere with respect to the age/gender distribution differed considerably from the average population in the Netherlands, and that the differences in morbidity were partly related to the specific age/gender structure of the Almere population. On the basis of the analyses presented in chapter 7 it was impossible to establish whether or not differences were related to other aspects of the AHCDP, such as concentrating $\mathrm{PHC}$-services in health centres.

In table 9.9 the number of contacts and interventions per 1,000 registered patients and per 1,000 contacts in general practice in Almere, can be compared with relevant subcategories in the Netherlands. For this comparison data for the individual GPS have been summed over the seven participating health care centres in Almere. Due to this transformation, the different rates can differ slightly from the figures on the GP-level presented in chapter 7 . Compared with the subcategories '(large) cities' and 'other health care centres' GPs in Almere saw significantly more patients than colleagues practising in similar settings. Especially the number of contacts during the comsultation hours in Almere were considerably higher. With reference to the number of home visits and the number of contacts that last llonger than 10 minutes. GPs in Almere resembled their colleagues in (large) cities and in other health care centres. With regard to the number of interventions per 1000 registered patients, GPs in Almere reported somewhat higher rates in requesting diagnostic activities (both inside and outside general practice), counselling, and the prescription of medicines that other GPs practising in multidisciplinary health centres.

Differences in the referral rates between the three subcategories shown in table 9.9 were small. In order to rule out differences in the number of patient contacts between the subcategories included in table 9.9, also data per 1,000 contacts are shown in this table. 
Table 9.9 Number of contacts and number of interventions per 1,000 registered patients and per 1,000 contacts in general practice in Almere and in different GP subcategories in the Netherlands (Source: Study 93-4)

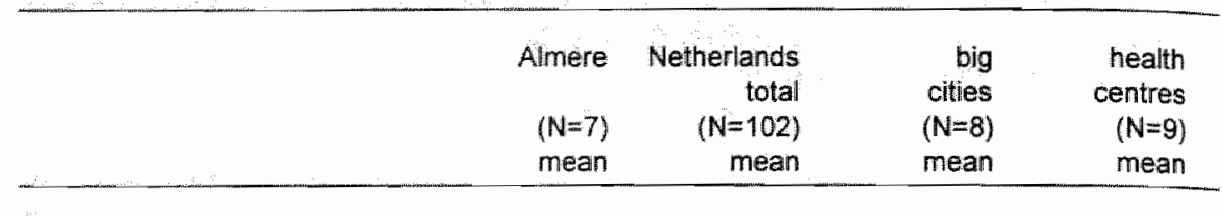

\section{Per 1000 registered patients}

\section{Number of contacts \\ - total \\ - with GP \\ kind of contact \\ - consultation \\ - home visit \\ - by telephone \\ - other and unknown \\ $\rightarrow 10$ minutes \\ procedures \\ diagnostics tatal \\ - diagnostic, intern \\ - diagnostic, external \\ counselling \\ prescription of medicine \\ referral secondary care \\ referral primary care \\ consultation after contact}

$\begin{array}{rccc}1257.2 & 1177.8 & 932.8^{* *} & 1038.6^{*} \\ 928.4 & 808.7^{* * *} & 719.1^{* *} & 774.7^{* *} \\ & & & \\ 693.7 & 566.7^{* * *} & 556.9^{* *} & 580.9^{* *} \\ 98.9 & 135.7 & 84.0 & 99.4 \\ 60.5 & 38.8 & 30.4 & 30.5 \\ 75.3 & 63.8 & 47.8 & 64.0 \\ 245.4 & 196.2 & 299.4 & 250.7 \\ & & & \\ 808.6 & 687.2^{*} & 627.0^{* *} & 675.9^{*} \\ 781.3 & 668.5^{*} & 601.4^{* *} & 653.1^{*} \\ 97.5 & 62.8^{* *} & 76.5 & 71.8 \\ 911.5 & 681.2^{* *} & 639.0^{*} & 731.7^{* *} \\ 736.8 & 775.6 & 588.9 & 610.9 \\ 69.7 & 69.8 & 75.4 & 68.3 \\ 49.7 & 33.9^{* *} & 43.4 & 47.2 \\ 30.8 & 17.9^{*} & 22.6 & 24.6\end{array}$

\section{Per 1000 contacts}

\section{Number of contacts}

- total

- with GP

\section{Kind of contact}

- consultation

- home visit

by telephone

- other

$\rightarrow 10$ minutes

procedures

diagnostics total

- diagnostic "intern

- diagnostic, external

counselling

1000.0

738.1

1000.0

701.2

1000.0

786.2

1000.0

750.1

552.8

78.9

48.9

57.5

196.8

638.6

617.1

77.3

725.4

prescription medicine

referral secondary care

585.9

referral primary care

55.6

39.7

495.9

$116.9^{*}$

612.6

92.7

564.3

33.7

54.7

174.4

31.2

97.2

27.4

49.7

61.2

$331.6^{*}$

242.4

consultation after contact

24.1

597.3

679.5

654.5

580.7

55.2

650.2

632.4

84.6

70.4

$586.8^{* *}$

686.8

710.4

651.4

627.7

589.9

61.7

$82.1^{*}$

66.5

$29.7^{* * *} \quad 45.7$

44.9

$15.4^{*}$

23.9

$*$ = significant $P<.05 * *=$ significant $P<.01$ 
With respect to the number of interventions per 1,000 contacts, general practitioners in Almere closely resembled the profile of GPs practising in health centres outside Almere. GPs working in (large) cities had significantly more contacts that last longer than 10 minutes. The same group of GPs had significant higher referral rates to medical specialists than GPs in Almere. Variation coefficients (not included in table 9.2) showed that general practitioners in Almere are more homogeneous in both the number of contacts and the procedures per 1,000 contacts than each of the other groups, although differences with GPs working in other health centres were relatively small for the prescription rate and the referral rates to medical specialists (for additional information about these variation coefficients, see: Sixma et al, 1993).

In table 9.10 more detailed information is shown about the number of interventions per 1000 contacts, including internal and external diagnostics, counselling, the prescription of medicines and referrals to secondary care and primary care institutions. With respect to the diagnostic services, the largest contribution to the relatively high number of these services on request of the Almere GPs was by the category 'physical examination'.

In all categories, differences between Almere and the two other relevant subcategories were small, except for the 'X-ray' and 'other' categories' where GPs in Almere reported somewhat higher rates than GPs working in multidisciplinary health centres outside Almere. Looking at the different forms of counselling, none of the differences between Almere and the two other subcategories from the national population reached the level of (statistical) significance. Within the different prescription categories, GPs in Almere prescribed significantly fewer analgetics than GPs in other health centres and somewhat less diuretics than GPs working in (large) cities. With respect to the referral rates to medical specialist table 9.10 illustrates that Almere GPs had the same pattern as GPs practising in health centres outside Almere. Here, general practitioners in (large) cities had relatively high referral rates to all categories of medical specialists.

Next, in table 9.11, details are presented on the number of preventive activities reported by GPs in Almere as compared with GPs practising in multidisciplinary health centres in the Netherlands. It is shown that GPs in Almere pay somewhat more attention to systematic screening programmes, whereas somewhat less attention is paid to a healthy life-style of patients. Regarding vaccination programmes differences between the two categories are non-significant. 
Table 9.10 Number of procedures per 1000 contacts in general practices in Almere, the Netherlands (Almere excluded) and two subcategories, in detail (Source: Study 93-4).

\begin{tabular}{|c|c|c|c|c|}
\hline & $\begin{array}{l}\text { Almere } \\
(\mathrm{N}=\overline{7}) \\
\text { mean }\end{array}$ & $\begin{array}{r}\text { Netherlands } \\
\text { total } \\
(N=102) \\
\text { mean }\end{array}$ & $\begin{array}{r}\text { big } \\
\text { cities } \\
(\mathrm{N}=8) \\
\text { mean }\end{array}$ & $\begin{array}{r}\text { health } \\
\text { centres } \\
(\mathrm{N}=9) \\
\text { mean }\end{array}$ \\
\hline dlagnostics & 638.6 & 597.3 & 679.5 & 654.5 \\
\hline diagnostics, internal & 6171 & 580.7 & 650.2 & 632.4 \\
\hline - physical examination & 569.3 & 545.3 & $603: 1$ & 584.3 \\
\hline - blaod & 27.2 & 18.1 & 15.2 & 21.3 \\
\hline - urine & 43.0 & 46.8 & 61.3 & 44.1 \\
\hline else & 16.5 & 10.8 & 7.6 & 13.7 \\
\hline diagnostics ${ }_{11}$ outside practice & 77.3 & $55.2^{*}$ & 84.6 & 70.4 \\
\hline - blood chemicals & 23.2 & 18.0 & 30.1 & 23.1 \\
\hline - haematology/serology & 25.8 & 18.8 & 28.9 & 25.8 \\
\hline - X-ray & 27.9 & $18.3^{* *}$ & 21.0 & 23.7 \\
\hline - else & 21.0 & 15.1 & 27.7 & 18.4 \\
\hline treatment in general practice & 725.4 & $586.8^{* *}$ & 686.8 & 710.3 \\
\hline - conversation & 307.2 & 252.7 & 367.5 & 234.9 \\
\hline - information + advice & 481.3 & $343.9^{k-k}$ & 380.8 & 442.9 \\
\hline - no immediate action & 41.2 & 40.1 & 31.9 & 59.4 \\
\hline - rules of life & 34.6 & 26.4 & 36.9 & 27.8 \\
\hline - medication without prescription & 32.1 & 21.9 & 31.9 & 21.1 \\
\hline - change in medication & 15.2 & 17.1 & 25.5 & 16.8 \\
\hline - medical/technical intervention & 60.6 & 66.1 & 42.5 & 68.2 \\
\hline - vaccination & 16.5 & 14.7 & 22.9 & 10.0 \\
\hline - else & 45.3 & 38.5 & 41.2 & 48.0 \\
\hline prescription of medicines & 585.9 & 651.4 & 627.7 & 589.9 \\
\hline - psycholeptics & 59.6 & 65.5 & 57.7 & 54.5 \\
\hline - systemic antibiotics & 43.6 & $57.2^{\star \star \star}$ & 56.8 & 47.3 \\
\hline - analgetics & 31.7 & $43.6^{* *}$ & 36.3 & $42.4^{*}$ \\
\hline - sex hormones & 41.4 & 39.7 & 45.1 & 41.0 \\
\hline - diuretics & 24.5 & $35.7^{* * *}$ & $344^{* *}$ & 27.8 \\
\hline - cough/cold medicines & 38.8 & 38.6 & 47.1 & 40.1 \\
\hline - beta blockers & 23.4 & 26.9 & 27.8 & 20.3 \\
\hline - antl-rheumatic medicines & 30.2 & 39.4 & 33.3 & 32.7 \\
\hline - Medicines against COPD & 18.5 & 21.9 & 16.3 & 47.2 \\
\hline - medicines for nasal use & 25.4 & 22.0 & 29.6 & 29.6 \\
\hline - other medications & 278.2 & 298.2 & 287.0 & 271.2 \\
\hline referrals secondary care & 55.6 & 61.7 & $82.1 *$ & 66.5 \\
\hline - surgical specialisms & 34.6 & 37.4 & $49.9^{* *}$ & 40.9 \\
\hline - non-surgicall specialisms & 20.8 & 24.0 & 31.6 & 25.2 \\
\hline - mental health care & 2.7 & 2.7 & 4.9 & 3.8 \\
\hline referrais primary care & 39.7 & $29.7^{* * *}$ & 45.7 & 44.9 \\
\hline - physiotherapy & 249 & 22.3 & 29.8 & 31.1 \\
\hline - else & 15.1 & $7.6^{* *}$ & 16.3 & 14.2 \\
\hline consultation & 241 & $154^{*}$ & 239 & 23.8 \\
\hline
\end{tabular}

* = significant $P<.05 \quad * *=$ significant $P<.01$ 
Table 9.11 Prevention activities of general practitioners in Almere and GPs in other health centres in the Netherlands, in percentages. (Source: Study 93-1)

\begin{tabular}{|c|c|c|c|c|}
\hline & \multicolumn{2}{|l|}{$\begin{array}{l}\text { Almere } \\
(\mathrm{N}=29)\end{array}$} & \multicolumn{2}{|c|}{$\begin{array}{l}\text { Netherlands } \\
(\mathrm{N}=15)\end{array}$} \\
\hline & $\begin{array}{r}\text { not } \\
\text { systema- } \\
\text { tically }\end{array}$ & $\begin{array}{c}\text { systema- } \\
\text { tically }\end{array}$ & $\begin{array}{r}\text { not } \\
\text { systema- } \\
\text { tically }\end{array}$ & $\begin{array}{r}\text { systema- } \\
\text { tically }\end{array}$ \\
\hline screening for hypertension & 82.8 & 17.2 & 80.0 & 20.0 \\
\hline screening for cervical cancer & 6.9 & 93.1 & 26.7 & 73.3 \\
\hline instructions on breast examination & 71.4 & 28.6 & 86.7 & 13.3 \\
\hline \multirow[t]{2}{*}{ screening for diabetics } & 96.4 & 3.6 & 93.3 & 6.7 \\
\hline & $\begin{array}{l}\text { always/ } \\
\text { most of } \\
\text { the time }\end{array}$ & $\begin{array}{r}\text { sometimes/ } \\
\text { seldom/ } \\
\text { never }\end{array}$ & $\begin{array}{l}\text { always/ } \\
\text { most of } \\
\text { the time }\end{array}$ & $\begin{array}{r}\text { sometimes } \\
\text { seldom } \\
\text { never }\end{array}$ \\
\hline \multicolumn{5}{|l|}{ Smoking } \\
\hline informing about smoking behaviour & 13.7 & 86.3 & 26.7 & 73.3 \\
\hline informing in case of complaints & 96.6 & 3.4 & 100.0 & 0.0 \\
\hline informing with risk patient & 93.1 & 6.9 & 100.0 & 0.0 \\
\hline \multicolumn{5}{|l|}{ Drimking alcohol } \\
\hline informing about alcohol use & 3.6 & 96.4 & 20.0 & 80.0 \\
\hline informing in case of complaints & 1000 & 0.0 & 100.0 & 0.0 \\
\hline \multirow[t]{2}{*}{ informing with risk groups } & 828 & 17.2 & 93.3 & 6.7 \\
\hline & $\begin{array}{l}\text { in case of } \\
\text { complaints }\end{array}$ & always & $\begin{array}{l}\text { in case of } \\
\text { complaints }\end{array}$ & always \\
\hline advising smokers to stop & 55.2 & 44.8 & 40.0 & 60.0 \\
\hline advising 'fatties' to lose weight & 69.0 & 31.0 & 73.3 & 26.7 \\
\hline \multirow[t]{2}{*}{ advising 'drinkers' to stop } & 27.6 & 72.4 & 33.3 & 67.7 \\
\hline & yes & no & yes & no \\
\hline \multicolumn{5}{|l|}{ Care of the elderly } \\
\hline extra care & 24.1 & 75.9 & 31.2 & 68.8 \\
\hline extra attention at consultation & 65.5 & 34.5 & 62.5 & 37.5 \\
\hline syst examination at consultation & 0.0 & 100.0 & 24.5 & 75.5 \\
\hline \multirow[t]{2}{*}{ home visits (syst) } & 17.2 & 82.8 & 25.0 & 75.0 \\
\hline & $\begin{array}{l}\text { per } 1000 \\
\text { patients }\end{array}$ & $\begin{array}{l}\text { per } 1000 \\
\text { contacts }\end{array}$ & $\begin{array}{l}\text { per } 1000 \\
\text { patients }\end{array}$ & $\begin{array}{r}\text { per } 1000 \\
\text { contacts }\end{array}$ \\
\hline vaccinations, total & 27.7 & 21.6 & 27.2 & 22.4 \\
\hline tetanus & 2.0 & 1.6 & 2.1 & 1.7 \\
\hline fllu & 23.0 & 18.0 & 22.3 & 18.0 \\
\hline hay fever & 0.9 & 0.7 & 1.0 & 0.9 \\
\hline DTP injection (also pertussis) & 0.3 & 0.3 & 1.0 & 0.9 \\
\hline bmr & 0.2 & 0.2 & 0.3 & 0.3 \\
\hline other & 1.3 & 1.0 & 1.3 & 1.1 \\
\hline
\end{tabular}


On the basis of the evidence presented in table 9.9 to 9.11 it can be established that general practitioners in Almere resemble the style of working of other GPs working in multidisciplinary health centres. Since working in such health centres is one of the key elements of the AHCDP, hypothesis H9.4 cannot be rejected. However, with respect to the preventive activities of the GPs in Almere hypothesis $\mathrm{H} 9.4$ cannot be confirmed.

\subsection{Conclusions}

During the implementation of the Almere Health Care Demonstration Project a series of evaluation studies was carried out. The majority of these were of a cross-sectional design. Due to absence of groups to compare with, it was difficult to compare figures for Almere with figures for the rest of the Netherlands. Therefore, as a consequence of the demonstration project being a field experiment, it is not possible to provide an unequivocal answer as to whether the instruments, conditions and goals were empirically related.

With respect to the quality of care related goals, the results of the analyses presented in section 9.3 of this chapter suggest that some of the aspects related to the Almere Health Care Demonstration Project were empirically related to the quality of care concept. The hypothesis that general practitioners working in health care centres and group practices perform better quality of care from the professional point of view cannot be rejected. Two-level analyses of the results with respect to GPs performances on eight professional guidelines (prior to the date these guidelines were published) showed the variable 'working in a multidisciplinary health centre' having an independent effect on the 'quality of care'. With multidisciplinary health centres being regarded as one of the cornerstones of the AHCDP, the hypothesis that this element of the 'Almere model' is related to better quality of care from the providers' perspective cannot be rejected.

The fact that patient satisfaction scores with the work of the general practitioner are relatively low in Almere, can be seen as one of the negative outcomes of the Almere Health Care Demonstration Project. These lower satisfaction scores were partly rellated to the special characteristics of the 'Almere model'. If we control for these characteristics, such as differences in the age structure of the population, higher morbidity rates at the population level, and the practice setting of the general practitioners satisfaction scores in Almere remain somewhat behind similar scores for general practitioners working in the rest of the country under different circumstances. 
With respect to their attitudes and the intervention patterns, general practitioners in Almere compared to their counterparts in the Netherlands showed lower prescription- and referral rates. These were related to the structure of the primary health care sector in Almere. However, focusing on health care centres, both attitudes and intervention patterns were almost similar in Almere and the rest of the Netherlands. Since the multidisciplinary health centre concept is an important element of the AHCDP, the hypothesis referring to the empirical relationship between instruments and goals on this subject cannot be rejected.

Table 9.12 Overview of the degree in which some of the outcomes of the Almere Health Care Demonstration Project are empirically related to the instruments applied and the conditions experienced

Hypotheses

Result

HQ. 1

empirical relationship between the quality of care from the professional point of view and the experimental setting of Almere

partly confirmed

$H 9.2$

empirical relationship between the quality of care from the patients point of wiew and the experimental setting in Almere

confirmed

H9.3.

empirical relationship between utilization of health care services and the experimental setting of Almere

partly confirmed

H9.4

empirical relationship between the workstyle of the GP

in Almere and the experimental setting of Almere

partly confirmed

Despite the relationship between the concentration of health care services in multidisciplinary health centres and output criteria such as production figures and levels of satisfaction, the 'Almere model' can still be considered as a 'black box' in which instruments, conditions and goals were theoretically related to each other. A 'black box' in which the majority of these were directed towards the structure of the health care system in Almere was realized. However, instruments directed at the care giving process were not implemented and expected conditions proved to be optimistic. Finally, the new health care system clearly differed from the system in the remainder of the Netherlands. The Almere health care system proved to offer good quality of care and some substitution of care, at approximately equal costs compared to the remainder of the Netherlands. Based on the evidence presented here it is difficult to establish a 'true' empirical relationship between instruments, goals and conditions of the Almere Health Care Demonstration Project. 
This chapter will summarize the most important results of the Almere Health Care Demonstration Project and provide an answer to the four research questions presented in chapter 1. The chapter will end with a brief conclusion.

\subsection{Conceptual framework and research questions}

The Almere project can be regarded as a field experiment testing the basic ideas of Dutch health care policy developed in the mid 1970s. The underlying factor of the experiment was that a more cost/effective system of health care services could be achieved by reinforcing the primary health care sector and limiting the capacity of the hospital sector, subsequently resulting in a less frequent use of secondary care institutions. In accordance with the policy of the World Health Organization, primary health care was organized in multidisciplinary health centres, with services provided under managed care conditions of one PHCorganization. Such a structure would facilitate more adequate problem solving by the health care system. Other important characteristics of the Aimere project were (1) to reduce the production stimuli within the secondary care sector as much as possible by implementing the employment status for all medical specialists in Almere; and (2) to limit all planning and financing activities in the hands of one authority: the local municipality to achieve structural and functional cohesion. An umbrella organization under the responsibility of local government would facilitate structural cooperation between the different sectors and echelons of care.

Both before and after the start of the Almere project government influence on health care organization was not as predominant as during the period between 1975 and 1985 . Therefore, the study on the demonstration project should be embedded in a policy analysis covering the pro-and preceding period. It should de taken into account that the national policy and Almere policy were in accordance and disaccordance at different times. Research question $\mathrm{Q} 1$, derived from this policy context, formed the background of this study.

Q1 How does the Almere Health Care Demonstration Project fit into the increased tendency to allow more government influence in the organization of the Dutch health services in the mid 1970s and the subsequent shift in national health policy towards the introduction of market elements in the mid 1980s? 
The idea was that a new structure of health care services, different from the health care structure in the rest of the Netherlands, was achievable since the entire system was yet to be set developed and vested interests therefore would play a less important role in Almere. The structure of health care facilities in Almere had to fulfil three goals: (1) substitution of care, based on a shift from into outpatient, from secondary to primary, from curative to preventive, and from professional to informal care, (2) provision of best possible quality of care, and (3) result in lower or equal expenditure than in the 'traditional' Dutch health care system.

Figure 10.1 Model for the evaluation of the Almere Health Care Demonstration Project, (Source: Stake, 1967)

PLANNED

PROGRAMME

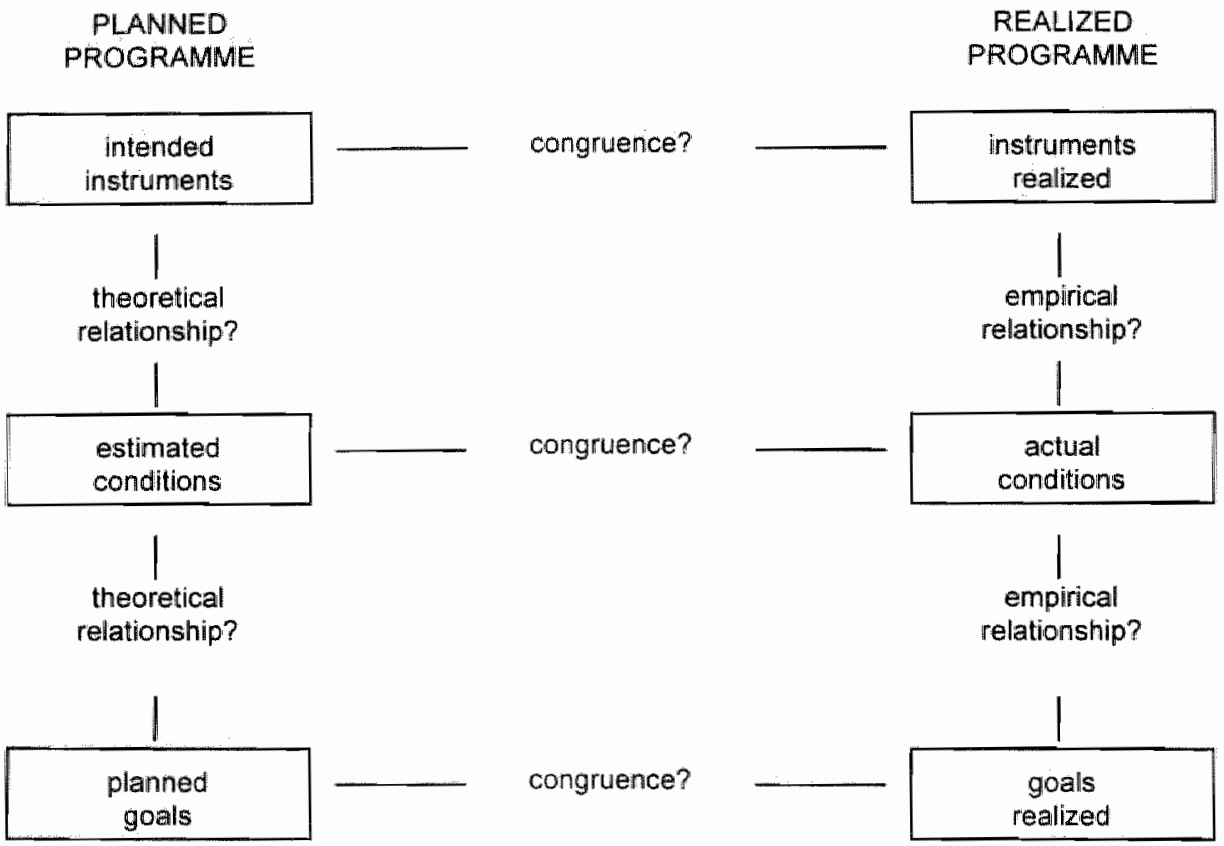

REALIZED

PROGRAMME

Goals, instruments, and conditions of the Almere Health Care Demonstration Project were related to each other. This is shown in the conceptual framework used for evaluating the policy programme (figure 10.1). When applied to the basic ideas of the Almere project, three fundamental research questions were derived from this conceptual model. These three questions were:

Q2 Was it realistic to expect that, given the instruments selected and the conditions expected, the Almere Health Care Experiment would be successful in achieving its goals of substitution, quality and costs? 
Q3 Was the experimental health care setting in Almere successfully implemented and were the goals formulated in 1983 actually achieved?

Q4 Are the goals of the Almere Health Care Experiment empirically related to the way the health care system in Almere was shaped?

\subsection{The political context of the Almere Health Care Demonstration Project; research question Q1}

How did the Almere Health Care Demonstration Project fit into the increased tendency to allow more government influence in the organization of the Dutch health services in the mid 1970 s and the subsequent shift in national health policy towards the introduction of market elements in the mid 1980 s?

The general aim of chapter 2 (and parts of chapter 5) of this book was to provide a description of the policy context in which the Almere project was developed and implemented. On a national level, political and economic developments were investigated for the period from 1945 to 1983 . This period was divided in three parts. Between 1945 and 1960 the political scene was dominated by a centre-left coalition government. Efforts concentrated on rebuilding and strengthening society by means of strong governmental influence, including the health care sector and were successful. At the end of this period, the entire country as well as its health care system were facing rapid growth facilitated by prosperous economic prospects.

Between 1960 and 1973, political power was in the hands of a central-right coalition. During this period governmental influence on the structuring and functioning of health care services gradually diminished. Continuous economic growth lead to a steady increase in health care expenditures. In addition, more people made use of an increasing number of health care services. Democratization among patients and patient groups, diversification and professionalization within the health care sector, a constant flow of new technical developments in health care and the increase of services included in the Sick Fund package, resulted in an increase in health care expenditure. However, this increase did not lead to significant problems due to a corresponding increase in the Gross National Product.

When the Netherlands, similar to other industrialized countries, encountered a period of economic recession in 1973, this however changed. In order to cope with the economic problems and to improve the central governments' weakened financial position, budgetary restrictions were considered to be necessary 
especially in the health care sector. In order to restore the cost-effectiveness balance, the centre-left government decided to concentrate on a shift towards more governmental influence in the health care sector, in combination with efforts to strengthen primary health care services. On the national level, the Almere Health Care Demonstration Project can therefore be seen as an effort to implement this governmental policy on a small scale under almost ideal circumstances. Goals and strategies of the Almere Health Care Demonstration Project were in line with national health care policy.

In chapter 5 the conditions experienced during the implementation process of the Almere Health Care Demonstration Project were discussed. The leading principle of health care policy in the Netherlands changed in the second half of the 1980 s. Starting with the 'Dekker proposals' in 1986 a shift, from a government regulated health care system (back) to a system where the organization and structure of health care services were dependent and sensitive to market conditions, became visible.

\subsection{The theoretical relationship between goals, instruments, and conditions; research question Q2}

Was it realistic that, given the instruments selected and the conditions
expected, the Almere Health Care Demonstration Project would be
successful in achieving its goals of substitution, quality of care, and costs?

More specifically, we have tried to answer whether it is reasonable to expect that substitution of care, and high quality and low costs could be achieved by developing a health care system like the one planned for Almere.

Goals, conditions and planned instruments were derived from the different projectplans of the health care demonstration project in Almere, and were linked to each other. The relationships between goals, instruments and conditions were examined on the basis of the existing literature.

The assumption that within a new polder the health care system, which differs considerably from the existing health care system, can be regarded as reasonable. The failure of similar plans in Lelystad and its surrounding area, proved that a 'tabula rasa' situation is no guarantee for success.

The planning of a reinforced, integrated primary health care system, combined with a limited capacity of the hospital sector, were appropriate instruments to achieve substitution of care from a theoretical point of view. The underlying assumption was, that some of the work carried out in hospitals (like emergency care or diagnostic services) could also be carried out in primary care. The 
empirical foundation for this hypothesis is supported by research data that show large variations in hospital care and primary care referral data. That such a shift could also lead to cost reduction is principally derived from the assumption that for the same treatment a visit to the hospital generates higher costs than a visit to one of the primary health care institutions. This assumption is also stpported by empirical evidence.

Regarding quality of care, it was assumed that following more cooperation between health care providers and improvement of the quality of care, more people would choose to be treated in the primary health care sector. This assumption is confirmed by empirical research.

The answer to our first research question can therefore be brief. In principle, the instruments chosen for implementation of the Almere Health Care Demonstration Project and expected conditions, were appropriate to achieve the goals formulated for this field study.

\subsection{The relationship between theory and practice; research question Q3}

Was the experimental health care setting in Almere successfully implemented and were the goals formulated in 1983 actually achieved?

To provide an answer to this fourth research question the main conclusions from chapter 4 to 9 will be summarized.

\subsubsection{The process of implementation}

in describing the period, between the first inhabitants moving to Almere in 1976 and the end of the Almere Health Care Demonstration Project in 1992, three periods were distinguished: (1) the pre-experimental period between 1976 and 1983, (2) the implementation period between 1983 and 1992, and (3) the postexperimental period from 1993 onwards.

With reference to the pre-experimental period, two important conclusions can be made. (1) A clean start in 1983 was not possible, due to health care workers and health care institutions having established themselves in Almere from 1976 onwards. (2) The decision to transfer an existing hospital from Amsterdam to Almere did not satisfy the expectations of the policy makers in Almere. The bureaucratic structure of this old hospital, in combination with medical staff and the board of directors resenting the move to Almere, resulted in a series of conflicts: first about the size of the hospital and secondly about the employment 
status of the medical specialists. The policy makers won the first conflict, a number of beds in accordance with the original plans was realized. The second conflict was won by the medical specialists, resulting in a situation where the majority of medical staff members worked as independent entrepreneurs.

The period in which the new health care structure in Almere was supposed to be implemented is probably best characterized by the conclusion "structure goes before process'. Following the original plans, the structure of a new health care system in Almere was almost completely implemented in the ten years period of the experiment. There are, however, two important exceptions. The first one concerns the employment status of hospital staff, which could not be forced into the status of salaried employees. This decision disrupted the relationship with primary health care workers in Almere for a long period of time. Secondly, due to the absence of adequate legislation it proved to be impossible to realize unity in the financial and structural planning of health care facilities in Almere. Apart from that, the process to build a new health care structure in Almere proved to be more difficult than expected, resulting in serious delays in completing all tasks on time. Due to these delays and the efforts that had to be vested in order to implement the structure, instruments directed towards the care giving process were no longer predominant during the process of implementation.

The post-experimental period, which started in November 1992, resulted in four important developments. (1) A shift, from the model in which all health care services worked together towards one health care policy under the authority of local government, to a model in which 'strategic alliances' were to become the dominant factor. Such alliances were established to coordinate health care services with hospital admissions, for the frail elderly, and for pre- and perinatal care. (2) Allowing a limited number of GPs to set up a single-handed practice, rather than insisting in all general practitioners to work in a multidisciplinary health care centre. (3) The central government's decision and that of the health insurance organization to discontinue additional financial support for the health care organization in Almere. (4) A reorganization of the Almere Primary Health Care Foundation in 1996, to illustrate differences between the organizational levels, followed by the announcement that the APHCF and the Delta Foundation were to merge on 1-1-1998 (Stichting EVA, 1997).

\subsubsection{Instruments directed towards the quality of care}

The goal to maximise quality of the health care system in Almere was further divided: (1) the quality of the organization and the organizational structure, (2) the quality of the health care workers, and (3) the quality of the process of health care delivery.

With the foundation of the Almere Health Care Cooperation (Samenwerkings- 
verband Almeerse Gezondheidszorg or SAG) in 1989, cooperation was realized between all health care services. Further umbrella organizations were created for primary care, care for the elderly and the care for the mentally and physically handicapped. At the end of the Almere Health Care Demonstration Project primary health care in Almere was almost exclusively provided by district or neighbourhood oriented health care centres. This was in accordance with the original goals and therefore can be regarded as a successful example of the central planning. Patient participation materialized in the form of management activities of health care centres and other provisions and through the realization of the Foundation of Information and Support Patient Association (Stichting Informatie en Organisatie Patientenverenigingen or SIOP). The development of the Health Care Information Model Almere (Gezondheidszorg Informatie Model Almere or G(MA) created the basis for a future coherent data collection, although so far this information model never became fully implemented.

Not, or not completely, realized were: (1) the epidemiological data collection of sentinel stations, (2) a commonly used system for the assessment of symptoms, (3) participation of PHC representatives on the management board of the hospital, (4) set consultation and meetings hours (apart from case meetings in which the medical staff of the hospital and general practitioners participate), (5) a complete set of guidelines and protocols for the treatment and transfer of patients within and between the different services ${ }_{\text {" }}$ and (6) the items mentioned in the preceding section, such as the employment status for all members of hospital staff and an integrated system of financial and structural planning.

\subsubsection{Instruments directed towards substitution of care}

Instruments directed towards substitution of care aiming at the structure of health care provisions were almost completely realized. The most important of these instruments were:

- the Almere Primary Health Care Foundation (the Eerstelijns Vereniging Almere or EVA), which became the umbrella organization and employer of nearly all primary care workers in Almere;

- the realization of the Delta Foundation, which umbrella organization united all services directed at care for the elderly;

- the realization of umbrella organizations for mental and psycho-social care;

- the realization of a relatively small hospital (the Flevo hospital), with comparatively large outpatient departments, considerable day care facilities and additional facilities to support PHC-services in Almere:

- the realization of a combined nursing/old people's home;

- the Almere Health Care Cooperation (the Samenwerkingsverband Almeerse Gezondheidszorg or SAG), which organization united all health care services in Almere. 
Not realized were:

- the instigation of a planning authority for the Almere health care provision system under municipal direction;

- unity in the planning and financing of health care facilities under the authority of the local authorities;

- salaried employment for all medical specialists in the new Flevo hospital in Almere.

Instruments aiming at the content of the care process and cooperation between the different health care sectors and services were only partly implemented. The realization of multidisciplinary thealth centres and the APHCF facilitated this process within the primary health care sector, resulting in guidelines for cooperation between services, extending the range of services and systematic medical education. Cooperation between the primary care sector and the hospital sector remained difficult, due to the late opening of the Flevo hospital. Despite the ambitious plans, only a few co-operative projects (e.g. oncology and obstetric) were set up in the years immediately before and after the opening of the Flevo hospital. When the Flevo hospital was opened in 1991, guidelines and protocols to formalize the relationships between the hospital and other health care services in Almere had still to be established and proceeded very slowly due to the lack of trust between the different partners.

\subsubsection{Instruments aimed at the costs of health care}

Apart from an integrated planning and financing system and the salaried employment status for all medical specialists, most instruments directed at the structure of the health care system were implemented. Instruments that were aimed at cost control by influencing the process of health care delivery, did not exist or had only be implemented to a limited extent at the end of the demonstration project.

\subsubsection{The operative conditions}

The first, and probably most important condition was the 'tabula rasa' situation of Almere. Two other conditions were specified in chapter 3 . The second condition concerned the consequences of building an entirely new city and the possibilities to tune the development of health care services into the broader planning activities. The third condition specified the continuity in governmental, regional and local policies towards the planning, organization and financing of care facilities. 


\section{The 'tabula rasa' situation in Almere}

At the start of the Almere Health Care Demonstration Project no 'tabula rasa' situation existed. The city had 23.000 inhabitants, five health centres and a number of outpatient facilities. However, many of the organizations concerned with Almere's health care, such as the Almere Primary Health Care Foundation or the Delta Foundation, started to function as 'new' organizations. For these 'new' organizations, the condition seemed to be satisfied.

For the Flevo hospital the situation differed. Taking over a new building and accepting a new name masked the fact that this consisted of no more than the transfer of the existing infrastructure and work culture. Problems appearing "such as extensive discussions concerning bed capacity and the employment status of the medical specialists "can be related to these differences in culture and workculture. That the hospital was completed in the final phase of the Almere experiment caused complications with respect to the coordination of services between the primary health care and hospital sector. On reflection, one important conclusions is that the decision to transfer the Burgerziekenhuis to Almere was not the most favourable one and in this respect was less successful than anticipated.

\section{The population of Almere}

An assumption of the Almere Health Care Demonstration Project, was that the population growth would be in parallel with the growth in health care provisions, which was confirmed. However, the population structure in Almere is atypical compared to the Netherlands, in respect to age and gender. Interpreting morbidity data and data about the use of health care services have therefore to be treated with caution.

A further assumption was, that morbidity rates in Almere would not differ from the rest of the Netherlands. However, in contrast with the Netherlands as a whole, morbidity in Almere is relatively high with regards to acute, somatic psychic and psycho-social complaints. The latter applies particularly to women. These differences in morbidity rates result in the Almere's population's higher medical consumption. These issues, therefore, need to be taken into account in examining the original goals of the project.

\section{Continuity in Dutch health care policy}

A main conclusion in chapters 4 and 5 , was that the existing Dutch legislation was hardly, if at all, applicable to an experiment such as that in Almere. This applies both to the legislation regarding the structure of health care provisions (e.g. the combined nursing/old people's home), and to the financiall constraints 
for the operation. Solutions for the incorporation of new ideas into existing legislation and planning procedures were achieved. This nevertheless caused serious delay, for example the combining of the nursing and old people's home "De Kjekendief, but also by the protracted process in achieving the Decree for the Almere Health Care Demonstration Project through parliament, thus giving it a legal basis. In the absence of legislation it was difficult to set up rules to enable planning and financing of all health care provisions through one financial and structural framework, thus rendering it impossible to reach a system based on integrated health care planning as anticipated by the Almere Health Care Demonstration Project. In the absence of such a comprehensive framework it was difficult to achieve the goal of such a system whereby disciplines, institutions and echelons are no longer in a competitive environment.

At the start of the Almere Health Care Demonstration Project it is was anticipated that there would be continuity in health care policy at the national and local level. Chapter 5 showed that at the government's level of attention shifted during the demonstration project from developments planned and directed by the government to a more prominent role for the market forces. At the local level, attention gradually shifted from the health care sector to other policy sectors, following the realization of important structural facilities (e.g. the new hospital, the combined nursing/old people's home, multidisciplinary health centres). Consequently, the local government did not take on the leading role previously fulfilled by the Steering Committee during the first six years of the demonstration project. As to whether these policy developments have influenced the implementation of the instruments and the achieved results is difficult to assess. However, it appears that lack of interest of local government and the loss of additional means to support the experiment were important factors in the decision to abandon the experimental setting in Almere.

\subsubsection{Goals realized}

Three of the most important goals of a new system of health care services focused on: (1) quality of care, (2) substitution of care, and (3) cost containment, and where possible a reduction in costs. Bearing these three goals in mind the conclusions from the chapters 6,7 and 8 will be briefly summarized.

\section{Goal: quality of care}

In respect to quality of care three aspects were examined: (1) the structure in which health care services and individual health care workers function, (2) the quality of the health care process from the prospective of the health care provider, and (3) the results from patient satisfaction studies conducted in Almere and the Netherlands. 
Building and maintaining a primary care based system of health services was one of the most important goals of the project. General practitioners and district nurses in Almere did not differ in their perceptions of tasks from those in the Netheriands. Their attitudes did not appear to be attuned to the goals formulated in the project plan, whilst their equipment seemed to be more complete than of the average practice. The existing infrastructure favoured an increase in the problem solving capacity of the primary health care services.

Regarding the care giving process general practitioners and district nurses provided a large number of their patients with information and advice. General practitioners in Aimere acted somewhat more in accordance with the (later published NHG) professional guidelines, although this conclusion did not apply to all eight guidellines investigated. The concentration of primary care services in multidisciplinary health centres resulted in a relatively high level of discussion and consultation between the different care providers in Almere. This can be described as more cohesion form of care. Regarding continuity of care, positive points included for instance the integration of nursing care and old people's home in 'De Kiekendief'; negative points included the relative high percentage of GPs in Almere who ceased practising or moved from managers.

Finally, in respect of the opinions of the inhabitants of Almere about the functioning of health care services and health care providers, the picture which emerged from the research regarding patient satisfaction was that the majority was satisfied. Furthermore, on a number of services Almere's inhabitants were more satisfied than their counterparts elsewhere, including the accessibility of health care services during office hours, the functioning of the emergency services, and waiting times in child health clinics. For other aspects, however, satisfaction was significantly lower than for the remainder of the Netherlands (e.g. the accessibility of the health care services outside the office hours other than emergency care, waiting times while visiting the GP). Possible explanations for these lower levels of patient satisfaction towards the general practitioners are, a (1) limited choice of GPs, (2) tendency towards bureaucratization with individual GPs feeling less responsible for activities "like the accessibility of primary care services, and (3) more critical attitude of the population of Almere due to the high expectations or previous experiences.

\section{Goal: substitution of care}

Project plans published as part of the Almere Health Care Demonstration Project, did not mention substitution of care as one of the main objectives. The starting-point was a coherent system of care provisions, related to the needs of Almere's inhabitants, with emphasis on the primary care sector and with secondary care in a supportive role. This primary health care based system was ideologically in line with the health care policy of the mid 1970s. During the 
demonstration project, substitution of care was regarded by the central government and the funding bodies as an instrument towards cost containment and reduction in costs. Three different aspects of substitution of care have been examined: (1) substitution within the hospital sector, (2) substitution of secondary to primary care, and (3) substitution of professional to informal care, and from curative to preventative care.

Data on the utilization of clinical facilities within Almere show that the operational goal to decrease the use of these facilities compared to the Netherlands was not realized. Furthermore, hospital utilization figures do not support a shift from hospital utilization to other forms of care. The average length of hospital stay per admission for the population of Almere was shown to be consequently lower than when compared to the rest of Netherlands, although differences are small.

An integrated system of primary health care services in Almere would result in a relatively low referral rate to medical specialists and lower hospital admission rates. Although the number of contacts with general practice in Almere per 1000 patients is relatively high, GPs' referral rates to the medical specialists compared to the average Dutch GP are low, suggesting that the increased morbidity rate of the population could be dealt with by the primary health care institutions in Almere. A further success of the demonstration project are the primary health care emergency centres. Emergency care is offered in the health centres during office hours, resulting in relatively few people directly attending the hospital's emergency department.

Examining the shift from professional to informal care, and from curative to preventive care, there is little evidence to suggest that such shifts occurred. Although information on informal care was scarce. With respect to prevention activities, GPs in Almere report somewhat more screening for cervical cancer and child health clinics pay generally somewhat more attention to such activities.

\section{Goal: cost containment}

For governmental policy makers and funding bodies, cost containment gradually became one of the most important objectives of the Almere Health Care Demonstration Project. However, there are no apparent reasons to assume that the implemented systern in Almere would cost less than the system in the rest of the Netherlands. Production figures for the hospital sector which is responsible for approximately $60 \%$ of health care expenditure, show no significant differences between Almere and the rest of the Netherlands. Lower production figures for general practitioners with respect to costs generating interventions, were compensated by the high morbidity rates of the population. However, the 'Almere model" is probably no more expensive that the traditional Dutch health care system. Given the fact that a cheaper health care system was 
clearly not part of the original goals, it could be considered that in this respect the project was a success for the policy makers.

\subsection{The empirical relationship between instruments, goals, and conditions; research question 4}

Were the goals of the Almere Health Care Demonstration Project empirically related to the way the health care system in Almere was shaped?

During the implementation of the Almere Health Care Demonstration Project a series of evaluation studies was carried out. The majority of these were of a cross-sectional design. Due to absence of groups to compare with, it was difficult to compare figures for Almere with figures for the rest of the Netherlands. Therefore, as a consequence of the demonstration project being a field experiment, it is not possible to provide an unequivocal answer as to whether the instruments, conditions and goals were empirically related.

On the whole it can be concluded that the morbidity level in Almere was higher than the Netherlands in general, after adjusting for age- and gender differences. These differences between Almere and the Netherlands might be attributed to relatively high morbidity level in Almere.

General practitioners compared to their counterparts in the Netherlands showed lower prescription- and referral rates and lower levels of patient satisfaction. These were related to the structure of the primary health care sector in Almere. However, focusing on health care centres patterns of both prescription and referral rates were almost similar in Almere and the rest of the Netherlands.

Despite the relationship between the concentration of health care services in multidisciplinary health centres and output criteria such as production figures and levels of satisfaction, the 'Almere model' can still be considered as a 'black box' in which instruments, conditions, and goals were theoretically related to each other. A 'black box' in which the majority of these were directed towards the structure of the health care system in Almere was realized. However, instruments directed at the care giving process were not implemented and expected conditions proved to be optimistic. Finally, the new health care system clearly differed from the system in the remainder of the Netherlands. The Almere health care system proved to offer good quality of care and some substitution of care, at approximately equal costs compared to the remainder of the Netherlands. Based on the evidence presented here it is difficult to establish a 'true' empirical relationship between instruments, goals and conditions of the Almere Health Care Demonstration Project. 


\subsection{Summary}

Strong goverimental influence on the planning and functioning of health care services was never popular in the Netherlands during the late 1950s and 1960s. This, however, started to change in the early 1970 s. Health care expenditure, and especially the hospital and medical specialist sector, continued to grow in a period of economic stagnation and a growing awareness of the necessity to have tighter control of governmental expenditure was noted. In this period a change in ideology from secondary to primary care became apparent, initiated by developments in the Scandinavian countries and supra-national developments. This can be characterized as a period with strong tendencies towards democratization, which effected the ideas about decision making process within the health care sector. With a central-left government taking control in May 1973, the Memorandum on the future structure of the health care system in the Netherlands published in 1974, marked the end of a long period of 'laissez faire' policy and the beginning of a period with strong emphasis on governmental control. The Almere Health Care Demonstration Project was developed and carried out in this timeframe.

In the years between 1974 and 1983, plans for the decentralization and regionalization of responsibilities in the health care sector were developed, but never fully implemented. The Almere Health Care Demonstration Project started in 1983. This left local authorities in Almere with the responsibility for the planning of the primary care sector, with no formal responsibility for secondary care planning and with inadequate instruments to combine planning and financing, since legislation in this field never reached Dutch parliament before 1983. Therefore, had local government wished to exercise financial and structural planning control over the entire health care system, the lack of any legislation made this impossible.

When the Almere Health Care Demonstration Project was implemented, the climate in health care policy also started to change. With the publication of the Dekker-report 'willingness to change' in 1987, it became obvious that future developments of Dutch health care policy would not follow the 'Almere-model' but rather a system with relatively strong emphasis on market forces and less governmental control. The Almere demonstration project therefore no longer functioned as a national experimental case study. Considering these circumstances it is difficult to blame the local government for not ensuring the further implementation of the Almere Health Care Demonstration Project. It can therefore be said that the Almere Health Care Demonstration Project was never provided with the opportunity to prove that an alternative system of health care facilities based on the principle of strong governmentall influence can function and bring about the goals set at the start of the experiment. 
The Aimere Health Care Demonstration Project, however, did illustrate that a primary-care-based organizational structure can function. Regarding one of the important goals of the experiment, the treatment of more people in primary care services, is both realistic and feasible. Overall, health care facilities in Almere have been able to deal adequately with Almere's relatively high level of morbidity. Higher morbidity rates in general practice were not mirrored in higher referral rates, suggesting that reinforcement and integration in primary care can be successful instruments in reducing the costs of health care services in general. Although, facts and figures presented did not provide a definite answer or prove, the results found could be interpreted as being due to the Almere experiment. They show that a system of health care facilities based on the "managed care' principle can function in a less favourable surrounding. Furthermore, the experiment indicated the difficulty in combining this goal with the wishes and demands of all patients, which is illustrated by the fact that patient satisfaction does not generally exceed and in some instances is lower than the national level. It also illustrated by the difficulties of controlling the utilization of hospital services. Albeit, one of the important goals, which was to reach a limited number of hospital admissions, was not achieved.

The Almere Health Care Demonstration Project also showed that the structural and functional integration of the three important echelons - basic care, primary care and secondary care - was difficult to realize, even under almost optimal conditions as in the 'new town' of Almere. Vested interests of the individual parties were not easily supplanted by a common interest. In general, it can be concluded that the process of integration showed to be more successful for the creation of new organizations and structure than for transferring existing organizations. One of the lessons to be learnt from the Almere Health Care Demonstration Project is that a drastic reorganization of a health care system will probably only succeed when sufficient support from all involved parties exists. If over a prolonged periad of time such support is questionable, it is perhaps more appropriate to apply a 'small step' strategy by introducing the most supported elements first.

The fact that the majority of goals of the Almere Health Care Project were not met during the 10 years between 1983 and 1993 was more likely due to the time than to the expectations during the project. One might say that the expectations set at the beginning of the demonstration project were simply too high.

This however, does not imply that there is no future for (parts of) the Almere Health Care Demonstration Project. One of the most important examples is the Almere Primary Health Care Foundation. The Foundation plays an extremely important role in negatiations with other parties, such as insurance companies. Speaking on behalf of more than 1,000 employees the APHCF is not only an interesting partner to co-operate with, but also a strong opponent where 
disagreement occurs. Secondly, a health care system organized on the basis of the 'Almere model' enables investments in health care services which could not be paid for or organized by a fragmented system (e.g. the primary care emergency centres, the installation of computer systems in all general practices, the possibility to develop and introduce tailormade protocols and standards for the different health care services). The introduction of computer systems can be beneficial for one or more party. For general practitioners it can reduce the practitioners" workload; it will facilitate the work and improve the quality of care from a professional point of view. For central management it will provide more insight in the performance-related employment data, including the possibilities for audit. 
In 1989 werden door de Engelse gezondheidszorgonderzoeker Martin Buxton drie stellingen geponeerd. De drie 'wetten van Buxton'. De eerste stelling luidde, dat nieuwe ontwikkelingen in de zorgsector pas aanleiding geven tot onderzoek op het moment dat het eigenlijk te laat is om zo"n evaluatie-onderzoek op een methodisch verantwoorde manier op te zetten. De derde stelling was, dat als de uitkomsten van een onderzoek niet passen in het beleid van de verschillende partijen, niet het geëvalueerde beleid maar de opzet van het onderzoek ter discussie wordt gesteld. Wetten waarschijnlijk op meer terreinen van toepassing zijn dan enkel de gezondheidszorg. Dat geldt ook voor de tweede wet van Buxton: tegen de tijd dat een onderzoek of experiment is afgelopen zal de belangstelling van de beleidmakers zijn verschoven naar andere problemen en ontwikkelingen. Deze tweede 'wet van Buxton' vormt een goede introductie van het centrale onderwerp van deze case-studie, de evaluatie van het beleidsexperiment gezondheidszorg Almere.

In de paragraaf die volgt op deze inleiding zal eerst een schets worden gegeven van de belangrijkste beleidsproblemen op het terrein van de gezondheidszorg in Nederland in het begin van de jaren 70 en de oplossingen die men voor deze problemen zag. Dit was immers het moment dat er niet alleen voor het eerst sprake was van de mogelijkheid om in Almere de gezondheidszorg op een experimentele wijze op te zetten, maar ook het tijdstip waarop op regeringsniveau uitdrukking werd gegeven om te komen tot herstructurering van de zorgsector. De nieuwe stad Almere bood de gelegenheid om een stelsel van gezondheidszorgvoorzieningen op te bouwen, dat paste bij het ideaalbeeld van die tijd. Een ideaalbeeld met een sterk sturende en plannende overheid, waarbij de nadruk lag op de structuur van het steisel yan zorgvoorzieningen. Aan de hand van de resultaten van het evaluatie-onderzoek rond het Experiment Gezondheidszorg Almere zal worden nagegaan wat er terecht is gekomen van deze idealen. In hoeverre is het afwijkende stelsel van gezondheidszorgvoorzieningen in Almere gerealiseerd en zijn de inhoudelijke doelstellingen gehaald? Maar ook: welke factoren hebben belemmerend (of juist stimulerend) gewerkt? Ter afsluiting wordt aandacht geschonken aan het gezondheidszorgbeleid van de overheid in de periode tussen het begin van het Experiment Gezondheidszorg Almere in 1983 en het aflopen van de experimentele status in 1992. Nagegaan zal worden of en op welke wijze het reilen en zeilen van het experiment is beînvloed door hetgeen zich in de beleidssector heeft afgespeeld, en op welke wijze het (afwijkend) stelsel van gezondheidszorgvoorzieningen in Almere heeft ingespeeld en nog kan inspelen op de herstructurering van de gezondheidszorg die in de jaren na het verschijnen van de adviezen van de Commissie Dekker gestalte heeft gekregen. 


\section{De onderzoeksvragen en het conceptuele kader}

Het Experiment Gezondheidszorg Almere is op te vatten als een beleidsexperiment dat vorm heeft gekregen in een politieke en economische context, waarbij internationale ontwikkelingen mede een rol speelden. De eerste twee onderzoeksvragen die aan dit proefschrift ten grondslag liggen hebben betrekking op deze context.

Q1 Hoe past het Experiment Gezondheidszorg Almere in het streven naar meer invloed voor centrale overheidsinstanties in de organisatie en planning van het stelsel van Nederlandse gezondheidszorg-voorzieningen in het midden van de jaren 70 , en de daaropvolgende introductie van marktwerking in de gezondheidszorg in het midden van de jaren 80 ?

Als conceptueel kader voor de evaluatie van het (veld) experiment Almere, is gekozen voor een model dat de mogelijkheid in zich heeft het project op een adequate wijze te beschrijven en dat ruimte biedt om na te gaan of de inhoudelijke verwachtingen zijn gerealiseerd (zie Schema 1).

Schema 1. Model voor de evaluatie van het Experiment Gezondheidszorg Almere (Bron: Stake, 1967)

GEPLAND

PROGRAMMA

GEREALISEERD

PROGRAMMA

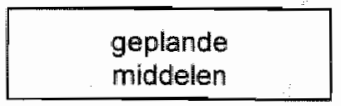

middelen

|

theoretische

samenhang?

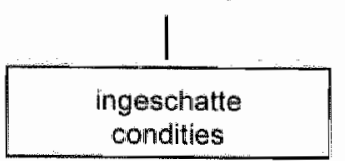

condities

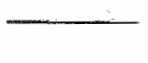

theoretische

samenhang?

gepland

resulltaat overeen-

stemming?

overeen-

stemming?

overeen-

stemming? gerealsisserde middelen

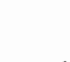

empirische samenhang?

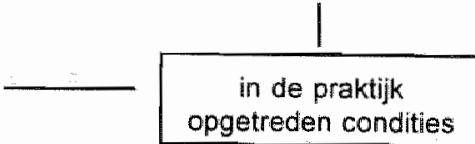

empirische samenhang?

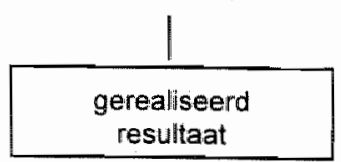


Uit het model kumnen drie onderzoeksvragen worden afgeleid die betrekking hebben op de feitelijke resultaten van het evaluatie-onderzoek.

Q2 Is er een theoretische samenhang tussen de geplande middelen, de ingeschatte condities en de beoogde doelen?

Q3 Is er overeenstemming tussen het geplande en het gerealiseerde programma, ofwel tussen de geplande middelen, condities en doelen en de daadwerkelijk in de praktijk gerealiseerde middelen, condities en doelen?

Q4 Is er sprake van een empirische samenhang tussen de gerealiseerde middelen, de in praktijk opgetreden condities, en de gerealiseerde doelen?

Behalve het (inhoudelijke) streven om mensen zelf verantwoordelijk te laten zijn voor hun gezondheid en hen te leren zo doeltreffend mogelijk gebruik te maken van de eigen mogelijkheden, werden met de nieuwe structuur drie doelen nagestreefd. Dit zijn: (1) substitutie van zorg, van tweede naar eerstelijnszorg, en van professionele naar mantel- en zelfzorg, (2) een goede kwaliteit van zorg, en (3) kosten die maximaal even hoog zouden zijn als in de 'traditionele' Nederlandse gezondheidszorg.

De middelen die men dacht in te zetten om deze doelen te bereiken richtten zich vooral op de structuur van voorzieningen en de inhoud van zorg die wordt geboden. Bij de structuur kan men denken aan zowel de wijze van organisatie van zorgvoorzieningen (koepelorganisaties, bestuursparticipatie, loondienst voor alle zorgverleners) als aan de wijze waarop instellingen in de praktijk vorm krijgen (gezondheidscentra, een relatief klein ziekenhuis). Middelen die zich richten op inhoudelijke vernieuwing van het zorgproces zijn vooral te vinden in bijvoorbeeld het op elkaar afstemmen van behandelingen, de invoering van protocollen, en het stimuleren van overleg en aanvullende scholingen.

Of deze middelen ook daadwerkelijk hebben geresulteerd in het bereiken van de doelen, zal mede afhangen van de mogelijkheden die de omstandigheden boden. De veronderstelling is, dat het van de grond af opbouwen van de gezondheidszorg in Almere goede mogelijkheden bood voor de realisatie van een fundamenteel andere opzet, mits de betrokken partijen zouden meewerken, de regelgeving een experiment als het EGA zou toelaten en mits men zou slagen de (structurele en inhoudelijke) opbouw van het stelsel van zorgvoorzieningen parallel te laten lopen aan de groei van de gemeente. 


\section{Het beleidskader en bijbehorende onderzoeksvragen}

De wens om te komen tot een nieuw type gezondheidszorg dateerde niet van vandaag of gisteren. Reeds in het begin van de jaren 40 werd vastgesteld dat de organisatie van de gezondheildszorg in Nederland eigenlijk anders zou moeten. Met een spilfunctie voor de huisarts, veel aandacht voor samenwerking tussen de verschillende disciplines, loondienst voor zorgverleners en een sterk sturende overheid. Dat veranderingen op papier eenvoudiger zijn dan in de praktijk, bleek zo'n 20 jaar later toen de gelegenheid zich aanbood om in de polder Oostelijk Flevoland en de nieuwe stad Lelystad op experimentele basis te komen tot een andere opbouw van de gezondheidszorg. Een mogelijkheid die uiteindelijk, om een veelheid van redenen, niet kon worden benut. De belangrijkste reden: de tijd was er simpelweg nog niet rijp voor.

Dat verandert in het begin jaren 70 , toen er op het terrein van de gezondheidszorg sprake was van een aantal ontwikkelingen. Als eerste moet worden genoemd de sterk oplopende kosten van de gezondheidszorg, met name voor wat betreft de ziekenhuissector. Kostenstijgingen die bij een groeiende economie wellicht zonder problemen konden worden opgevangen, maar in tijden van recessie zoals die zich op dat moment aandiende een extra zwaar gingen drukken op de overheidsbegroting. Ten tweede drong het besef door, dat er in Nederland eigenlijk sprake was van een sterk versnipperde, verzuilde en daardoor weinig efficiënte gezondheidszorg, met een lappendeken van financieringsstromen.

Een aanzet om te komen tot het oplossen van de problemen, die het gevolg waren van deze ontwikkelingen, bood de in 1974 door het Ministerie van Volksgezondheid en Milieuhygiëne onder verantwoordelijkheid van de toenmalige staatssecretaris Hendriks uitgebrachte Structuurnota Gezondheidszorg. Kernbegrippen uit deze nota waren; regionalisatie en decentralisatie, echelonnering, en substitutie van zorg. Planningstaken op het terrein van gezondheidszorgvoorzieningen moesten verschuiven naar gemeentelijke en provinciale overheden, waarbij op regionaal niveau een netwerk van voorzieningen tot stand diende te worden gebracht afgestemd op de behoeften binnen die betreffende regio. De gezondheidszorg diende gestructureerd te moeten worden in echelons. De toegang tot de tweede lijn (ziekenhuiszorg, specialistische zorg) en de derde lijn (langdurige intramurale zorg in bijvoorbeeld verpleeghuizen en zwakzinnigenvoorzieningen) kwam te lopen via de eerste lijn (direct toegankelijke, generalistische zorg) en meer in het bijzonder via de huisarts. De basis van een dergelijke opbouw in de vorm van een piramide wordt gevormd door de 'nulde' lijn, ofwel de basisgezondheidszorg, die was gericht op collectieve preventie. Door het 'oplossend vermogen' van de eerste lijn te vergroten, zou het mogelijk moeten zijn te komen tot substitutie van zorg. Er zouden minder mensen kunnen 
worden verwezen naar de medisch specialist en patiënten zouden door een adequaat opnamebeleid van ziekenhuizen na een behandeling eerder naar huis kunnen. Al deze doelstellingen wilde men bereiken door een pakket van maatregelen, waarin de sturende hand van de overheid zichtbaar zou zijn. Genoemd kunnen worden een beperking van de capaciteit van de tweedelijnszorg ('beddenreductie"), volumegroei in de eerstelijn (het aanstellen van meer hulpverleners), het verbeteren van de opleiding (instelling huisartsopleiding) en het stimuleren van samenwerking tussen hulpverleners in de eerstelijn (stimuleringspremies voor gezondheidscentra). Deze ideeën, verwoord in de Structuurnota Gezondheidszorg van 1974 en verder uitgewerkt in een aantal aanvullende nota's en adviezen, zouden uiteindelijk moeten resulteren in een nieuw, wettelijk verankerd stelsel van gezondheidszorgvoorzieningen in Nederland. Een stelsel dat naadloos aansloot bij de ontwikkelingen gepropageerd door de World Health Organisation (WHO) in zijn 'Health for all by the year 2000' strategie en ontwikkelingen in de Scandinavische landen. De nieuwe gemeente Almere bood daarbij een uitgelezen mogelijkheid om te kijken of een dergelijk ideaalbeeld ook daadwerkelijk in de praktijk kon worden gerealiseerd en ook daadwerkelijk die resultaten zou opleveren die de beleidmakers op dat moment voor ogen stonden.

Daarmee is de eerste onderzoeksvraag beantwoord. Het Experiment Gezondheidszorg Almere ademt in al zijn beleidsplannen het streven naar meer invloed voor overheidsinstanties op de organisatie en planning van het stelsel van gezondheidszorgvoorzieningen in het midden van de jaren 70 .

\section{Evaluatie-onderzoek rondom het Experiment Gezondheidszorg Almere; de drie resterende onderzoeksvragen}

Het Experiment Gezondheidszorg Almere (EGA) was een omvangrijk en veelomvattend project. Achtergrondgedachte was, dat door het tot stand brengen van een hechte en sterke eerstelijnsgezondheidszorg, er minder een beroep gedaan zou hoeven te worden op de tweede lijn, zodat deze krap kon worden bemeten. Een hechte eerste lijn stond in Almere voor het binnen éen organisatie brengen van alle hulpverleners in de eerstelijnsgezondheidszorg, met zorgverlening vanuit wijkgerichte gezondheidscentra. Een sterke eerste lijn hield in, dat de capaciteit boven het landelijk gemiddelde lag. Een krap bemeten tweede lijn betekende een capaciteit aan beschikbare ziekenhuisbedden die nadrukkelijk lager zou liggen dan het landelijk gemiddelde. Om productieprikkels binnen de tweede lijn zo laag mogelijk te houden was de gedachte dat medisch specialisten van het toekomstige Almeerse ziekenhuis in loondienst moesten komen. De samenhang in het hele stelsel van voorzieningen zou tot stand worden gebracht via een planning onder gemeentelijke regie (bestuurlijke samenhang), éen 
financieel kader voor de gehele Almeerse gezondheidszorg (financiële samenhang) en beheersorganisaties per zorgsector (structurele en inhoudelijke samenhang). De inschatting was dat deze afwijkende structuur in Almere tot stand gebracht kon worden, omdat het voorzieningenapparaat van de grond af moest worden opgebouwd, waardoor men veel minder met gevestigde belangen te maken had dan in de rest van Nederland. Men kon met een schone lei beginnen. Evaluatie-onderzoek zou daarbij antwoord moeten geven op de vraag of zo'n nieuw stelsel van zorgvoorzieningen tot stand kon worden gebracht "en of zo'n nieuw stelsel ook daadwerkelijk zou functioneren zoals de beleidmakers voor ogen stond.

\section{Onderzoeksvraag 2}

Onderzoeksvraag 2 was praktisch van aard. Mocht men op grond van eerdere ervaringen, de beschikbare literatuur en 'gezond verstand' redeneringen verwachten dat het experiment Almere ook daadwerkelijk datgene zou opleveren wat de beleidmakers in 1983 voor ogen stond? Het antwoord op deze onderzoeksvraag is terug te vinden in hoofdstuk 3 . In dit hoofdstuk werd, op grond van de beschikbare (nationale en internationale) onderzoeksbevindingen en 'gezond verstand-redeneringen', vastgesteld dat het er in theorie voor Almere goed uitzag. Middelen en doelen sloten in principe op elkaar aan. Tevens werd in dit hoofdstuk vastgesteld dat de drie belangrijkste condities die aan het model Almere ten grondslag lagen voldoende realiteitsgehalte hadden. In principe bestond er in Almere een 'tabula rasa' situatie, zij het dat er inmiddels zeven jaren waren verstreken tussen het moment dat de eerste inwoners naar Almere kwamen en de feitelijke start van het experiment Almere. Met betrekking tot de gewenste continuiteit in overheidsbeleid (conditie 2) waren er in 1983 geen tekenen die erop wezen dat deze conditie onhaalbaar was. Hetzelfde geldt voor conditie 3: de mogelijkheid om de op-en uitbouw van de gemeente Almere hand in hand te laten gaan met de opbouw van het gewenste stelsel zorgvoorzieningen. Ook dleze conditie was niet irreëel. Daarmee werd onderzoeksvraag 2 beantwoord.

\section{Onderzoeksvraag 3}

Onderzoeksvraag 3 werd, op grond van het door ons gekozen conceptuele kader, opgesplitst in drie deelvragen. (1) Zijn de beoogde middelen van het EGA ook daadwerkelijk in de praktijk gerealiseerd? (2) Zijn de invoeringsmogelijkheden of condities juist ingeschat? (3) Zijn de beoogde doelen op het terrein van substitutie, kwaliteit van zorg en kostenontwikkeling in de praktijk gehaald?

(1) Middelen. In hoofdstuk 4 is vastgesteld dat de mididelen, die in structureel opzicht gericht zijn op het tot stand brengen van een sterke eerstelijn en een krap bemeten tweedelijn, tussen 1983 en 1993 voor een belangrijk deel zijn 
gerealiseerd. Koepelorganisaties voor de eerstelijnszorg (EVA), de ouderenzorg (Delta) en voor de zorg aan geestelijke en lichamelijk gehandicapten zijn tot stand gebracht. Hetzelfde geldt voor het Samenwerkingsverband Almeerse Gezondheidszorginstellingen (SAG), één overkoepelende patiëntenorganisatie (SIOP), het (bijna) exclusief werken vanuit buurtgerichte gezondheidscentra. Het Flevo ziekenhuis en het gecombineerde verpleeg/ verzorgingshuis 'De Kiekendief' hebben in grote lijnen de vorm en omvang gekregen die is terug te vinden in de oorspronkelijke projectplannen van het EGA. Niet, of in beperkte mate, gerealiseerd zijn de beoogde planning onder gemeentelijke regie, een integraal financieel kader voor de hele Almeerse gezondheidszorg en loondienst voor alle specialisten in het Flevo ziekenhuis.

De nadruk die tijdens de werkingsduur van het EGA heeft gelegen bij de opbouw van de structuur van voorzieningen, lijkt ten koste te zijn gegaan van de middelen die zich vooral richten op de inhoud van het zorgproces. De inhoudelijke vernieuwing van het zorgproces heeft lange tijd op het tweede plan gestaan; van de ambitieuze plannen voor inhoudelijke samenwerking tussen echelons en binnen de intramurale sector lijkt vooralsnog weinig terecht te zijn gekomen. Behalve een te optimistische inschatting van de mogelijkheden tot integrale invoering van het EGA, zijn mogelijke oorzaken de late opening van het Flevo ziekenhuis en de verschillen in cultuur tussen de verschillende echelons.

(2) Invoeringsmogelijkheden. Hoofdstuk 5 maakt duidelijk dat, voor wat betreft de gerealiseerde condities of invoeringsmogelijkheden, de inschatting dat in Almere 'met een schone lei' kon worden begonnen te veel op 'wishful thinking' gebaseerd is geweest. Bestaande regelgeving bleek een lastig te omzeilen klip bij een grootschalig zorgexperimenten als het Experiment Gezondheidszorg Almere. Nieuwe organisaties bleken moeilijker van de grond te tillen dan in de oorspronkelijke projectplannen werd verondersteld, terwijl bestaande organisaties zich soms maar moeilijk konden schikken in de voor Almere vastgestelde structuur en werkwijze. Daarbij komt, dat een aantall externe ontwikkelingen die sterk van invloed zijn geweest op het experiment, tevoren niet waren voorzien of te optimistisch zijn ingeschat. Een voorbeeld van zo'n ontwikkeling was de geplande groei van de bevolking. Een snelle bevolkingsgroei was verwacht; niet dat de Almeerse bevolking minder gezond zou zijn dan de doorsnee inwoner van Nederland, hetgeen belangrijke consequenties had voor het gebruik van medische voorzieningen. Een ander voorbeeld in de sfeer van het overheidsbeleid zijn de ontwikkelen in het midden van de jaren 80 . In het overheidsbeleid vond in deze periode een verschuiving plaats in het denken over de gezondheidszorg, waardoor het Experiment Gezondheidszorg Almere in feite als "mosterd na de maaltijd' kwam. De plannende en sturende overheid maakt plaats voor een positie van de overheid op de achtergrond en een meer prominente rol voor aanbieders en financiers. Een verschuiving in het overheidsdenken over de gezondheidszorg die weliswaar geen directe consequenties had voor de uitvoe- 
ring van de Almeerse experiment, maar indirect zijn schaduwen vooruit wierp en op de achtergrond wel degelijk zall hebben meegewogen bil de opstelling van de verschillende partijen bij het uitstippelen van de te volgen koers.

(3) Doelen. Kernvraag bij het EGA is of de beoogde doelen - substitutie van zorg, kwalitatief goede zorg en kostenbeheersing - daadwerkelijk zijn gerealiseerd. In de hoofdstukken 6,7 en 8 wordt hier nader op ingegaan. Uit deze hoofdstukken blijkt dat een eenduidig antwoord op deze vraag moeilijk te geven is. Met betrekking tot zowel de verschuivingen binnen de intramurale sector als bij de verschuivingen van intramurale zorg naar zorg verleend in de Almeerse eerste lijn zijn de uiteindelijke resultaten mager. Wordt rekening gehouden met het feit dat de bevolking van Almere relatief jong is, dan geldt dat het gebruik van klinische voorzieningen in Almere bij het aflopen van het experiment niet lager is dan in de rest van Nederland, terwijl een verschuiving van klinische zorg naar poliklinische zorg en dagbehandeling en van verpleeghuis naar verzorgingshuis in 1992 nog niet kan worden aangetoond. Wel iets lager is de ligduur bij ziekenhuisopname, maar het verschil tussen Almere en de rest van Nederland is gering. Uitgangspunt van het experiment Almere was, dat versterking van de eerste lijn zou moeten resulteren in relatief lage verwijscijfers naar medisch specialisten en, indirect, tot lage aantallen ziekenhuisopnamen. Een lage opnamecoëfficiënt is (nog) niet gerealiseerd. Een laag verwijscijfer voor de Almeerse huisartsen wel, tenminste als we kijken naar het aantal verwijzingen per 1000 contacten. Echter, omdat de doorsnee inwoner van Almere zieker is en bij ziekte vaker bij de huisarts komt, heeft dit op het moment van aflopen van het experiment niet geresulteerd in een laag verwijscijfer per 1000 patiënten. Toch mag geconcludeerd worden dat de het wat 'zieker' zijn van de inwoners van Almere goed en adequaat werd opgevangen door een 'sterke' eerstelijnszorg.

Kwaliteit van zorg laat zich moeilijk meten. Er kan worden gekeken naar de structuur van de zorgverlening en zorgvoorzieningen of naar het zorgproces, maar bijvoorbeeld ook naar het oordeel van de inwoners van Almere over de gezondheidszorg. Een maat voor de kwaliteit van de structuur van voorzieningen is het aantal beroepsbeoefenaren en de wijze waarop wordt gewerkt. Enerzijds geldt dat de aantallen zorgverleners bij de meeste beroepsgroepen voldoen aan de doelstellingen van het EGA. Anderzijds moet worden vastgesteld dat individuele beroepsbeoefenaren qua taakopvattingen niet of weinig verschillen van hun beroepsgenoten in de rest van Nederland. In de zorg zelf zien we in Almere relatief veel voorlichting en informatie aan de patiènt en veel onderling overleg. Kortom kwalitatief goede zorg. Kijken we naar de continuiteit van zorg, dan zijn er naast positieve punten - zoals de integratie van zorgvoorzieningen in het gecombineerde verpleeg- en verzorgingshuis 'De Kiekendief'- ook negatieve punten. Aangetoond is dat het verloop onder zorgverleners in Almere relatief groot was en patiënten hebben vaak te hadden met wisselende personen. Bij de gebruiker van de Almeerse zorgvoorzieningen overheerste een gevoel van 
tevredenheid. Tevreden, maar niet meer dan elders in willekeurige gemeente in de rest van Nederland en op een aantal punten duidelijk wat meer scepsis. Deze grotere ontevredenheid gold met name de gepercipieerde bereikbaarheid en toegankelijkheid van de eerstelijnsvoorzieningen buiten de kantooruren en de wachttijden bij een bezoek aan het gezondheidscentrum.

Onze eindconclusie met betrekking tot het kostenaspect kan kort zijn. In zijh algemeenheid zijn er weinig redenen aan te nemen dat de totale kosten van de Almeerse gezondheidszorg in 1992 of 1993 duidelijk lager liggen in vergelijking tot de rest van Nederland. Dit was overigens ook niet de doelstelling van het Experiment Gezondheidszorg Almere. Immers, hierin werd gesproken van optimale kwaliteit van zorg tegen acceptabele kosten. De kosten van de ziekenhuissector in Almere zijn niet lager dan in de rest van Nederland. Bij de kosten van de eerstelijnszorg en ouderenzorg komt het 'Almeerse model' een fractie duurder uit dan Nederland "maar (ook) hier geldt dat op deelterreinen wel degelijk sprake was van een succesvol beleid. Voorbeeld is het lagere aantal kostengenererende verrichtingen door de Almeerse huisartsen, zoals het voorschrijven van medicijnen of de aantallen verwijzingen per 1000 contacten. Een eindconclusie dat bij het eind van het Experiment Gezondheidszorg Almere de uitgaven op het terrein van de gezondheidszorg nagenoeg gelijk of een fractie hoger zijn dan in de rest van Nederland is verdedigbaar.

\section{Onderzoeksvraag 4}

Onderzoeksvraag 4 betrof de vraag of er in de praktijk daadwerkelijk sprake was van een empirische samenhang tussen gerealiseerde middelen, opgetreden invoeringsmogelijkhedlen en de mate waarin de uiteindelijke doelen zijn gerealiseerd. Deze vraag laat zich moeilijk eenduidig beantwoorden als gevolg van de manier waarop het evaluatie-onderzoek rondom het Experiment Gezondheidszorg Almere is opgezet. Keiharde conclusies op basis van een veldexperiment zoals het Experiment Gezondheidszorg Almere zijn in de regel niet goed mogelijk. Almere is geen laboratorium waarin men, op wetenschappelijk verantwoorde wijze, kan nagaan of een verondersteld effect ook daadwerkelijk optreedt ander invloed van de experimentele factor. Het feit dat Almere is op te vatten als een 'black box' met een groot aantal input-variabelen in de vorm van in te zetten middelen en een groot aantal output-variabelen in de vorm van resultaten, maakt dat het buitengewoon moeilijk is oorzaak-gevolg relaties te leggen. Voor een aantal afzonderlijke resultaten kan (binnen statistische grenzen) aannemelijk worden gemaakt dat een gevonden effect niet het gevolg is van een aantal variabelen waarvoor gecontroleerd kan worden. Weliswaar kan op een aantal punten de situatie in Almere worden vergeleken met de rest van Nederland, en kan aannemelijk worden gemaakt dat de verschillen die er zijn te maken hebben met bijvoorbeeld de keuze in het experiment om te werken vanuit wijkgerichte 
gezondheidscentra. Echter, om effecten eenduidig toe te kunnen schrijven aan 'het Almeerse model' ontbreken de mogelijkheden.

Dit gezegd hebbend kon, in hoofdstuk 9 , worden vastgesteld dat er het voor een aantal zaken aannemelijk is dat er sprake is van de veronderstelde empirische samenhang. Dit gold met name een aantal van de doelen die betrekking hebben op de kwaliteit van de zorg in Almere in professioneel opzicht zowel als vanuit het perspectief van de gebruiker van zorgvoorzieningen. Een van de werkzame bestanddelen van het experiment Almere lijkt hier de concentratie van eerstelijnsvoorzieningen in multidisciplinaire gezondheidscentra te zijn. Een duidelijk negatief punt was de tevredenheid van patiënten met het functioneren van de huisarts. Weliswaar is ook in Almere het overgrote deel van de bevolking tevreden, maar de percentages lagen significant lager dan in de rest van Nederland. De relatie tussen (on)tevredenheid en het 'Almeerse model' kon niet worden 'wegverklaard' met behulp van andere variabelen.

\section{Het (voorlopige) eindoordeel}

Een eindoordeel over thet Experiment Gezondheidszorg Almere in termen van 'geslaagd' of 'mislukt' is eigenlijk niet te geven. Wel kan worden vastgesteld dat het Experiment Gezondheidszorg Almere in zijn opzet, doelstellingen en uitwerking aansloot bij het beleid op het terrein van de gezondheidszorg dat tot het midden van de jaren 80 gold, als testcase voor geplande landelijke ontwikkelingen. Dat het overheidsbeleid uiteindelijk (althans op papier) een andere richting insloeg, kan men de opstellers van de Almeerse plannen moeilijk verwijten.

Terugblikkend kan de eindconclusie worden getrokken dat de structuur, zoals die was voorzien in de plannen die ten grondslag liggen aan het Experiment Gezondheidszorg Almere en die als het ware een vertaling vormen van de cultuur in het overheidsbeleid aan het eind van de jaren 70 en het begin van de jaren 80 , grotendeels tot stand is gebracht. Uitzonderingen daarop zijn centrale planning, één financieel kader voor alle instellingen werkzaam op het terrein van de Almeerse gezondheidszorg en het loondienstverband voor alle medisch specialisten werkzaam in het ziekenhuis in Almere. Met betrekking tot de op de inhoud van het zorgproces gerichte middelen moet worden vastgesteld, dat deze in mindere mate zijn gerealiseerd. Wel zijn met een goed functionerend stelsel van koepelorganisaties gunstige voorwaarden geschapen om deze inhoudelijke doelen alsnog te bereiken.

Kijken we naar de doelstellingen op het terrein van de substitutie van zorg, de kwaliteit van hetgeen de inwoners van Almere op het terrein van de zorg wordt 
geboden en de kostenfactor, dan moet onze eindconclusie luiden dat de ambitieuze doelstellingen bij het einde van het project in 1993 vooralsnog voor het grootste deel niet zijn waargemaakt. Een veelheid van ambities, de wens om alles ineens te doen en een te groot optimisme met betrekking tot de mogelijkheden tot invoering van de experimentele opzet lijken zich hier te wreken.

Is het voor het voormalig Experiment Gezondheidszorg Almere toch mogelijk te overleven in een omgeving die qua cultuur zo duidelijk afwijkt van de omstandigheden waaronder van het nieuwe stelsel van zorgvoorzieningen oorspronkelijk op de rails werd gezet? Wij denken van wel. Reeds tijdens de implementatiefase van het experiment, toen de beleidsomslag bij de landelijke overheid zichtbaar werd, is een aantal bakens verzet. Het oorspronkelijke ideaal, een sterk centralistisch gestuurd stelsel van zorgvoorzieningen, maakte nog tijdens de uitvoering van het experiment plaats voor een meer decentraal gestuurd systeem, met werkmaatschappijen in het bezit van een eigen budgetverantwoordelijkheid. De stringente koppeling tussen woonadres en het ingeschreven staan bij een specifiek gezondheidscentrum werd opgeheven en vrije vestiging van zorgverleners buiten de gezondheidscentra werd (mondjesmaat) toegestaan. Op het inhoudelijke viak werd de aandacht "conform de heersende trend in tweede heift van de jaren 90 , gericht op functionele samenwerking binnen netwerken rond categorieën zorggebruikers. Tenslotte kan worden gewezen op de bundeling van krachten op twee deelterreinen van de zorg, die Almere ook bij een nieuwe inrichting van de gezondheidszorg conform het concurrentiemodel wellicht een voorsprong geven ten opzichte van andere gemeenten. Dat zijn de Stichting Eerstelijns Voorzieningen Almere (EVA) en de Stichting Informatie en Ondersteuning Patiëntengroepen (SIOP). Met de EVA beschikt Almere over éen aanspreekbare organisatie voor zorgverleners in de eerstelijn. Een organisatie met managementservaring, die sterk genoeg is om te controleren en te onderhandelen met financiers en die zich in potentie in de richting van 'fundholder' of een organisatie vergelijkbaar met de Amerikaanse Health Maintenance Organisations (HMOs) zoul kunnen ontwikkelen. Wat de EVA is voor de Almeerse eerstelijn, is de SIOP voor de Almeerse gebruikers van zorgvoorzieningen: een overkoepelende organisatie, die namens patiënten op plaatselijk of regionaal niveau een vuist kan maken naar onderhandelingspartners. Of deze beide organisaties ook daadwerkelijk de rol gaan spelen die hen hier in 1997 wordt toebedacht zal de toekomst leren. 


\section{REFERENCES}

Abel-Smith B. Cost containment in health care. Bedford Square Press/NCVO, London 1984.

Abel-Smith B. Cost Containment and New Priorities in Health Care. Ashgate Publishing Ltd., Avebury 1992.

Abma TA. Responsief evalueren. Dissertatie. Eburon, Erasmusuniversiteit, Rotterdam 1996.

Amstel J van, Dekker I. Opties voor een ziekenhuis. Medisch Contact 8, 43; 1988: 243 244.

Andersen R, Newman JF. Societal and individual determinants of medical care utilization in the United States. Milbank Memorial Fund Quarterly, 51, 1973: 95-124.

Anoniem. Nieuwe bewindslieden Volksgezondheid en Milieuhygiëne presenteren zich aan de pers. Medisch Contact (28) 1973; 22: 677-678.

Anoniem. Verslag begrotingsdebat Volksgezondheidbeleid 1973. Medisch Contact, November 1972.

Anoniem. Verslag begrotingsdebat Volksgezondheidsbeleid 1972. Medisch Contact, November/December 1971.

Anoniem. Verslag opening vakbeurs 'Medica '73' met passages uit de rede van DR. LBJ Stuyt (demissionair) minister van Volksgezondheid en Milleuhygiëne. Medisch Contact, 28, 1973; 18: 571-573.

ANOZ-Verzekeringen. Verwijscijfers Almere 1994 en 1995. Interne rapportage. ANOZ, Utrecht 1996.

Aro S. Re-organizing primary health care in Finland: from growth to quality. Cah. Socio. Démo. Mé. (30) 1990; 3: 349-362.

Bäckman G. Health Policy in Finland; Organization, Planning, and High Technology Development. International Journal of Technology Assessment in Health Care, 1988, 4: $375-384$.

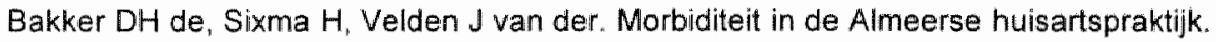
Deelonderzoek: Ziekten en Verrichtingen in de Almeerse Huisartspraktijk. Nederlands instituut voor onderzoek van de eerstelijnsgezondheidszorg (NIVEL), Utrecht 1992. 
Bakker DH de, The district concept for primary health care planning: attempts at implementation in the Netherlands. Health Policy. $1989: 13: 55-64$.

Beljaars $H$, Ceuninck van Capelle $C$ de, Dillman $R$, Eikelboom L, Mast $M$ van der, Raalte $\mathrm{B}$ van. Voonwaarden voor vernieuwing; rapport van de werkgroep Financiering Amsterdamse Gezondheidscentra. Amsterdam 1982.

Bent $J$ wan der, Klinische Consumptie in Aimere 1984-1991. Nationaal Ziekenhuis instituut (NZi), Utrecht 1986-1992.

Biewenga $\mathrm{JH}_{\mathrm{H}}$ Kraan JR, Boer-van Schaik, CJ de. Samenwerking in de eerstelijnsgezondheidszorg vanuit het algemeen maatschappelijk werk bezien: een orienterend onderzoek. Ministerie van CRM/Joint, Rijswijk 1978.

Boerma WGW, De Jong FAJM, Mulder PH. Health care and general practice across Europe. Netheriands Institute of Primary Health Care (NIVEL), Utrecht 1993.

Boom-van Duin FT de, Bastiaenen JPJ, Goudriaan G. Twee onderzoeken bij de bevolking in Ommoord en Hoensbroek ten aanzien van de aldaar gevestigde gezondheidscentra. Instituut voor Toegepast Sociaal Wetenschappelijk Onderzoek, Amsterdam 1975.

Boot $J M$, Knapen MH.M. De Nederlandse gezondheidszorg. Uitgeverij Het Spectrum B. $V_{\text {. }}$ Utrecht 1993.

Brink-Muinen A van den, Sixma H. De zorg voor ouderen in Almere. Project Evaluatie Gezondheidszorg Almere 7. Nederlands instituut voor onderzoek van de eerstelijinsgezondheidszorg (NIVEL), Utrecht 1990.

Brouwer AG. Het maatschappelijk werk in 1991/1995: Kernclifers. Stichting Eerstelijns Voorzieningen Almere (EVA), Almere/Maarsbergen, 1993-1996.

Bryk $A_{*}$ Raudenbush $S$. Hierarchical linear models. Sage, London 1992.

Buxton M. Presentation during the 5th annual Meeting of the International Society of Technology Assessment in Health Care. London 1989.

Calltorp J. The "Swedish Model" under pressure - how to maintain equity and develop quality? Quality Assurance in Health Care, 1, 1989, 1: 13-22.

Centraal Bureau voor de Statistiek. Negentig jaren statistiek in tijdreeksen: 1899-1989. SDUHitgeverij, "s-Gravenhage 1989.

Centraal Bureau voor de Statistiek. Statistisch Jaarboek 1993-1996. SDU/uitgeverij, 'sGravenhage 1994-1997. 
Centraal Bureau voor de Statistiek. Vijfennegentig jaren statistiek in tijdreeksen: $1899-$ 1994. SDU/Uitgeverij, 's-Gravenhage 1994.

Centraal Orgaan Tarieven Gezondheidszorg (COTG). Jaarverslag 1991. COTG, Utrecht, 1992.

Centrum voor Staatkundige Vorming. Grondslagen voor een wettelijke regeling van de gezondheidszorg. Centrum voor Staatkundige Vorming, 's-Gravenhage 1950.

Commissie Banning. Rapport inzake reorganisatie van de volksgezondheidszorg. 's Gravenhage, 1946.

Commissie van Advies Gezondheidszorg Zuiderzeepolders. Organisatie gezondheidszorg voormalige Zuiderzeepolders. Verslagen en mededelingen betreffende de Volksgezondheid 1962, 12.

Commissie Van Rhiin. Rapport Sociale Zekerheid, Deel I, II en II. 1945.

Committee on the Structure and Financing of the Health Care System. 'Readiness for Change', DOP, The Hague, 1987.

Crebolder HFJM. Onderzoekingen rond een gezondheidscentrum. Katholieke Universiteit Nijmegen, Nijmegen 1977.

Cromme, PVM. Toetsing als argument voor praktijkverkleining. Medisch Contact 1980 , 35; 8: 245-247.

Culyer AJ, Evans RG, Schulenburg JM Graf von der, Ven WPMM van der, Weisbrod BA. International Review of the Swedish Health Care System. Occasional Paper Nr. 34. Stockholm: Den Svenska Sjukvarden 1991

Dekker L. Verslag inzake de Bestuurlijke Samenhang. Project Evaluatie Gezond heidszorg Almere 2. Nationaal Ziekenhuisinstituut (NZi). Utrecht 1985.

Dekker L. Tussenbalans Almere. In: Kwartel AJJ van der, Made JH van der: De relatie tussen overheid en particulier initiatief. Uitgeverij De Tijdstroom, Lochem, 1987.

Dekker J, Pet RK. Het Medisch Centrum Almere. Medisch Contact 9, 43; 1988: 275277.

Delnoij DMJ. Physician Payment Systems and Cost Control. Dissertatie. Nederlands instituut voor onderzoek van de gezondheidszorg (NIVEL), Utrecht 1994.

Diderichsen F. Market reforms in health care and sustainability of the welfare state: lessons from Sweden. Health Policy 32, 1995: 141-153.

Dienst van de Nederlandse Staatscourant. Verslagen en mededelingen betreffende de Volksgezondheid. Rijksuitgeverij, 's-Gravenhage 1945 
Donabedian A. Evaluating the quality of medical care. Milbank Memorial Fund Quarterly, 1966: $166-206$.

Donabedian $A$. The definition of quality and approaches to its assessment. Health Administration Press, Ann Arbor, MI, 1980.

Donker MCH. Principes en praktijk van programma-evaluatie: opzet en renidement in de Geestelijke Gezondheidszorg. Dissertatie. Nederlands centram Geestelijke volksgezondheid (NCGv), Utrecht 1990.

Dopheide JP, Kersten TJJMT, Nijhout FP, Speld GDJ van der. Een ziekenhuis op nieuw land. Nederlands instituut voor onderzoek van de eerstelijnsgezondheidszorg (NIVEL), Utrecht 1986.

Dopheide JP, Nijhout FP. Een ziekenhuis op nieuw land; 1e Interimrapport. Nederlands Huisartsen Instituut, Utrecht 1983.

Dopheide JP, Nijhout FP. Een ziekenhuis op nieuw land; 2e Interimrapport. Nederlands instifuut voor onderzoek van de eerstelijnsgezondheidszorg (NIVEL), Utrecht 1984.

Dopheide JP. Overheidsbeleid met betrekking tot de Eerstelijnsgezondheidszorg. In: Sluijs EM, Dopheide JP, Van der Zee J. Overzichtsstudie onderzoek eerstelijn. NIVEL, Utrecht 1985.

Dopheide JP. Verwijzingen door de huisarts: enkele determinanten van het verwijscijver van solo-huisartsen op het verstedelijkt platteland en in forensengemeenten. Gezondheid en Samenleving 1982, 3: 141-151.

Dr. Wiardi Beckman Stichting. Rapport: Naar een nationale gezondheidszorg. Utrecht, Dr. Wiardi Beckman Stichting, Amsterdam 1967.

Duuren R van, Hupkens LAJ. Verschillen in verwijsgedrag door samenwerkingsverband: de financiele consequenties van de verschillen in verwijsgedrag tussen solo-artsen en samenwerkende artsen. Medisch Contact 1981, 36; 31: 933-936.

Fahrenfort $M$, Plaisier Av. Evaluatie Experiment De Kiekendief Almere. Nationaal Ziekenhuisinstituut (NZi), Utrecht 1993.

Feen, JAE van der. Evaluatie van nascholing: Warffumcursussen voor huisartsen. Medisch Contact 1984, 39; 13: 413-416.

Flevo ziekenhuis Almere. Jaarverslagen 1991-1995. Flevo ziekenhuis, Almere 19921996.

Flierman HA. Changing the payment system of general practitioners. Dissertatie. Nederlands instituut voor onderzoek van de eerstelijnsgezondheidszorg (NIVEL), Utrecht 1991. 
Foets $M$, Sixma $H$. Een Nationale Studie van Ziekten en Verrichtingen in de Huisartspraktijk. Basisrapport: Gezondheiden Gezondheidsgedrag in de Praktijkpopulatie. Nederlands instituut voor onderzoek van de eerstelijnsgezondheidszorg (NIVEL), Utrecht 1991.

Foets $M$, Stokx $L_{\text {" }}$ Hutten $J_{\text {"Sixma }} H$. Een Nationale Studie van Ziekten en Verrich* tingen in de Huisartspraktijk. Basisrapport: De Huisartsenquête van de Nationale Studie: datareductie door schaalconstructie. Nederlands instituut voor onderzoek van de eerstelijnsgezondheidszorg (NIVEL), Utrecht 1991.

Foets M, Velden J van der, Bakker DH de. Dutch National Survey of General Practice; a summary of the study design. Nederlands instituut voor onderzoek vande eerstelijnsgezondheidszorg (NIVEL). Utrecht 1992.

Foets $M_{1}$ Velden $J$ van der. Een Nationale Studie van Ziekten en Verrichtingen in de Huisartspraktijk. Basisrapport: Meetinstrumenten en Procedures, Bijlagen. Nederlands instituut voor onderzoek van de eerstelijnsgezondheidszorg (NIVEL). Utrecht 1991.

Gaag $J$ van der. An econometric analysis of the Dutch health care system. Rijksuniversiteit Leiden, Leiden 1978.

Gemeente Almere. Nieuwsbrief Projekt Gezondheidszorg Almere 1-14. Gemeent Almere, Almere 1983-1989.

Gemeente Almere. Statistisch overzicht 1985 en volgende jaren. Gemeente Almere, Almere 1986 e.v.

Goldstein $\mathrm{H}$. Multilevel Models in Education and Social Research. Oxford University Press, Oxford 1987.

Groef LMJ. Perspectieven voor het vrije beroep, vrij ondernemerschap of dienstverband? Medisch Contact 1985, 40; 13: 379-382.

Groenewegen PP. Bakker DH de, Velden J van der. Een Nationale Studie naar ziekten en verrichtingen in de huisartspraktijk; Basisrapport verrichtingen in de huisartspraktijk'. Nederlands instituut voor onderzoek van de eerstelijnsgezondheidszorg (NIVEL), Utrecht 1992.

Groenewegen PP, Kerkstra A, Jansen GA. Wachtlijsten in de thuiszorg. Nederlands instituut voor onderzoek van de eerstelijnsgezondheidszorg (NIVEL). Utrecht 1993.

Groenewegen PP. The Shadow of the Future: Institutional Change in Health Care. Health Affairs 138, 1994: 137-148.

Grol, RPTM. Preventieve attitudes wan huisartsen. Nijmeegs Univrsitair Huisartsen Instituut. Nijmegen 1981. 
Ham C. Reforming the Swedish health services: The international context. Health Policy. 21. 1992:129-141.

Heesters JP. Aankleden of uitkleden: een kritische beschouwing van de honorering van de huisarts-vrij beroepsbeoefenaar ten opzichte van de ambtenaar. Katholieke Hogeschool, Tilburg 1981.

Heesters JP. De honorering van de Nederlandse huisarts als vrij-beroepsbeoefenaar en de relatie met de goodwill-problematiek. Dissertatie. Katholieke Hogeschool, Tilburg 1983.

Helsloot RSM: Challenges for an 'open' EVA. The Almere Foundation for Primary Care, Almere 1991.

Hermans W. Bewonersparticipatie in het Project Gezondheidszorg Almere. Afstudeerscriptie, studie Gezondheidswetenschappen, Rijksuniversiteit Limburg. Maastricht 1985.

Hingstman L, Pool JB. Cijfers uit de Registratie van Beroepen in de Eerstelijnsgezondheidszorg 1992; statistische gegevens per 1 januari 1992 over huisartsen en verloskundigen. Nederlands instituut voor onderzoek van de eerstelijnsgezondheidszorg (NIVEL), Utrecht 1992.

Hofstede B. Onderzoek Wijkgezondheidscentrum Wesselerbrink. Afdeling Onderzoek en Statistiek Gemeente Enschede, Enschede 1981.

Huige C, Leenen B. Enquete Gezondheidscentrum De Hazenkamp: resultaten en analyse. Gezondheidscentrum De Hazenkamp, Nijmegen 1979.

UJsselmeerziekenhuizen Emmeloord/Lelystad. Jaarverslag 1991-1995. IJsselmeerziekenhuizen, Lelystad 1992-1996.

Janssen $\mathrm{R}$, Made J van der. Privatisation in health care: concepts, motives and policies. Health Policy, 14, 1990: 191-202.

Jaspers. F. Hamel $G$, Schrijvers $G$ (eds). Artsen in dienstverband. Kluwer, Deventer 1980.

Juffermans P (red). Overheidsbeleid en Ziekenfondsen 1945-1977. SUN, Nijmegen 1977.

Juffermans P. Staat en Gezondheidszorg in Nederland. Dissertatie. SUN, Nijmegen 1982.

Knook H. Huisarts en specialistische wereld. In: Dukkers van Emden Th, Fleuren $M$, Wijkel D. Vijf jaar zorgvernieuwing door samenwerking. Vuga Uitgeverij, Amsterdam 1991. 
Kommissie van Advies Gezondheidszarg Zuiderzeepolders. Organisatie gezondheidszorg voormalige Zuiderzeepolders. Verslagen en mededelingen betreffende de valksgezondheid no.12, 1982.

Kortbeek LMThS. Wat verwacht de specialist van regionalisatie. Medisch Contact, 1969, 23: 653-659.

Kruidenier HJ. Afstand tot ziekenhuis van invloed op verwijspatroon. Imzet 1977,$1 ; 1$ : 32-39.

Lambers H. Overheidsbeleild en gezondheidszorg. Medisch Contact, 1966: 678-691.

Landheer T. Gezondheidszorg in een nieuw gebied. Dissertatie. Rijksuniversiteit Leiden, 1978.

Landheer T. Impressies uit Finland (I, II, III). Medisch Contact 20, 1965; 13/14/15: 245$246,258-259,286-288$.

Lapré R. A change of direction in the Dutch health care policy. Health Policy, 10, 1988: 21-32.

Leger des Heils. Jaarverslagen Zorgcentrum Buitenhaege. Leger des Heils "Almere 1989-1993.

Leger des Heils. Jaarrekening Zorgcentrum Buitenhaeghe. Leger des Heils, Almere 1992 .

Leighton AH. Caring for mentally ill people. Psychological and social barriers in historical context. Cambridge University Press, Cambridge 1982.

Lindgren O. Health care in Sweden. In: Alban A, Christiansen T. The Nordic Lights: new initiatives in health care systems. Odense University Press, Odense 1995.

Linnakko E, Bade J. From planning to market allocation in Finnish health care. In: Alban A, Christiansen T. The Nordic Lights: new initiatives in health care systems. Odense University Press, Odense 1995.

Loeffler RT. Measuring quality of care in physicians' offices. Journal of Ambulatory Care Manage $15,1992,2: 62-68$.

Lorsheijd JJG. Enkele kerngetallen algemene en academische ziekenhuizen 1991. Nationaal Ziekenhuisinstituut (NZi), Utrecht 1992.

Maarse JAM. The insurer-provider relationship in health care: from administration to strategic management: the Dutch case. European Joumal of Public Health, 3, 1993. 2: $72-76$. 
Maarse JAM. Gezondheidszorg in Europa: vele gemeenschappelijke kenmerken. Het Ziekenhuis $1993,13: 630-633$.

Maesen LJO van der. Transformatie van de Gezondheidszorg in Nederland tussen 1974 en 1987. Dissertatie. Van Gorcum, Assen/Maastricht 1987.

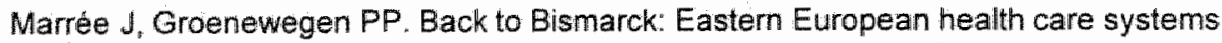
in transition. Avebury, Aldershot 1997.

Mechanic D. The Americanization of the British National Health Service. Health Affairs, 1995 (summer): $51-67$.

Melosh B. 'The Physician's Hand': Work Culture and Conflict in American Nursing. Temple University Press, Philadelphia 1982.

Ministerie voor Volksgezondheid en Milieuhygiëne. Tweede nota over de ruimtelijke ordening in Nederland. Staatsuitgeverij, "s-Gravenhage 1966

Ministerie van Sociale Zaken en Volksgezondheid. Volksgezondheidsnota 1966. Staatsuitgeverij, 's-Gravenhage 1966.

Ministerie van Volksgezondheild en Milieuhygiëne. Structuurnota Gezondheidszorg. Staatsuitgeverij, 's-Gravenhage 1974.

Ministerie van Volksgezondheid en Milieuhygiène. Nota beleidsvoornemens betreffende de kostenbeheersing in de gezondheidszorg. Tweede Kamer, zitting 1975-1976. 14044, nr. 1.

Ministerie van Volksgezondheid en Milieuhygiëne. Nota betreffende het beleïd terake van de gezondheidszorg met het oog op de kostenontwikkeling. Staatsuitgeverij, 'sGravenhage 1979 .

Ministerie van Volksgezondheid en Milieuhygiëne. Schets van de Eerstelijnsgezondheidszorg. Staatsuitgeveri], 's-Gravenhage 1980.

Ministerie van Welzijn, Volksgezondheid en Culluur. Nota Eerstelijnszorg. Staatsuitgeveriil, "s-Gravenhage 1983a.

Ministerie van Welzijn, Volksgezondheid en Cultuur. Volksgezondheidsbeleid bij] beperkte middelen. Staatsuitgeverij, 's-Gravenhage $1983 \mathrm{~b}$.

Ministerie van Welzijn, Volksgezondheid en Cultuur. Nota 2000. Staatsuitgeverij, sGravenhage 1987.

Ministerie van Welzijn, Volksgezondheid en Cultuur. Verandering Verzekerd. Staatsuitgeverij, "s-Gravenhage 1988. 
Ministerie van Welzijn, Volksgezondheid en Cuttuur. Financieel Overzicht Zorg 1990 en voigende jaren. SDU uitgeverij, 's-Gravenhage 1989 e.v.

Montfoort GLM, Galen WCC van, Harris S. Ongevallen in Nederland. Stichting Consument en Veiligheid; Amsterdam 1988.

Muller F. Primary health care: lessons from 25 years of experience in developing countries. In: Velden $\mathrm{K}$ van der et al (eds), Health Matters; public health in NorthSouth perspective. Bohm Stafleu Van Lochum, Houten 1995.

Muntendam P. Sociale Zekerheid, Medisch Contact, 1965: 939-941.

Nationaal Ziekenhuisinstituut (NZi). Beschikbaarheid en gebruik van ziekenhuisvoorzieningen. $\mathrm{NZi}$, Utrecht 1976.

Nationaal Ziekenhuisinstituut. Evaluatie-onderzoek Medisch Centrum Almere. Utrecht 1986.

Nationaal Ziekenhuis Instituut (NZi). Beschikbaarheid en gebruik van ziekenhuisvoorzieningen. NZi, Utrecht 1990.

Nationaal Ziekenhuisinstituut (NZi). Financiële statistiek gecombineerde verpleeghuizen 1991. NZi, Utrecht 1992.

Nationale Raad voor de Volksgezondheid. Discussienota Begrippenkader Kwaliteit van Instellingen. Nationale Raad voor de Volksgezondheid (NRV), Zoetermeer 1990.

Nijhout FP. Een ziekenhuis op nieuw land; 3e Interimrapport. Nederlands instituut voor onderzoek van de eerstelijnsgezondheidszorg (NIVEL), Utrecht 1985.

Okma GH. Studies on Dutch Health Politics, Policies and Law. Dissertatie. Universiteit Utrecht, Rijswijk 1997.

Organization for Economic Co-operation and Development (OECD). OECD Health Systems; The Socio-economic Environment, Statistical References. Paris, OECD 1993.

Organization for Economic Co-operation and Development (OECD). Health Policy Studies 1-3. OECD, Paris 1989-1993.

Organization for Economic CO-operation and Development (OECD). OECD Health Data 96; A Software for the Comparative Analysis of 27 Health Systems. Credes, Paris 1996

Organization for Economic Co-operation and Development (OECD). Health care systems in transition. OECD. Paris 1990. 
Paes AHP. Samenwerking arts-apotheker Pharmaceutisch Weekblad 49, 1982: 11631167.

Pekurinen M, Vohlonen 1, Hakkinen U. Reallocation of resources in favour of primary health care: the case of Finland. World Health Statistics Quarterly, 40, 1987: 314325.

Pekurinen M, Vohlonen 1. Reforms in the Finnish health care system. University of Kuopio, Kuopio 1991.

Phaff JML. Zweden, splegel voor onze gezondheidszorg (II, II, III). Medisch Contact 28, $1973 ; 10 / 11 / 12$ : $291-294,333-336,358-360$.

Pool JB, Hingstman L. Ciffers uit de Registratie van Beroepen in de Eerstelijnsgezondheidszorg 1991; statistische gegevens per 1 januan 1991 over in de eerste lijn werkzame fysiotherapetten. Nederlands instituut voor onderzoek van de eerstelijnsgezondheidszorg (NIVEL), Utrecht 1993.

Posthuma $\mathrm{BH}$, Zee $\downarrow$ van der. Tussen eerste en tweede echelon. Nederlands Huisartsen Instituut, Utrecht 1977.

Purola T, Kalimo E, Nyman K. Health Services Use and Health Status under National Sickness Insurance. Research Institute for Social Security, Helsinki 1974.

Raak A van, Mur-Veeman. Home care poicy in the Netherlands. Reforming legislation to facilitate the provision of multi-disciplinary home care. Health Policy $36,1996: 37$ 51.

Raudenbush S. "Centering" Predictors in Multilevel Analysis: Choices and Consequences. Multilevel Modelling Newsletter 1989; 1: 10-12.

Rijsenbrij JA, Lee APM van der. Zorgconsumptie Almere 1990 en 1991, verwijzingen huisarts \& ziekenhuisverpleging. Anoz Gool Apeldoorn Groep, Regio Gool Flevoland Nijkerk, Huizen 1992.

Ringeling AB. Beleidstheorieën en theorieenn over beleid. Beleid en Maatschappij, 1985:" $275-284$.

Roscam Abbing EW. Bouw en werking van de gezondheidszarg in Nederiand. Bohn, Scheltema \& Holkema, Utrecht 1979.

Rosenthal MM. Frenkel M. Health care systems and their patients: an international perspective. Westview Press, Colorado 1992.

Rotem A, Bandaranayake R. How to plan and conduct programme evaluation. Medical Teacher, $1983,5,4: 127-131$ 
Rutten FFH. The use of health care facilities in the Netherlands; an econometric anaiysis. Rijksuniversiteit, Leiden 1978.

Salmela R. Health policies and Health For All strategies in the Nordic countries. Health Policy, 1991, 18: 207-218.

Saltman RB, Otter C won (eds). Implementing planned markets in health care: Balancing social and economic responsibilities. Open University Press, Buckingham 1995.

Saltman RB, Otter $C$ von. Reforming Swedish health care in the 1990s: The emerging role of 'Public Firms'. Health Policy, 21, 1992: 143-154.

Saltman RB. Recent health policy initiatives in Nordic countries. Health Care Financing Review 13, 1992, 4: 157-166.

Samenwerkingsprojekt Eerste Lijn. Onderzoek naar dle organisatorische vormgeving van de eerstelijnsgezondheidszorg in Almere. Fase 1: Voorbereiding. S-1 Project, Bunnik 1981.

Samenwerkingsprojekt Eerste Lijn. Onderzoek naar de organisatorische vormgeving van de eerstelijnsgezondheidszorg in Almere. Fase 2: Karakteristiek Eersteiijnsgezondheidszorg Almere. S-1 Project, Bunnik 1981.

Samenwerkingsprojekt Eerste Lijn. Onderzoek naar de organisatorische vormgeving van de eerstelijnsgezondheidszorg in Almere. Fase 3: Hoofdlijnen van een toekomstige struktuur. S-1 Project, Bunnik 1981.

Samenwerkingsprojekt Eerste Lijn. Onderzoek naar de organisatorische vormgeving van de eerstelijnsgezondheidszorg in Almere. Fase 4: Eindadvies. S-1 Project, Bunnik 1981.

Samenwerkingsverband Almeerse Gezondheidszorg (SAG). Jaarverslagen 1989 en volgende jaren. SAG. Almere 1990 e.v.

Samenwerkingsverband Almeerse Gezondheidszorg (SAG). SAG-nieuwsbulletin 19891993. SAG, Almere 1989-1993

Samenwerkingsverband Almeerse Gezondheidszorg (SAG). Zorgbegroting 1991. SAG, Almere 1991.

Schrijvers G. Regionalisering en financiering van de Engelse, Zweedse en Nederlandse gezondheidszorg. Dissertatie. Uitgeversmaatschappij De Tijdstroom, Lochum 1980.

Schrijvers G. Gezondheidsplanning in plaats van gezondheidszorgplanning; een Zweedse paging voor de jaren negentig. Tijdschrift voor Sociale Gezandheidszorg. 1983, 61: $466-471$. 
Schrijvers A.JP (ed). Health and Health Care in the Netherlands. De Tijdstroom, Lochum 1997.

Schut FT, Greenberg W, Ven WPMM van de: Antitust policy in the Dutch health care system and the relevance of EEC compettion policy and US antitrust practice. Health Policy 17, 1991, 3: 257-284.

Sixma $H_{4}$ Voort $\mathrm{C}$ van de. Situatieschets van Almere Project Evaluatie Gezondheidszorg. Almere 1. Nederlands instituut voor onderzoek van de eerstelijnsgezondheidszorg (NIVEL)/ Nationaal Ziekenhuisinstituut (NZi), Utrecht 1984.

Sixma H. Bewoners over de Almeerse Gezondheidszorg. Project Evaluatie Gezondheidszorg Almere 3 . Nederlands instituut voor onderzoek van de eerstelijnsgezondheidszorg (NIVEL), Utrecht 1986.

Sixma $\mathrm{H}$. Contacten en verwijzingen bij de Almeerse huisartsen. Project Evaluatie Gezondheidszorg Almere 4. Nederlands instituut voor onderzoek van de eerstelijnsgezondheidszorg (NIVEL), Utrecht 1986.

Sixma H. EHBO in Almere. Project Evaluatie Gezondheidszorg Almere 5. Nederlands instituut voor onderzoek van de eerstelijnsgezondheidszorg (NIVEL), Utrecht 1987. Sixma H. Huisarts, spreekuur en huisbezoek. Medisch Contact 12,43; 1988: 378-380.

Sixma H. Het verwijzen naar medisch specialist en fysiotherapeut. Medisch Contact, 13, $43 ; 1988: 400-402$.

Sixma H. EHBO: patièntenstromen. Medisch Contact 16, 43; $1988: 503-505$.

Sixma H. EHBO: de mening van de patiënt. Medisch Contact 17, 43; 1988: 535-537.

Sixma HJM, Thomassen $\mathrm{C}$, de Bakker DH, Foets $M$. Zlekten en Verrichtingen in de Almeerse Huisartspraktijk; gezondheid en gezondheidsgedrag in de praktijkpopulatie. Nederlands instituut voor onderzoek van de eerstelijnsgezondheidszorg (NIVEL) Utrecht 1991.

Sixma $H$, Bakker DH de, Groenewegen PP. Velden $J$ van der. Verrichtingen in de Almeerse huisartspraktijk. Deelonderzoek: Ziekten en Verrichtingen in de Almeerse Huisartspraktijk. Nederlands instituut voor onderzoek van de eerstelijnsgezondheidszorg (NIVEL), Utrecht 1992.

Sixma $H$, Bakker DH de, Velden J van der, Foets M. Samenvattend rapport. Deelonderzoek: Ziekten en Verrichtingen in de Almeerse Huisartspraktijk. Nederlands instituut voor onderzoek van de eerstelijnsgezondheidszorg (NIVEL). Utrecht 1992.

Sixma H. Hackenitz E. EHBO in Almere 2; de effecten van de opening van het Flevoziekenhuis. Netherlands Institute of Primary Health Ciare (NIVEL). Utrecht 1992. 
Sixma HJM, Bakker DH de, Bent 3 van der. Het Experment Gezondheldszorg Almere. Utrecht; Netherlands Institute of Primary Care (NIVE) / National Hospital Institute (NZi) 1993

Sixma H, Langerak EH, Schrijvers GJP, Bent J van der. Attempting to Reduce Hospital Costs by Strengthening Primary Care Institutions; the Dutch Health Care Demonstration Project in the New Town of Almere. Joumal of the American Medical Association, 1993, 269, 19: 2567-2572.

Sixma HJM, Bakker DH de. Het experiment Gezondheidszorg Almere. In: Sorber A, Bax JR, Hendriks AJM (eds), Beleidsevaluatie; Wisselwerking tussen Cultuur en Structuur. Sdu Uitgeveri], Den Haag 1995.

Sixma $H J$, Bakker DH de. Emergency Care, GP or Hospital? Joumal of Accident \& Emergency Medicine 1996, 13; 4: 264-268.

Sixma H, Spreeuwenberg $P$, Pasch $M$ van der. Patient satisfaction with the General Practitioner; a multi-level approach. In press.

Sixma $H J$ "Campen $C$ van, Kerssens $\mathbb{J}$, Doeglas $D$, Peters $L$. Quality of care from the Patients' Perspective; Four New Measuring Instruments. Submitted.

Sint Antonius Ziekenhuis Nieuwegein. Jaarverslagen 1991-1995. Sint Antonius Ziekenhuis, Nieuwegein 1992-1996.

Snijders T. Bosker J. Modeled Variance in Two-Level Models. Sociological Methods \& Research 1994; 22: 342-363.

Staatsblad van het Koninkrijk der Nederlanden. Besluit 55 van 1 februari 1988 , houdende vaststelling van een algemene maatregel van bestuur als bedoeld in artikel 41 , alsmede 52 junctu 41,55 en 84 van de Wet voorzieningen gezondheidszorg, ten behoeve van een experiment in de gemeente Almere (Besluit Experiment Gezondheidszorg Almere). Den Haag, Staatsblad 1988, 5.5.

Staatscourant, 3 augustus 1971

Staatscourant, 9 meï 1985

Stake. RE. The countenance of educational evaluation. In: Teachers College Record $1967,7: 523-540$.

Starr P. The Social Transformation of American Medicine. Basic Books, New York 1982.

Stephen WJ. An analysis of Primary Medical Care; an international study. Cambridge University Press, Cambridge 1979 
Stichting Algemeen Ziekenhuis Zoetermeer. Jaarverslag 't Lange Land Ziekenhuis 1991 1995. Stichting Algemeen Ziekenhuis Zoetermeer, Zoetermeer 1992-1996.

Stichting De Schoor. Jaarverslag 1991 en volgende jaren. Stichting De Schoor, Almere 1992 e.v.

Stichting De Schoor. Jaarrekening 1991. Stichting De Schoor, Almere 1992.

Stichting Delta. Jaarverslag 1991 en volgende jaren. Stichting Delta, Almere 1992 e.v.

Stichting Delta. Financieel Jaarverstag 1991. Stichting Delta Almere 1992.

Stichting Eerstelijns Voorzieningen Almere (EVA). Jaarverslag 1987/1988 en volgende jaren. EVA, Almere 1988 e.v.

Stichting Eerstelijns Voorzieningen Almere (EVA). Nieuwsbulletins Info 1989-1996. Stichting EVA. Almere 1989-1996.

Stichting Eerstelijns Voorzieningen Almere (EVA). Jaarrekening 1991. Stichting EVA, Allmere 1992.

Stichting Eerstelins voorzieningen Almere (EVA). Notitie 'De managementsstructuur en de managementsondersteuning binnen de Stichting EVA. Interne notitie. EVA, Almere 1996.

Stichting Eerstelijns Voorzieningen Almere (EVA). Rapport Patiëntenraadpleging periode 1992-1994. EVA, Almere 1995.

Stichting Eerstelijns Voorzieningen Almere (EVA). Fusiebericht 17 juni 1997. Stichting EVA, Almere 1997.

Stichting Informatie en Ondersteuning Patiëntengroepen (SIOP). Jaarverslag 1986 en volgende jaren. SIOP, Almere 1987 e.v.

Stuurgiroep Project Gezondheidszorg Almere (PGA). Diskussienota Organisatie en Ontwikkeling Infrastruktuur Eerstelijnswoorzieningen Almere. Stuurgroep PGA Almere 1985

Stuurgroep Project Gezondheidszorg Almere (PGA). Projectplan Gezondheidszorg Almere. Stuurgroep PGA, Almere 1983.

Stuurgroep Project Gezondheidszorg Almere (PGA). Vergaderingsverslagen 1983-1989. Stuurgroep PGA Almere 1983-1989.

Stuurgroep Project Gezondheidszorg Almere (PGA). Zorgbegrotingen 1985 envolgende jaren. Stuurgroep PGA, Almere 1985 e.v. 
Stuurgroep Project Gezondheidszorg Aimere (PGA). Hoofolijnenplan 1985-1989' al doende beter'. Stuurgroep PGA, Almere 1985.

Stuurgroep Project Gezondheidszorg Almere (PGA). Projectplan PGA II. Stuurgroep PGA, Almere 1986.

Stuurgroep Project Gezondheidszorg Almere (PGA). Tien jaar gezondheidszorg in Almere. Stuurgroep PGA, Almere 1988.

Sub-commissie Willems. Onderzoek besluitvorming volksgezondheid. Tweede Kamer, $1993 / 1994,23666$ nr. 3.

Suchman EA. Action for what? A critique of evaluation research. In: $R$ O'Toole (ed. $)_{\text {. }}$ The organisation, management and tactics of social research. Schenkman, Cambridge, Mass. 1970.

Swaan A de. in care of the state; health care, education and welfare in Europe and the USA in the modern era. Polity Press, Cambridge 1988.

Thomassen $\mathrm{C}$, Sixma H, Bakker $\mathrm{DH}$ de. De zorg voor zuigelingen en kleuters in Almere. Project Evaluatie Gezondheidszorg Almere 6. Nederlands instituut voor onderzoek van de eerstelijnsgezondheidszorg (NIVEL), Utrecht 1989.

Tuntler JH, Wassink WF. Rapport aan de Gezondheidsraad inzake de gezondheidszorg in de Noordoostpolder. Amsterdam 1943.

Tuntler JH. De medische en hygiënische verzorging van de bevolking in de droogkomende Zuiderzeepolders. Maadblad voor het Nederlands volksgeheel 'Het Gemenebest' 1953, 13, 11: 321-331.

Velden J van der, Bakker DH de, Claessens AAMC, Schellevis FG. Dutch National Survey of General Practice; Morbidity in General Practice. Netherlands Institute of Primary Care (NIVEL), Utrecht 1992.

Vorst-Thijssen TML. De zorg voor zuigelingen en kleuters. Nederlands instituut voor onderzoek van de eerstelijnsgezondheidszorg (NIVEL), Utrecht 1987.

Vreeze, JThM de Overheidsinmenging en particulier initiatief in de gezondheidszorg, Medisch Contact, 1966: 1058.

Vreeze JThM de. Het rapport 'Gezondheidszorg' van de Dr. Wiardi Beckman Stichting. Medisch Contact. 1968: 673-677.

Vuori, $H$. Health for all, primary health care and general practitioners. Journal of the Royal College of General Practitioners, 1986, 36: 398-402. 
Waterland Zlekenfuis Pumerend. Jaarvertagen 1991-1995. Waterland Ziekenhuis, Purmerend 1992-1996.

Werkgroep Eerste Hulp. Op weg naar de huisarts: eindrapport. Werkgroep Eerste Hulp, Utrecht 1988.

Wetenschappelike Raad voor het Regeringsbeleid (WRR). Volksgezondheidbeleid. Sdu Uitgevers, Den Haag 1997.

Wijkel D. Samenwerken en verwijzen: praktijkvorm en produktiecijfers. Nederlands Huisartsen Instituut; Utrecht 1983.

Wijkel D. Samenwerken en Verwijzen. Dissertatie. Nederlands instituut voor onderzoek van de eerstelininsgezondheidszorg (NIVEL), Utrecht 1986.

Wilsford D. Doctors and the State: The politics of Health Care in France and the United States. Duke University Press, Durhan/London 1990.

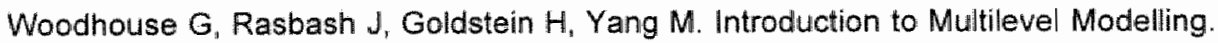
In: Woodhouse G (Ed): A Guide to ML3 for New Users. Multilevel Models Project, Institute of Education, University of London, London 1993.

World Bank. World Development Report 1993; Investing in health. Oxford University Press, Washingtan DC 1993.

World Health Organization (WHO). Alma Ata 1978: Primary Health Care (Health for Afl' Series, No. 1). World Health Organization, Geneva 1981.

Zee J van der. The Netherlands: the hurdie race to primary heaith care. In: Tarino, E., Creese, M. (eds), Achieving health for all in the year 2000. World Health Organization, Geneva 1990.

Ziekentondsraad. Jaarverslagen Ziekenfondsraad 1950-1965. Ziekenfondsraad. Amstelveen $1951-1966$.

Ziekenfondsraad. Onderzok naar het functioneren van gezondheiscentra. Amstelveen, Ziekentondsraad 1979. 


\section{APPENDIX}

In this thesis the Almere Health Care Demonstration Project (AHCDP) was evaluated as a policy programme, according to the conceptional framework that was described in chapter 3 . The three research questions linked to this conceptional framework were answered in Chapter 4 to $9_{i}$ with much of the data coming from a series of evaluation studies conducted during the course of the AHCDP. Section 3.4 provided an overview of the different studies carried out as part of the AHCDP. Whilst not dealing with the methodological issues, it provides the reader with basic information regarding the general aims of the different studies, the methods used and the main conclusions.

The appendix will provide the reader with more insight in the relevance of these studies, especially with regard to the methods that were used. In this way, it can serve as an additional methodological chapter, in which the methodology of the separate studies is further explained. Each section of this appendix will consist of a brief introduction stating the objective of the study and a somewhat larger methodological part presenting details about the data collection methods, sample and response rates, and instruments used. Sections are concluded by mentioning the relevant publications with respect to each of the separate studies. 


\section{Study 84-1: The situation in Almere in 1983 ("Situatieschets van Almere")}

\section{Objective}

(1) To present a general overview of the situation in Almere at the start of the Almere Health Care Demonstration Project (AHCDP), with respect to the population structure of Almere, the availability of health care services, and the way these health care services were functioning in 1983. (2) To gain insight in the goals, instruments and conditions of the AHCDP, as seen through the eyes of key-persons and stakeholders involved in the demonstration project.

\section{Methods}

The method used in this evaluation study was desk research, an additional series of semi-structured interviews with key-persons associated with the development and early implementation phase of the Almere Health Care Demonstration Project. The unformation refers to the situation in 1982 and 1983 , with interviews being conducted in the first half of 1984 . The information that was used in the desk research part consisted of the yearly reports of the different health care services already established in Almere at the start of the AHCDP, demographic statistics published by the Openbaar Lichaam Zuidelijke J Jsseimeerpolders (o.I. ZIJP), the notes and report from the study group established prior to the functioning of the Steering Committee and national statistics with respect to the situation in Almere and in the remainder of the Netherlands.

The qualitative part of this study consisted of a series of eight interviews with key-persons of the AHCDP, with a topic list functioning as a point of reference. Persons interviewed were governmental and local health care authorities, patient representatives, financing organizations of health care services in Almere, and representatives of the different health care services already established or planned in Almere. All interviews were tape-recorded, subsequently transcribed in pre-chosen format, and authorized by the persons that were interviewed.

\section{Publications}

Sixma $H_{3}$ Voort $\mathrm{C}$ van de. Situatieschets van Almere ("The Situation in Almere"). Nederlands instituut voor onderzoek van de eerstelijnsgezondheidszorg (NIVEL)/Nationaal Ziekenhuisinstituut (NZ|), Utrecht 1984. 


\section{Study 85-1: The policy context in Almere Health Care Demonstration Project ("Verslag inzake de bestuurlijke samenhang")}

\section{Objective}

To clarify and describe the situation in Almere in 1983/84, with respect to the policy frame-work and legal framework in which the Almere Health Care Demonstration Project was to be implemented

\section{Methods}

The method used consisted of desk research, in combination with unstructured, qualitative interviews with a small number of (unspecified) key persons and stakeholders involved in financial and legal planning procedures regarding the AHCDP. For the desk research part of the study, the policy context at the start of the AHCDP functioned as the point of reference, paying special attention to the specific situation in Almere with respect to the policy context at the regional and local level.

\section{Publications}

Dekker L. Verslag inzake de Bestuurlijke Samenhang ("Report on the Policy Context"). Nationaal Ziekenhuisinstituut (NZi), Utrecht 1985.

Dekker L. Tussenbalans Almere ("The prevalent situation in Almere)". In: Kwartel AJJ van der, Made JH van der: De relatie tussen overheid en particulier initiatief. Uitgeverij De Tijdstroom, Lochem, 1987. 


\section{Study 86-1 Inhabitants evaluation Almere's prevalent system of health care services ("Bewoners over de Almeerse gezondheidszorg")}

\section{Objectives}

To explore the expectations and experiences of the Almere population with respect to the functioning of the prevalent existing system of health care services in Almere. The study was meant to (1) gain insight in the possible bottlenecks in the existing system of health care services as part of a programme towards quality control and quality improvement, (2) to function as a point of reference for future population studies in Almere with respect to quality and substitution of care.

\section{Methods}

A written questionnaire was mailed to a random sample of 1000 inhabitants of Almere of 16 years or older, during the second half of 1984 . The sample was drawn from local population administration in Almere. Response rate was $71.8 \%$, and on the basis of non-response analyses it was concluded the group of respondents was representive for Almere's population at the end of 1984 .

Measures included were social-demographic variables, variables referring to the use of health care services, items referring to patient satisfaction with the functioning of health care services, and a series of variables to measure the attitudes of the population of Almere with respect to the use of professional and informal health care services (including 'locus of controll' scales) and the specific situation in Almere. Data were analyzed in a quantitative way, using uni- and multivariate analysing techniques.

\section{Publications}

Sixma H. Bewoners over de Almeerse Gezondheidszorg ("Inhabitants evaluating the prevalent system of health care services in Almere"). Nederlands instituut voor onderzoek van de eerstelijnsgezondheidszorg (NIVEL), Utrecht 1986. 


\section{Objectives}

To position the outpatient clinic of the Amsterdam 'Burger' hospital (the Medisch Centrum Almere or MCA) in Almere, with respect to the services offered and the functioning of these hospital services prior to the opening of the hospital.

\section{Methods}

Methods used in this study consisted of desk research and a series of semistructured interviews with stakeholders in the field of hospital care in Almere. Data that were gathered through desk research consisted of the administrative records of the outpatient clinic, in combination with data on the functioning of hospital services around Almere. During the quantitative part of the study six general practitioners and medical specialists were interviewed. The research was conducted in 1985, with data covering the period after the opening of the MCA department in May, 1983. The outpatient clinic was the predecessor of the Flevo hospital in Almere, and was closed at the moment the new Flevo hospital was opened in 1991.

\section{Publications}

Nationaal Ziekenhuisinstituut. Evaluatie-onderzoek Medisch Centrum Almere ("Evaluation research Medical Centre Almere"). Nationaal Ziekenhuisinstituut (NZi), Utrecht 1986.

Amstel J van, Dekker 1. Opties voor een ziekenhuis ("Options for a hospital"). Medisch Contact 8,$43 ; 1988: 243-244$.

Dekker J, Pet RK. Het Medisch Centrum Almere (The Medical Centre Almere"). Medisch Contact 9, 43; 1988: 275-277. 


\section{Study 1986-3: Contacts and referral rates of general practitioners in Almere ("Contacten en verwijzingen bij de Almeerse huisartsen")}

\section{Objective}

(1) To explore the number of contacts and referral rates of the general practitioners in Almere, including differences between subcategories of Almere's population and between the different multidisciplinary health centres and individual GPs in Almere, in a period prior to the opening of a hospital. (2) To gain insight in possible differences with respect to the functioning of GPs in Almere, as compared to GPs in other cities (e.g. Lelystad) and national figures.

\section{Methods}

Regarding the number of patient contacts in general practice, registration data were gathered during a ten (working) days registration period in 1984 . Instruments were developed on the basis of earlier research conducted in Lelystad, and tested in Almere among a small sample of GPs. Information included in the registration form consisted of patient characteristics, type of consultation, interventions and follow-up appointments. Consultations by telephone were excluded from the study. All 22 general practitioners in Almere participated, with data referring to 199 working days. Information was received on 5,052 patient-physician contacts.

With respect to the referral rates of GPs in Almere, data were collected over a 10-week period in the first half of 1985, with all 22 GPs in Almere participating in the study. Information included patient characteristics, type of referral, type and perceived necessity of complaints, diagnostic activities conducted in general practice, initiative for the referral, type of service patients were referred to. contacts with services prior to the referral, and possible follow-up appointments. The data set comprised information on 2198 referred patients.

\section{Publications}

Sixma $H$. Contacten en verwijzingen bij de Almeerse huisartsen ("Contacts and referral rates of general practitioners in Almere"). Nederlands instituut voor onderzoek van de eerstelijnsgezondheidszorg (NIVEL), Utrecht 1986.

Sixma H. Huisarts, spreekuur en huisbezoek. Medisch Contact 12, 43; 1988 : 378-380.

Sixma $H$. Het verwijzen naar medisch specialist en fysiotherapeut. Medisch Contact, 13,$43 ; 1988: 400-402$. 


\section{Study 87-1: Utilization of hospital services in Almere in 1984 en daaropvolgende jaren ("Medisch consumptie in Almere 1984 and subsequent years")}

\section{Objectives}

(1) To explore the use of hospital facilities by the population of Almere during the implementation of the AHCDP on a year-to-year basis, starting in 1984. (2) To compare trends in the use of hospital services, with national figures.

\section{Methods}

Data presented in the yearly reports - apart from study $87-1$, similar publications refer to Study 87-2, Study 88-1, Study 90-1, Study 92-2, Study 93-5 covering the period between 1984 and 1992 - were based on the national hospital registration systems. For all hospital patients in the Netherlands, administrative information is available on patient characteristics (e.g. gender, age, insurance, place of residence), hospitals patients are admitted to, length of stay in hospital, and specialisms patients are referred to. In the AHCDH publications, admission rates (per hospital and specialism), length of stay, and occupied hospital beds by the Almere population, are presented. Data for Almere were compared with national data, that were adjusted for age/gender differences (by direct standardization).

\section{Publications}

Nationaal Ziekenhuisinstituut. Medische cunsuptie Almere 1984 ("Clinical consumption Almere 1984"). Nationaal Ziekenhuisinstituut (NZi), Utrecht 1987.

Nationaal Ziekenhuisinstituut. Medische cunsuptie Almere 1985 ("Clinical consumption Almere 1985"). Nationaal Ziekenhuisinstituut (NZi), Utrecht 1987.

Nationaal Ziekenhuisinstituut. Medische cunsuptie Almere 1986 ("Clinical consumption Almere 1985"). Nationaal Ziekenhuisinstituut (NZi), Utrecht 1988

Bent J van der. Klinische Consumptie Almere 1987/1988 ("Clinical Consumption Almere 1987/1988"). Nationaal Ziekenhuisinstituut (NZi), Utrecht 1990.

Bent $J$ van der. Klinische Consumptie Almere 1989/1990 ("Clinical Consumption Almere 1989/1990"). Nationaal Ziekenhuisinstituut (NZi), Utrecht 1992

Bent J van der. Klinische Consumptie Almere 1991 ("Clinical Consumption Almere 1991"). Nationaal Ziekenhuisinstituut (NZi), Utrecht 1993. 


\section{Study 87-3 Emergency care in Almere, part I ("EHBO in Almere, part l")}

\section{Objective}

(1) To explore patient flows and patient satisfaction scores in Almere, in the situation prior to the opening of a hospital. (2) To provide benchmarking data for future developments in Almere with respect to the emergency care function and the opinions of the population of Almere regarding emergency care.

\section{Methods}

Methods used included: (1) registration of all doctor-patient and paramedicspatients contacts that refer to emergency care initiated by patients from Almere, and (2) a survey among a convenience sample of emergency care patients. Participating GPS ( $90 \%$ of the GPs in Almere in 1986), were equally spread over the three parts of the town of Almere and completed a registration form for each emergency care patient over a 10-week period. Similar registration forms were used in the hospitals surrounding Almere - the AMC hospital and Gooi-Noord hospitals - and the MCA outpatient clinic in Almere. Information was collected about the type of complaint, seriousness of the complaints, interventions, time of the day the patient was encountered, follow-up treatments, and patient characteristics In total, 859 registration forms were completed and analyzed. A sample of 740 patients from the registration study, were invited to participate by completing a postal questionnaire. Response rate, after two reminders, was approximately $55 \%$. Questions included referred to the reasons for requesting emergency care treatment, waiting times, satisfaction judgements, general attitudes towards the functioning of GP and hospital care services, attitudes towards the treatment of emergency care patients in different settings and patient characteristics. Data were subjected to uni- and multivariate analyses.

\section{Publications}

Sixma H. EHBO in Almere, deel 1 ("Emergency care in Almere, part 1"). Nederlands instituut voor onderzoek van de eerstelijnsgezondheidszorg (NIVEL), Utrecht ${ }_{1} 1987$.

Sixma H. EHBO: patiëntenstromen ("Emergency care: patient flows"). Medisch Contact 16, 43; 1988: 503-505.

Sixma $H$. EHBO; de mening van de patiënt ("Emergency care: patient's opinions"). Medisch Contact 17, 43; 1988: 535-537. 


\section{Study 1989-1 The functioning of child health clinics in \\ Almere ("De zorg voor zuigelingen en kleuters in Almere")}

\section{Objective}

(1) To compare the Almere situation with respect to baby and infant care and the functioning of the child health clinics in Almere, with the national data on the functioning of these services. (2) To explore the functioning of the child health clinics in Almere with respect to improving the quality of care in these services.

\section{Methods}

In this quantitative study, questionnaires were sent to (1) $68 \mathrm{GPs}$ and district nurses in Almere participating in child health clinics, (2) a random sample of 400 families in Almere with children between 0-1 years of age, and 400 families with children in the age category between 1 and 3 years. With respect to the sample of health care professionals the response rate, after two reminders by telephone, was $88 \%$. Response rates for both groups of clients were $80 \%$ and $83.5 \%$, with two reminders being sent out to non-respondents. No difference were found between respondents and non-respondents. Data for all three groups in Almere were compared with national survey data with respect to the functioning of child health clinics that were organized in a way similar to Almere (see Vorst-Thijsen, 1987). The research in Almere was conducted in 1988.

Quality of care with respect to the functioning of Child Health Clinics was operationalized through 26 hypotheses, covering the following dimensions: coordination and continuity of care, technical quality of care, accessibility of the child health clinics, information and advices, overall satisfaction with the functioning of the child health clinics. Differences between Almere and the remainder of the Netherlands were tested using Chi-square statistics for differences in percentages and T-Tests for difference in means.

\section{Publications}

Thomassen $\mathrm{C}$. Sixma H, Bakker DH de. De zorg voor zuigelingen en kleuters in Almere ("The Functioning of Child Health Clinics in Almere"). Nederlands instituut voor onderzoek van de eerstelijnsgezondheidszorg (NIVEL), Utrecht 1989. 


\section{Study 1990-2 Care for the elderly in Almere ("De zorg voor ouderen in Almere")}

\section{Objective}

(1) To explore the need and use of home help services for elderly people in Almere. (2) To explore the variables that influence the decision to make use of the different home help services, including informal care, by frail elderly people in Almere.

\section{Methods}

A two-stage study design was used. To answer the first research question, the entire age-group all persons being 75 years or older $(\mathrm{N}=901)$ and a random sample of 875 people between 65-75 years of age received a mailed questionnaire to assess the needs and to look at their use of home help services. A total of 1776 questionnaires were sent out. After two reminders, response rates varied between $75 \%$ for the $75+$ group and $79 \%$ for elderly people between 65 and 75 years of age. Research among $25 \%$ of the non-respondents ( 94 persons) showed that he main reasons for not responding were lack of interest and the overall heaith condition. No (significant) differences were found between respondents and non-respondents. Perceived health, the use of health care services and ADL-functions were operationalized by using validated instruments. Other information included socio-demographic characteristics of the respondents and information about their social network.

To answer the second part of the research question, two groups of elderly people were selected from the original sample on the basis of (1) informed consent, (2) ADL scores, and (3) use of professional and informal home help services. Respondents were matched on the basis of ADL-scores and whether or not professional services were used. In total 53 pairs (or 106 persons) were interviewed by telephone. Based on a theoretical framework derived from Andersen and Newman (1973) the computer assisted questionnaire included information on expectations and experiences with respect to home help services, subjective health, feelings of loneliness, dependency and internal/external orientations, social networks, additional needs and client satisfaction. Data were analyzed using T-test and Wilcoxon-tests for matched pairs.

\section{Publications}

Brink-Muinen A van den, Sixma H. De zorg voor ouderen in Almere ("Care for the elderly in Almere"). Nederlands instituut voor onderzoek van de eerstelijnsgezondheidszorg (NIVEL). Utrecht 1990. 


\section{Study 1993-1/4 Morbidity and interventions in general \\ practice in Almere ("morbiditeit en \\ verrrichtingen in de Almeerse huisarts- praktijk")}

\section{Objective}

To gather morbidity and age/gender specific data on (1) the perceived health of the Almere population, in combination with attitudes towards the health and health related behaviour and the use of professional health care services, (2) morbidity and interventions in general practices in Almere, and (3) the practice setting , attitudes and task profiles of general practitioners in Almere. Data for Almere were to be compared with data for the Netherlands, and specific subcategories in the national data, coming from Dutch national survey of general practice (see Foets et al, 1992)

\section{Methods}

The study is based upon four central elements: (1) the registration of the practice population, (2) the registration of contacts between patients and GPs/practice assistants, (3) the health interview, including a health diary, and (4) the GP/practice assistant questionnaire, also in combination with a diary. A combination of methods was used. With respect to (1) the registration of the practice population, information was collected on the age, sex, marital status, ethnic background, profession "education, type of health insurance and housing conditions of all patients registered in the practices of participating GPs. Regarding (2) all GP-patient contacts, all participating GPs kept a complete record of the morbidity presented in their practice and of all the associated activities and interventions over a three months period (between October 1987 and April 1988). Contacts registered included face-to-face consultations as well as consultations with the receptionist. Consultations by telephone were registered only when they were followed by a (repeat) prescription or referral. Data registered included: point of time, length of consultation, character of consultation, initiator of the consultation, morbidity data and data on the intervention (e.g. diagnostic tests, health promotion and counselling, prescription of medicines, referrals, consultations with colleagues). The (3) GP-questionnaire that all doctors have been asked to complete included information on GP-and practice characteristics (socio-demographic variables, practice setting, organisational aspects) and factors that may explain differences in the GPs diagnostic and therapeutic interventions (e.g. task perceptions, attitudes). Finally, the health interviews (4) with a sample of patients from each participating GP were used to collect information on patient characteristics, perceived health, 
common symptoms experienced over a 14-days period, chronic diseases, disabilities (based on OECD-indicator) and mental health (based on GHQ and BIOPRO scores). Other questions included in the health interviews focused on attitudes of patients regarding health and illness, patient satisfaction scales, health related habits, social networks and social support, and the utilization of professional health services

In Almere, seven health centres (with 19 GPs) participated in part (1) and (2) of this study. GPs and health centres were equally spread over the three parts of the town. Information was collected regarding 37,403 doctor-patient contacts, with 40,847 problems presented in general practice. All problems were classified according the ICPC-classification scheme. The GP-questionnaire was completed by $30 \mathrm{GPs}$ practising in Almere $(=80 \%)$. Finally, health interviews were completed by 1189 inhabitants of Almere, registered in eight different health centres. Sapling method was based on a quota-sample of between 50 and 75 patients per GP out of a maximum of 120 addresses per GP available.

The data set for Almere was compared to national data that refer to a random, non proportional stratified sample of GPs. Stratification variables were: region, distance from the practice location to the nearest hospital, and degree of urbanization. In total 408 GPs were invited to participate, with recruitment procedures resulting in 161 participating GPs working at 103 locations. Nonresponse analysis has shown that the average age of the participating GPs was lower than the national average, that there were more female doctors included and less doctors working in single handed practices. Therefore, all national data were weighted to national data. In total approximately 335,000 persons were registered. Information about consultation was collected for approximately 386,000 doctor-patient contacts, including 300,000 episodes of care, 34,000 lab tests, 275,000 prescriptions of medicines and 32,000 referrals. Health interviews were completed for approximately 13,000 patients.

To compare the data for Almere with national data, a weighting procedure was carried, for both the contact registration data as well as the results of the health interviews. Correction factors for Almere were calculated on the basis of difference between the age/gender distribution in Almere and in the Netherlands in general, with population data on 31 December 1987 acting as a point of reference. Patients under-represented in Almere (as compared to national figures) received a relatively high weight factor; patients over-represented received a relatively low weight factor. Tables with the weight factors applied to the Almere dlata can be found in Sixma et al (1991) and De Bakker et al (1992). Data were analyzed using the SPSS programme. Analysing techniques comprised of different forms of uni- and multivariate analyses, including multilevel analysis. 


\section{Publications}

Sixma HJM, Thomassen $\mathrm{C}$, de Bakker $\mathrm{DH}$, Foets $M$. Ziekten en Verrichtingen in de Almeerse Huisartspraktijk; gezondheid en gezondheidsgedrag in de praktijkpopulatie ("Survey of General Practice in Almere; Population morbidity and health related behaviour"). Nederlands instituut voor onderzoek van de eerstelijnsgezondheidszorg (NIVEL), Utrecht $1991 .$.

Sixma $H$, Bakker DH de, Groenewegen PP, Velden $J$ van der. Ziekten en Verrichtingen in de Almeerse huisartspraktijk; Verrichtingen in de Almeerse Huisartspraktijk ("Survey of General Practice in Almere; Interventions in General Practice in Almere" eerstelijnsgezondheidszorg (NIVEL), Utrecht 1992.

Bakker $\mathrm{DH}$ de, Sixma $H_{*}$ Velden $J$ van der. Ziekten en Verrichtingen in de Almeerse Huisartspraktijk; Morbiditeit in de Almeerse huisartspraktijk ("Survey of General Practice in Almere; Morbidity in General Practice in Almere"). Nederlands instituut voor onderzoek van de eerstelijnsgezondheidszorg (NIVEL), Utrecht 1992.

Sixma $H$, Bakker $D H$ de, Velden J van der, Foets $M$. Ziekten en Verrichtingen in de Almeerse Huisartspraktijk; Samenvattend Rapport ("Survey of General Practice in Almere; Summary of Research Findings"). Nederlands instituut voor onderzoek van de eerstelijnsgezondheidszorg (NIVEL), Utrecht 1992.

Sixma $H$, Langerak EH, Schrijvers G.JP, Bent J van der. Attempting to Reduce Hospital Costs by Strengthening Primary Care Institutions; the Dutch Health Care Demonstration Project in the New Town of Almere. Journal of the American Medical Association, 1993, 269, 19: 2567-2572. 


\section{Study 1992-2 Emergency care in Almere II ("EHBO in Almere (I")}

\section{Objective}

(1) To explore the effects of the opening of the Flevo hospital on the patients flows in Almere. (2) To explore attitudes and opinions of patients who make use of the emergency care services in and around Almere shortly before and after the opening of the Flevo hospital. (3) To explore the developments, with respect to patients flows and attitudes of patients, compared to the situation in 1986.

\section{Methods}

As in 1986, the study comprised of a combination of a 10-week registration on all emergency care contacts and a survey among the patients that made use of emergency care services. Participating services were: paramedic services in Almere, all multidisciplinary health centres in Almere, the two PHC-emergency centres in Almere, the Flevo hospital in Almere, and the AMC and Gooi Noord hospitals in neighbouring towns. Registration forms and patient questionnaires resembled the instruments that were used in 1986. Additional information, concerning a prolonged period of time, was supplied by the A\&E Department of the Flevo hospital and the PHC-centres in Almere.

In total 1,736 emergency care contacts were registered and subsequently analyzed. Of the approximately 1,700 patients involved, 969 were interviewed. When possible interviews were made by telephone (approximately $2 / 3$ ), the remainder of the interviews being done by sending out postal questionnaires. In overall ${ }_{\text {in }}$ response rate varied between approximately $50 \%$ for the patients treated in hospital and $65 \%$ for patients that made use of the PHC-facilities in Almere. The data set was analyzed using uni- and multivariate techniques. Data for 1991 were compared to data from the 1986 survey.

\section{Publications}

Sixma $\mathrm{H}_{1}$ Hackenitz E. EHBO in Almere 2; de effecten van de opening van het Flevoziekenhuis ("Emergency Care in Almere 2; the effects of the opening of the Flevo-hospital"). Nederlands instituut voor onderzoek van de eerstelijnsgezondheidszorg (NIVEL). Utrecht 1992.

Sixma HJ, Bakker DH de. Emergency Care, GP or Hospital? Journal of Accident \& Emergency Medicine 1996, 13; 4: 264-268. 


\section{Study 1993-6 Evaluation Experiment De Kiekendief ("Evaluatie experiment De Kiekendief")}

\section{Objective}

(1) To evaluate the functioning of the combined old-people/nursing home in Almere. (2) To explore the possibilities for the implementation of programmes towards quality improvement.

\section{Methods}

A combination of qualitative and quantitative methods was used, including the collection of (1) observational data, (2) the results of a series of delphi-rounds and panel discussions, (3) consensus conferences, and (4) interviews with clients based on structured questionnaires.

As part of the study, an expert panel visited the combined nursing/old people's home on a number of occasions to observe the functioning of the 'De Kiekendief' in detail. The results of this observations were discussed in a series of delphirounds and panel discussions during the different phases of the study., followed by a concluding consensus conference. Additional data on the functioning of ' $\mathrm{De}$ Kiekendief' were collected by oral interviews with residents. Questions included in this instrument, which was especially developed for this study, refer to value judgments on the different services, task differentiations, the use of heaith and home care services, perceived health care status, and personal characteristics.

\section{Publications}

Fahrenfort M, Plaisier AJ. Evaluatie Experiment De Kiekendief Almere ("Evaluation Experiment 'De Kiekendief' Almere"). Nationaal Ziekenhuisinstituut (NZi), Utrecht 1993. 


\section{Study 1993-7 The Almere Health Care Experiment ("Het Experiment Gezondheidszorg Almere")}

\section{Objectives}

To gain insight in the most important results of the Almere Health Care Demonstration Project, by evaluating the experienced conditions, the instruments to be implemented and the goals to be achieved.

\section{Methods}

For this concluding study of the AHCDP, a combination of qualitatative and quantitative methods was used. The qualitative part consisted of a series of open interviews with key persons and stakeholders (5 interviews) of the AHCDP. with transcribed versions of the interviews approved by the persons interviewed. Desk research was based on information provided by the (bi) monthly bulletins of the Almere Primary Health Care Foundation and the Almere Health Care Cooperation, yearly reports published by the different health care organizations including, and other publications concerning the developments in Almere. This information was supplemented by national data on the use of PHC-services and hospital services, including hospital utilization in towns comparable with Almere with respect to the age/gender distribution.

Additional data were based on secondary analyses of the material that was collected as part of the 18 evaluation studies conducted during the implementation phase of the AHCDP. All data were presented in a conceptual framework based on the relationships between (operationalized) goals, conditions and instruments.

\section{Publications}

Sixma HJM, Bakker DH de, Bent $\downarrow$ van de. Het Experiment Gezondheidszorg Almere ("The Almere Health Care Experiment"). Utrecht, Netherlands Institute of Primary Care (NIVEL) / National Hospital Institute (NZi) 1993.

Sixma HJM, Bakker DH de. Het experiment Gezondheidszorg Almere ("The Almere Health Care Experiment"). In: Sorber A, Bax JR, Hendriks AJM (eds), Beleidsevaluatie; Wisselwerking tussen Cultuur en Structuur. Sdu Uitgeverij, Den Haag 1995.

Sixma $H$, Bakker $\mathrm{DH}$ de, Bent J van der. Eindafrekening of Tussenbalance? ("The end or just a point in between?). In: SAG Nieuwsbrief Gezondheidszorg Almere, September 1993. 


\section{ACKNOWLEDGEMENTS}

Many people contributed to this book, all in their own specific way. First of all 1 would like to thank my professors Jouke van der Zee and Peter Groenewegen. I am grateful for the time they invested in reading the different drafts of this thesis, and for the discussing their comments.

Secondly I would like to thank my co-authoirs of the concluding report concerning the Almere Health Care Demonstration Project: Dinny de Bakker and Jaap van der Bent. The report that resulted from our combined efforts, provided the the framework for this thesis.

Thirdly, I would like to thank all the people involved in the Almere Health Care Demonstration Project: patients that participated in the separate evaluation studies, health care professionals working in the different sectors, health care authorities involved in the administration and financing departments, and the members of the Steering and Advisory Committees of the Almere Health Care Demonstration Project.

Fourthly, I would like to thank my colleagues at the NIVEL who provided me with support and help (and sometimes a shoulder to cry on). Special thanks go to Christine Abrams and Keith Meadows from Hull University for their assistance in transforming an earlier draft of this thesis into the final English version.

Finally, I wish to thank my parents, parents-in-law, and especially Jeanine and Leanne for their patience and moral support. From now on I have to find another excuse for listening to my favourite music with my ear-phones on. 


\section{ABOUT THE AUTHOR}

Herman Sixma was barn in Groningen, the Netherlands, on April 22, 1949. After completing High School (HBS-B) in 1969 and having finished his 18 months of military service, he worked as a civil servant for the city council of Amersfoort. Being a civil servant, he studied social sciences at the University of Utrecht from 1975 onwards. In 1981 he graduated in the department of Theoretical and Methodological Sociology. After graduation he worked for two years at the University of Utrecht on a project about social stratification and occupational prestige. Since April 1984 he is working at the Netherlands Institute of Primary Health Care (NIVEL) as a researcher on various projects, including the evaluation study around the Almere Health Care Demonstration Project. Other projects focused on the functioning of emergency care services, the prevalence of burnout among health care professionals, and the functioning of assistant radiologists. Since 1993 he is involved in a series of projects funded by the Netherlands Organization for Scientific Research (NWO) in the field of patient satisfaction and quality of care from the patients' perspective. 